\title{
Miete, Lage, Preisdiktat
}

Strukturelle Effekte der Lageregulierung im mietrechtlich geschützten Wiener Wohnmarkt

MICHAEL PICHLMAIR

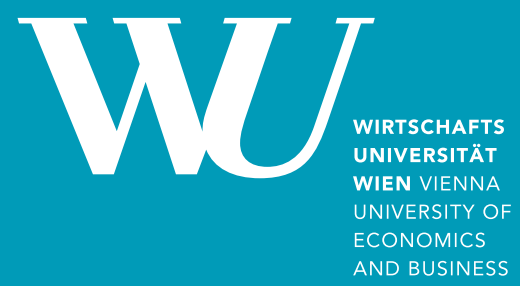


Miete, Lage, Preisdiktat 


\section{Forschungsergebnisse der Wirtschaftsuniversität Wien}

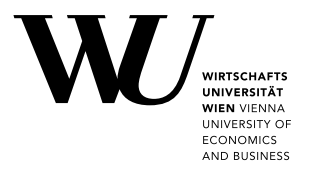

Band 57

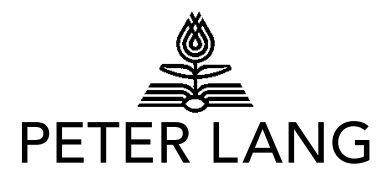

Frankfurt am Main · Berlin · Bern · Bruxelles · New York · Oxford · Wien 


\section{Miete, Lage, Preisdiktat}

Strukturelle Effekte der Lageregulierung im mietrechtlich geschützten Wiener Wohnmarkt

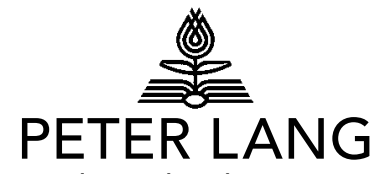

Internationaler Verlag der Wissenschaften 
Bibliografische Information der Deutschen Nationalbibliothek Die Deutsche Nationalbibliothek verzeichnet diese Publikation in der Deutschen Nationalbibliografie; detaillierte bibliografische Daten sind im Internet über http://dnb.d-nb.de abrufbar.

Gefördert durch die Wirtschaftsuniversität Wien.

\author{
Umschlaggestaltung: \\ Atelier Platen, nach einem Entwurf \\ von Werner Weißhappl. \\ Universitätslogo der Wirtschaftsuniversität Wien: \\ Abdruck mit freundlicher Genehmigung \\ der Wirtschaftsuniversität Wien.
}

\author{
ISSN 1613-3056 \\ ISBN 978-3-653-03356-4 (E-Book) \\ DOI 10.3726/978-3-653-03356-4 \\ ISBN 978-3-631-62275-9 (Print) \\ (C) Peter Lang GmbH \\ Internationaler Verlag der Wissenschaften \\ Frankfurt am Main 2012 \\ Alle Rechte vorbehalten.
}

Das Werk einschließlich aller seiner Teile ist urheberrechtlich geschützt. Jede Verwertung außerhalb der engen Grenzen des

Urheberrechtsgesetzes ist ohne Zustimmung des Verlages unzulässig und strafbar. Das gilt insbesondere für Vervielfältigungen, Übersetzungen, Mikroverfilmungen und die Einspeicherung und Verarbeitung in elektronischen Systemen.

www.peterlang.de 


\section{Inhalt}

1 Einleitung _ 13

1.1 Problemstellung __ 13

1.2 Aufbau der Arbeit

1.3 Forschungsfrage 17

2 Mietregulation und der Markt ___ 19

2.1 Charakteristika des Mietwohnungsmarktes ___ 19

2.1.1 Dauerhaftigkeit von Wohnungen und Langfristigkeit von

Marktbewegungen 20

2.1.2 Heterogenität von Wohnungen__ 20

2.1.3 Immobilität von Wohnungen _ 20

2.1.4 Der Einfluss von Transaktionskosten __ 21

2.1.5 Die Rolle des Leerstands __ 22

2.1.6 Marktmiete versus Kostenmiete___ 23

2.2 Zwei Generationen der Regulation __ 24

2.3 Typologie der Mietkontrollprogramme _ 25

2.4 Konsequenzen der Mietkontrolle __ 26

2.4.1 Ökonomischer Mechanismus von Mietkontrollregimes___ 27

2.4.2 Reduzierte Profitabilität und Bestands-Deterioration___ 29

2.4.3 Effekte des Nachfrageüberschusses __ 29

2.4.4 Umverteilung und Effekte auf nicht-regulierte Mietmärkte__ 30

2.4.5 Effekte auf den Eigentumsmarkt: verkaufen statt vermieten? 31

2.4.6 Segregationseffekte 33

2.4.7 Auswirkungen von Mietkontrolle auf andere Märkte__ 33

2.4.8 Regulierung kostet den Mietern __ 34

2.5 Zur Notwendigkeit von Mietkontrolle __ 34

2.5.1 Mehr Wohlstand mit milder Mietkontrolle___ 35

2.5.2 Wettbewerbsprobleme: asymmetrische Information __ 35

2.5.3 Wettbewerbsprobleme: Übervorteilung der Mieter _ 36

2.5.4 Die „Hauspreis-Mietenspirale“ der AK-Wien ___ 36

2.5.5 Sonstige Argumente für Mietkontrolle___ 39

2.6 Deregulierung _ 39

2.7 Empirische Befunde zu Mietregulierung __ 40

2.7.1 „Weniger Wohnung, mehr Konsum“__ 40 
2.7.2 Mietkontrolle macht örtlich unflexibel __ 40

2.7.3 Tschechischer Schwarzmarkt für Mietwohnungen___ 41

2.7.4 Auswirkungen von vacancy decontrol-recontrol-Programmen __ 42

2.7.5 Asymmetrische Information der Mieter: Kurzmieter benachteiligt_42

2.7.6 Schrumpfen des Mietmarktes 43

2.7.7 Spieltheoretische Untersuchungen___ 43

2.7.8 Österreichisches Mietrecht im Regressionsmodell___ 44

3 Mietregulierung in Österreich und Wien _ 47

3.1 Geschichte des Mietrechts und der Wohnungsnot ___ 47

3.1.1 Mieten zu Monarchiezeiten __ 47

3.1.2 Das Mietengesetz (MG) $192 \overline{2 \text { und die Zwischenkriegszeit ___ }} 48$

3.1.3 Mieten nach 1945

3.1.4 Das Mietrechtsgesetzt (MRG) 1981 und seine Entwicklung __ 50

3.1.5 Der Liberalisierungsschritt über den Richtwertmietzins ___ 51

3.1.6 Umfang des heutigen Mietrechts __ 51

3.2 Mietrecht: einmal gilt es, einmal nicht $\quad 52$

3.2.1 Vollausnahme vom MRG__ 52

3.2.2 Teilanwendung des MRG_ 53

3.2.3 Vollanwendung des MRG _ 54

3.3 Mietzinsbilung _ 54

3.3.1 Der Richtwertmietzins _ 55

3.3.2 Angemessener Hauptmietzins gem. §16 Abs $1 \mathrm{MRG} \_58$

3.3.3 Sonstige Mietzinsarten __ 59

3.3.4 Der freie Mietzins ___ 61

3.4 Höhe und Bedeutung des Richtwertmietzinses __ 62

3.4.1 Zuschlagsberechnung im Richtwertsystem _ 62

3.4.2 Valorisierung des Richtwertzinses und das „Inflationslinderungsgesetz“ 66

3.4.3 Verbraucherpreisindex statt Baukostenindexierung___ 66

3.4.4 Rechtliche Unschärfen des Richtwertsystems ___ 66

3.5 Sanktionsmöglichkeiten des MRG und seine Folgen___ 70

3.5.1 Verjährungsfristen in Mietrechtssachen _ 71

3.5.2 Gerichtliche Zuständigkeit bei Mietzinsanfechtungen___ 71

3.5.3 Beispielrechnung Mietzinsherabsetzung __ 72

4 Lage und Lageregulierung _ _ 75

4.1 Neoklassische Standortmodelle ___ 75

4.1.1 Thünens Bodennutzungstheorie: Das Zentrum und die Transportkosten 
4.1.2 Alonsos Stadtstrukturtheorie 76

4.1.3 Rentengebotskurve und Auslesemechanismus___ 79

4.1.4 Lagerente und Wohnimmobilien ___ 81

4.1.5 Kritik an formalen, deduktiven Modellen __ 81

4.2 Standortfaktoren und deren Entwicklung__ 82

4.2.1 Harte Standortfaktoren $\quad 82$

4.2.2 Weiche Standortfaktoren __ 83

4.3 Stadtentwicklung durch Regionale Polarisation___ 84

4.4 Empirische Standortuntersuchungen mit hedonischen Modellen _ 85

4.4.1 Einfluss von Luftverschmutzung _ 86

4.4.2 Nähe zu Uni und Schnellstraße als Mietentreiber 86

4.4.3 Wien im hedonischen Modell__ 86

4.4.4 Polyzentren: Mieter sind auf Nähe von Einkaufsmöglichkeiten angewiesen 187

4.5 Der zulässige Lagezuschlag ___ 88

4.5.1 Rechtliche Grundlagen der Zulässigkeit eines Lagezuschlags __ 88

4.5.2 Festsetzung der „Gründerzeitviertel“ _ 89

4.5.3 Geographischer Überblick von Lagezuschlagszonen___ 91

4.5.4 Rechtliche Grundlage zur Berechnung des Lagezuschlags___ 94

4.5.5 Rechnerische Logik des Richtwert- und Zuschlagsystems __ 95

4.5.6 Residualwertverfahren zur Berechnung des Grundkostenanteils _ 96

4.5.7 Beispielrechnung für den Lagezuschlag__ 98

4.5.8 Empfehlungen der Stadt Wien für den Lagezuschlag ___ 99

4.5.9 Vertragliche Voraussetzungen für den Lagezuschlag __ 101

4.6 Lageregulierung im Marktkontext ___ 101

4.7 Exkurs: „Marktpräferenzen“ als Regulierungsvorschlag ___ 103

5 Befunde zum heutigen Wiener Wohnmarkt___ 105

5.1 Statistische Auswertungen zum Wohnmarkt 105

5.1.1 Wohnungs- und Eigenheimbestand in Österreich und Wien _ 105

5.1.2 Gebäudebestand in Wien 109

5.1.3 Größe und Bedeutung der Gründerzeitviertel___ 109

5.1.4 Mietwohnkosten in Österreich und Wien__ 110

5.2 Richtwertmieten und freie Mieten in Wien im Jahr 2004

5.3 Hohe Zuschläge im Richtwertsystem 114

5.3.1 „Lagezuschläge“, eine rechtliche Grauzone?___ 114

5.3.2 Ignorierte Befristungsabschläge ___ 117

5.3.3 Kritische Anmerkung ___ 117 
5.4 Erste Bewertung der Mietrechtsreform 118

5.5 Einfluss des Richtwertsystems auf die Mietenentwicklung in Österreich

5.5.1 Förderrückgang erhöht Marktmieten

5.5.2 Einfluss des Richtwertsystems auf das Mietniveau

6 Hypothesen zu Effekten der Lageregulierung 120

6.1 Einflussfaktoren auf den „Preis der Lage“

6.2 Vermutete Probleme bei der Lagezuschlagsbegrenzung

6.2.1 Problematik der Gründerzeitviertel

6.2.2 Problematik der scharfen Abgrenzung der Zuschlagszonen

6.3 Auswirkungen einer "Grauzone“

6.3.1 Umgehungsmechanismen des Lagezuschlags-Regimes

6.3.2 Mietrecht und Erhaltungszustand der Häuser

6.3.3 Selektionseffekte als Ursache für Segregation

6.3.4 Flucht aus dem Markt

7.1 Methode

7.1.1 Quasi-experimentelle Designs

7.1.2 „Matching“ und Variablenkontrolle über ein hedonisches Modell_133

7.2 Datengenerierung und Datenbereinigung

7.2.1 Mietangebotsdaten und deren Operationalisierung 136

7.2.2 Operationalisierung der Grundbuchsdaten 142

7.3 Erwartete Probleme bei der Datenerhebung

7.4 Deskriptive Auswertung des Datenmaterials _ 146

7.4.1 Datenbasis Maklerangebote

7.4.2 Geographische Streuung

7.4.3 Anteil mietengeschützter Wohnungen

7.4.4 Verteilung der Miethöhe

7.4.5 Wohnungsgrößen, Zimmerzahlen und Ausstattungszustand

7.5 Hypothesenprüfung

7.5.1 Miethöhe und Mietregulierung

7.5.2 Miethöhe und Lage

7.5.3 Erhaltungszustand unter Mietregulierung__ 167

7.5.4 Mieterselektion und soziodemographische Beobachtungen 173

7.5.5 Mietregulierung und Mietangebot

7.5.6 Mietregulierung und Wohnungsangebot 
7.7 Zusammenfassung der empirischen Ergebnisse 188

8 Fazit 195

9 Literaturverzeichnis 203 



\section{Abkürzungsverzeichnis}

\begin{tabular}{ll} 
z.B. & zum Beispiel \\
usw. & und so weiter \\
o.ä. & oder ähnliche/r/s \\
u.a. & unter anderem \\
v.a. & vor allem \\
ca. & cirka, ungefähr \\
u.U. & unter Umständen \\
uvm. & und viele mehr \\
lt. & laut \\
m.E. & meines Erachtens \\
etc. & et cetera, und so weiter \\
bzw. & beziehungsweise \\
bzgl. & bezüglich \\
p.a. & per annum, jährlich \\
o.A. & ohne Angabe \\
Abb. & Abbildung \\
Kap. & Kapitel \\
i.d.R. & in der Regel \\
MRG & Mietrechtsgesetz \\
ZSP & Zählsprengel \\
GZV & Gründerzeitviertel \\
NB & mietrechtlicher „Neubau“ (Gebäude mit Baubewilligung ab 1945) \\
AB & mietrechtlicher „Altbau“ (Gebäude erbaut vor 1945) \\
LZ & Lagezuschlag \\
CBD & Central Business District = Stadtzentrum \\
GKA & Grundkostenanteil \\
MZ & Mietzins \\
\hline
\end{tabular}





\section{Einleitung}

Die elegant formulierte Erkenntnis hat schon einen Bart: „Lage, Lage, Lage“, antworten nämlich Immobilienpraktiker stets gefragt nach den drei wichtigsten Kriterien einer Immobilie. Gute Lagen würden immer teurer, heißt es, während schlechte Lagen immer billiger werden. Die Preisschere geht mit zunehmender „Gentrifizierung“ auseinander, gerade in Bestlagen in großen Ballungszentren wie Wien. Auch die Mieten steigen überproportional wo es die Nachfrage zulässt - oder, wo es das Mietrecht zulässt.

Die Mietzinsregulierung hat in Österreich ebenfalls einen Bart. Vieles davon ist in Stein gemeißelt. Insbesondere seit dem letzten Liberalisierungsschritt im Jahr 1994 sind auch die Fronten zwischen Mietenschützern und Liberalisierungsverfechtern verhärtet. Damals wurde eine Art Kostenmiete eingeführt, ein starres Instrument, das der Miethöhe eine gläserne Decke einzieht: Geschaffen wurde der „Richtwertmietzins“, der lediglich Inflationsangepasst werden darf, aber Zuschläge erlaubt, die den Selbstkosten entsprechen.

Mit dem strengen Mietzins-Regulativ ist Österreich allein auf weiter europäischer Flur. In den wenigen anderen Ländern, die den Mietzins regulieren (etwa Deutschland), wird ein ortsüblicher Angemessener Mietzins als Richtwert eruiert. Der Markt bleibt in seiner Funktion erhalten, während in Österreich das Preisdiktat von Gesetzbuch und Stadtverwaltung regiert.

Für besonders gute Lagen darf aber auch in Wien (das Thema betrifft de facto nur die Bundeshauptstadt) ein Zuschlag zur Miete verrechnet werden, bei Neuvermietungen ist ein „Lagezuschlag“ möglich. Dieses Instrument ist relativ starr und richtet sich nur über Umwege nach einem Marktwert, wie später gezeigt wird. Bei zunehmenden Preisunterschieden zwischen guten und schlechten Lagen würde die Spannung auf dem Markt steigen - nämlich die Differenz zwischen jener Miete, die verlangt werden darf, und jener, die verlangt werden könnte. Wie verhalten sich Marktteilnehmer in Gebieten, wo dieser „MarktStress" zunehmend größer wird? Gibt es Umgehungsmechanismen, und welche Effekte hat die Regulierung auf Gegenden, die keinen Zuschlag erlauben?

\subsection{Problemstellung}

Die Mietregulierung in Österreich ist eine Regulierung der zweiten Generation. Die Miete richtet sich strikt nach einer Kostenmiete. Während bei üblichen internationalen Mietzinsmodellen die Neuvermietungen in großzügigen Bandbreiten erfolgen können (,vacancy decontrol“, vgl. McFarlane 2003, 306), dafür aber weitere Mietzinssteigerungen auf einen Preisindex limitiert sind 
(,recontrol“), ist in Österreich auch die Miethöhe bei einer Neuvermietung bis ins Detail vorgegeben.

Der lokale Mietmarkt wird dabei de jure ausgeblendet. Bei zunehmendem Nachfrageüberschuss müsste das zu Wohlstandsverlusten auf dem Markt führen: Fehlallokationen, Flexibilitätsverlust der Mieter und verbotene Ablösezahlungen (vgl. Diskussion in Kap. 2.4). Wird der Mietzins auf einem zu niedrigen Niveau eingefroren, findet der Markt ein Ventil - wodurch der „Wohlstand“ meist noch ineffizienter verteilt wird als durch eine völlige Liberalisierung des Marktes.

In den meisten Fällen dürfte der Markt aber lediglich in eine Grauzone gleiten, was ebenfalls negative Konsequenzen auf Rechtssicherheit und Investitionsbereitschaft hat. Wird etwa eine nach heute modernem Standard ausgestattete Wohnung in Durchschnittslage befristet vermietet, so beträgt die Nettomiete 3,68 Euro pro Quadratmeter (Richtwert-A abzüglich des „Befristungsabschlags"). Der Markt würde möglicherweise bis zu 7,00 Euro pro Quadratmeter Monatsmiete zulassen. Dieses Beispiel soll lediglich das Spannungsfeld illustrieren, in dem sich das Thema bewegt.

Dieses Spannungsfeld wird um eine Komponente reicher, wenn die Lage der Immobilie betrachtet wird. Ist diese besonders gut, so darf in Wien ein Lagezuschlag verlangt werden. Auch hier liegt ein Kostenmechanismus zugrunde: der Lagezuschlag richtet sich nach den Bodenpreisen. Steigt der Grundkostenanteil einer Wohnung, also der in der Wohnnutzfläche inhärente Preis für den Boden, so kann dies als Zuschlag zum Richtwertmietzins verrechnet werden. Der Vermieter soll dadurch eine Bodenpreisverzinsung in Höhe von vier Prozent des über dem städtischen Durchschnitt liegenden Bodenpreises erhalten.

Dieses Instrument könnte steigende Bodenpreise dynamisch im Mietzins abbilden. Bodenpreise nehmen nach den Regeln der Stadtstrukturtheorie zu, je näher sie zu einem Stadtzentrum (Central Business District) liegen. Auch in Wien entwickeln sich Bodenpreise grundsätzlich kreisförmig um ein Zentrum. Diese Entwicklung kann allerdings im Lagezuschlag kaum abgebildet werden.

In der Praxis ist der Lagezuschlag kompliziert zu eruieren, weshalb regelmäßig auf vorgefertigte Zuschlagstabellen der Stadt Wien zurückgegriffen wird. Die darin für jede Adresse dogmatisch ausgewiesenen „Zuschlagszonen“ verschieben sich kaum und bilden die wahren Grundkostenanteile mangelhaft ab. So klaffen die von der Stadt Wien vorgegebenen Lagezuschläge oft um 100 Prozent auseinander, je nachdem, auf welcher Straßenseite sich der Mietgegenstand zufällig befindet (Kothbauer et al. 2006, 54).

$\mathrm{Ob}$ der Lagezuschlag ein effizientes Instrument ist, eine Kostenmiete ,gerecht“" abzubilden, wird bereits in einer ersten Analyse 1994 bezweifelt: „Die im MRG enthaltene Reglementierung des Lagezuschlags [darf] als Musterbeispiel für eine am Verständnis der Normadressaten vorbeizielende Gesetzgebung an- 
gesehen werden“ (Dirnbacher et al. 1994, 95), selbst für den ,intellektuell überdurchschnittlich begabten Laien“ scheine es unmöglich, den Lagezuschlag korrekt (und unanfechtbar) zu ermitteln.

Eine besondere Herausforderung für die Marktteilnehmer hat sich der Gesetzgeber in den Gründerzeitvierteln überlegt. Dort darf kategorisch kein Lagezuschlag verrechnet werden. In Wien steht jedes zweite Althaus (gebaut vor 1945) in einem solchen Viertel. Diese früher prekären Stadtgebiete haben inzwischen vielerorts eine positive Entwicklung erfahren. In den erlaubten Mieten kann dies kaum berücksichtigt werden. Gerade in Gründerzeitvierteln entfaltet sich eine Grauzone auf dem Mietmarkt, in dem Sinne, dass Beliebtheit und Marktmiete dem gesetzlich zulässigen Mietzins davon galoppieren. Darauf deuten mehrere Untersuchungen von Mieterverbänden hin (Czasny et al. 1995).

In dieser Grauzone entwickeln Vermieter Umgehungsmechanismen, so die Hypothese. Rational handelnde Vermieter selektieren ihre Mieter nach Problemvermeidungsstrategien, verrechnen andere Zuschläge als Kompensation für den fehlenden Lagezuschlag oder flüchten aus dem Markt, was an zunehmenden Parifizierungen sichtbar wird. Die Spirale dreht sich damit weiter: Der Abverkauf der Mietshäuser an Wohnungseigentümer ist lukrativer als die Vermietung. Das entzieht dem Mietmarkt zunehmend Angebot in guter Lage, was den Nachfrageüberschuss nach Mietwohnungen verschärft. Die Marktmieten steigen und damit vergrößert sich die mietrechtliche Grauzone.

\subsection{Aufbau der Arbeit}

Im theoretischen Teil der Arbeit wird zu Beginn (Kapitel 2) die Systematik des Mietwohnungsmarktes erklärt. Er unterscheidet sich von anderen Märkten, womit auch die Notwendigkeit von Mietregulierung argumentiert wird. Mietregulierung ist wiederum ein Spiel mit dem Feuer. Werden einseitige Wohlstandseffekte erzwungen, indem etwa die Miethöhe auf einen Betrag begrenzt wird, der weit unter dem Marktwert ist, dann kann dies den Wohlstand des gesamten Systems verringern. Dabei spricht man von Mietregulierungen der ersten Generation. Die zweite Generation der Regulierung weicht von extrem starren „rentfreezes“ ab. Sanfte Mietkontrolle kann auch positive Effekte haben, wie einige theoretische Beispiele zeigen. Empirische Befunde gibt es vereinzelt, auch wenn Mietregulierung ein schwer greifbares und entsprechend ungern bearbeitetes Phänomen zu sein scheint.

Das österreichische Mietrechtsgesetz mit besonderem Fokus auf Wien ist schließlich der Inhalt von Kapitel 3. Um die Entstehung des Mietrechts nachvollziehen zu können, muss ein geschichtlicher Abriss gemacht werden. Es wur- 
de zu Zeiten größter Wohnungsnot installiert - und einfach nie mehr abgeschafft. Aus den verschiedenen Gesteinsschichten des Mietengesetztes sind unterschiedliche Anwendungsstufen entstanden. Die schärfste Auslegung des Rechts gilt heute für „Altbauten“, die vor dem Jahr 1945 gebaut wurden, und die einen Großteil des Wiener Wohnungsbestands beherbergen. Das Kapitel befasst sich ausführlich mit dem Richtwertsystem, das ab 1994 ein erster (und wohl vorläufig letzter) Liberalisierungsschritt ist. De facto handelt es sich dabei um eine Kostenmiete, die „faire“ Returns-on-Investments ermöglichen soll, aber zugleich auch erhebliche rechtliche Unsicherheiten birgt. Immerhin gesteht sie dem Vermieter einen jeweils höheren Bodenertrag zu, je besser die Lage ist, in der sich sein Haus befindet.

Lage und Lageregulierung und eigentlicher Kern der Arbeit ist schließlich das 4. Kapitel. Ausführlich wird auf Bodenrentenmodelle (Thünen) und ihre zentralistische Ausrichtung eingegangen, die sich auch in der Stadt Wien widerspiegelt. Auch sind es nicht nur harte - sondern auch weiche Standortfaktoren, die den Wert einer Lage heben. Dieser Wert, auf dem Eigentumsmarkt ausgedrückt im Grundkostenanteil einer Wohnfläche, determiniert schließlich die Lage-Entlohnung für den Vermieter, den im Richtwertgesetz definierten Lagezuschlag. Dieses mietrechtliche Lagebewertungssystem ist Kern der Arbeit, hat heute und in Zukunft eine enorme Bedeutung in der Wiener Wohnpolitik, und ist wissenschaftlich ein völlig unangetastetes Konstrukt. Schließlich ist der Lagezuschlag das einzige Instrument im Richtwert, das außerhalb des strengen Preisdiktats eines Verbrauchpreisindex steht und (zumindest theoretisch) den „Markt“ einfangen könnte. In der Praxis dürfte diese Eigenschaft einerseits Opfer der Komplexität sein. Zum anderen ist der Lagezuschlag, also eine marktgerechte Verzinsung des Bodenwertes, in jedem zweiten Haus kategorisch unmöglich (Gründerzeitviertel).

Welche Implikationen das Mietrecht hat, wird in Kapitel 5 anhand mehrerer empirischer Befunde erörtert. Die meisten Marktbeleuchtungen stammen aus Aufträgen von Mietenschützern. Symptomatisch ist hier, dass gerade Vermieterseitig wenig Interesse an der (semi-)wissenschaftlichen Befassung mit der Vermietungspraxis an den Tag gelegt wird. Das Kapitel führt eine deskriptive Analyse über den Wiener Wohnungsbestand an.

Kapitel 6 fasst schließlich das breite Spektrum an möglichen Effekten dieses Lagezuschlagsinstruments zu Hypothesen zusammen.

Der Kern der Arbeit findet sich im empirischen Teil des Kapitels 7. Nach einer Methodendiskussion über die Anwendung eines Quasi-Experiments als post-hoc Studie wird hier auf Basis verschiedener umfassender Datensätze versucht, die Hypothesen zu verifizieren. Der Empirie liegen u.a. mehr als 30.000 Wiener Mietangebotsdaten zugrunde. Die Daten werden mithilfe eines Regres- 
sionsmodells über den Einfluss von verschiedenen Parametern - darunter die „Anwendbarkeit“ des Mietrechts - Aufschluss geben.

Das Fazit in Kapitel 8 rundet diese Arbeit ab und fasst die wichtigsten Erkenntnisse zusammen.

\subsection{Forschungsfrage}

Die Forschungsfrage für dieses Dissertationsprojekt lautet:

Welche Auswirkungen hat die Regulierung von Lagezuschlägen auf Gebiete des Wiener Altbau-Wohnungsmarktes, in denen der Lagezuschlag nicht gestattet ist?

Daraus ergeben sich die folgenden Sub-Fragen:

1) Wird die Regulierung der Lagezuschläge im mietengeschützten Bereich des Wiener Wohnmarkts eingehalten?

2) Welche lokalen Auswirkungen haben scharfe preistopographische Abstufungen zwischen Gebieten mit hohen und niedrigen Lagezuschlägen?

3) Wie unterscheidet sich die soziodemographische Bewohnerstruktur in Gründerzeitvierteln von Wohnvierteln, in denen ein Lagezuschlag möglich ist?

4) Wie gehen Marktteilnehmer mit Begrenzungen des Lagezuschlags um? Gibt es Umgehungsmechanismen?

5) Welche lokalen Auswirkungen hat eine durch die Begrenzung der Lagezuschlagsmöglichkeit erhöhte Abweichung zwischen Marktmiete und Richtwertmiete?

6) Wie hängen die erlaubte Miethöhe und der Erhaltungszustand der jeweiligen Immobilie zusammen? 



\section{Mietregulation und der Markt}

In diesem Kapitel wird die Systematik des Mietwohnungsmarktes erklärt. Er unterscheidet sich von anderen Märkten, und diese Unterschiede sind die Grundlage, auf der die Notwendigkeit der Mietregulierung argumentiert wird. Mietregulierung hat viele Gesichter und ist wie jedes Regulativ ein zweischneidiges Schwert. Sie kann in Form von ,sanfter“ Kontrolle positive Effekte haben, wie einige theoretische Beispiele zeigen, aber auch höchst unerwünschte Nebenwirkungen verursachen. Empirische Befunde gibt es, vor allem aus den USA. In diesem Abschnitt wird die grundlegende Mechanik von Mietmarkt und Mietkontrolle erörtert.

\subsection{Charakteristika des Mietwohnungsmarktes}

Was unterscheidet nun das Gut Mietwohnung vom Gut Rasierklinge? Beide decken zwar ein Grundbedürfnis des täglichen Bedarfs, doch eine Vielzahl von Parametern ist ihnen verschieden. Rasierklingen sind ein mobiles Gut im Gegensatz zu einer Immobilie. Und die Nachfrage nach Rasierklingen ist preislich „elastischer“"1 als jene nach Wohnraum. Schließlich würde eine Verdoppelung des Klingenpreises eher zu einer Neuorientierung der Bartmode führen - eine Verdoppelung der Mietpreise könnte aber nicht im gleichen Maße die nachgefragte Wohnungsmenge reduzieren. Irgendwo müssen die Menschen wohnen. Vor diesem Hintergrund greift die Politik in den Wohnungsmarkt ein. Im Gegensatz zu Rasierklingenherstellern ${ }^{2}$ sollen Vermieter ihr „örtliches Monopol“ nicht frei ausnutzen dürfen, denn das hätte gravierende gesellschaftliche und volkswirtschaftliche Folgen, so das Argument.

Was zeichnet den Mietwohnungsmarkt nun aus? Wieso weicht der Mietmarkt von einem neoklassischen Marktmodell ab? Dies hat mit der Struktur des Gutes Mietwohnung zu tun. Es sind in erster Linie die Dauerhaftigkeit und die Heterogenität, die dem Mietmarkt eine besondere Note geben, aber auch die Immobilität, die eine Rolle spielt (Jaeger, Bühler 1995, 38ff).

1 Die Elastizität ist die Anpassungsfähigkeit eines Marktes. Eine hohe Preiselastizität lässt bei steigenden Preisen schnell die Nachfrage einbrechen.

2 Wie wohl auf die monopolistische Angebotsstruktur bei Rasierklingen hingewiesen werden darf: Gillette und Wilkinson teilen sich den 15 Mrd. Dollar Weltmarkt. Die Handelsspannen auf die Herstellkosten betragen 5000 Prozent. Die Presse, online unter http://diepresse.com/home/wirtschaft/international/557519, abgerufen am 11.04.2010. 


\subsubsection{Dauerhaftigkeit von Wohnungen und Langfristigkeit von Marktbewegungen}

Olsen (1969) unterscheidet zwischen Wohnungen als Investitionsgut (Housing Stock) und der Wohnleistung innerhalb der Zeitperiode aus deren Bestand (Housing Services). Wer eine Wohnung (Housing Stock) besitzt, kann in dieser Zeit eine gewisse Menge Wohnleistung (Housing Services) konsumieren, oder konsumieren lassen (Olsen 1969, 612, 614).

Der Zuwachs an Wohnungsbestand und Wohnungsleistungen bildet sich auf dem Housing Flow Market. Das Angebot ergibt sich aus Neubauten und Totalsanierungen abzüglich der Abgänge durch Abbruch, Umwidmung und Totalsanierungen von Wohnungsbestandseinheiten. Die Nachfrage wird durch den Nettozuwachs von Haushalten festgelegt.

Die Unterscheidung zwischen Housing Stock und Housing Services ist wichtig, wenn die Preiselastizität der verschiedenen Märkte erläutert wird. Der Wohnungsbestand kann nicht kurzfristig auf eine Nachfrage reagieren, die ohnehin geringe Preiselastizität des Angebots nimmt mit zunehmendem Auslastungsgrad weiter ab (Jaeger, Bühler 1995, 42), doch dazu später.

In einem nicht-regulierten Mietwohnungsmarkt müsste jedoch auch das Angebot preiselastisch sein, indem ein primärer Mietpreisanstieg zur Verbesserung der quantitativen und qualitativen Wohnraumversorgung motiviert. Für einen solchen ausgleichenden Funktionsmechanismus ist die Gewinnorientierung der Vermieter erforderlich.

\subsubsection{Heterogenität von Wohnungen}

Jede Wohnung ist unterschiedlich und die Ausprägungen hinsichtlich Alter, Größe, Lage und Ausstattung sind mannigfaltig. Der Mietwohnungsmarkt zerfällt in viele kleine Teilmärkte, deren Zahl im Extremfall so groß ist wie die Anzahl der Wohnungen. In der Theorie hilft man sich mit der Betrachtung homogener Bestandseinheiten, die bei gleicher Ausstattung und Lage einer bestimmten Wohnnutzfläche gleichwertiger Qualität entsprechen. Alte, aber sehr geräumige Wohnungen können so mitunter derselben homogenen Bestandseinheit entsprechen wie neue, kleine Wohnungen (Jaeger, Bühler 1995, 39).

\subsubsection{Immobilität von Wohnungen}

Die Lage ist vielleicht das wichtigste Charakteristikum einer Wohnung, sie lässt sich für eine spezifische Bestandseinheit nicht ändern. Nur das Umfeld ändert 
sich durch externe Effekte, beispielsweise durch die Verkehrserschließung oder durch eine Umwidmung. ,Acccessibility“ oder Anbindung (an das Verkehrsnetz bzw. Zentrum) ist dabei die Königin unter den Lageparametern (Cheshire, Sheppard 1995, 247).

Die Immobilität hat wesentlichen Einfluss auf den Marktmechanismus von Mietwohnungen. Schließlich kann ein Mieter die Wohnung nicht mitnehmen, wenn er seinen Standort verändern möchte. Der Umzug (für den Mieter) und der Auszug (für den Vermieter) spielen eine wesentliche Rolle in Bezug auf die Transaktionskosten, die auf dem Wohnungsmarkt auftreten (Jaeger, Bühler 1995, 40).

\subsubsection{Der Einfluss von Transaktionskosten}

Die Transaktionskosten, die durch eine Weiter- oder Übergabe einer Wohnung entstehen, beeinflussen den Wohnungsmarkt. Der Mieter muss etwa Umzugsund Reinigungskosten tragen, der Vermieter muss in die Instandsetzung investieren. „Man darf wohl davon ausgehen, dass die Transaktionskosten der Mieter in der Regel insgesamt höher sind als jene der Vermieter" (Jaeger, Bühler 1995, 44). Sie beeinflussen jedenfalls das Verhalten der jeweiligen Akteure.

Der Vermieter ist in der Lage seine Transaktionskosten eher auf den Mieter zu überwälzen, je preisunelastischer sich die Nachfrage nach Wohnungen verhält bzw. je marktmächtiger er ist. Auf Vermietermärkten (mit Tendenzen zu Nachfrageüberschüssen) sind die Vermieter im Vorteil, auf Mietermärkten verhält es sich umgekehrt (Jaeger, Bühler 1995, 44). Dass etwa der Wiener Wohnmarkt eher ein Vermietermarkt ist, spiegelt sich bei der Überwälzung der Maklerkosten wider. Sie werden (in Wien) fast ausschließlich von den Mietern getragen, wiewohl auch der Vermieter eine Vermittlungsleistung erhält. ${ }^{3}$

Solange die Summe von etwaigen Mietpreiserhöhungen (diskontiert) kleiner ist als die Transaktionskosten, die ein neues Mietverhältnis verursacht, wird ein ökonomisch rationaler Mieter seine Wohnung nicht wechseln. Erst wenn die Mietpreiserhöhung die „periodisierten“ Transaktionskosten (TK) übersteigt, reduziert der Mieter seine Nachfrage. Das ergibt eine doppelt geknickte Nachfragekurve, und bedeutet, dass der Mieter innerhalb eines Preisintervalls $\left(\mathrm{P}_{1}-\mathrm{P}_{0}\right)$, das den ins Kalkül einbezogenen Transaktionskosten entspricht, eine völlig

3 Dieses Missverhältnis sorgte auf dem angespannten und mietengeschützten Wohnmarkt Wien stets für Debatten, bis eine Novelle 2010 die Maklerprovision von drei auf zwei Monatsmieten begrenzte. Dass überhaupt in den meisten Fällen die höchstzulässige Provision bezahlt wird, ist bisweilen ein Zeichen dafür, wie hoch der Nachfrageüberschuss in Wien sein muss. Der Vermittlungsmarkt durch Makler erweist sich als Überdruckventil im mietengeschützten Wohnmarkt. 
preisunelastische Nachfrage beschreibt. Ein ökonomisch rationaler Vermieter versucht, diesen Spielraum auszunutzen (Jaeger, Bühler 1995, 46) und die Rente $\mathrm{P}_{0}-\mathrm{G}_{0}-\mathrm{G}_{1}-\mathrm{P}_{1}$ abzuschöpfen (vgl. Abbildung 1).

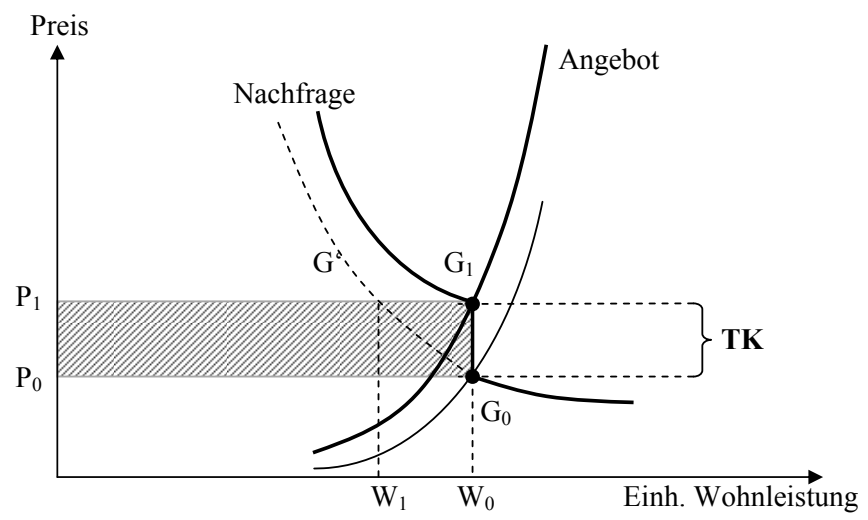

Quelle: nach Jaeger/Bühler 1995, 45

Abbildung 1: Hohe Transaktionskosten für den Mieter verursachen Nachfrageknick

Da die Transaktionskosten bei älteren Wohnungen - unter der Annahme von erhöhten Reparaturerfordernissen - für den Vermieter tendenziell höher sind als für den Mieter, würde hier die Angebotskurve den oben gezeigten Knick beschreiben. Auf eine separate Grafik wird an dieser Stelle verzichtet. Kommt es nun zu einer (exogen-marktbedingten) Senkung des Mietpreises von $\mathrm{P}_{0}$ auf $\mathrm{P}_{-1}$, so wird ein Vermieter so lange sein Angebot aufrecht erhalten, solange die periodisierten Transaktionskosten das Ausmaß der Preissenkung nicht übertreffen. Die Angebotskurve ist in diesem Preisintervall vollständig unelastisch (Jaeger, Bühler 1995, 47). „Für den Mieter eröffnet sich ein Preisspielraum, der umso größer ist, je höher die Transaktionskosten des Vermieters sind.“ Auch der rationale Mieter wird versuchen, die schraffiert dargestellte Rente abzuschöpfen.

Bei neuen Wohnungen werden die Preise aufgrund der Transaktionskostenasymmetrien systematisch zuungunsten der Mieter beeinflusst, weshalb Jaeger/Bühler $(1995,49)$ den Anwendungsbereich von Mieterschutzregulierungen zur Lösung von Transaktionskostenproblemen für bescheiden halten.

\subsubsection{Die Rolle des Leerstands}

Der Wohnungsmarkt ist kein friktionsloser Markt - auf Anbieter- und/oder Nachfragerseite bestehen Informationsmängel (Jaeger, Bühler 1995, 41). Ver- 
mieter versuchen ihre Nettorendite zu maximieren. Doch selbst in einem freien, nicht regulierten Wohnungsmarkt wird es aufgrund Bestandnehmerwechsels zu einem Leerstand kommen, der im Preisniveau der vermieteten Wohnungen berücksichtigt wird. Aus Sicht der Vermieter ist der Leerwohnungsbestand so etwas wie ein Puffer, der selbst bei einer großen Überschussnachfrage immer bestehen bleibt.

Da der Housing Stock nicht kurzfristig verändert werden kann, verhalten sich die Angebots- als auch die Nachfragekurve bei höherer Auslastung preisunelastisch, wobei die Preiselastizität des Angebots bei wachsendem Auslastungsgrad weiter ansteigt. Jaeger/Bühler 1995 zeigen, dass neben der effektiven Schnittkurve, die die Angebots- und Nachfragekurve ergeben, aufgrund der Marktfriktionen ein gewisser Leerstand vorhanden ist. Die Kurve der effektiv bewohnten Wohnungen muss somit leicht links versetzt von dieser Schnittkurve verlaufen. Je ausgeprägter die Informationsdefizite der Marktteilnehmer sind, und je stärker die Angebots- und Nachfrageprofile (Wünsche) von Mietern und Vermietern auseinanderklaffen, desto höher ist der ,natürliche“ Leerstand (Jaeger, Bühler 1995, 43f).

\subsubsection{Marktmiete versus Kostenmiete}

Die Marktmiete bezeichnet den Mietpreis, ,der in einem nicht-regulierten, funktionsfähigen Markt unter wirksamen Wettbewerbsbedingungen zu einer Markträumung führt und weder durch Mismatchbedingungen noch durch das Auftreten von Transaktionskosten nachhaltig beeinflusst wird“ (Jaeger, Bühler 1995, 52). Die Marktmiete beeinflusst somit über die erzielbare Rendite die nötigen Anreize für Investitionen in den Häusermarkt (Housing Flow Market). Mietregulierung versucht den Mietpreis an kurzer Leine zu halten und ihn an einen Kostenmietpreis zu binden.

Die Kostenmiete wird am Sachwert einer Immobilie gemessen, der sich in einen Grundanteil und einen Gebäudeanteil gliedert. Steigen die Bodenpreise oder die Baukosten, so erhöhen sich die Mietpreise, die somit ihrerseits nicht direkt von der Mietnachfrage abhängen.

Während steigende Marktmieten zu Investitionsanreizen führen, haben steigende Kostenmieten diesbezüglich keinen oder einen negativen Effekt. Mietregulierungen erlauben meist nur Kostenmietsteigerungen. Das langfristig orientierte Anreizsystem für den Wohnungsbau wird damit außer Kraft gesetzt. 


\subsection{Zwei Generationen der Regulation}

Einigkeit unter Ökonomen ist eher die Ausnahme als die Regel. Dennoch hat eine Umfrage von Alston, Kearl, and Vaughan (1992) eine Vielzahl von ökonomischen Grundsätzen auf ihre Konsensfähigkeit unter Wirtschaftswissenschaftern überprüft. Unter 40 Aussagen hat keine so viel Zustimmung bekommen wie jene, dass „Rent Ceilings“, also Mietzinsbegrenzungen, schlecht seien (Bradburd et al. 2006, 455). Die überwältigende Mehrheit der Ökonomen hält Mietkontrolle für ineffizient und für einen inadäquaten Umverteilungsmechanismus (Bradburd et al. 2006, 455f).

Streng genommen bezieht sich der Begriff „Mietkontrolle“ nur auf die maximale Höhe der Mieten, die ein Vermieter von Gesetz wegen verlangen darf (Arnott 2002, 1). In diesem Abschnitt wird auf einen weiter gefassten Begriff der Mietkontrolle eingegangen. In seiner Anwendung geht es nicht nur um die Höhe der Mietzinse, sondern um ein weit gefasstes Reglement zu finanziellen und praktischen Bedingungen, zu denen Vermieter mit Mietern ein Mietverhältnis eingehen. Übergeordnetes Ziel der Mietregulation ist es stets, den Mieter in irgendeiner Form zu schützen.

$\mathrm{Zu}$ unterscheiden sind jedenfalls zwei Begriffe, die in dieser Arbeit manchmal synonym verwendet werden: Miet-Kontrolle und -Regulation. Manche Autoren benutzen das Wort "Mietkontrolle" für die sogenannte erste Generation der Mietregulierung, und "Mietregulierung" für die zweite (Arnott 2002, 2).

Mietkontroll-Programme entstanden stets zu Notzeiten. Zur „ersten Generation“ ${ }^{4}$ derartiger Programme gehören ,rent freezes“, eingefrorene Mieten werden nur mit Unterbrechungen angehoben. Diese Art der Mietkontrolle war in den meisten großen Städten Westeuropas während des Ersten Weltkrieges eingeführt worden, um „Profitmacherei zu verhindern“ (Arnott 2002, 3). In manchen Städten wurden diese Programme nach dem Krieg abgeschafft, in anderen währten sie weiter.

Die Definition dieser ersten Generation der Mietkontrolle präzisiert Lind (2001): „Mietkontrolle der Ersten Generation ist ein nominelles Einfrieren der Miete, das zu einem Rückgang der realen Mieten und zu einem Mietniveau führt, das signifikant unter der Marktmiete liegt“" (Lind 2001, 43).

Auch während des Zweiten Weltkriegs waren die Mieten überall in Westeuropa und Nordamerika eingefroren worden. Während in Nordamerika nach dem Jahr 1950 lediglich die Stadt New York kontrollierte Mieten hatte, galten ,rent ceilings“ in Europa beachtlich länger, vor allem wegen der großen Kriegsschäden. Bis 1973 wurde in London, Paris, Stockholm und Wien ein strenges Miet-

Die Einteilung nach erster und zweiter Generation erfolgte erstmals in Arnott 1995. 
reglement gelebt. Erst danach begann die Ära der "zweiten Generation" von Mietkontrolle. (Arnott 2002, 2-3).

Mietkontrollen der „second generation“ besteht aus einem komplexen System optionaler Bedingungen, die nicht nur den Mietzins und dessen Anhebung regeln. Sie greifen tief in das Mieter-Vermieter-Verhältnis ein, indem etwa Kündigungsrecht und Erhaltungskosten reglementiert werden. Üblicherweise ist eine Mieterhöhung im Ausmaß des Verbraucherpreisanstiegs erlaubt.

Mietregulierung der zweiten Generation lässt meist einen Teil des Mietmarktes unberührt, etwa das hochpreisige Segment. Manche Regulierungen fallen bei einem Mieterwechsel weg (Arnott 2002, 3). So erlaubt die zweite Generation der Mietregulierung vielerorts die freie Vereinbarung von Mieten nach einer Bestandsfreiwerdung einer Wohnung (,vacancy decontrol“), allerdings darf diese neue, frei vereinbarte Miete meist nicht frei verändert werden (,recontrol“), sondern steigt mit einem Kostenindex. Das Mietenwachstum ist damit limitiert, nicht aber die „base-rent“ (McFarlane 2003, 306). McFarlane führt als Beispiele die Mietprogramme in Brasilien, Belgien, Finnland, Frankreich, Indien, Niederlande, Portugal, Schweden, Schweiz, USA und schließlich auch Österreich $^{5}$ an.

\subsection{Typologie der Mietkontrollprogramme}

Mietkontrollprogramme sind unterschiedlich wie die Farben der Europäischen Nationalflaggen. Für einen detailreichen Blick sei auf Lind (2001) verwiesen. Die Programme unterscheiden sich im Wesentlichen nach ihrem Ziel (vgl. Tabelle 1). Typ B etwa würde die willkürliche Anhebung der Mieten während des Mietverhältnisses unterbinden, durch das Mieter gezwungen würden eine höhere Miete zu zahlen, solange ihre Transaktionskosten höher sind als die Mieterhöhung.

Die nach dieser Typologie strengste Mietkontrolle erfahren Schweden und Österreich. Demnach soll die Miete sowohl für Neu- als auch für Altmieter unter dem Marktniveau gehalten werden, und zwar für immer.

5 In Österreich ist „vacancy decontrol“ nur in dem Sinne möglich, dass ein Vermieter nach dem Auszug eines Mieters und nach einer Sanierung der Wohnung eine höhere Miete verlangen kann. Eine freie Festsetzung der Miete ist - im mietengeschützten Bereich - de jure nicht möglich. 
Tabelle 1: Typologie von Mietkontrollprogrammen

\begin{tabular}{|c|c|c|c|c|c|}
\hline Country & $\begin{array}{l}\text { Type A } \\
\text { Weak trans- } \\
\text { actions cost } \\
\text { related }\end{array}$ & $\begin{array}{l}\text { Type B } \\
\text { Strong trans- } \\
\text { actions cost } \\
\text { related }\end{array}$ & $\begin{array}{l}\text { Type C } \\
\text { Monopoly } \\
\text { related }\end{array}$ & $\begin{array}{l}\text { Type C } \\
\text { Overshooting } \\
\text { related }\end{array}$ & $\begin{array}{l}\text { Type E } \\
\text { Segregation } \\
\text { related }\end{array}$ \\
\hline Austria & $\rightarrow$ & $\rightarrow$ & $\rightarrow$ & $\rightarrow$ & Yes \\
\hline France & $\rightarrow$ & Yes & Yes & (Yes) & No \\
\hline Germany & $\rightarrow$ & Yes & Yes & Yes & No \\
\hline Great Brit. & $?$ & No & $?$ & No & No \\
\hline Netherlands & $\rightarrow$ & Yes & Yes & (Yes) & No \\
\hline Spain & $\rightarrow$ & Yes & $?$ & No & No \\
\hline Sweden & $\rightarrow$ & $\rightarrow$ & $\rightarrow$ & $\rightarrow$ & Yes \\
\hline Switzerland & $\rightarrow$ & Yes & $?$ & No & No \\
\hline
\end{tabular}

Quelle: Lind 2001, 50. $\rightarrow$ bedeutet, es handelt sich um eine Implikation eines weiter umfassenden Systems.

\subsection{Konsequenzen der Mietkontrolle}

Rent-Control ist ein Phänomen, das sich in der Literatur ausführlich erörtert findet. Vor allem die theoretischen Mechanismen von Mietkontrollprogrammen bilden die damit einhergehenden Probleme logisch ab. In den folgenden Ausführungen wird auf diese theoretischen Auswirkungen ausführlich eingegangen, wie sie auch in jeder politischen Argumentationsrichtung genutzt werden. Empirische Befunde finden sich in Kapitel 2.7. 


\subsection{1 Ökonomischer Mechanismus von Mietkontrollregimes}

Jede Kontrolle und jedes Reglement ist ein Eingriff in den Markt und führt daher zwangsläufig zu Verschiebungen. Würden etwa Goldmünzen per Gesetz nur noch die Hälfte kosten dürfen, wären sie über Nacht ausverkauft. Keiner würde mehr Goldmünzen anbieten wollen, da der inhärente Wert als höher bemessen wird. Genauso führen Skeptiker von strengen Mietregimes gerne das Argument ins Treffen, dass ein gesetzliches Preisdumping zu geringerem Angebot und schlechterer Qualität führen würde. Sie berufen sich auf das simple Gleichgewichtsmodell, das Angebot und Nachfrage in einem freien Markt in Waage und Zaum hält (Abbildung 2). Diese theoretische Anschauung eines Marktes setzt allerdings voraus, dass alle Wohnungen homogen sind, dass der Mietmarkt einen perfekten Wettbewerb kennt, dass die Nachfragekurve nach Mietwohnungen nach unten zeigt und die Angebotskurve nach oben (Albon, Stafford 1987. 16).

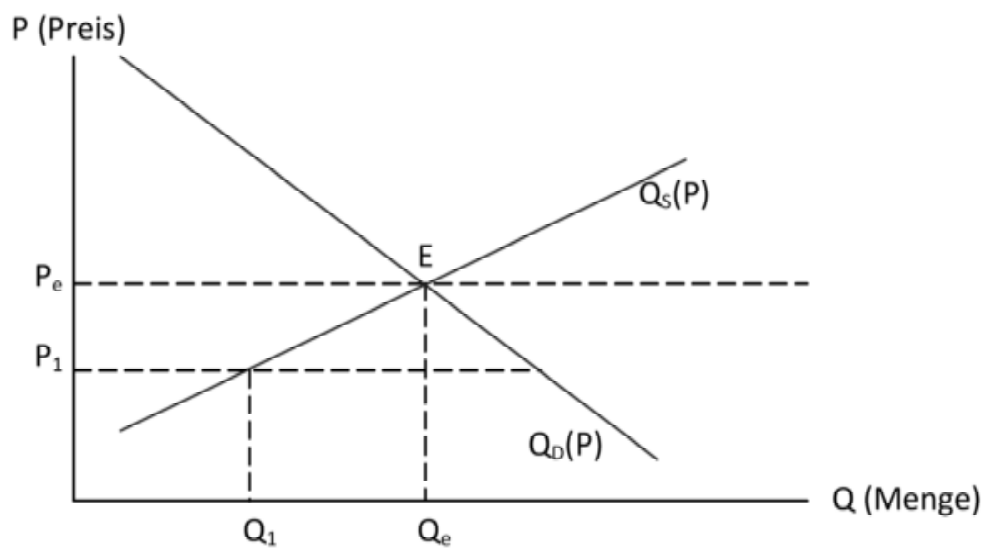

Abbildung 2: Angebot und Nachfrage im kontrollierten Markt

Die Angebotskurve (QS) und die Nachfragekurve (QD) determinieren mit ihrem Schnittpunkt den optimalen Preis $\left(\mathrm{Q}_{\mathrm{e}}\right.$ und $\left.\mathrm{P}_{\mathrm{e}}\right)$. Was passiert nun, wenn der Preis auf dem Niveau $\mathrm{P}_{1}$ eingefroren wird? Es kommt zu Wohlstandsverschiebungen, wie Abbildung 3 zeigt. 


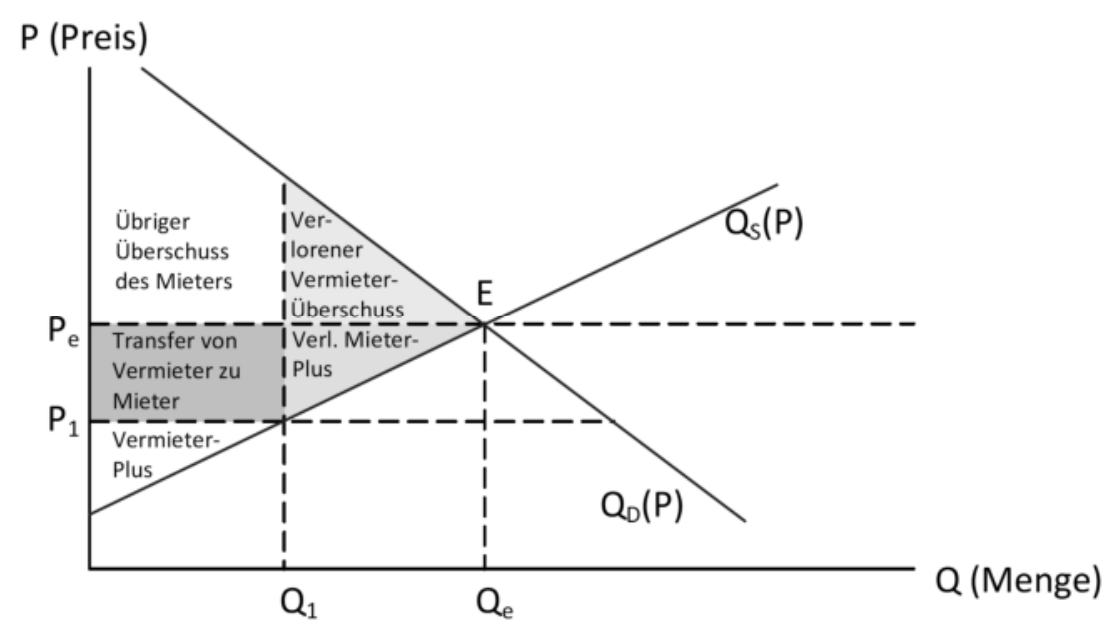

Abbildung 3: Klassische Analyse von Wohlstandsverlusten durch Mietkontrolle

Die Zahl der belegten Wohnungen würde auf $\mathrm{Q}_{1}$ zurückgehen, es gäbe einen Nachfrageüberschuss in Höhe von $\mathrm{Q}_{\mathrm{e}}-\mathrm{Q}_{1}$ (zu den Effekten des Nachfrageüberschusses siehe Arnott 2002, 4f).

Wohlstand würde von den Vermietern zu den Mietern transferiert, und zwar im Ausmaß des Quadrats $\left(\mathrm{P}_{\mathrm{e}}-\mathrm{P}_{1}\right)^{*} \mathrm{Q}_{1}$. Und Wohlstand würde verloren gehen, sowohl auf Seiten der Mieter, als auch auf Seiten der Vermieter (hell schraffierte Dreiecke zwischen $\mathrm{Q}_{\mathrm{e}}$ und $\mathrm{Q}_{1}$ ). Jede weiter gesteigerte Nachfrage würde den Nachfrageüberschuss verstärken, aber zu keiner Erhöhung des Angebots führen, und jede Kostenerhöhung für die Vermieter würde zu einer weiteren Verknappung des Angebots führen (Albon, Stafford 1987, 18).

Dieser Mechanismus zeigt sich sehr unelastisch, vor allem kurzfristig. Das ist nicht nur im kontrollierten Markt so. Auch für den freien Markt gilt bei einem Nachfrageüberschuss: Wohnungen können nicht schnell genug gebaut werden, einerseits wegen der kleinen jährlichen Produktion im Vergleich zum großen Bestand und wegen der räumlichen Immobilität von Häusern, andererseits wegen des vergleichsweise hohen Kapitalbedarfs, der lange Zeit für eine Refinanzierung benötigt (Albon, Stafford 1987, 16). Langfristig werden die Nachfrage- und Angebotskurven „flacher“, und somit elastischer.

Die (möglichen) Effekte einer rigiden Mietzinsobergrenze auf die wirtschaftliche Praxis sind vielfältig und in der Literatur ausführlich erörtert (Arnott 2002, 4f; Albon/Stafford 1987, 18; Olsen 1972, 1081ff). Die wichtigsten werden in den nachfolgenden Kapiteln diskutiert: 


\subsubsection{Reduzierte Profitabilität und Bestands-Deterioration}

Die Mietdeckelung reduziert die Profitabilität der Vermietung und schreckt von Instandhaltungsinvestitionen ab. Damit verschleißt der Bestand an Wohnungen schneller, bei gleichzeitiger Baureduktion von neuen Wohnungen. „Any resulting lack of maintenance and repair is worsened by the landlord's uncertainty as to whether he will be able to repossess the property, given that provisions exist in respect of tenants' security of tenure“ (Albon, Stafford 1987, 21f). Der Mieter erhält effektiv eine Subvention vom Vermieter in Höhe der Differenz von Markt- und kontrollierter Miete.

\subsubsection{Effekte des Nachfrageüberschusses}

Ein weiterer Effekt von Mietdeckelung ist ein hoher Nachfrageüberschuss; das Mietangebot ist künstlich billig, aber kaum ausreichend vorhanden. „Wie sich der Nachfrageüberschuss offenbart, hängt davon ab, wie der Mietmarkt zugeteilt ist" (Arnott 2002, 5).

1. Der offensichtlichste Effekt ist, dass Altmieter lieber zu günstigen Konditionen in ihrer bisherigen Wohnung bleiben, während neue Mieter aus dem Markt gedrängt werden. In Extremfällen kann das zur Obdachlosigkeit führen. Normalerweise ist die Konsequenz aber, dass neu gegründete Haushalte in kleineren Einheiten unterkommen müssen und dass Kinder später ausziehen.

2. Vermieter suchen aus, wem sie die Wohnung vermieten. Ist die Wohnungsnot groß genug, können Vermieter komfortablere Mieter (etwa gut verdienende Singles statt Familien) bevorzugen.

3. Illegale, quasi-legale oder legale Ablösen bzw. Bestechnungsgelder fließen, um in Besitz einer mietregulierten Wohnung zu kommen (Grampp 1950, 437 nach Olsen 1972, 1097). „Obwohl diese gesetzlich verboten sind (New York Rent and rehabilitation Administration 1965), gibt es keinen Grund zu glauben, dass sie (die Bestechungsgelder, Anm.) mit geringer Häufigkeit auftreten“ (Olsen 1972, 1097). Dieses Phänomen war in Österreich zu Zeiten noch strengerer Mietkontrolle bis in die 90er Jahre besonders ausgeprägt.

4. Eine weitere Konsequenz aus einem Nachfrageüberschuss ist eine geringere Mobilität, gepaart mit höherem Verkehrsaufkommen. Kein Mieter gibt gerne seine Wohnung auf, wenn er damit hohe Suchkosten und das Risiko einer erfolglosen Wohnungssuche ein Kauf nehmen muss, unge- 
achtet seiner arbeitsbedingten Ortspräferenzen. Das kann zu einer geringeren Arbeitsmobilität führen.

Wie Friedrich August von Hayek (1930) über Wien ausführt: Lohnempfänger entscheiden sich zu pendeln anstatt zu übersiedeln, um nicht den günstigen Mietzins zu verlieren. Diese Immobilität führt dazu, dass sich Löhne in verschiedenen Regionen nicht angleichen. Zudem steigt das Verkehrsaufkommen, wenngleich das Pendlerleben ,auf keinen Fall zufriedenstellend" ist. Von 1913 bis 1928 hat sich der Straßenbahnverkehr verdoppelt während die Bevölkerungszahl in Wien zurückging. Das kann nur durch die behinderte Mobilität aufgrund der Mietkontrolle erklärt werden (Hayek 1930, $7 \mathrm{ff}$ in Albon/Stafford 1987, 60f).

5. Fehlallokationen und ineffiziente Aufteilung des Wohnraums wären die Folge, wenn etwa eine mittellose Witwe aus Kostengründen in jener großen - aber aufgrund der Mietkontrolle billigen - Wohneinheit bleibt, in der sie einst ihre Kinder aufgezogen hatte, während junge Familien in enge Räumlichkeiten ziehen müssen.

6. Höhere Suchkosten für Mieter: „Die Zeit, die für die Wohnungssuche in Anspruch genommen wird, ist in New York sicher aufgrund der Mietkontrolle größer. Nicht nur für jene, die schließlich eine derartige Wohnung bekommen, sondern auch für jene, die keinen Erfolg dabei haben“ (Grampp 1950, 438 nach Olsen 1972, 1079).

\subsubsection{Umverteilung und Effekte auf nichtregulierte Mietmärkte}

Mietkontrolle hat Eigentumseffekte und führt zur Umverteilung sowohl von der Gruppe der Vermieter als auch von der Gruppe der von Wohnraum ausgeschlossenen Neumieter hin zur Gruppe der Altmieter.

„Die Mieter von Altbauwohnungen werden begünstigt, da eine billige Wohnung für den Benützer einen gewaltigen Vermögenswert in Höhe des kapitalisierten Differenzbetrages [...] darstellt. Die Höhe dieser Differenz kann aus den zwar verbotenen, aber trotzdem verlangten und auch tatsächlich bezahlten Ablösen ermessen werden“ (Sandner 1962, 239f).

Auch die Eigentümer von nicht-mietkontrollierten Häusern können betroffen sein. Alleine die Existenz von Mietkontrolle macht sie auf Änderungen der Mietgesetze sensibel, da eine Ausweitung der Gesetze einen Verlust für sie bedeuten könnte. „Daher muss man erwarten, dass Immobilien-Investoren in New 
York eine höhere Risikoprämie verlangen und erhalten“ (Olsen 1972, 1098). Dies hätte einen umgekehrten Effekt zum politischen Willen der Mietkontrolle.

\subsubsection{Effekte auf den Eigentumsmarkt: verkaufen statt vermieten?}

Ist die regulierte Miete zu gering, so kann dies zum einen ein Marktventil öffnen (verbotene Ablösen, etc.). Zum anderen kann sich der Vermieter entscheiden, den Markt zu verlassen. Dieses Phänomen wird in bisherigen Studien nicht behandelt.

Der Wohnungsmarkt besteht aus einem Mietmarkt und einem Eigentumsmarkt, wobei letzterer Eigentumswohnungen für Eigennutzer als auch Anlegerwohnungen für Investoren umfasst. Wohnungen können vermietet oder verkauft werden. Der Wert einer Wohnimmobilie steht in der Regel in Verhältnis zum erzielbaren Mietpreis, und zwar über den Ertragswert einer Liegenschaft, der sich aus den Mieteinnahmen und einer Liegenschaftsverzinsung ergibt. Ob ein Investment in eine Anlageimmobilie Sinn macht, darüber gibt wiederum der Barwert Aufschluss. Bei der Barwertberechnung werden zukünftige Cashflows auf die Gegenwart diskontiert (Dasso et al. 1995, 106ff):

$$
B W=\sum_{t=1}^{n} \frac{C F_{t}-\text { Inst }_{t}}{(1+r)^{t}}+\frac{V P_{n}}{(1+r)^{n}}
$$

BW Barwert gegenwärtig

$\mathrm{CF}_{\mathrm{t}}$ Cash Flow der Periode $\mathrm{t}$

Inst $_{\mathrm{t}}$ Instandhaltungsaufwand der Periode $\mathrm{t}$

$\mathrm{VP}_{\mathrm{n}} \quad$ Verkaufspreis am Ende im Jahr $\mathrm{n}$

$\mathrm{r} \quad$,rate of return“, interner Zinsfuß, wobei: $r=r_{f}+p$; der interne Zinsfuß setzt sich aus $r_{f}$, dem risikofreien Zinsfuß, und $p$, einer Risikoprämie, zusammen

(Dasso et al. 1995, 63)

Von wesentlicher Bedeutung ist der interne Zinsfuß. Dieser preist das Risiko des Investments ein. Das Risiko, und damit die „Liegenschaftsverzinsung“, hängen vom Standort der Immobilie ab. Gute Lagen erlauben geringe Verzinsungen, schlechte Lagen müssen aufgrund des Risikos (Leerstand, Abwertung, geringer Sachwert), einen höheren Liegenschaftszins einbringen. In der Praxis der Immobilienbewertung wird gerne der Ertragswert errechnet. Bei diesem wird 
der Reinertrag einer Immobilie mit einem „Vervielfältiger“ multipliziert. Das ermöglicht eine heuristische Herangehensweise, denn die Vervielfältiger ${ }^{6}$ berücksichtigen automatisch den Liegenschaftszins (damit das Risiko der Immobilie) sowie die Restnutzungsdauer. Der Einfachheit halber bleibt bei nachstehender Formel die Restnutzungsdauer unberücksichtigt, sodass lediglich der Liegenschaftszins den Ertragswert determiniert.

$$
E W=\frac{M-I n s t}{\operatorname{LiZi}}+B W_{\text {kap }}
$$

$\begin{array}{ll}\text { EW } & \text { Ertragswert } \\ \mathrm{M} & \text { Mietertrag/Jahr } \\ \text { Inst } & \text { Instandhaltungs- und Werbungskosten } \\ \text { LiZi } & \text { Liegenschaftszins (i.d.R. zW. } 3 \text { und 9 Prozent) } \\ \text { BW }_{\text {kap }} & \text { Bodenwert, kapitalisiert }\end{array}$

Nun kommt das Mietrecht zu tragen, und der Mietertrag M sowie der Ertragswert sinken. Unter strenger Mietkontrolle kann damit der Ertragswert sogar unter den Sachwert der Immobilie sinken. Das ist dann der Fall, wenn die Rendite unter Mietregulierung weit unter der (de facto vom Markt generierten) Liegenschaftsverzinsung zum Liegen kommt, und auch andere oben genannte Marktventile verschlossen bleiben. Dann wird sich der rational handelnde Vermieter entscheiden, die Wohnung zum in diesem Falle höher liegenden Sachwert zu verkaufen. Dieser stellt in diesem Fall den Verkehrswert des Objekts dar, und wird in der Regel von Nachfragern nach Eigentumswohnungen zur Eigennutzung bezahlt. Dies gilt wenn

$$
\begin{array}{ll}
M_{\text {kontr }}-\text { Inst }+M V_{\text {kap }} & \text { LiZi } \\
\hline & \text { Regulierte Miete } \\
\mathrm{M}_{\text {kontr }} & \text { Instandhaltungskosten } \\
\text { Inst } & \text { Integenschaftszins } \\
\text { LiZi } & \text { Liegens } \\
\text { MV }_{\text {kap }} & \text { Marktventil (illegale Ablöse etc.), kapitalisiert } \\
\text { BW }_{\text {kap }} & \text { Bodenwert, kapitalisiert } \\
\text { VK } & \text { Verkehrswert (Sachwert) }
\end{array}
$$

Oder vereinfacht: es kommt zu Verkäufen, wenn die erzielbare Rendite geringer ist als der inhärente Liegenschaftszins. ${ }^{7}$ Ein begrenzter Mietertrag muss

6 Bei ,normalen“ städtischen Immobilien wird gerne ein Vervielfältiger von 20 gewählt, was einer Restnutzungsdauer von 40 Jahren bei einem Zinsfuß von 4,0\% entspricht.

7 In Wien etwa gesteht der Gesetzgeber dem Vermieter eine Kostenmiete von vier Prozent des Kapitals zu (etwa für Investitionen, die als Zuschläge verrechnet werden kön- 
bei entsprechender Nachfrage auf dem Eigentumswohnungsmarkt zu Wohnungsabverkäufen führen. Mietshäuser werden parifiziert und die Wohnungen einzeln abverkauft ${ }^{8}$. Die bisherigen Mietwohnungen werden an neue Einzeleigentümer verkauft, die möglicherweise nicht vermieten, da dies im gesetzlichen Rahmen nicht lukrativ ist, sondern eine Geldanlage suchen. Das reduziert das Mietangebot.

\subsubsection{Segregationseffekte}

Haushalte mit ähnlichen Wohnpräferenzen bevorzugen Häuser und Wohnungen mit ähnlichen Eigenschaften. Wenn ähnliche Wohnungen nun örtlich konzentriert sind, werden Haushalte mit ähnlichen Präferenzen in den gleichen Wohngegenden leben. Weil Präferenzen immer Budgetgrenzen ausgesetzt sind, werden sich Haushalte mit ähnlichem Einkommen in bestimmten Gegenden konzentrieren. „In a housing market without any regulation, housing-market dynamics tend to enhance the income-based concentration of similar groups of households" (Giffinger 1998, 1792). Es kommt zu Segregation, vor allem wenn Wohnungen eines bestimmten Marktsegments (schlechten Standards) örtlich konzentriert sind (Giffinger 1998, 1793).

Freilich entscheiden sich Individuen auch bewusst für eine räumliche Konzentration. Etwa, um in einem ,ethnisch prädominierten Wohnviertel“ zu leben, da dort gewisse infrastrukturelle Annehmlichkeiten zu finden sind (Giffinger 1998, 1794).

\subsubsection{Auswirkungen von Mietkontrolle auf andere Märkte}

1) Realitätenmarkt: Wohnen wird allmählich nicht zur Miet- sondern zur Eigentumssache, da es für den Vermieter lukrativer ist, eine frei werdende Wohnung zu verkaufen, als weiter zu vermieten. Der Markt dreht in Richtung Eigentum, Mietangebote werden knapp.

2) Verbrauchermarkt: Haushalten bleibt mehr Geld für Konsum, die Konsummärkte profitieren.

3) Unrestringierte Mietmärkte: Neben dem regulierten gibt es meist einen unregulierten Mietmarkt, der aufgrund von Nachbarschaftseffekten durch

nen). Läge der Liegenschaftszins über dieser regulierten Rendite, dann müsste dies die Investitionen hemmen.

8 Nicht selten haben so etwa in Wien bestehende Altmieter ,ihre“ Wohnung günstig gekauft. 
die Mietregulation unter Druck kommt (Olsen 1972, 1098). Einerseits sind Vermieter dieses Marktsegments sensibel auf mögliche Gesetzesänderungen, die auch deren Bestandsobjekte unter Mietkontrolle stellen könnten, andererseits verlangen sie dafür eine höhere Risikoprämie: „This implies that occupants of uncontrolled housing were worse off than they would have been in the absence of rent control.“(Olsen 1972, 1098)

\subsubsection{Regulierung kostet den Mietern}

Dass auch eine „sanfte“ Regulierung der Mieten, nämlich über verschiedene Erhaltungsregelungen und Kündigungsschutz zugunsten der Mieter, einen unerwünschten Effekt auf die Mietpreise haben kann, zeigen Albon und Stafford (1987) in einem einfachen, theoretischen Gedankenbeispiel. Gesetzt den Fall, dass die Mieten „frei“ wären, und keinerlei staatliche Intervention bestünde, würde sich der Preis im Schnittpunkt von Angebots- und Nachfragekurve ergeben (vgl. Abbildung 2, Schnittpunkt E). Angenommen die Regierung würde plötzlich verschiedene Mieterrechte einführen, aber die Miethöhe nicht beschränken. Die Mieter würden diese Rechte positiv bewerten und demnach ihre „willingness-to-pay“ anpassen. Die Nachfragekurve verschiebt sich entsprechend nach rechts. Allerdings bedeuten diese Rechte auch Kosten für den Vermieter, dessen Angebotskurve sich in entgegengesetzter Richtung, nach links, bewegt. Diese Linksbewegung ist größer als die Rechtsbewegung der Nachfragekurve, da die Kosten für den Vermieter i.d.R. größer sind als der Zahlungswille der Mieter für ein etwaiges eingeräumtes Recht.

Der Preis steigt somit überproportional und sogar die scheinbar bevorteilten Mieter zahlen nun mehr als ihnen diese zusätzliche Mieterrechte eigentlich wert sind; der Vermieter kommt ohnehin schlechter weg. Diese ungünstige Konstellation kommt unbedingt auch durch „sanfte Mietregulierung“ zustande, außer es herrschen signifikante Informationsdefizite auf dem Markt. „The iron fist is less effective than the invisible hand“" (Albon, Stafford 1987, 115f).

\subsection{Zur Notwendigkeit von Mietkontrolle}

Auch wenn strenge Mietkontrollen von den meisten Ökonomen kritisiert werden, heißt das für Arnott $(2002,8 \mathrm{f}) \mathrm{nicht}$, dass eine ,zeitweilige Mietkontrolle immer schlechte Politik ist", etwa in Kriegszeiten, wenn weder Vermietern noch Mietern durch Mietkontrollen ein großer Schaden zugefügt wird. Ein Problem entstünde zu Kriegsende: einerseits will man heimkehrenden Soldaten günstigen Wohnraum zur Verfügung stellen, andererseits gilt, ,je länger Kontrollen in 
Kraft sind, desto politisch schwieriger ist es, sie wieder abzuschaffen" (Arnott 2002, 8).

\subsubsection{Mehr Wohlstand mit milder Mietkontrolle}

Arnott (2000) berücksichtigt in seinem Mietkontroll-Modell auch die Suchkosten der Mieter und Vermieter. Gäbe es keine Mietkontrolle, so hätte das auf dem Markt drei Effekte: Längere Suchkosten, höhere Leerstandsraten und „mismatch-costs“. Ein von Haus aus geringerer Mietpreis würde die Vermietungen abkürzen und insgesamt den volkswirtschaftlichen Wohlstand steigern. Dadurch könne eine Einsparung von 1,98 Prozent an „social savings“ durch die optimale Mietkontrolle erwirkt werden (Arnott, Igarashi 2000, 264). „The uncontrolled equilibrium vacancy rate is inefficiently high" (Arnott, Igarashi 2000, 277). Den umgekehrten Effekt hätte im Übrigen eine extrem strenge Mietkontrolle, die derartig hohe mismatch-costs verursacht, dass Mieten doppelt so teuer wird wie unter freien Marktbedingungen.

Keine Mietkontrolle ist somit besser als eine strenge. Sie abzuschaffen würde zumindest auch ein politisches Risiko ausschalten, nämlich dass Regierungen in Bezug auf die Mietrechtsgesetzgebung in mietengeschützten Ländern nicht immer berechenbar sind (Arnott, Igarashi 2000, 276).

Immerhin wird der Mietregulierung durch Arnott eine Lanze gebrochen. Lind (2001) bringt das Gegenargument: „The article indicates that such rent regulation could lead to rents roughly $5 \%$ below the laissez-faire level. This is less than the margin of error in estimations of the market rent. Taking into account the imperfections and costs of any regulating authority, rent regulation with this limited purpose would not pass a cost-benefit analysis" (Lind 2001, 192).

\subsubsection{Wettbewerbsprobleme: asymmetrische Information}

Arnott argumentiert heutige Mietregulierungen aber anders. Der Markt selber arbeitet nicht effizient genug und braucht Regulierung, denn er steht nicht unter vollständigem Wettbewerb. Es gibt asymmetrische Informationen (Chang 2008, 174). Die Mieter können leicht übervorteilt werden, und müssten daher geschützt werden, zumal es sich um wirtschaftlich Schwächere handelt. Die soziale Komponente wird stets politisch argumentiert (Chang 2008, 174). 


\subsubsection{Wettbewerbsprobleme: Übervorteilung der Mieter}

Würden Angebot und Nachfrage ausgeglichene Faktoren in einem System vollkommenen Wettbewerbs sein, dann würden sich auch auf dem Angebotsmarkt die Hausherren konkurrenzieren. Theoretisch könnte ein solcher Wettbewerb stattfinden, wenn der Mietmarkt frei von Preisvorgaben wäre. Die Mietpreise würden mittelfristig wieder ein Gleichgewicht finden, das für alle Beteiligten fair sei. So argumentieren Liberalisierungsbefürworter.

Gerade in der Geographie schafft allerdings ,die Existenz räumlicher Distanz eine bestimmte Art von Monopol“" (Dicken et al. 1999, 207). Ein vollkommener Wettbewerb sei unmöglich, wenn Raum und Distanz berücksichtigt werden. Diese Erkenntnis bezieht sich zumindest auf Firmenstandorte, die einem einzelnen Wirtschaftstreibenden die Macht geben, 1) den Output einer ganzen Branche zu kontrollieren, 2) den Verkaufspreis festzusetzen und 3) starke Eintrittsbarrieren für Konkurrenten zu besitzen. Ein derart „,modifizierter“ vollkommener Wettbewerb - sei es durch räumliche Fragmentierung der Märkte wird als monopolistischer Wettbewerb bezeichnet.

Auch Lind (2001) stellt fest, dass ein Vermieter eine bestimmte Monopolmacht aufgrund der Heterogenität des Wohnungsangebots hat. „This power can be used to get a rent from a specific household, that is higher than the market rent" (Lind 2001, 46). Wenn etwa ein Mieter genau diese bestimmte Wohnung benötigt, da sie unmittelbar neben seiner Familie situiert ist, dann könnte der Vermieter dieses Wissen zu seinem Vorteil nutzen. Das gilt auch für Suchende, die bereits dringend eine Wohnung benötigen, oder die keine Ahnung über die Mietmarktlage haben.

\subsubsection{Die „Hauspreis-Mietenspirale“ der AK-Wien}

Die Wiener Arbeiterkammer, einer der aktivsten Mieterschützer, kritisiert stets, dass auf dem Rücken der Mieter (in Wien) Immobilienspekulation betrieben wird. Durch steigende Hauspreise steigen die Ertragserwartungen der Vermieter in Bezug auf Ihre Mieterlöse. Wer teuer kauft, muss einen hoch kalkulierten Mietertrag erwirtschaften, damit sich das Immobilieninvestment rechnet. Höhere Mieten wiederum führen zu steigenden Ertragswerten und Verkaufserlösen (Feigelfeld et al. 2007, 4).

Auch wenn die Mieten ja rechtlich von einer derartigen „HauspreisMietenspirale“ geschützt sein sollten: Steigende Immobilienpreise führen freilich dazu, dass auch die jeweiligen Grundkostenanteile (GKA) der Häuser steigen. In Lagen, die zu einem Lagezuschlag berechtigen, wirkt ein steigender 
Grundkostenanteil direkt auf die Höhe des berechtigten Lagezuschlags ${ }^{9}$. Dies sei anhand von Abbildung 4 verdeutlicht.

9 Im Übrigen werden die dadurch steigenden Grundkostenanteile (GKA) in den Empfehlungen der MA 25 über die Höhe des jeweils örtlichen Lagezuschlags nicht vollständig abgebildet, wie später noch einmal aufgezeigt wird. Die den Empfehlungen zugrunde liegenden Grundkostenanteile stammen aus Daten der MA 69, deren Berechnungen über örtliche Grundkosten ausschließlich über Preisdaten aus dem Verkauf unbebauter oder bebaubarer Grundstücke resultieren. 


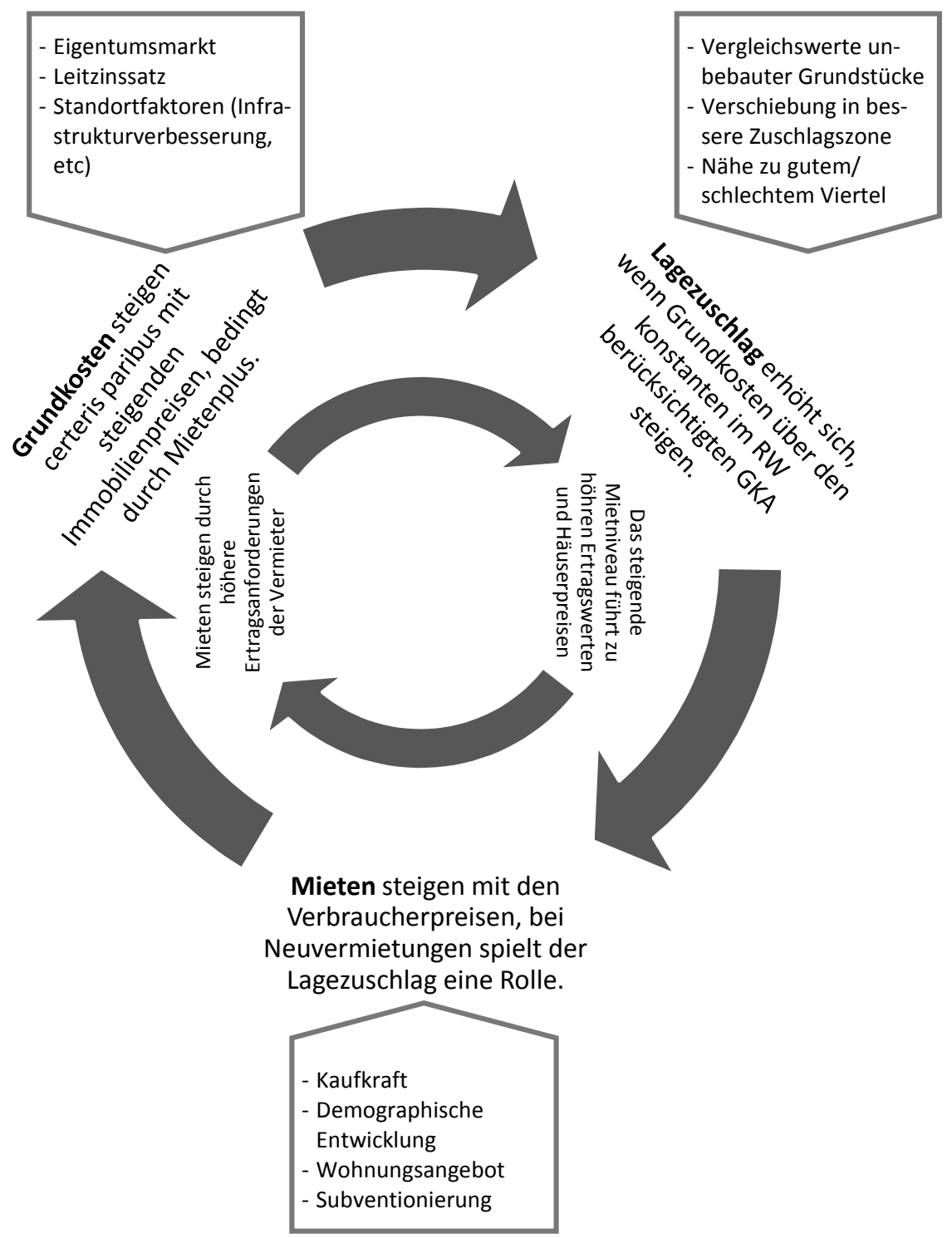

Abbildung 4: Steigende Immobilienpreise verursachen steigende Immobilienpreise 


\subsubsection{Sonstige Argumente für Mietkontrolle}

Die Kritik, dass Mietkontrolle zwangsläufig zu geringeren Erhaltungsinvestitionen führen müsse, weist Olsen (1988) zurück. Schließlich würden Mietkontrollen den Mieter ermutigen, länger in seiner Wohnung zu bleiben. Der Mieter hat daher ein intrinsisches Interesse an der Erhaltung des Wohnraums und einen Anreiz, selbst zu investieren. Diese Argumentation ist nicht neu. „Einige Bewohner von mietregulierten Wohnungen finden es vorteilhaft, Geld in die Erneuerung ihrer Wohnungen zu stecken" (Grampp 1950, 437).

Volkswirtschaftlich kann die Regulation von Mieten den Vorteil haben, dass den Konsumenten mehr Geld für Konsum bleibt. Olsen meint, dass dieser Effekt bei weitem unterschätzt wird (Olsen 1972, 1097). Dass freilich auch die Mieten einen Multiplikatoreffekt zur Stärkung der regionalen Bauwirtschaft haben können, bleibt dabei unbeachtet.

Ist der Mietmarkt monopolistisch? Basu/Emerson schreiben dazu: „Assuming rental housing markets to be monopolistic may be an abstraction from reality, but, with all of the evidence to suggest large amounts of concentration and possible collusion (through landlord's associations) in many rental housing markets, it is certainly no more of an abstraction than models assuming perfect competition (as is the norm in the literature)." (Basu, Emerson 2003, 230)

Auf wissenschaftlicher Ebene ruft Arnott (1995) zu einem Umdenken auf: „Modern, second-generation rent controls are so different that they should be judged largely independently of the experience with first-generation rent controls. [. . .] The case against second-generation rent controls is so weak that economists should at least soften their opposition to them." (Arnott 1995, 118)

\subsection{Deregulierung}

„Decontrol is more likely to occur when the rental vacancy rate is relatively high and when the government in power is politically secure" (Arnott 2002, 16). In Kanada führten alle 10 Provinzen im Jahr 1975 Mietregulierungen ein. Seither haben sechs davon die Mietkontrollen wieder aufgegeben, von den vieren sind sie nur in einer Provinz (Ontario) härter geworden und ansonsten weiter liberalisiert worden.

Auch Anhänger der Liberalisierung sehen die Deregulierung differenziert. „Die immer von den Hausbesitzerkreisen geforderte völlige Freigabe aller Mieten ist entschieden abzulehnen. Eine solche Maßnahme wäre nur dann gerechtfertigt, wenn auf dem Wohnungsmarkt vollständiges Gleichgewicht herrschte. Da aber in Österreich sowohl ein quantitatives als auch qualitatives Wohnungsdefizit besteht, hätte ein plötzlicher Übergang zur freien Marktmiete zur Folge, 
dass die Mieten weit über die Kostenmiete hinaus solange steigen würden, bis die Kaufkraft der zahlungsschwächsten Mieter nicht mehr ausreicht, die Steigerung zu bezahlen“" (Sandner 1962, 241).

\subsection{Empirische Befunde zu Mietregulierung}

Die folgenden Seiten geben einen Literaturüberblick zu verschiedenen und verschiedenartigen Studien zum Thema Mietkontrolle, sie wurden teilweise bereits zuvor zitiert.

\subsection{1 „Weniger Wohnung, mehr Konsum““}

Mietkontrolle hat Auswirkungen auf die Ressourcenverteilung und den Wohlstand. In New York im Jahr 1968, zur Zeit starker Mietkontrolle, haben die Mieter aufgrund der Regulierung weniger für Wohnen und mehr für übrigen Konsum ausgegeben. Die Ausgaben für Wohnen lagen um 4,4 Prozent unter, jene für alle übrigen Güter um 9,9 Prozent über dem Volumen, das sie haben würden, würde es keine Mietkontrolle geben (Olsen 1972, 1082).

\subsubsection{Mietkontrolle macht örtlich unflexibel (Svarer/Rosholm/Munch 2005)}

In Dänemark greift Mietkontrolle in unterschiedlichen Intensitäten auf den Mietmarkt ein. In jenen 10 Prozent der Wohnungen, wo die Mietregulierung am strengsten ist, bleiben die Mieter durchschnittlich sechs Jahre länger wohnen als in den 10 Prozent am wenigsten regulierten Wohnungen. Svarer/Rosholm/ Munch (2005) gehen der Frage nach, wie stark sich das Mietrecht auf die Arbeitsmobilität auswirkt. Sie greifen die Hypothese auf, dass strenge Mietkontrolle - und demnach günstige Mieten - die Mobilität der Mieter einschränkt. Schließlich würden sie mit einem Ortswechsel das günstige Mietobjekt verlieren.

Tatsächlich schlägt sich diese Immobilität auf die Strukturen von Beschäftigung nieder. Basierend auf den dänischen Daten kann gezeigt werden, dass die Wahrscheinlichkeit, einen auswärtigen Job zu finden, unter Mietkontrolle abnimmt. Die Arbeitsmobilität der Dänen ist grundsätzlich eher gering. Noch geringer ist sie allerdings bei jenen Bürgern, die in einer mietengeschützten Wohnung leben. Sie finden eher auf dem lokalen Arbeitsmarkt eine Anstellung, wäh- 
rend „ungeschützte“ Mieter eher den Schritt in einen anderen, geographisch entfernteren Arbeitsmarkt wagen (Svarer et al. 2005, 2178f).

Besonders immobil zeigen sich Arbeitslose. Es kann allerdings nicht gezeigt werden, dass in mietenregulierten Wohnungen lebende Arbeitslose längere Pendeldistanzen auf sich nehmen würden, um einen Arbeitsmarkt zu erschließen.

\subsubsection{Tschechischer Schwarzmarkt für Mietwohnungen}

Buzar (2005) untersucht die Auswirkungen der Mietkontrolle in Tschechien und argumentiert, dass regulierte Mieten ineffizient sind, da die Subvention auch besser Verdienenden zukommt. „Rent control is poorly targeted in terms of income because there is significant, leakage' to families who do not require such support" (Buzar 2005, 390f). Außerdem seien Eigentümer nicht motiviert, mit den geringen Mieteinnahmen energieeffiziente Maßnahmen in den Gebäuden zu setzen, wodurch Mieter mit geringen Einkommen zusätzlich unter Druck kämen (vgl. Buzar 2005, 399). Buzar belegt, dass in Regionen, wo Wohnen teurer ist, die Zahl der Empfänger von Wohnbeihilfe zurückgeht. Mietkontrolle führt zu einer rechtlichen Grauzone: „Familien in Regionen mit großer Wohnnachfrage sind mit unleistbar hohen Preisen im privaten Mietbereich fertig geworden, indem sie Zuflucht beim aufkeimenden Black-Housing-Market nahmen, dessen Aufkommen eine direkte Forge von regulierten Mieten ist" (Buzar 2005, 391). Das System behilft sich über illegale Untervermietungen und Ablösen. Das funktioniert etwa, indem teuer ,untervermietet“ wird, oder Wohnungen ,getauscht" und Ablösen gezahlt werden.

Die Differenz zwischen regulierten Mieten und Marktmieten wird besonders an begehrten Standorten größer. ,The most-visible changes have pertained to the inability of the regulated rent system to keep up with the sharp differences in market rents that have been created by the new patterns of housing demand and supply. Even though the state has attempted to introduce a degree of spatial differentiation in the policy of regulated rent increases, such measures have been too weak to prevent the widening gap between market and controlled rents in desirable locations (such as the city centers)" (Buzar 2005, 397). Obadalová $(2000,387)$ meint, dass das regulative System verfassungswidrig sei, da es das Recht auf Eigentum diskriminiert, und das Recht der Eigentümer, eine finanzielle Kompensation für ihr Eigentum zu bekommen. 


\subsubsection{Auswirkungen von ,vacancy decontrol recontrol Programmen"6}

In den meisten Staaten mit rigiden Mietenbeschränkungen wurden diese zu Gunsten milderer Mietkontrolle aufgegeben. Die zweite Generation der Mietregulierung erlaubt vielerorts die freie Vereinbarung von Mieten nach einer Bestandsfreiwerdung einer Wohnung (,vacancy decontrol"), allerdings darf diese neue, frei vereinbarte Miete meist nicht frei verändert werden (,recontrol“), sondern steigt mit einem Kostenindex (McFarlane 2003, 306). Diese mietrechtliche Vorgabe hat Auswirkungen auf den Markt, stellt McFarlane in einem theoretischen Modell fest: Vacancy-decontrol-recontrol führt zu kürzeren Mietdauern und zu einem hastigen „Redevelopment“ nach einem Mieterwechsel. Die Indexgebundene Mietstabilisierung erhöht nämlich später die Mietsteigerung bei einem Mieterwechsel, aber erhöht auch die Opportunitätskosten, diese Wiedervermietung zu verzögern. Den Mietern nutzt die Mietenstabilisierung folglich nicht, oder würde lediglich dann nützen, wenn auch die Miethöhe bei Neuvermietungen reguliert würde (McFarlane 2003, 331f). Wesentliches Kriterium ist dabei die Mietdauer, die von vornherein nur dem Mieter bekannt ist, und damit eine asymmetrische Information zugunsten des Mieters darstellt. Siehe zu diesen „tenancy control programs“ auch Basu/Emerson 2000 und Basu/Emerson 2003.

\subsubsection{Asymmetrische Information der Mieter: Kurzmieter benachteiligt (Basu 2000)}

Basu/Emerson (2000) befassen sich mit der Mieterselektion, die aus asymmetrischer Information entsteht, wenn ,vacancy decontrol-recontrol“ wirkt, wenn also Vermieter nur bei einem Mieterwechsel die Miete erhöhen können und ansonsten die Miete lediglich mit einem Preisindex steigt. Der Vermieter hätte in diesem Zusammenhang Interesse, jene Mieter auszuwählen, die kürzer in der Wohnung wohnhaft zu bleiben planen, bzw. entsprechende Befristungen vorzugeben. Weiß der Vermieter nicht, ob der Mieter lange oder kurz bleibt, so kann er nicht nach diesem Kriterium diskriminieren. Daher profitieren ,longer staying tenants", und kürzer bleibende Mieter werden von dieser Art der Mietkontrolle benachteiligt (Basu, Emerson 2000, 958). Wieder ist es die asymmetrische Information, die den Markt beeinträchtigen würde. Nur der Mieter selbst kann wissen, ob er lange oder kurz bleiben will (Basu, Emerson 2000, 939). 


\subsubsection{Schrumpfen des Mietmarktes}

Mehrere Untersuchungen belegen den Rückgang des Mietangebots bei Mietkontrolle. Langzeit-Mietkontrolle in Großbritannien und Israel hat zu Zerfall und Schrumpfen des Mietmarktes geführt (Coleman 1988; Werczberger 1988). Friedrich Hayek zeigt, welch schädliche Konsequenzen die Mietkontrolle in der Zwischenkriegszeit in Wien hatte. Diese Meinung teilen auch George Stigler, Milton Friedman, Bertrand de Jouvenel (Fraser Institute 1975) und zahllose andere Ökonomen.

\subsubsection{Spieltheoretische Untersuchungen}

Bradburd et al. (2006) untersuchen spieltheoretisch die Effekte von Mietdeckelungen. Dafür wurden Marktteilnehmer mit unterschiedlichen Preislimits unter variierenden „rent ceilings“ simuliert. Die Ergebnisse lassen am Ziel der Mietdeckelung, nämlich weniger wohlhabenden Mietern entgegenzukommen, zweifeln: „At most rent ceiling levels, the great preponderance of the gains to renters go to high reservation-price renters rather than those with low reservation prices, exacerbating inequality while achieving little benefit for the poorest renters" (Bradburd et al. 2006, 487).

Würde ein Mietpreis $\mathrm{P}_{\mathrm{MV}}$ durch Verhandlung zustande kommen, so würde das Ergebnis folgende Lösung sein: Mieter und Vermieter haben ein Preislimit $\mathrm{P}_{\text {Res. }}$ Sie haben aber auch einen möglichen Gewinnverlust, wenn sie ein Angebot annehmen und nicht auf ein günstigeres Angebot weiter warten $\left(\mathrm{G}_{\mathrm{M} \text { sowie } \mathrm{V}}\right)$.

$$
P_{M V}=\frac{\left(P_{\mathrm{Re} s-M}-G_{M}\right)+\left(P_{\mathrm{Re} s-V}+G_{V}\right)}{2}
$$

$\mathrm{P}_{\mathrm{MV}} \quad$ Mietpreis

$\mathrm{P}_{\text {Res-M }} \quad$ Preislimit des Mieters

$P_{\text {Res-V }} \quad$ Preislimit des Vermieters

$\mathrm{G}_{\mathrm{M}} \quad$ Möglicher Gewinnverlust, wenn der Mieter ein (höheres) Angebot annimmt, und nicht auf ein günstigeres Angebot wartet

$\mathrm{G}_{\mathrm{V}} \quad$ Möglicher Gewinnverlust, wenn ein Vermieter ein niedriges Mietangebot annimmt und nicht auf ein höheres wartet

Ist die Miethöhe gesetzlich begrenzt, so ergibt sich der Preis automatisch:

$$
P^{*}=\min \left(P_{M V}, P_{\text {Kontr }}\right)
$$


Würde in einem Nicht-Walrasianischen Markt (Angebot und Nachfrage sind nicht per Gesetz ausgeglichen) eine Mietendecke eingezogen werden, würden jene mit höheren Preislimits (Reservation-Prices) zugunsten jener mit geringeren verlieren. Tatsächlich würden ,reiche“ Mieter mit hohen Preislimits überproportional von einer Mietenbeschränkung profitieren, den ,armen“ Mietern würde weniger zu Teil werden, insbesondere, wenn ihre Preislimits noch unter der Mietenbeschränkung lägen. „The asymmetry between the increases in total surplus that can be obtained by choosing the right rental price ceiling and the decreases that result from choosing the wrong ceiling price provides further grounds for caution in implementing rental price ceilings" (Bradburd et al. 2006, 487).

\subsection{8 Österreichisches Mietrecht im Regressionsmodell}

Mit hedonischen Modellen können die heterogenen Eigenschaften von Gütern aufgeschlüsselt und preislich gewichtet werden. Auch dann, wenn diese Eigenschaft fest miteinander verwoben sind, wie es bei Immobilien der Fall ist. Brunauer et al. (2008) liefern mit einem hedonischen Regressionsmodell als „Nebenprodukt" ein Indiz, wie die Mietregulierung in Österreich auf den Mietpreis von Wohnungen wirkt. So gelten die rigiden Bestimmungen über die Mietobergrenze nicht bei Wohnungen über 130 Quadratmeter Nutzfläche ${ }^{10}$ (siehe Abbildung 5 links). Daher steigt auch ab dieser Fläche die Miete pro Quadratmeter. Normalerweise müsste der Grenznutzen der größeren Wohnfläche stetig abnehmen.
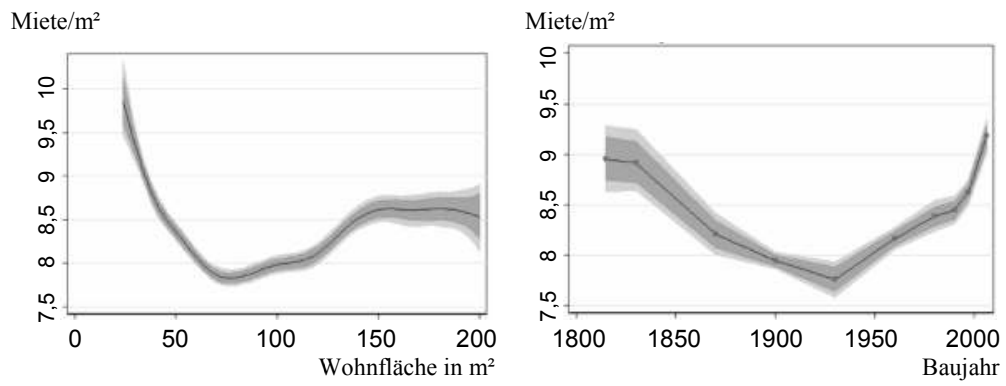

Quelle: Brunauer et al. 2008, o.S.

Abbildung 5: Der Quadratmeterpreis steigt bei Wohnungen über $130 \mathrm{~m}^{2}$ und solchen mit Baujahr nach 1945 ekladant 
Ebenso zeigen Wohnungen aus den Jahren vor 1945 den geringsten Quadratmetermietpreis auf, da grundsätzlich für alle älteren Baujahre das MRG in Vollanwendung gilt (siehe Kapitel 3.2.2). Noch ältere Bauten aus der Biedermeierzeit bis 1850 haben höhere Mietkosten, was strukturelle Gründe hat. Diese Bauten liegen oft in der teuren Innenstadt und gestatten dem Vermieter einen Lagezuschlag, oder es handelt sich um denkmalgeschützte Häuser, die für den sogenannten „Angemessenen Mietzins“ qualifizieren (vgl. Kap. 3.3.2). 



\section{Mietregulierung in Österreich und Wien}

Die marktwirtschaftlichen Mechanismen von Angebot und Nachfrage gelten zwar grundsätzlich auch für den Mietmarkt in Wien; allerdings aufgrund eines strengen Mietrechtsgesetztes (MRG) in stark abgeschwächter Form. Wohnungen, die dem Vollanwendungsbereich des Mietrechtsgesetzes unterliegen (Altbauten) dürfen nicht zu einem frei festgelegten Mietzins vermietet werden. Dabei handelt es sich - neben den „Gemeindewohnungen“ der Stadt Wien - um etwa 310.000 Wohnungen in Wien (vgl. Blaas/Wieser 2004, 6f). Der Mietzins dieser Wohnungen unterliegt laut §16a MRG dem Richtwertgesetz von 1994. Das Richtwertgesetz (RichtWG) ist eine Ergänzung zum MRG; in vielen Passagen wird wechselseitig Bezug genommen. Für eine Standardwohnung der Ausstattungskategorie A darf nach dem RichtWG ein Zins von 4,91 Euro pro Quadratmeter verlangt werden (gültig bis April 2012). Dabei sind in gewissem Rahmen $\mathrm{Zu}$ - und Abschläge für die Ausstattung erlaubt, sowie der Lagezuschlag für eine überdurchschnittliche Lage des Wohnobjekts.

In diesem Abschnitt werden für diese Arbeit relevante Teile des MRG analysiert. Zuvor allerdings erfolgt ein geschichtlicher Abriss über die Ursprünge des Mietrechts.

\subsection{Geschichte des Mietrechts und der Wohnungsnot}

\subsubsection{Mieten zu Monarchiezeiten}

Im 19. Jahrhundert gab es kein gesondertes Mietrecht in Österreich. Einzig das Allgemeine Bürgerliche Gesetzbuch (ABGB) regelt bis heute das Mieten im Rahmen der Privatautonomie ${ }^{11}$. Mit der Industrialisierung keimte ein rasantes Bevölkerungswachstum in den Städten auf. Das Phänomen der Landflucht gab es europaweit. Von 1800 bis 1950 wuchs die Einwohnerzahl der 13 größten Europäischen Städte um das elffache (Sandner 1962, 11ff). Wiens Bevölkerungszahl stieg von 1850 bis zum Ersten Weltkrieg um den Faktor 4,8: von 430.000 auf 2.070.000 Menschen. Ein Teil dieses Zuwachses geht auf die Stadterweiterung auf umliegende Dörfer zurück. Die soziale Segregation wurde durch den Zuzug verstärkt (Stampfer 1995, 5f).

11 Die Regelungen des ABGB sind wenig restriktiv und heute noch für jene Mietobjekte gültig, die nicht in den Anwendungsbereich des Mietrechtsgesetzes fallen. 
In einer Wohnung lebten im Schnitt 4,5 Personen. Die Nachfrage trieb die Mieten auf dem freien Wohnungsmarkt in die Höhe. Einzelne Schlafstellen wurden an Tagelöhner vermietet, wodurch sich ein „Bettgehertum“ entwickelte. Auch jene, die eine Wohnung hatten, konnten sich nur durch die Untervermietung an Bettgeher die hohen Mieten leisten (Stampfer 1995, 8f). Zur Jahrhundertwende entstanden die meisten Wiener Zinshäuser mit Kleinwohnungen aus Zimmer und Küche, die etwa 30 Quadratmeter hatten und die sanitären Anlagen im Stiegenhaus mit Nachbarn teilten. Die Bauordnung ließ eine Bebauungsdichte von 85 Prozent zu, was zu ungünstigen Belichtungs- und Belüftungsverhältnissen führte (Drbalek 1992, 52).

Um die kriegsbedingte Inflation zu lindern, ließ die kaiserliche Regierung Preise und Mieten einfrieren, und zwar auf den Stand des letzen Friedensmonats (Juli 1914). Von daher stammt die heute noch geläufige Bezeichnung „Friedenskronenzins“.

Die Wohnungsnot nach dem Krieg gebar die erste Mieterschutzverordnung (MschVO) aus 1917. Sie sollte heimkehrende Soldaten schützen. Weitere Verordnungen folgten, und innerhalb von drei Jahren hatte der österreichische Gesetzgeber ein mietrechtliches Instrumentarium aus Mietzinsbegrenzungen, Kündigungsschutz, Ablöseverbot, Befristungsbeschränkungen und Rückforderungsrecht für zu viel bezahlte Mietzinse geschaffen, wie es heute noch in Verwendung steht. Neben den Kriegsheimkehrern wollte man in der wirtschaftlichen Notzeit auch sozial Schwache vor der hohen Inflation schützen.

Die Inflation senkte den realen Mietzins, der 1922 praktisch den Nullpunkt erreichte. „Diese Wirkung war natürlich von niemandem vorauszusehen oder gar beabsichtigt“ (Sandner 1962, 53). „Ins Auge stechen die kleine Anzahl an Beamten und Experten [...] und der auffallende Konsens - auch mit Hausherrenvertretern": die 1. Mieterschutzverordnung erfolgte mit deren Zustimmung (Stampfer 1995, 2). In Österreich nicht unüblich: Ein Provisorium erlangte Permanenz.

\subsubsection{Das Mietengesetz (MG) 1922 und die Zwischenkriegszeit}

Das erste Mietengesetz im Jahr $1922^{12}$ fror die gesetzlich zulässige Miethöhe auf das 150-fache der Miete vom August 1914 (vor Kriegsbeginn) ein. Damit lag die maximale Miethöhe bei einem Prozent der ursprünglichen Realmiete, denn die Hyperinflation zu Kriegszeiten führte zu einer Geldentwertung um das

12 Bundesgesetz vom 7.12.1922 über die Miete von Wohnungen und Geschäftsräumlichkeiten (Mietengesetz): BGB1. Nr. 872/1922 
14.000-fache. Großhandelspreise stiegen nominal um das 18.339-fache, die Mietpreise nur um das 496-fache. Die Häuser waren mit diesen Mieten nicht instand zu halten (Sandner 1962, 28f). Mit den Novellen in den Jahren 1925, 1929, 1933, 1936 und 1937 wollte man einerseits die Wohnungsnot lindern und die Wohnqualität steigern - die Hauseigentümer konnten ihre Häuser nicht instand halten - andererseits wurde die Umgehung des Mietgesetzes durch die Vermieter zu verhindern versucht (Jahn 1994, 223f). Neubauten nach 1917 waren vom MG ausgenommen.

Die wichtigste Reform geschah 1929, mit der erstmals der Begriff „Hauptmiete" verwendet wurde. Der Gesetzgeber teilte die Mietgegenstände in drei Klassen ein: jene, für die das Mietengesetz gilt, jene, für die nur die Kündigungsbestimmungen des Mietengesetzes gelten, und jene, für die es nicht gilt. Heute spricht man von Voll- und Teilanwendung des Mietrechts und von Vollund Teilausnahmen. Die Klassen blieben erhalten (Jahn 1994, 238f; Sandner 1962, 36f). Während des Zweiten Weltkrieges blieb das MG weitgehend gültig.

\subsubsection{Mieten nach 1945}

Nach dem Zweiten Weltkrieg wurde das Mietengesetz 1946 und 1948 novelliert $^{13}$. Der Mietzins wurde mit einem Schilling pro Friedenskrone von 1914 begrenzt, dies sollte bis zum Jahr 1968 gelten. 1949 wollte der Gesetzgeber mit dem Preisregelungsgesetz ${ }^{14}$ schließlich auch Wohnungen einer Mietzinsobergrenze unterwerfen, die bis dato frei vermietet werden durften, nämlich Neubauten seit dem Jahr 1917. Erst Neubauten ab dem 30. Juni $1953^{15}$ sollen nicht mehr den Mietzinsobergrenzen unterliegen, aber auch nur dann, wenn sie ohne Zuhilfenahme öffentlicher Fördermittel gebaut wurden. Diese Regelung findet sich heute noch als Teilausnahme im $§ 1$ Abs 4 MRG.

Sandner (1962) zeigt die ungewünschten Allokationseffekte auf: „In Wien sollen 25.000 Wohnungen leerstehen. Es handelt sich dabei aber um keine echten Leerstehungen, sondern um Wohnraumhortung, d.h. die Wohnung wird, obwohl die Notwendigkeit gar nicht mehr besteht, behalten, weil die monatliche Mietbelastung unbedeutend ist" (Sandner 1962, 241).

Das „Zinsstoppgesetz“ 1954 war eine Reaktion des Gesetzgebers auf eine Erkenntnis des Verfassungsgerichtshofes ${ }^{16}$ (VfGH), wonach einige preisbindende Regelungen verfassungswidrig seien. Das Zinsstoppgesetz unterwarf Be-

13 BG vom 24.7.1946 BGB1 Nr. 160/1946 und BG vom 8.7.1948 BGB1 Nr. 150/1948

14 BG 30.6.1949 BGB1 Nr. 136/1949

15 Damit sind ganze Mietshäuser gemeint. Eigentumswohnungen fallen seit jeher bereits ab Baujahr 1945 in den Teilanwendungsbereich ohne Mietzinsobergrenzen.

16 VfGH 25.3.1954 ÖJZ 1954: 408; Zinsstoppgesetz: BGB1. Nr. 132/1954 
standgegenstände, die vom Mietengesetz ausgenommen waren (Häuser mit Baujahr nach 1917) einer nachträglichen Preisbindung, was dem Vertrauen auf die Rechtssicherheit mietrechtlicher Normen nicht gerade gut tat (Jahn 1994, 286).

Die Rechtsunsicherheit hatte massive Auswirkungen auf die Realwirtschaft. „Die Unsicherheit der Kapitalanlage sowie die unstete Rechtslage ließ die private Bautätigkeit zurückgehen. Wer garantiert dem Bauenden, dass ihn nicht dasselbe Schicksal wie den Althausbesitzer trifft? Um den Ausfall der privaten Wohnbautätigkeit auszugleichen, versuchte der Staat, die Aufgabe des Wohnungsbaues zu übernehmen“ (Sandner 1962, 56). Für Private ist „das Risiko einer Nachziehung der Mietpreiskontrolle auf Neubauten zu groß geworden“ (Sandner 1962, 215).

Das Mietrechtsänderungsgesetz $1968^{17}$ dehnte die Zulässigkeit freier Mietzinsvereinbarungen bei Neuvermietungen aus, zumindest bei Geschäftsräumlichkeiten. Eine wesentliche Änderung der Mietbestimmungen ließ bis 1981 auf sich warten.

\subsubsection{Das Mietrechtsgesetzt (MRG) 1981 und seine Entwicklung}

Das MRG $1981^{18}$ beinhaltet eine vollständige Neuformulierung des Mietrechts. Zahlreiche Nebengesetze wurden damit aufgehoben. Auch der Bezug zum Friedenskronenzins fiel, dafür wurde allerdings der „Kategoriemietzins“ eingeführt, der fixe Höchstbeträge pro Quadratmeter für ganz Österreich und unabhängig von der Ausstattung des Gegenstands vorsieht. Es hieß, das MRG 1981 sei alter Wein in neuen Schläuchen. Denn an einschlägigen Vorschriften der Mietkontrolle hielt das Gesetzt fest. Einzig für Geschäftsraummieten führte man den „Angemessenen Mietzins“ ein. Der orientierte sich auch an Ausstattung, Größe, Lage, Art und Beschaffenheit.

Erstmals wurde aber eine Wertsicherung der Miethöhe an die Veränderung der Verbraucherpreise zugelassen, die Kategoriesätze sollten in 10-ProzentSchritten steigen können. Freilich lagen sie fernab der Realität des unregulierten Mietmarktes, wo Mieten das 12- bis 30-fache der gesetzlichen Höchstgrenzen kosteten (vgl. Jahn 1994, 551-556). Eine kleinere Liberalisierung erfuhr das Mietrecht mit der MRG-Novelle 1985, als gut ausgestattete Wohnungen mit einer Größe über 130 Quadratmeter vom Kategoriemietzins ausgenommen wurden.

17 BG 30.6.1967 BGBl Nr. 281/1967

18 BG 12.11.1981 BGB1 Nr. 520/1981 


\subsubsection{Der Liberalisierungsschritt über den Richtwertmietzins}

Ein wenig liberalisiert wurde die Mietkontrolle erst mit dem 3. Wohnrechtsänderungsgesetz (3. WÄG) ${ }^{19}$ 1993. Das Richtwertgesetz (RichtWG) sollte eine Annäherung an den Markt bringen und ist heute noch eine zentrale Norm zur Bildung des Mietzinses im Althausbestand. Es berücksichtigt erstmals die Lage und den Erhaltungszustand und preist diesen in der höchstzulässigen Miete ein. Die seither sieben weiteren Novellen des Mietrechts (WRN 1997, WRN 1999, WRN 2000, MRN 2001, WRN 2002, 2006 und 2009) beziehen sich auf Befristungen, Erhaltungspflichten und andere Nebenbestimmungen.

\subsubsection{Umfang des heutigen Mietrechts}

Das heute für Österreich gültige Mietrechtsgesetz ist, wie oben beschrieben, über Jahrzehnte historisch gewachsen. Vieles davon scheint in Stein gemeißelt zu sein. Obschon die ursprüngliche Mietzinsbegrenzung nicht mit der Absicht beschlossen worden war, die Vermieter in ihrer Ertragsabsicht nachhaltig zu beschneiden, ist der harte Kern trotz aller Novellen erhalten geblieben. Die Regulierung trägt ,gleichsam Gesteinsschichten aus verschiedenen Zeitabschnitten unseres Jahrhunderts mit sich“ (Stampfer 1995, 1). Manche Abschnitte dieser komplexen Materie stoßen heute auf Unverständnis, sowohl bei Experten als auch bei Laien. Aus dem ersten MG wurde ein unvorstellbar komplexes Regelwerk, wie Sandner (1962) bemerkt: „Die im Laufe des ersten Weltkrieges einsetzende Mieterschutzgesetzgebung, die sich im Lauf von 45 Jahren (Anm.: aber auch darüber hinaus) zu einer Gesetzeshypertrophie entwickelte, setzte das marktwirtschaftliche Prinzip außer Kraft" (Sandner 1962, 246).

Das tragende Element des österreichischen Mietrechts, der Mieterschutz, fußt auf drei Säulen: Regelungen über die Miethöhe (Preisbindung, Mietzinsobergrenze), Regelungen über Dauer und Beendigung von Mietverhältnissen (Kündigungsschutz, Befristungen) sowie Regelungen über die Aufteilung von Erhaltungspflichten.

Das Mietrecht gilt grundsätzlich für alle Wohnungen und Geschäftsräumlichkeiten, allerdings variiert der Geltungsumfang je nach Alter, Beschaffenheit und Widmung des Objekts, siehe später Kap. 3.2. Das MRG reguliert im Wesentlichen die Höhe des erlaubten Mietzinses (§16), die Kündigungsfristen ( $\$ 31 \mathrm{ff})$, die Erhaltungspflichten und Verbesserungsrechte von Mietern und 
Vermietern ( $\$ 3$ bis $\S 7)$, sowie die Verwaltungsbestimmungen oder das Mietrecht im Todesfalle.

\subsection{Mietrecht: einmal gilt es, einmal nicht}

Die „Anwendbarkeit“ des MRG unterteilt sich in drei Stufen. Das Gesetz spricht von Vollanwendung, Teilanwendung und Vollausnahme vom MRG. Diese Unterscheidung ist stets die Gretchenfrage, wenn es um die Beurteilung einer bestimmten Rechtslage geht.

Ist das MRG nämlich gar nicht anwendbar, dann fußt ein Mietverhältnis ausschließlich auf dem Allgemeinen Bürgerlichen Gesetzbuch (ABGB). $\$ 1090$ ABGB definiert einen „Bestandsvertrag“, der übergeordnete Begriff für Mietund Pachtverträge: „Der Vertrag, wodurch jemand den Gebrauch einer unverbrauchbaren Sache auf eine gewisse Zeit und gegen einen bestimmten Preis erhält, heißt überhaupt Bestandvertrag.“ Auch im MRG sind Mietverhältnisse über deren Geltungsbereich definiert. Das Gesetz gilt „für die Miete von Wohnungen, einzelnen Wohnungsteilen oder Geschäftsräumlichkeiten aller Art [...] samt den etwa mitgemieteten Haus- oder Grundflächen [...] und für die genossenschaftlichen Nutzungsverträge über derartige Objekte (im folgenden Mietgegenstände genannt)“" (§1 MRG Abs 1) - um gleich in Abs 2 desselben Paragraphen Voll- und Teilausnahmen zu definieren. Wo das Mietrecht nicht gilt, und somit nach ABGB vermietet werden kann, sind die Vorschriften für die Vermietung hinsichtlich Kündigungsschutz, Miethöhe und Erhaltungspflichten grundsätzlich liberaler.

\subsubsection{Vollausnahme vom MRG}

Die Faustregel im Mietrecht besagt, dass dieses für Altbauten gelte, für Neubauten nicht; wobei in Wien unter „Neubau“ ein Baujahr nach 1945 gemeint ist. Tatsächlich gelten nur Teile des Mietrechts in „Neubauten“ nicht, darunter im Wesentlichen die rigiden Mietzinsobergrenzen, wie sie für Altbauten gelten. Eine Vollausnahme vom Mietrecht hat nichts mit dem Baujahr zu tun, sondern mit dem Objekt und dem Mieter. Für folgende Verhältnisse gilt das Mietrecht nicht - wohl aber das Allgemeine Bürgerliche Gesetz (ABGB):

- Zweitwohnsitze für Ferienwohnungen ( $\$ 1$ Abs 2 Z 4 MRG), 
- Halbjahresverträge, die arbeitsbedingt einen kurzfristigen Ortswechsel erfordern ( $\$ 1$ Abs 2 Z 3 MRG), ${ }^{20}$

- Wohnungen in Häusern mit maximal zwei Mietobjekten (§1 Abs 2 Z 5 MRG),

- sowie Spezialobjekte, wie karitative Einrichtungen, Garagen, Pflegeheime oder Dienstwohnungen.

Für Mietobjekte und -verhältnisse, die eine Vollausnahme vom MRG darstellen, gilt das Mietrecht nach ABGB ( $\$ 1090 \mathrm{ff}$ ABGB). Das ABGB ist grundsätzlich für Vermieter angenehmer, da es zumindest dispositiv ist. Einzelne Bestimmungen des Gesetzes können in Mietvertraglicher Übereinkunft zwischen Mieter und Vermieter ausgeschlossen werden. So hat etwa der Vermieter nach ABGB mehr Erhaltungspflichten als nach MRG, wo grundsätzlich der Mieter die Erhaltung der Benützbarkeit seiner Wohnung regelt. Allerdings können die Erhaltungspflichten nach ABGB auf den Mieter überwälzt werden (Prader 2009, 826f).

Die Miethöhe darf grundsätzlich frei vereinbart werden, wenn das Mietverhältnis und Mietobjekt eine Vollausnahme (oder auch Teilausnahme, siehe nächsten Absatz) zulassen. Die einzige Beschränkung der Miethöhe ergibt sich aus $\$ 879$ Abs 2 Z 4 ABGB - Wucher $^{21}$ - und aus $§ 934$ f ABGB, der „laesio enormis" oder Verkürzung über die Hälfte ${ }^{22}$.

\subsubsection{Teilanwendung des MRG}

Für alle „Neubauten“ gilt grundsätzlich nur ein Teil der Bestimmungen des $\mathrm{MRG}$, nämlich die Kündigungsbestimmungen (§29ff MRG), die Befristungsbestimmungen ( $\$ 29$ Abs 1 und 4 MRG), sowie das Mietrecht im Todesfall ( 14 MRG).

20 Dies ist der „Philharmoniker-Paragraph“, der eingeführt wurde, weil die berühmten Musiker jeweils ein halbes Jahr in Wien bzw. Salzburg verbrachten. Durch die Vollausnahme ist es möglich, dass derartige kurzfristige Mietverhältnisse keinen Befristungserfordernissen (Mindestbefristung auf drei Jahre) nach MRG unterliegen.

21 Wucher: ,wenn jemand den Leichtsinn, der Zwangslage, Verstandesschwäche, Unerfahrenheit oder Gemütsaufregung eines anderen dadurch ausbeutet, daß er sich oder einem Dritten für eine Leistung eine Gegenleistung versprechen oder gewähren läßt, deren Vermögenswert zu dem Werte der Leistung in auffallendem Mißverhältnisse steht.“

22 Hat bei einem Rechtsgeschäft der Eine nicht einmal die Hälfte des gemeinen Wertes als Gegenleistung des Anderen erhalten, kann er das Geschäft anfechten. Außer, er ist sich dieses Ungleichgewichts bewusst und willigt dem Vertrag aufgrund einer persönlichen Vorliebe ein. 
Die Mietvereinbarungen können frei getroffen werden, sofern sie nicht wucherisch sind oder dem Mieter mehr als das Doppelte der Marktmiete abverlangen (ABGB, s.o.). Unter die Teilanwendung fallen im Übrigen ( $\$ 1$ Abs 4 MRG):

- Mietwohnungen (in nicht parifizierten Mietshäusern, Anm.), die ohne öffentliche Fördermittel mit Baubewilligung nach dem 30. Juni 1953 erbaut wurden ( 1 Abs 4 Z 1 MRG),

- Eigentumswohnungen, die nach dem 8. Mai 1945 gebaut wurden (Z 3),

- Dachgeschoßausbauten ab dem Jahr 2002 (Z 2),

- Zubauten (auch in Altbauten) nach dem 30. September 2006 (Z 2a).

\subsubsection{Vollanwendung des MRG}

Liegt bei einem Mietverhältnis keine Voll- oder Teilausnahme vom MRG vor, so unterliegt es dem Mietrechtsgesetz mit sämtlichen Bestimmungen.

Im Vollanwendungsbereich liegen somit auch Dachgeschoßausbauten vor dem Jahr 2002 und Zubauten vor Oktober 2006, soweit sie sich in Altbauten befinden, sowie nach dem Zweiten Weltkrieg wiederaufgebaute Zinshäuser, die bis Mitte 1953 errichtet worden sind. Die Miethöhe ist dazu in §16 MRG geregelt. Sie unterliegt bei Neuvermietung grundsätzlich dem Richtwert-Mietzins; in vielen Ausnahmefällen (ältere Dachgeschoße und Zubauten) aber auch dem Angemessenen Mietzins (Dirnbacher 2009, 262).

\subsection{Mietzinsbildung}

„Miete ist nicht Miete“623 - in Österreich können Wohnungen nach fünf verschiedenen Mietzinsen bzw. Mietzinsobergrenzen vermietet werden. Liegt das Mietobjekt in einem Neubau, so gilt der freie Mietzins. Im Vollanwendungsbereich ist der Richtwert bzw. der Angemessene Mietzins (etwa für Dachgeschoßausbauten vor dem Jahr 2002) anzuwenden. Für schlecht ausgestattete Wohnungen der Kategorie D (mit Gang-WC, das allenfalls mit dem Nachbarn geteilt werden muss), gilt der Kategoriezins, ebenso für Mieterhöhungen aufgrund des Eintritts eines Angehörigen in die Mietrechte. Der Friedenskronenzins oder andere Relikte aus dem alten Mietengesetz sind nur noch beim Eintritt eines privilegierten Angehörigen (etwa Minderjährige, die in die Mietrechte der Großmut-

23 Eine journalistische Abhandlung des Autors über den österreichischen „MietzinsDschungel“ findet sich im Internet unter http://diepresse.com/home/wirtschaft/economist/539444/ (abgerufen am 10.03.2010). 
ter eintreten) anzuwenden. Auf Spezial-Mietzinse nach dem WGG (WohnungsGemeinnützigkeitsgesetz) soll hier nicht eingegangen werden, da diese lediglich bei Genossenschaftswohnungen angewandt werden.

\subsubsection{Der Richtwertmietzins}

Mit der Einführung des Richtwertsystems mit dem Richtwertgesetz (RichtWG) im Jahr 1994 ist das österreichische Mietzinssystem „liberalisiert“" worden. ${ }^{24}$ Zuvor unterlagen die Vermietungen im Vollanwendungsbereich grundsätzlich dem Kategorie-Zins (dzt., bis 31.07.2011, 3,08 Euro pro Quadratmeter). Die Zinsobergrenze ist für alle neun Bundesländer per 1. April 2010 (gültig bis April 2012) unterschiedlich neu festgesetzt:

\begin{tabular}{|c|c|}
\hline Burgenland... & 4,47 \\
\hline Wien & 4,91 \\
\hline Niederösterreich & 5,03 \\
\hline Oberösterreich $\ldots . .$. & 5,31 \\
\hline Kärnten & 5,74 \\
\hline Salzburg & 6,78 \\
\hline Steiermark & 6,76 \\
\hline Tirol & 5,99 \\
\hline Vorarlberg & 7,53 \\
\hline
\end{tabular}

Die zitierten Beträge gelten für Wohnungen des Ausstattungskategorie A (siehe dazu Kap. 3.3.1.2). Eine „C-Wohnung“ darf etwa nur zu 50 Prozent des ARichtwerts vermietet werden. Bezeichnend ist, dass gerade in der Bundeshauptstadt der Richtwertmietzins am zweitniedrigsten ist. Dabei ist davon auszugehen, dass die Marktmiete höchstens noch in Vorarlberg und Salzburg so hoch ist wie in Wien. Bei der erstmaligen Festsetzung der Werte sind (angeblich) die unterschiedlichen Grund- und Baukosten der Bundesländer berücksichtigt worden.

Das RichtWG definiert die mietrechtliche Normwohnung, die der Ausstattungskategorie A entspricht. Sie hat zwischen 30 und 130 Quadratmeter, besteht aus „Zimmer, Küche (Kochnische), Vorraum, Klosett, und einer dem zeitgemäßen Standard entsprechenden Badegelegenheit" (§2 Abs 1 RichtWG), außerdem verfügt sie über eine Etagen- oder Zentralheizung, hat keinen Erhaltungsrückstau (z.B. Elektrik ohne Erdung o.ä.) und liegt in einer durchschnittlichen Wohnlage.

24 3. WÄG, BGBl 1993/800 im §16 Abs 2 MRG 
Die Logik des Richtwertmietzinses folgt der einer Kostenmiete. Ausgehend von einer „Normwohnung“, für die das oben zitierte, normativ festgesetzte Preisschema gilt, dürfen Zuschläge verrechnet werden (siehe dazu Kap. 4.5.5 über den Lagezuschlag und andere Zuschläge). Besondere Annehmlichkeiten bzw. über das Normmaß hinausgehende Investitionen können zwar dem Mieter verrechnet werden, allerdings lässt sich das Gesetz so interpretieren, dass eine Rendite dafür mit 4 Prozent ${ }^{25}$ begrenzt ist.

\subsubsection{Geltungsbereich des Richtwertsystems}

Salopp könnte man formulieren: Der Richtwertmietzins gilt in Altbauten immer - außer wenn er nicht gilt. Er kommt als nicht zur Anwendung bei

- Vollausnahme und Teilanwendung des MRG (s.o.),

- bei Wohnungen, die nach dem 8.5.1945, etwa durch Zu- und Aufbauten geschaffen wurden,

- bei Wohnungen der Ausstattungskategorie D (WC am Gang und keine Wasserentnahmestelle), dort gilt der noch strengere Kategorie-Zins,

- Geschäftsräumen,

- Mietobjekten, auf die $\$ 53$ MRG zur Anwendung kommt, ${ }^{26}$

- Wohnungen, für die einvernehmlich ein Angemessener Mietzins vereinbart wird, dazu später. (Dirnbacher 2009, 262)

Der Richtwertmietzins ist auch anzuwenden, wenn ein Eintrittsberechtigter die Mietrechte an einer Wohnung übernimmt (Kinder, Lebensgefährten) - in diesem Fall ist der Mietzins aber mit dem niedrigeren Kategoriezins A begrenzt, der bei 3,08 Euro liegt - oder unter Umständen beim Wohnungstausch.

\subsubsection{Ausstattungskategorien im Richtwertsystem}

Österreichische Wohnungen können vier bzw. fünf verschiedene Ausstattungskategorien aufweisen. Diese können wie folgt aus dem Gesetz entnommen werden:

25 Was über eine 4-prozentige Marge hinausgeht, ist im Mietrecht nicht erlaubt. Dieser Logik zufolge müsste eine Wiener Wohnung der Ausstattungskategorie A, für die der Richtwert von 4,91 Euro gilt, exakt 1.470 Euro pro Quadratmeter kosten, um einen 4prozentigen Liegenschaftszins zuzulassen (Instandhaltungsaufwendungen unberücksichtigt). Auf dem Wohnungsmarkt ist eine so günstige Wohnung kaum zu finden.

26 Wurde der Wiederaufbau eines Althauses nach dem Zweiten Weltkrieg mit öffentlichen Mitteln gefördert, und zahlte der Hausherr dieses Darlehen nach dem Rückzahlungsbegünstigungsgesetz (RBG) 1971 bzw. dem RBG 1987 zurück, so darf er seither den freien bzw. Angemessenen Mietzins verlangen. 
Tabelle 2: Ausstattungskategorien nach österreichischem Mietrecht

\begin{tabular}{|l|l|l|l|l|}
\hline Kategorie & \multicolumn{2}{l}{$\begin{array}{l}\text { Wohnungs- Notwendige Räume } \\
\text { größe }\end{array}$} & $\begin{array}{l}\text { Warmwasser- Heizung } \\
\text { aufbereitung }\end{array}$ \\
\hline A & $\begin{array}{l}\text { Mind. } \\
30 \mathrm{~m}^{2}\end{array}$ & $\begin{array}{l}\text { Zimmer, Vorzimmer, WC, } \\
\text { Küche (Nische), Bad }\end{array}$ & Ja & Ja \\
\hline B & - & $\begin{array}{l}\text { Zimmer, Vorzimmer, WC, } \\
\text { Küche (Nische) Bad }\end{array}$ & $\begin{array}{l}\text { Nein, nur im } \\
\text { Bad }\end{array}$ & Nein \\
\hline C & - & $\begin{array}{l}\text { WC in der Wohnung, } \\
\text { Wasserentnahme }\end{array}$ & Nein & Nein \\
\hline $\mathrm{D}^{27}$ & - & Zimmer (WC am Gang) & Nein & Nein \\
\hline $\begin{array}{l}\text { D- } \\
\text { unbrauchbar }\end{array}$ & & $\begin{array}{l}\text { Zimmer, } \\
\text { nicht bewohnbar }\end{array}$ & Nein & Nein \\
\hline
\end{tabular}

Für schlechtere Kategorien als die mietrechtliche Normwohnung (= Kategorie A) müssen Abschläge vom Mietzins gemacht werden. „Kategorie C“ bedeutet etwa 50 Prozent Mietzinsabstrich.

Die einzelnen Erfordernisse sind sehr genau definiert und entpuppen sich in der Praxis oft als Stolperfalle. Weist ein Badezimmer etwa keine Entlüftung nach außen auf, so ergibt sich daraus sofort Kategorie C, ungeachtet dessen, wie großartig die Wohnung auch sonst sein mag. Zu den wichtigsten Erfordernissen, siehe Dirnbacher 2009, 231ff. Der Zeitpunkt für die Kategorie-Beurteilung ist jener des Mietvertragsabschlusses. Im Detail gilt zu beachten:

- Brauchbarkeit: Die Wohnung darf keine gefährlichen Sicherheitsmängel aufweisen. Fehlt etwa die Erdung (Schutzleiter) in einem Nassraum, so muss der Mieter die mangelnde Brauchbarkeit nicht einmal gesondert rügen - die Wohnung ist „unbrauchbar“ und entspricht der Kategorie Dunbrauchbar. ${ }^{28}$ Seit 2006 hat der Vermieter ein Nachbesserungsrecht.

27 Eine „D-Wohnung“ wird nach dem Kategorie-D-Mietzins vermietet, nicht nach dem Richtwert. Die Wohnung muss dennoch einen „,brauchbaren Zustand haben“, bei übermäßigem Schimmel oder einer uralten Elektrik fällt die Wohnung in Kategorie DUnbrauchbar, wieder 50\% Mietzinsabstrich (ca. 77 Cent pro Quadratmeter Wohnnutzfläche).

28 „Symptomatisch dafür die geradezu drakonische Konsequenz in einer Entscheidung des BG Döbling vom 16.03.2006: Herabsetzung des für die rund $280 \mathrm{~m}^{2}$ große Wohnung (bestehend aus 7 Zimmern, Küche, Vorzimmer, 2 Bäder, 2 WCs und Zwischenräumen) in Wien Döbling vereinbarten monatlichen Hauptmietzins von Euro 2.500,-- auf monatlich Euro 183,99 (Grund: gefährliche elektrische Anlage im Zeitpunkt der Anmietung)“ Dirnbacher 2009, 231. 
- Badegelegenheit: Der Baderaum darf keine Nische in der Küche sein, wie sie in vielen Altbauwohnungen vorzufinden ist. Der Raum muss zudem Platz zum Aus- und Ankleiden bieten, eine Entlüftung ins Freie haben, und feuchtigkeitsisoliert (und verfliest) sein, sowie eine Beheizungsmöglichkeit haben.

- WC: es muss im inneren des Wohnungsverbands liegen, auch Anlagen mit Häckseleinrichtungen sind zulässig.

- Kochgelegenheit: Abwaschen und Kochen muss möglich sein, eine Heizung ist erforderlich, sowie eine Entlüftung nach außen bzw. ein Fenster. Ein Backrohr ist nicht notwendig, wohl aber ein ordentlicher Herd (kein Campingherd).

- Heizung: alle Haupträume müssen automatisch beheizbar sein, also mit einer Heizung versehen, die nicht ständiges Nachfüllen von Brennstoff erfordert.

Grundsätzlich können auch Kategoriemerkmale derart ausgeglichen werden, dass ein A-Merkmal aus einer C-Wohnung eine B-Wohnung macht. Wenn etwa eine vorhandene Gasetagenheizung (Kat. A) einen fehlenden Vorraum (Kat. C) substituiert und solcherart aus der Wohnung eine Kategorie-B macht.

\subsubsection{Angemessener Hauptmietzins gem. §16 Abs 1 MRG}

Der Angemessene Hauptmietzins unterscheidet sich vom freien Mietzins nicht so sehr durch die Miethöhe - welcher Mieter würde aus freien Stücken einen unangemessenen Mietzins zahlen wollen - sondern dadurch, dass er einer nachträglichen Herabsetzungsmöglichkeit durch die Schlichtungsstelle oder ein Gericht unterliegt und ,angefochten“ werden kann (Dirnbacher 2009, 246).

$\mathrm{Er}$ ist in seiner Höhe an vergleichbare Mietobjekte gebunden, und zwar in Bezug auf

- Größe

- Art und Beschaffenheit

- Lage

- Ausstattungszustand

- Erhaltungszustand

In der Praxis bedarf es dafür meist der Beiziehung eines Sachverständigen, der nach der Vergleichswertmethode vorgeht. Dabei darf auch mit Objekten, die dem freien Mietzins unterliegen, verglichen werden (Dirnbacher 2009, 247).

Der Angemessene Mietzins gilt einerseits für Geschäftslokale, und im Wohnungsbereich für Neubauten nach 1945, sofern sie nicht aufgrund einer Voll- 
oder Teilausnahme vom MRG ohnehin der freien Miete unterliegen. Dazu zählen etwa auch (Dirnbacher 2009, 252ff):

- Dachgeschoßausbauten (und seien sie in einem Altbau), die vor dem 31.12.2001 baubewilligt worden sind, oder Zubauten vor 2006,

- Wohnungen in Gebäuden unter Denkmalschutz, in die erhebliche Eigenmittel des Eigentümers geflossen sind,

- Großwohnungen der Kategorie A oder B ab 130 Quadratmeter Nutzfläche,

- Freiwillige Mietzinsvereinbarungen, etwa mit unbefristeten Hauptmietern, die bereits mindestens ein Jahr in der Wohnung gelebt haben,

- Zeitlich befristete Vereinbarungen für befristete Mietverhältnisse, wenn die Erhöhungsfrist vor Ablauf des Mietverhältnisses endet,

- Wohnungen in Altbauten, die von der öffentlichen Hand gefördert nach dem Zweiten Weltkrieg wiederaufgebaut worden sind, und deren Förderung nach dem Rückzahlungsbegünstigungsgesetz 1987 frühzeitig zurückbezahlt worden ist. Dabei handelt es sich freilich um einen Sonderfall.

Wie auch der Richtwertmietzins muss der Angemessene Mietzins um 25 Prozent vermindert werden, wenn die Wohnung befristet vermietet wird (§16 Abs 7 MRG, §26 Abs 3 MRG).

\subsubsection{Sonstige Mietzinsarten}

\subsubsection{Friedenskronenzins}

Wie oben beschrieben bezieht sich das Wort „Friedenskrone“ auf den letzten Monat vor Kriegsausbruch des Ersten Weltkriegs. Die dann bezahlte Mietzinshöhe wurde über den Krieg eingefroren. Auch nach dem Zweiten Weltkrieg nimmt das Mietrecht wieder Bezug auf die Friedenskrone (FK): pro Friedenskrone 1 Schilling Miete galt die Faustregel bis zum Jahr 1968, wobei die Friedenskrone als eine Art „Nutzwert-Einheit“ galt und auch nach Friedenskronen Häuser parifiziert wurden. 3600 Friedenskronen für eine Wohnung bedeutete 300 Schilling Miete im Monat. Manche Mietverhältnisse aus dieser Zeit haben auch heute noch Bestand, oder wurden über Generationen ,vererbt“. Die Mietbelastung war geradezu lächerlich, wodurch es zu Hortungen von Wohnungen kam, und weshalb in den 70er und 80er-Jahren viele Hausbesitzer nicht einmal die nötigsten Erhaltungsmaßnahmen in ihren Häusern durchführen konnten oder 
wollten. Sie verdienten indes an der üblichen illegalen Ablöse. Erst später ließ sich der Gesetzgeber eine Art „Mindestmietzins“ einfallen, in Form eines „Erhaltungs- und Verbesserungsbeitrags“.

\subsubsection{2 „Mindestmietzins“ nach $§ 45 \mathrm{MRG}$}

Das MRG 1981 sah für Vermieter eine Möglichkeit vor, bestehende BagatellMietzinse leicht anzuheben, und damit in bestehende Mietverträge einzugreifen. Unter Begehr eines „Erhaltungs- und Verbesserungsbeitrags“ (EVB) konnten zumindest die extrem günstigen „Friedenszinse“ auf einen genau festgelegten Betrag pro Quadratmeter erhöht werden. Der Gesetzgeber vermied den Begriff „Mindestmietzins“, de facto war dies jedoch darunter gemeint. In $\S 45$ Abs 1 MRG wird der Mietzins für eine Kategorie A Wohnung mit (heute) 2,04 Euro ausgewiesen $^{29}$, für Kategorie B (also etwa ohne Heizung) 1,54 Euro, Kategorie C oder D-brauchbar 1,03 Euro (Dirnbacher 2009, 541ff). Mit der Mietrechtsnovelle (MRN) 2001 wurde der EVB einfach gesetzlich in einen fixen Teil des Mietzinses umgewandelt, womit die Terminologie „Erhaltungs- und Verbesserungsbeitrag“ als weiteres Zwischenregelwerk in die Mietrechtsgeschichte einging.

Das Wort „Mindestmietzins“ findet sich auch heute nicht im Gesetzestext. Vermutlich, weil dieses Wort politisch nicht opportun ist (Dirnbacher 2009, 543). Die Miethöhe nach $\S 45 \mathrm{MRG}$ hat der Gesetzgeber mit „Wertbeständigkeit des Mietzinses“ tituliert, sie kann in nahezu allen Fällen eingefordert werden. Ein Mindestmietzins von etwa 1,50 Euro pro Quadratmeter für eine klassische Altbauwohnung beträgt dennoch nur einen Bruchteil der heutigen Marktmiete.

\subsubsection{Kategoriezins}

Der Kategoriezins wurde mit dem Mietrechtsgesetz (MRG) 1981 eingeführt, um für die Marktteilnehmer leicht errechenbare Mietobergrenzen zu schaffen. Schließlich bezieht sich der Zins auf die jeweilige Ausstattungskategorie, die mit dem MRG 1981 erstmals eine Rolle für die Mietzinsberechnung spielte (Würth et al. 2009, 192f). Die Kategoriemerkmale, die für den jeweiligen Kategoriezins qualifizierten, wurden später in der Richtwertgesetzgebung übernommen.

Inzwischen muss der Kategoriezins lediglich für Wohnungen der Ausstattungskategorie D vereinbart werden, und hat damit nur noch eine theoretische Anwendbarkeit. Der Kategorie-D-Zins liegt derzeit bei 1,54 Euro pro Quadratmeter (unbefristet). Es ist fraglich, ob eine derartige Substandard-Wohnung tatsächlich zum Kategoriezins vermietet würde. Auf dem Wiener Mietmarkt dürfte

29 Oder zwei Drittel des jeweiligen Kategoriezinses. 
sich selbst für eine Wohnung ohne eigenes WC eine Miete von zumindest 4 Euro pro Quadratmeter erzielen lassen.

Die Obergrenze von 1,54 Euro schafft Anreize für eine Kategorieanhebung, schließlich ist das Risiko einer Mietzinsminderung gerade bei schlecht ausgestatteten Wohnungen enorm. Und ist der Zustand der Wohnung rechtlich als „unbrauchbar“ zu bezeichnen, so gilt der „Kategorie-D-unbrauchbar Mietzins“. Dieser liegt bei 0,77 Euro/m². Nach dem Gesetz „unbrauchbar“ kann auch eine bestens ausgestattete Wohnung relativ schnell werden. Es reicht, wie erwähnt, wenn die Elektrik der Wohnung schadhaft ist oder bei bestimmten Steckdosen die Erdung fehlt, schon kann der Mieter eine Kategorieherabsetzung in Ansatz bringen.

Der Kategoriezins, zu dem noch viele Altmietverträge in Wien existieren, bietet keine Zuschlagsmöglichkeiten für eine bessere Ausstattung oder Lage der Wohnung. Der Mietzins ist „flat" pro Quadratmeter zu errechnen. Kategorie-A liegt bei 3,08 Euro/ $\mathrm{m}^{2}$ monatlich, die Kategorien B und C/D-brauchbar berechtigen wieder zu einem Abschlag von 25 bzw. 50 Prozent. Der Kategoriezins wird weiter als wertgesichert veröffentlicht, er steigt, sobald der Verbraucherpreisindex eine 5\%-Schwelle überschritten hat. Die Anpassung erfolgt jeweils im Oktober - im Gegensatz zum Richtwertmietzins, der jeweils im April und inzwischen nur alle zwei Jahre angepasst wird.

Bedeutung hat der Kategoriezins heute noch, wenn uralte Mietrechte nach $\S 14$ vererbt oder nach $\S 12$ MRG unter lebenden weitergegeben werden, und etwa zur Berechnung des gesetzlichen Honorars für Immobilienverwalter (pauschal der Kategorie-A-Zins pro Quadratmeter und Jahr) oder als ,fiktiver Mietzins" in der Hauptmietzinsabrechnung nach $\S 20$ Abs $1 \mathrm{Z} 1$ lit b (Würth et al. 2009, 193).

\subsubsection{Der freie Mietzins}

Der freie Mietzins ist jener, den das Mietrechtsgesetz gar nicht erwähnt. Er richtet sich nach den Marktverhältnissen - Angebot und Nachfrage determinieren den Preis. Lediglich allgemeine zivilrechtliche Schranken können auch den freien Mietzins limitieren; etwa Vorschriften nach dem Allgemeinen Bürgerlichen Gesetzbuch wie Wucher ( $\$ 879$ ABGB) und Verkürzung über die Hälfte bzw. laesio enormis ( $\$ 934$ ABGB), sowie Sittenwidrigkeit, List, Zwang, Drohung und Irreführung beim Vertragsabschluss. 


\subsection{Höhe und Bedeutung des Richtwertmietzinses}

Der Richtwertmietzins ist nicht als starres Mietregulativ gedacht. Er geht lediglich von einer Standardwohnung aus, für die der jährlich verlautbarte Richtwert gilt. Werterhöhende oder -vermindernde Abweichungen von dieser „,mietrechtlichen Normwohnung" können allerdings als Zu- und Abschläge im Mietzins berücksichtigt werden (Würth et al. 2009, 223).

So gesehen könnte der Richtwertmietzins als Kostenmiete bezeichnet werden. Sind die Baukosten aufgrund etwaiger Sonderausstattungen übergebührlich hoch, so kann das dem Mieter verrechnet werden. Dasselbe gilt grundsätzlich für die Grundkosten, die über den Lagezuschlag eingepreist werden können.

Der Richtwertmietzins war 1993 somit ein Liberalisierungsschritt, der notwendig wurde, nachdem der Oberste Gerichtshof mit einer für Mieter ungünstigen Entscheidung einen relativ hohen Angemessenen Mietzins vom Zaun brach. Dieser entwickelte sich immer mehr zur marktkonformen Miete, weswegen die Regierung eine Neudefinition (und Begrenzung) der Angemessenheit anpeilte.

„Leider zählt gerade diese Regelung zu den unübersichtlichsten im gesamten Wohnrecht und - weit darüber hinaus - im mietrechtlichen Normenbestand der westlichen Hemisphäre“ (Dirnbacher 2009, 261).

Da der Richtwert als „Mittelding“ zwischen dem Angemessenen Mietzins und dem Kategoriezins gilt, dürfte das die Ober- und Untergrenze für den Richtwertmietzins sein (Würth et al. 2009, 223f).

\subsubsection{Zuschlagsberechnung im Richtwertsystem}

Die Richtwertberechnung erfolgt nach $§ 16$ Abs 2 MRG, wo sechs (bzw. sieben) Kriterien die Abweichung von der ,mietrechtlichen Normwohnung" definieren. Diese Abweichungen - es können dies Zuschläge aber auch Abschläge sein erfolgen nach:

- Zweckbestimmung der Wohnung,

- Stockwerkslage,

- Lage innerhalb des Stockwerks,

- Zubehör an der Liegenschaft (Balkone, Keller, Dachböden),

- Sonstige Ausstattung,

- Grundrissgestaltung.

Wie hoch der exakte Zuschlag etwa für einen Balkon ist, geht aus dem Gesetz nicht hervor. Allerdings wurden vom nach dem Richtwertgesetz gebildeten Beirat für Wien und von der Zentralen Schlichtungsstelle der Gemeinde Wien Vor- 
schläge zur Ermittlung der Zu- und Abschläge erarbeitet, denen die Judikatur weitgehend folgt (Stabentheiner 2010, 130). Diese „Auflistung und Bewertung einzelner Fakten kann aber nur ein Kontrollinstrument sein; die Justierung hat im Einzelfall nach richterlichem Ermessen zu erfolgen“" (Stabentheiner 2010, 130f).

Von der Magistratsabteilung 25, die im Auftrag der Schlichtungsstelle Richtwertgutachten anfertigt, werden die folgenden Zuschläge verwendet (MA 25 2010, 5ff):

1. Stockwerkslage
a. unterstes Wohngeschoss unter Niveau
von - $15 \%$ bis $-30 \%$
b. unterstes Wohngeschoss niveaugleich
i. unmittelbar an der Straße
von - $5 \%$ bis - $15 \%$
ii. nicht unmittelbar an der Straße (z.B. hofseitig) bis - $10 \%$
c. unterstes Wohngeschoss bis 2,5 m über Niveau (im Mittel)

i. unmittelbar an der Straße bis - $10 \%$

ii. nicht unmittelbar an der Straße (z.B. hofseitig)

d. 1. Stock (zweites Hauptgeschoss) bis - $5 \%$

e. Geschosszuschlag nach Marktauffassung, ab dem 2. Stock (drittes Hauptgeschoss) pro Stock

f. Abstrich für nicht vorhandenen Lift, ab dem 2. Stock (drittes Hauptgeschoss) pro Stock

$$
\pm 0 \%
$$$$
+1,5 \%
$$$$
-4 \%
$$

2. Lage innerhalb des Stockwerkes:
a. Lage mit durchschnittlichen Beeinträchtigungen, etwa durch Lärm oder Geruchseinwirkungen $\pm 0 \%$
b. Lage mit überdurchschnittlichen Beeinträchtigungen, etwa durch Lärm oder Geruchseinwirkungen
c. besondere Ruhelage, oder Grünlage bis $+20 \%$
d. sonstige Beeinträchtigungen (z.B. schlechte Belichtung, Nordlage, enge Verbauung) bis - $5 \%$
e. sonstige Vorzüge (z.B. gute Belichtung, Fernblick) bis $+5 \%$
f. Lage über offener Durchfahrt oder offenem Durchgang, bzw. Lage unter Terrasse oder Flachdach

3. Ausstattung der Wohnung mit anderen Teilen der Liegenschaft, für die kein besonderes Entgelt berechnet wird:

a. Wohnung mit Balkon, Loggia oder Terrasse bis

b. Wohnung ohne Kellerabteil

$+10 \%$

c. Wohnung mit Dachbodenabteil

$-2,5 \%$

d. Wohnung mit Garten (ausschließliche Nutzung)

$+2,5 \%$ bis $+10 \%$ 
4. Sonstige Ausstattung und Grundrissgestaltung der Wohnung:

a. Gangküche $-5 \%$

b. Kochstelle bei Einzelraumwohnung - - $5 \%$

c. zusätzliches Bad oder zusätzlicher Duschraum $\quad+5 \%$ bis $+10 \%$

d. zusätzliches WC $+5 \%$

e. Dachschrägen, Dachflächenfenster und Dachgauben bis - $10 \%$

f. Bad und WC in einem Raum $-2,5 \%$

g. Fläche kleiner als $30 \mathrm{~m}^{2}$ (damit aber keine Kat.-A) $\quad+10 \%$

h. Fläche größer als $130 \mathrm{~m}^{2}-5 \%$

i. sehr guter Zustand (neu) bis $+5 \%$

j. brauchbarer Zustand (Normwohnung) $\quad \pm 0 \%$

k. mäßiger bis sehr schlechter Zustand von - $2,5 \%$ bis - $30 \%$

1. Duschgelegenheit im Wohnungsverband ${ }^{30} \quad$ bis $+5 \%$

$\mathrm{m}$. Vorraum vorhanden ${ }^{\text {Fußnote oben }}+2,5 \%$

n. Warmwasseraufbereitungsanlage vorhanden ${ }^{\text {Fußnote oben }}+2,5 \%$

o. höherwertiger Parkettboden (z.B. Sternparkett o.ä.) bis $+3 \%$

p. Zuschlag für Telefonanschluss, Telekabelanschluss, Gegensprechanlage, Waschmaschinenanschluss $\quad$ je $+1 \%$

q. Über dem Stand der Technik der mietrechtlichen Normwohnung liegende Ausstattung Anteilige Kosten (s.u.)

5. Grundrisslösung:

a. Schlechte Grundrisslösung bis $-10 \%$

b. Zentrales Vorzimmer (bei Wohnungen ab $100 \mathrm{~m}^{2}$ ohne Durchgangszimmer) bis $+3 \%$

\section{Zusatzverpflichtungen}

a. Verpflichtung des Vermieters zur Erhaltung der Heizanlage $+5 \%$

Eine Höchstgrenze für die gesamten, addierten Zuschläge gibt es nicht. Jedoch muss jedes einzelne Kriterium zunächst einer isolierten Betrachtung unterzogen werden. Eine allfällige Abweichung zur Normwohnung ist als $\mathrm{Zu}$ - oder Abschlag prozentual im Richtwert zu berücksichtigen. Maßgeblich für die absolute Höhe eines Zuschlags ist nicht die Richtwert-Kategorie der bestimmten Wohnung, sondern der Kategorie-A-Richtwert: Wird etwa ein Balkon bei einer Wohnung ohne Heizung (Kategorie B) mit $+10 \%$ berücksichtigt, so ist dieser

30 Diese Zuschläge sind nur dann zulässig, wenn sie nicht für die jeweilige Kategorieeinstufung notwendige Merkmale sind. Ein Vorraum ist für eine Kategorie A-Wohnung notwendig. Hat eine C-Wohnung, für die ein Vorraum kein Kategoriemerkmal ist, einen solchen, so ist ein Zuschlag erlaubt. 
Prozentsatz als Zuschlag zum Kategorie-A-Richtwert von 4,71 Euro zu verstehen. Er macht also 47 Cent aus, und nicht, wie in der Praxis manchmal fälschlicherweise angenommen, 36 Cent, was $10 \%$ des Richtwerts für Ausstattungskategorie B entspräche (Stabentheiner 2010, 129f).

Punkt 4) q) bedarf einer näheren Erklärung: Investiert ein Vermieter in eine Ausstattung, die weit über das Maß der ,,mietrechtlichen Normwohnung“ und den jeweiligen Stand der Technik hinausgeht (etwa in ferngesteuerte Lichtsysteme o.ä.), so steht ihm ,ein Zuschlag in der Höhe von 4 \% der Eigenkapitalverzinsung sowie eine auf 15 Jahren gerechnete, nicht der Wertsicherung unterliegende jährliche Abschreibung von 1/15 von den Anschaffungskosten bzw. vom Zeitwert" zu (MA 25 2010, 7).

Kostet eine derartige Annehmlichkeit etwa 1.500 Euro, so ist dieser Wert mit 0,007362 zu multiplizieren, um den entsprechenden Zuschlag zum Richtwert $\mathrm{zu}$ erhalten (11,04 Euro pro Monat insgesamt). Bei einer $50 \mathrm{~m}^{2}$-Wohnung sind das 22,09 Cent pro Quadratmeter Aufschlag. Die diesbezügliche Berechnungsformel würde so aussehen:

$$
Z_{\epsilon / m^{2}}=\frac{I_{i} * F_{4 \% * 1 / 15}}{N F}
$$

Z: Zuschlag

$\mathrm{I}_{\mathrm{i}}$ : $\quad$ Investitionswert zum Zeitpunkt i (Rechnungssumme bzw. Zeitwert)

$\mathrm{F}_{4 \% * 1 / 15}$ : Multiplikationfaktor, konstant $0,007362^{31}$

NF: $\quad$ Nutzfläche der Wohnung

Dieser Mechanismus soll in dieser Arbeit lediglich verdeutlichen, wie sehr die Regulierung der Miethöhe dem System der Kostenmiete gehorcht, in dem die Marktkräfte eines Mietmarktes grundsätzlich keinen Platz haben.

31 Dieser ergibt sich aus der nachschüssigen Rente vom Barwert 1 bei einer jährlichen Verzinsung von $4 \%$ über 15 Jahre (0,0899411), multipliziert mit der Teilrate an Stelle der nachschüssigen Rente 1 (einfache Zinsen) bei jährlicher Verzinsung zu $4 \%$ am Ende jedes Monats $(0,08183306)$. 


\subsubsection{Valorisierung des Richtwertzinses und das "Inflationslinderungsgesetz ${ }^{\text {“ }}$}

Der Richtwert ist bis zum Jahr 2008 jährlich an die Indexsteigerungen des Verbraucherpreisindex angepasst worden und erlangte im jeweils darauffolgenden Jahr per 1. April Gültigkeit. Als Gradmesser für die Teuerung der Mieten diente traditionell die Dezember-Inflationsrate. Mit dem ,mietrechtlichen Inflationsminderungsgesetz" stellte die Richtwerterhöhung plötzlich auf den Jahresdurchschnitt ab, da dies im betreffenden Jahr 2008 politisch opportun war, zumal die Dezemberinflation des Jahres 2007 überdurchschnittlich hoch gewesen ist. Mit der Wohnrechtsnovelle 2009 dürfen Richtwertanpassungen nur noch jedes zweite Jahr erfolgen (Würth et al. 2009, 587). Der letzte - für diese Arbeit aktuelle Richtwert wurde für den Zeitraum ab 1. April 2010 verlautbart.

\subsubsection{Verbraucherpreisindex statt Baukostenindexierung}

Der §6 RichtWG hatte ursprünglich eine zusätzliche Veränderungsmöglichkeit für den Richtwertmietzins vorgesehen. Wenn der Baupreisindex für den Wohnungs- und Siedlungsbau um mehr als 25 Prozent seit der letztmaligen Festsetzung des Richtwerts (1994) abweicht, müsse der Justizminister nach Einholung eines Gutachtens die Richtwerte neu festsetzen.

Die §§6-9 RichtWG wurden mit Juli 2006 ersatzlos aufgehoben, weil nach Ansicht des Gesetzgebers eine Neufestsetzung der Richtwerte nicht mehr erforderlich erschien und die Prüfung der Voraussetzungen für eine Richtwertänderung nur ,mit unnötig hohen Kosten verbunden wäre“. Somit bleibt nur eine jährliche Valorisierung nach dem Verbraucherpreisindex. „Damit sind die in den Verordnungen der einzelnen Bundesländer festgesetzten Werte als Ausgangsbasis für die Richtwertberechnung versteinert; sie können nicht mehr geändert werden“ (Würth/Zingher/Kovanyi 2007, 136).

\subsubsection{Rechtliche Unschärfen des Richtwertsystems}

Immer, wenn eine Regel Auslegungsspielraum zulässt, werden ökonomisch rational handelnde Unterworfene in ihrer Auslegung zumindest bis zum Rand der Grauzone gehen, vor allem, wenn Informationen asymmetrisch verteilt sind. Je weniger verständlich und nachvollziehbar die Norm ist, desto größer wird auch die Versuchung der Nichtbefolgung sein.

Eine Grauzone an sich ist das Zuschlagssystem. Besonders gut ausgestattete Wohnungen sollen schließlich einen Zuschlag gegenüber jenen Wohnungen der- 
selben Kategorie (z.B. Kat.-A) zulassen, die eine schlechtere Ausstattung haben. Die mietrechtliche Normwohnung ist im Gesetz nicht ganz scharf geregelt.

- Etwa wurde für eine Kategorie-A-Wohnung nicht definiert, dass eine Warmwasseraufbereitungsmöglichkeit gegeben sein muss, was manche Juristen als Redaktionsversehen bewerten (Würth/Zingher/Kovanyi 2004, 571).

- Weiters herrscht ein Regeldefizit was die Größe einer solchen Normwohnung anbelangt. Sie muss zwischen 30 und 130 Quadratmeter aufweisen. Einzelne Juristen schlagen vor, dass innerhalb dieser Bandbreite bei kleinen Wohnungen Abstriche, bei größeren Wohnungen Zuschläge möglich sein sollen. Aus der Sicht des Vermieters ist ein Quadratmeter in einer kleinen Wohnung wiederum ertragreicher und wertvoller als in einer großen Wohnung. Zumal die absoluten Kosten für die Haustechnik bei kleinen Einheiten ähnlich groß sind, und somit relativ hohe Kosten im Verhältnis zur Nutzfläche verursachen.

- Ist ein hohes Stockwerk ein Zuschlag oder ein Abschlag? (Böhm 2003, 27).

- Die Normwohnung soll zudem eine ,durchschnittliche Grundrissgestaltung" aufweisen, doch auch diese Festsetzung lässt gehörigen Interpretationsspielraum zu, zumal ein ,guter" Grundriss als Zuschlag verrechnet werden könnte. Unklar ist, ob nun mehrere kleine Räume „wertvoller“ sind als wenige große Räume. Für zwei Kriterien spielt das eine Rolle: die Abstrichstauglichkeit eines Durchgangszimmers bzw. einer Gangküche (Böhm 2003, 28).

- Soll das Fehlen eines Kellerabteils einen Abstrich zur Folge haben oder ist das Vorhandensein ein Zuschlag zum Richtwert? Darüber sind sich Experten uneinig.

- Das Richtwertgesetz verlangt weiters, dass sich die Wohnung in einem Gebäude mit „ordnungsgemäßem“ Erhaltungszustand befindet. Gibt es einen besseren als den ,ordnungsgemäßen“ Zustand?

- Hinsichtlich der Lage (Wohnumgebung) erlaubt das Richtwertgesetz einen Lagezuschlag, sofern die Lage überdurchschnittlich ist, und zwar bezogen auf die „Erfahrungen des täglichen Lebens“. „Es bedarf keiner näheren Begründung, dass diese ,Spezifizierung' für die Vertragserrichtungspraxis gänzlich unbrauchbar ist" (Böhm 2003, 24f). Überwiegen zum Zeitpunkt der Errichtung des Gebäudebestands (Gründerzeit von 
1870 bis 1917) in einer Gegend kleine und mangelhaft ausgestattete Wohnungen der Kategorie D, dann soll dies einen Lagezuschlag unmöglich machen. Was hier als Parameter für die Feststellung eines sogenannten "Gründerzeitviertels“ zugezogen werden soll, geht aus dem Gesetz nicht hervor. In Wien hat man sich zu einer pragmatischen - und dogmativen - Auslegung dieser Gesetzespassage entschlossen, ohne dass es der Gesetzgeber so vorgeschrieben hätte. Die Lagezuschlagsberechnung ist sehr komplex. Welche Daten zur Berechnung herangezogen werden müssen, ist dem Mieter (und womöglich auch dem Vermieter) nicht bekannt (Böhm 2003, 34). Doch dazu in folgenden Teilen der Arbeit.

- Es fehlt im Gesetz ein Hinweis, ob die durchschnittliche Ausstattung der Normwohnung zum Zeitpunkt ihrer Einrichtung oder zum Zeitpunkt des Mietvertragsabschlusses gegeben sein muss.

- Warum die Richtwerte in den neun Bundesländern derart voneinander abweichen (Steiermark: 6,76 Euro; Kärnten 5,74 Euro; Wien: 4,91 Euro) geht auf die Zusammensetzung der entsprechenden Beiräte zurück, die jeweils für das eigene Bundesland im Jahr 1993 den Richtwert festgesetzt haben. Mit den Baukosten oder Grundpreisen können sie wenig zu tun haben. ${ }^{32}$

- Die restliche Ausstattung der Wohnung kann ebenfalls Zuschlagsbegründend sein, wobei unklar ist, ob ein Telekabel-Anschluss nicht eher zum Standard zu rechnen ist, dasselbe gilt für eine Gegensprechanlage.

- Die Stockwerkslage soll zu Zu- oder Abschlägen berechtigen. Der Feststellungsparameter ist wiederum die „Erfahrung des täglichen Lebens“. Unklar ist, ob eine niedrige Stockwerkslage nun einen Abschlag bedeutet (höhere Lärmbelastung), wenn sie in einem Haus ohne Lift doch einen besseren Stiegenkomfort bedeutet (Böhm 2003, 27).

- Die Erhaltung der Gasetagenheizung bzw. der Gas-Kombitherme könnte als Zuschlag verrechnet werden - oder auch nicht. Derzeit herrscht über die Erhaltungspflichten von Thermen im Vollanwendungsbereich des MRG Unklarheit.

32 Bezeichnend ist in diesem Zusammenhang vielleicht, dass sich selbst Böhm (2003) über die unverständlich geringe Höhe des Wiener Richtwerts wundert. „Bereits der oberflächliche Befund legt den Verdacht der weitgehenden Willkür bei der Richtwertfestsetzung nahe“ (Böhm 2003, 23). Das Zitat findet sich in einem Auftragswerk der mieterfreundlichen Arbeiterkammer. 
Zusammenfassend stellt Böhm (2003) fest: „Die Verständlichkeit des Richtwertzinssystems ist bereits auf einer ganz allgemeinen Ebene massiv in Frage gestellt. Den Rechtsunterworfenen ist in vielen Fällen nicht klar, ob die Richtwertzinsbestimmungen überhaupt auf den konkreten Mietvertrag zur Anwendung gelangen“ (Böhm 2003, 37). Besonders unscharf gestalten sich die möglichen $\mathrm{Zu}$ - und Abschläge. Hinzu kommt, dass der Vermieter die einzelnen $\mathrm{Zu}-$ schläge in keiner Silbe anführen oder ihre Höhe dartun muss - mit Ausnahme des Lagezuschlags, der zumindest verbal begründet sein muss.

Der Richtwertmietzins ist offenbar ein Kochrezept, aus dem jeder Koch eine andere Suppe zaubert. Das zeigt sich unvergleichlich deutlich anhand von Beispielen zur Richtwertzinsberechnung in Dirnbacher/Heindl/Rustler (1994). Dieses inhomogene Autorenteam hat den höchstzulässigen Richtwert zahlreicher konkreter Wohnungen in zwei Varianten berechnet, einmal „günstig“, einmal „teurer“, wobei Dirnbacher/Rustler die eine, und Heindl die andere Variante „errechnet" hat. ${ }^{33}$

Tabelle 3: Ergebnisunterschiede bei der Richtwertberechnung pro $\mathrm{m}^{2}$, Auszug

\begin{tabular}{|c|c|c|}
\hline Objekt & $\begin{array}{l}\text { Ergebnis Berechnung } \\
\text { Dirnbacher/Rustler }\end{array}$ & $\begin{array}{l}\text { Ergebnis Berechnung } \\
\text { Heindl }\end{array}$ \\
\hline $\begin{array}{l}\text { 1010, Falkestraße, } 3 . \\
\text { Stock ohne Lift, Kategorie } \\
\text { C }\end{array}$ & 71,60 Schilling & 53,96 Schilling \\
\hline $\begin{array}{l}\text { 1010, Seilergasse, } 90 \mathrm{~m}^{2} \text {, } \\
\text { 5. Liftstock, saniertes } \\
\text { Haus, Kategorie A }\end{array}$ & 173,83 Schilling & 144,07 Schilling \\
\hline $\begin{array}{l}\text { 1020, Taborstraße, } 70 \mathrm{~m}^{2} \text {, } \\
\text { 3. Liftstock, Kat. C, mit- } \\
\text { telmäßig }\end{array}$ & 44,03 Schilling & 34,61 Schilling \\
\hline $\begin{array}{l}\text { 1030, Reisnerstraße, „Dip- } \\
\text { lomatenviertel“, Kat. B, } \\
35 \mathrm{~m}^{2} \text {, Erdgeschoß }\end{array}$ & 74,32 Schilling & 45,68 Schilling \\
\hline
\end{tabular}

33 Dirnbacher und Rustler sind ideologisch gesehen „branchenfreundlich“ und haben ihre Berechnungsmethode angewandt, während Heindl, seines Zeichens Leiter der städtischen MA 50, eher mieterfreundlich argumentiert. Auf Heindls Engagement ist die Einteilung in Lagezuschlagszonen und Gründerzeitvierteln zurückzuführen, die er im Auftrag des sozialdemokratischen Wohnbaustadtrats Rudolf Edlinger(SPÖ) 1994 in ein parteikonformes Licht gerückt hat. Sowohl die Berechnungen von Dirnbacher/Rustler als auch jene von Heindl sind unter dem Gesichtspunkt ihrer ideologischen Absichten zu deuten. 


\begin{tabular}{|c|c|c|}
\hline $\begin{array}{l}\text { 1030, Schlachthausgasse, } \\
\text { Kat. C, 4. Liftstock, } \\
125 \mathrm{~m}^{2} \text {, Industrie- } \\
\text { Immissionen, schlechter } \\
\text { Hauszustand }\end{array}$ & 14,80 Schilling & 17,82 Schilling \\
\hline $\begin{array}{l}\text { 1040, Johann-Strauß- } \\
\text { Gasse, Kat. C, } 160 \mathrm{~m}^{2}, 2 . \\
\text { Liftstock, mit Garage, } \\
\text { Nutzung auch als Ordina- } \\
\text { tion }\end{array}$ & 106,31 Schilling & 54,62 Schilling \\
\hline
\end{tabular}

Quelle: Dirnbacher/Heindl/Rustler (1994, 120ff).

Dass es selbst Mietrechts-Experten, die zwar wohlgemerkt unterschiedliche Ideologien verfolgen, nicht gelingt, sich über die Höhe des Richtwertmietzinses „handelseins“ zu werden, bestätigt die Kritik Böhms (2003), wonach ein Regelsystem, das derartig viele Unschärfen birgt, zum Vorteil des jeweils Auslegenden interpretiert werden kann.

\subsection{Sanktionsmöglichkeiten des MRG und seine Folgen}

Neben dem Kündigungsschutz oder Bestandsschutz ist der Preisschutz eine der Hauptsäulen des Österreichischen Mietrechts. Damit soll verhindert werden, dass es im Falle einer Wohnungsknappheit zur Übervorteilung der Mieter durch die übermächtigen Vermieter kommt. Diese Mieter-Rechte sind zwingend und nicht dispositiv. Man kann sie also nicht ,vertraglich ausschließen“. Von der Norm kann immer nur zu Gunsten der Mieter, nicht aber zu Gunsten der Vermieter abgewichen werden (Stabentheiner 2010, 40).

Für die Höchstgrenze des Mietzinses gilt daher, dass diese durch vertragliche Regelungen nicht überschritten werden darf. „Soweit dennoch ein Mietzins vereinbart wird, der über der gesetzlichen Zulässigkeitsgrenze liegt, ist die Mietzinsvereinbarung hinsichtlich des den Grenzbetrag überschreitenden Mietzinsteils teilnichtig“ (Stabentheiner 2010, 123). Die Folge: der Mieter kann seine künftige Zinszahlungspflicht entsprechend auf den gesetzlich zulässigen Betrag herabsetzen lassen, und außerdem die Rückzahlung bereits geleisteter Überschreitungsbeträge (gerichtlich) erwirken. 


\subsubsection{Verjährungsfristen in Mietrechtssachen}

Allerdings gelten Präklusions- und Verjährungsfristen. Bei einem unbefristeten Mietverhältnis muss der Mieter die Miethöhe innerhalb der ersten drei Jahre rügen, andernfalls eine allfällig überhöhte Miete als akzeptiert und konform gilt. Ein besonderes Risiko hat sich der Gesetzgeber für jene Vermieter ausgedacht, die nicht nur zu viel Miete verlangen, sondern darüber hinaus ihre Mietverhältnisse zeitlich beschränken. In diesem Fall besteht ein etwaiger Zinsminderungsanspruch eines Mieters für die vergangenen zehn Jahre (Stabentheiner 2010, 155), und kann bis zu sechs Monate nach dem Auszug des Mieters geltend gemacht werden. Darüber hinaus wird die Befristung mit einem Abschlag von 25 Prozent bestraft (,Befristungsabschlag“). Bei unbefristeten Mietverhältnissen gibt es hinsichtlich des $\$ 27$ Abs 1 MRG, der unter anderem die ,illegale Ablöse von Mietrechten“ regelt, eine Verjährungsfrist von 10 Jahren.

\subsubsection{Gerichtliche Zuständigkeit bei Mietzinsanfechtungen}

In $\S 37$ (1) MRG ist vorgesehen, dass insbesondere für Verfahren über die Angemessenheit der vereinbarten Hauptmietzinse (§12a, §16ff) das örtliche Bezirksgericht zuständig ist, und dass die Bestimmungen über das gerichtliche Verfahren in „Rechtsangelegenheiten außer Streitsachen“ (Abs 3) gelten. Ein mietrechtliches Außerstreitverfahren kann jedoch in jenen Städten, in denen eine Schlichtungsstelle besteht, nur eingeleitet werden, wenn zuvor die Schlichtungsstelle angerufen wurde (Stabentheiner 2010, 189). Dort soll eine ,gütliche Einigung" unter Berufung auf die Gesetze gefunden werden. Die Entscheidung der Schlichtungsstelle ergeht als Bescheid. Gegen diesen kann nicht berufen werden, allerdings kann jede Partei durch eine Anrufung des Gerichts das Schlichtungsstellenurteil außer Kraft setzen.

Das zuständige Gericht muss die Verhandlung über die zulässige Miethöhe auf dem Außerstreitwege führen. Der wesentliche Unterschied besteht darin, dass ein Außerstreitverfahren weniger förmlich ist, dass sich die Parteien selbst vertreten können und in erster und zweiter Instanz keinen Rechtsvertreter benötigen, und dass daher die Vertretungskosten von den jeweiligen Parteien grundsätzlich selbst zu bezahlen sind.

Die Verfahrenskosten können allerdings vom Gericht aufgeteilt werden, je nachdem, in welchem Ausmaß die Parteien mit ihren Anträgen durchgedrungen sind, und welcher ,nicht zweckentsprechende Verfahrensaufwand zumindest überwiegend durch das Verhalten einzelner Parteien verursacht wurde“ (Stabentheiner 2010, 185). Der Kostenersatz für Vertretungskosten beträgt 400 Euro für das Verfahren in erster Instanz und jeweils 180 Euro für das Verfahren 
in zweiter und dritter Instanz (letztere vor dem Obersten Gerichtshof). Im Gegensatz zu einem Zivilprozess ist das Außerstreitverfahren damit relativ kostenextensiv.

Zusammenfassend besteht die Sanktionsmöglichkeit des Mietrechts darin, dass Vermieter eine allfällige zu viel verlangte Miete bei befristeten Mietverhältnissen für die vergangenen zehn Jahre, bei unbefristeten für die vergangenen drei Jahre zurückbezahlen müssen. Darüber hinaus ist eine verbotene Ablöse für die Mietrechte 10 Jahre rückforderbar, sämtliche Rückzahlungen sind natürlich zuzüglich Zinsen zu leisten (Würth et al. 2009, 328ff).

\subsubsection{Beispielrechnung Mietzinsherabsetzung}

Das folgende Beispiel soll die Problematik verdeutlichen, die sich aus der Grauzone einer überhöhten Mietvorschreibung ergibt. Nehmen wir an: Das Mietverhältnis für eine 33 Quadratmeter große Garçonnière im Fasanviertel (GZV) im 3. Bezirk beginnt am 1.1.2009. Die nach Richtwert zulässige Miete beträgt 150 Euro bei einem unbefristeten Mietverhältnis; bei einem befristeten würde es um ein Viertel weniger betragen („Befristungsabschlag“), also 112,50 Euro. Tatsächlich verlangt der Vermieter die Marktmiete von 250 Euro netto (ergibt etwa 350 Euro ink1. Betriebskosten und Umsatzsteuer). Heute ist der 01.07.2011.

a) Bei einer unbefristeten Hauptmiete: Der Mieter kann seine künftigen Mietzahlungen um 100 Euro reduzieren. Für die vergangenen 2,5 Jahre (gerechnet bis Juli 2011) erhält er 3.000 Euro zuzüglich Zinsen. Der verringerte Mietzins gilt unbefristet und über den Tod des Mieters hinaus (Mietverhältnisse sind nach §14 MRG ,vererbbar“). Der „Schaden“ durch die entsprechende gerichtliche Mietzinsherabsetzung für den Vermieter kann bis zu einer dauerhaften Ertragswertminderung der Wohnung führen. Der Mieter muss seine Mietzinsminderungsansprüche bis zum 31.12.2011 geltend machen, ansonsten verjähren sie.

b) Bei einer auf drei Jahre befristeten Hauptmiete: Der zulässige Hauptmietzins muss um den Befristungsabschlag von 25 Prozent vermindert werden, er liegt damit bei 112,50 Euro. Mietvertrag läuft am 31.12.2011 aus, der Mieter kann seine Mietzahlungen bis dahin um 137,50 Euro reduzieren. Für die vergangenen 2,5 Jahre erhält der Mieter 4.125 Euro zzgl. Zinsen zurückbezahlt. Dieser Anspruch der Rückforderung erlischt erst Ende Juni 2012. Einziger Trost für den Vermieter: Er wird das Mietverhältnis nach Ablauf der Befristung nicht verlängern. Eine dauerhafte Wertminderung der Wohnung ist nicht gegeben. 
Die beiden Beispiele halten in Anbetracht dessen, dass der Richtwert in Wien meist weit niedriger liegt als die erzielte Marktmiete, ein Problem vor Augen: Risikoaversen Vermietern ist es zu gefährlich, unbefristete Mietverhältnisse einzugehen. Womöglich würde die Wohnung ansonsten dauerhaft zu einer gefürchteten und ertragslosen „Altmieterwohnung ${ }^{\text {‘34 }}$. Eher gehen Vermieter kurzfristig das Risiko einer höheren Mietzinsminderung ein, nach dem Motto: lieber ein Ende mit Schrecken (höhere Rückzahlung) als ein Schrecken ohne Ende (dauerhafte Mietzins- und damit Wertminderung). Der Nachteil dieser Politik ist freilich, dass sehr wenige Mietverhältnisse unbefristet vergeben werden, und entsprechend die Mieter ständig mit der Unsicherheit über ihren weiteren Verbleib in der Wohnung, und die Vermieter zugleich mit Fluktuation leben müssen. Investitionen des Mieters rechnen sich während seines befristeten Mietverhältnisses ebenso wenig wie sich die Durchsetzung seiner Rechte lohnt (etwa in Bezug auf Erhaltungspflichten des Vermieters): Mieter, die "Stress machen“ werden schließlich nicht ,verlängert“.

$\mathrm{Zu}$ diesem spieltheoretisch leicht verständlichen Mechanismus kommt die Unsicherheit über die eigentliche Sache hinzu, wie Stabentheiner (2010) feststellt: „Meiner Ansicht nach führt die hohe Komplexität des Richtwertsystems dazu, dass letztlich kein Marktbeteiligter exaktes Wissen darüber hat, welcher Mietzins für eine bestimmte Wohnung gesetzlich zulässig ist. Deshalb ist auch der Ausgang einer gerichtlichen Auseinandersetzung über die zulässige Mietzinshöhe nicht einmal der Größenordnung nach einigermaßen verlässlich einschätzbar. Meiner Überzeugung nach dürften viele gerade wegen dieser Unsicherheit den Gang $\mathrm{zu}$ den Schlichtungsstellen und Gerichten scheuen“" (Stabentheiner 2010, 133-134). Stabentheiner ist als Abteilungsleiter in der Zivilrechtssektion des Justizministeriums u.a. für Mietrecht zuständig.

34 Darunter versteht man landläufig Mietverhältnisse, die lange vor dem Richtwertgesetz zum Kategoriezins oder gar zum Friedenskronenzins eingegangen worden waren. Um die entsprechende Wertminderung aufzuzeigen: Eine Wohnung in einem Außenbezirk mit einem unbefristeten Altmieter, der üblicherweise eine Miete von 1,0 bis 1,5 Euro pro Quadratmeter pro Monat zahlt, kostet etwa 600 bis 1000 Euro pro Quadratmeter Nutzfläche. Ohne diesen Mieter wäre die Wohnung das Dreifache wert. 



\section{Lage und Lageregulierung}

Das Wort „Lage“ kommt aus dem Mittelhochdeutschen. Mit Lâge wurde eine „liegende Lauerstellung“ bezeichnet. ${ }^{35}$ Je besser die Lage des Jägers ist, desto höher sind auch seine Beutechancen. Verblüffend analog funktioniert die heutige Immobilienwirtschaft.

Der frühe Jagdbegriff erhält mit der Intensivierung der Landwirtschaft in der frühen Neuzeit eine neue Bedeutung, und zwar aus einer landwirtschaftlichen Standortbetrachtung. Gilt es, mit dem bäuerlichen Produkt eine Distanz zu einem zentralen Absatzmarkt zurück zu legen, so sinkt der Gewinn des Produzenten mit den steigenden Transportkosten ins Ballungszentrum. Den Transportkosten kommt nach der neoklassischen, mikroökonomischen Standorttheorie dabei eine bedeutende Rolle zu (Maier/Tödtling 2006a, 47).

Dieser Abschnitt geht zuerst auf Bodenrentenmodelle und ihre zentralistische Ausrichtung sowie auf Standortfaktoren und empirische Standortuntersuchungen ein, um danach das mietrechtliche Lagebewertungssystem zu erörtern. Dies ist Kern der Arbeit und wissenschaftlich ein unangetastetes Konstrukt.

\subsection{Neoklassische Standortmodelle}

\subsubsection{Thünens Bodennutzungstheorie: Das Zentrum und die Transportkosten}

Johann Heinrich von Thünen (1826) hat auf der Transportkostenproblematik aufbauend das Konzept der Lagerente begründet. Würde ein Produzent nur seine Produktionskosten verrechnen und den Transport separat an den Kunden überbinden, so würde die Nachfrage nach einem bestimmten Gut mit zunehmender Distanz sinken. Denn die steigenden Transportkosten und somit steigenden Endnutzerpreise machen das Gut nur noch für wenige Kunden interessant.

Gebiete näher am Absatzmarkt rechtfertigen die Produktion anderer Güter als Gebiete in größerer Entfernung. Umgemünzt auf die „Geschäftsmöglichkeit“", die der Boden bietet, ergibt sich nach Thünen die Lagerente. Die Lagerente ist jener Betrag, den ein Produzent erzielen kann, wenn ihm der Boden kostenlos zur Verfügung stünde. Das ist somit auch jene Summe, die die Bodennutzung maximal kosten darf, um einen Gewinn zu erwirtschaften (Maier/Tödtling 2006a, 125f). Unterschiedliche Entfernungen von einem (Absatz-) Zentrum füh-

35 Vgl. Wikipedia, online unter http://de.wikipedia.org/wiki/Lage, abgerufen 18.02.2010 
ren zu unterschiedlichen Lagerenten - und letztlich dazu, dass an jedem Ort nur jenes Gut produziert wird, das dort die höchste Lagerente erwirtschaftet (Maier/Tödtling 2006a, 128).

Thünen gießt die Lagerente (L) in folgende Formel:

$$
L=y p-y k t
$$

wobei

$\mathrm{L}=$ örtlich erzielbare Lagerente (in Euro $/ \mathrm{km}^{2}$ )

$\mathrm{y}=$ Anbauertrag $\left(\right.$ in $\left.\mathrm{t} / \mathrm{km}^{2}\right)$

$\mathrm{p}=$ Marktpreis der Feldfrucht (in Euro / $\mathrm{t}$ )

$\mathrm{t}=$ Entfernung zum Markt (CBD) (in km)

$\mathrm{k}=$ Transportkosten (in Euro $/ \mathrm{t} * \mathrm{~km}$ )

Die Konkurrenz der Nutzungsarten des Bodens führt zu unterschiedlichen Bodennutzungen, sofern der Bodenmarkt funktioniert. Jedes Grundstück so viel wert wie der auf die Gegenwart diskontierte zukünftige Ertragsstrom. Sämtliche übereinander gelegte Lagerentenkurven für sämtliche Güter würden eine Außenhülle-Kurve ergeben, die der Bodenpreiskurve in Abhängigkeit vom Zentrum entspricht (Maier, Tödtling 2006, 126). Thünens Modell findet sich heute vor allem im Bereich der Stadtstrukturtheorie wieder. „Thünen versucht auch die städtische Grundrente als Arbeitsersparnisrente zu deuten“ (Lüpkes 1992, 38). Hohe Preise im Zentrum haben mit Arbeitsersparnis und Bequemlichkeit zu tun (Lüpkes 1992, 38).

\subsubsection{Alonsos Stadtstrukturtheorie}

In Städten bilden sich unterschiedliche Gebiete, je nachdem, wo und wie die Bewohner ihre Nachfrage befriedigen können. Vereinfachend geht Alonso (1964) von einem „central business district“ (CBD) aus. Das ist ein einzelnes Zentrum einer monozentristischen Stadt, in dem die Stadtbewohner einkaufen oder arbeiten. Je nachdem wie weit entfernt sie von diesem Attraktionszentrum wohnen, steigen die Distanzüberwindungskosten. In Zentrumsnähe müssen die Bewohner wiederum höhere Bodenpreise in Kauf nehmen (Alonso 1974, 20).

Der Haushalt hat auf der Suche nach dem optimalen Wohnstandort eine Budgetrestriktion. Das Budget muss neben den Kosten für Boden und für Transportkosten auch alle übrigen (Konsum-) Güter abdecken: 


$$
y=p_{z} z+P(x) q+t(x)
$$

wobei

y: Einkommen des Haushalts

$\mathrm{p}_{\mathrm{z}}$ : $\quad$ Preis des zusammengesetzten Gutes (übrige Dienstleistungen, etc.)

$\mathrm{z}$ : $\quad$ Menge des zusammengesetzten Gutes

$\mathrm{P}(\mathrm{x})$ : Bodenpreis in der Entfernung $\mathrm{x}$ vom $\mathrm{CBD}$

q: $\quad$ Menge an konsumiertem Boden

$t(x)$ : Transportkosten bei einer Entfernung $x$

Diese Budgetrestriktion ergibt, dreidimensional nach den Dimensionen q (Menge des Bodens), z (Menge der übrigen konsumierten Güter) und x (Distanz zum CBD) dargestellt, eine Fläche, auf der jeder Punkt eine Kombination ergibt, die sich ein Haushalt mit seinem verfügbaren Einkommen (y) gerade noch leisten kann.

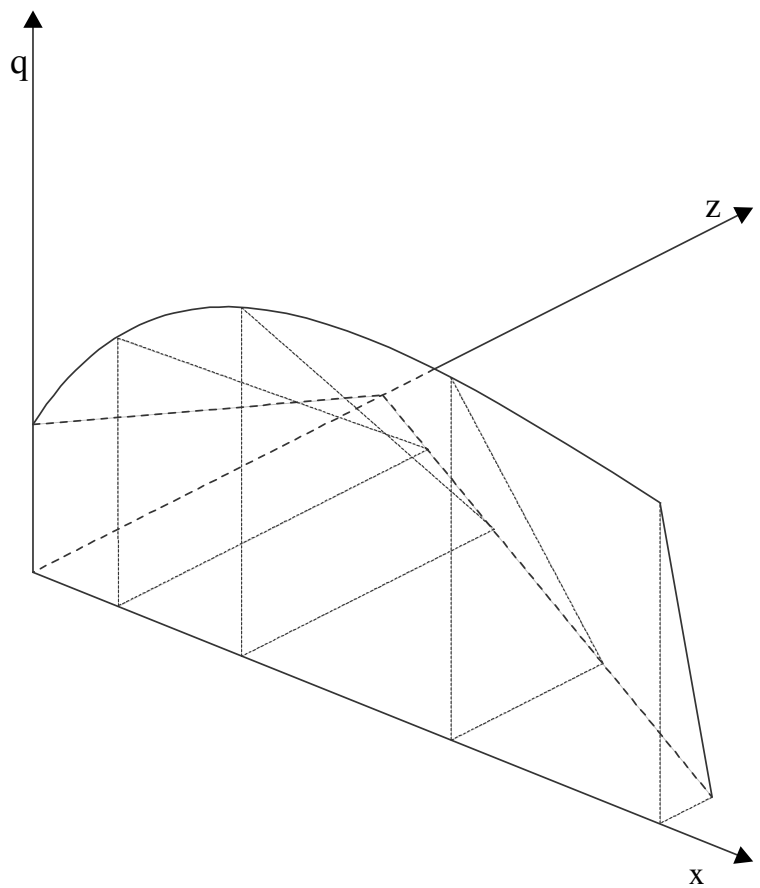

Quelle: eigene Darstellung nach Alonso 1974, 25 und Maier 2006, 130. Abbildung 6: Budgetrestriktion nach Alonso 
Der Konsument ist in Bezug auf die Zusammensetzung dieser drei Mengen (Entfernung, übriger Konsum und Bodenmenge) unter bestimmten Voraussetzungen indifferent, nämlich wenn er das „Level of satisfaction“ konstant hält. Wie würden jedoch die verschiedenen Gütermengen variieren, um diese Konstanz zu gewährleisten? Würde man etwa den übrigen Konsum (z) erst einmal ausblenden und lediglich die konsumierte Bodenfläche und die Distanz zum CBD in Verhältnis setzen, so würde man folgendes beobachten: „a small increase in distance will produce dissatisfaction, and will have to be compensated for by a small increase in the quantity of land for satisfation to remain the same“ (Alonso 1974, 26). Die Indifferenzkurve würde somit mit zunehmender Entfernung vom CBD immer stärker nach oben, hin zu mehr Bodenkonsum, zeigen.

Ebenso lässt sich der übrige Konsum in Verhältnis zu $t$ und q setzen, sodass dreidimensional dargestellt eine Indifferenzfläche entsteht. Jeder Punkt auf dieser Fläche stiftet für den Konsumenten denselben Nutzen nach der Nutzenfunktion $\mathrm{U}=\mathrm{U}(\mathrm{z}, \mathrm{q}, \mathrm{x})$.

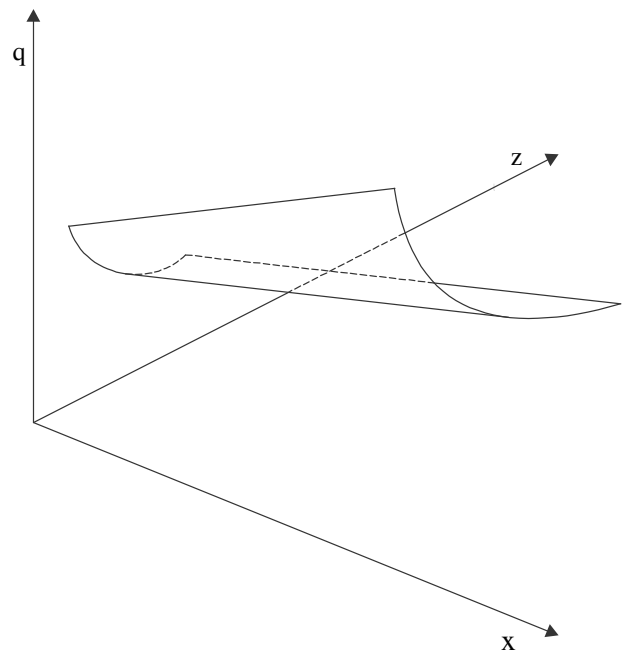

Quelle: eigene Darstellung nach Alonso 1974, 25 und Maier 2006, 131. Abbildung 7: Indifferenzkurve aus Bodenmenge, Entfernung und übrigem Konsum

„Der optimale Standort ist dort erreicht, wo die Indifferenzfläche die Fläche der Budgetrestriktion gerade berührt.“ (Maier, Tödtling 2006, 131). An diesem Punkt zeigt der Abstand t vom CBD den optimalen Standort für den Haushalt, bei dem er den höchsten Nutzen mit seinem Einkommen erzielen kann. 
Betrachten wir verschiedene Entfernungen $x$ vom CBD. Sollen diese Entfernungen stets dieselben Nutzenniveaus $\mathrm{U}_{\mathrm{x} 1}=\mathrm{U}_{\mathrm{x} 2}$ ergeben, so werden Haushalte je nach Entfernung unterschiedliche Bodenpreise zu zahlen bereit sein. Dieser Preis kann in Form von „Rentengebotskurven“ dargestellt werden. Bei größerer Entfernung vom CBD steigen die Transportkosten, und das Nutzenniveau sinkt zusätzlich durch die längeren Anfahrtszeiten. Die Rentengebotskurve wird daher mit zunehmender Entfernung $x$ fallen.

\subsubsection{Rentengebotskurve und Auslesemechanismus}

Die Rentengebotskurve ähnelt damit der Lagerente sehr stark. Eine steigende Entfernung führt zu fallenden Rentengebotskurven und somit zu fallenden Bodenpreisen. Haushalte haben unterschiedliche Präferenzen und damit unterschiedliche Rentengebotskurven. Jene Haushalte mit den am steilsten abfallenden Rentengebotskurven werden sich näher am Stadtzentrum ansiedeln als jene mit flacheren Rentengebotskurven. Für letztere ist - salopp formuliert - die Wertschätzung für die kürzeren Distanzüberwindungskosten geringer. Vergleiche Abbildung 8: Haushalt 1 hat eine flachere, Haushalt 2 eine steilere Rentengebotskurve.

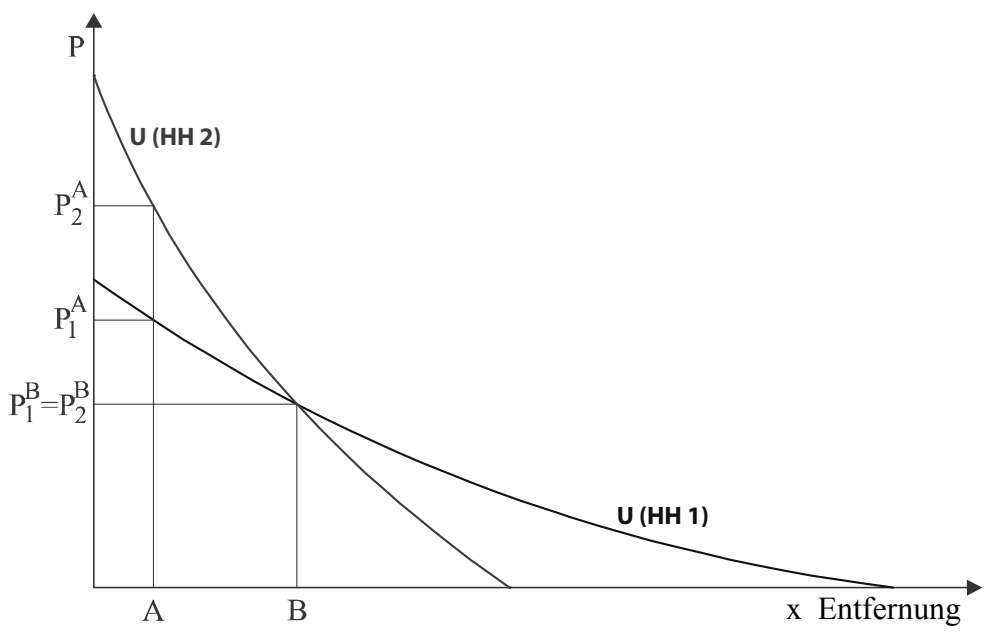

Quelle: eigene Darstellung nach Maier 2006, 134.

Abbildung 8: Auslesemechanismus, jedem Haushalt "seinen" Standort 
Nun stehen zwei Standorte, $\mathrm{A}$ und $\mathrm{B}$, zur Verfügung. Bei einem Preis von $\mathrm{P}_{1}{ }^{\mathrm{A}}$ für Standort $A$ und einem Preis von $\mathrm{P}_{1}{ }^{\mathrm{B}}$ für Standort $\mathrm{B}$ ist Haushalt 1 völlig indifferent. Der „bessere“ Standort A ist geringfügig teurer, hat aber Vorteile. Das Nutzenniveau, ausgedrückt in der flachen Kurve, bleibt gleich. Nun drängt Haushalt 2 auf den Markt. Dieser hat eine steilere Rentengebotskurve, die Wertschätzung für eine gute Lage ist höher. Für Standort B kann Haushalt 2 noch gleich viel wie Haushalt 1 ausgeben, doch für Standort A kann dieser Haushalt einen weit höheren Preis $\left(\mathrm{P}_{2}{ }^{\mathrm{A}}\right)$ zahlen, um dasselbe Nutzenniveau (steile Kurve) zu erreichen.

Die bereits mehrfach genannte Konsequenz ist, dass eine geringere Entfernung zum CBD zu höheren Bodenpreisen führen muss. Die hohen Preise in der Innenstadt werden bei den Bewohnern offenbar durch ein hohes Nutzenniveau gerechtfertigt. Eine gelungene Illustration der vergleichsweise exorbitanten Zentrumspreise liefert Knos (1962) für die Stadt Topeka, Kansas (vgl. Abbildung 9).

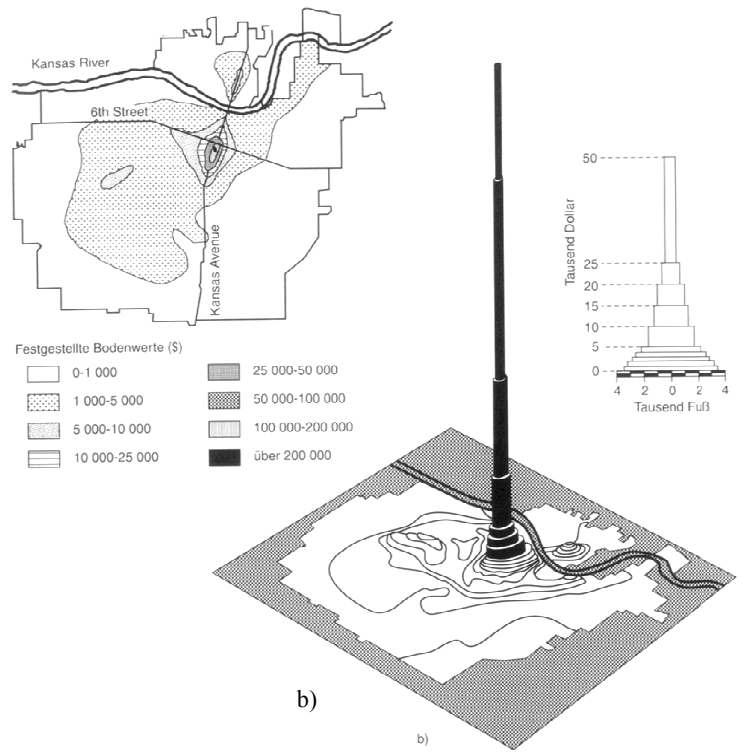

Quelle: Knos (1962) in Dicken 1999, 50.

Abbildung 9: Bodenwerte in Topeka, Kansas:

a) festgestellte Bodenwerte 1954-1959, b) isometrische Bodenwerte 


\subsubsection{Lagerente und Wohnimmobilien}

Die Rentengebotskurven und Thünens Lagerente sind eng verwandt. Die theoretischen Überlegungen haben in Bezug auf das Dissertationsthema, den Wohnmarkt, große Bedeutung. Die Ursache, warum die Grundrente der Häuser zur Mitte der Stadt hin immer mehr steigt, liegt in der ,Arbeitsersparung, der größeren Bequemlichkeit und der Verminderung des Zeitverlustes, bei der Betreibung der Geschäfte“; Grundrente und Landrente werden „durch ein und dasselbe Prinzip reguliert“ (Lüpkes 1992, 38).

Im Alonso-Modell sind das Haushaltseinkommen und die Transportkosten als determinierende Variable geführt. Ändern sich die Transportkosten, etwa durch den Ausbau der Infrastruktur, so hat der Haushalt die Möglichkeit zu Optimierungsentscheidungen bezüglich seiner Wahl an Entfernung vom CBD und an Konsum der übrigen Güter. Das muss zu einer Veränderung der Rentengebotskurven führen. In Modellversionen zeigt sich, dass Einkommenserhöhungen und das Sinken von Transportkosten stets dazu führen, dass a) Pendelentfernungen steigen, b) die Bevölkerungsdichte am CBD sinkt und c) die Bevölkerungsdichte am Stadtrand steigt (Maier, Tödtling 2006, 135).

Indes können freilich auch die Lebensqualität und damit die Nutzenfunktion zur Stadtmitte hin abnehmen, und zwar aufgrund von Verkehrslärm, Autoabgasen, Smog und dichter Verbauung. Zudem könnten Familien und Kinder die ländlichen Gegenden mit „Spiel- und Wandermöglichkeiten“ bevorzugen. In Göttingen etwa waren schon Mitte des 19. Jahrhunderts zwei Gebiete außerhalb des Stadtwalls (Rosdorfer Weg und Weender Landstraße) die beliebtesten Wohngegenden, und sind heute noch eine der teuersten Gebiete (Lüpkes 1992, 38). In Wien ist Döbling (19. Bezirk) seit jeher ein „Hotspot“, auch wenn es in ordentlicher Entfernung vom Stadtzentrum liegt. „Man wird also nicht sagen können, dass die Produktionsfaktoren durch Arbeit kommensurabel sind“" (Lüpkes 1992, 39). Dennoch gilt auch in Wien: die Innenstadt ist die bei weitem teuerste Lage der Stadt.

\subsubsection{Kritik an formalen, deduktiven Modellen}

Die Stadtstruktur ist viel zu komplex, um in einem monozentrischen Modell abgebildet zu werden, zumal Agglomerationseffekte in bestimmten Stadtteilen da$\mathrm{zu}$ führen, dass es mehrere Sektoren und mehrere Agglomerationspunkte gibt (Studentenviertel, Botschafterviertel, etc.). Formale Modelle können nur eine beschränkte Zahl von Wechselwirkungen handhaben. Reale Städte werden aber von einer Vielzahl von positiven und negativen Einflussfaktoren gekennzeichnet, die zu einer Ballung oder zu einer wechselseitigen Abstoßung von Aktivitä- 
ten (Segregation) führen können. Agglomerationseffekte können nur sehr vereinfacht berücksichtigt werden (Maier, Tödtling 2006, 135f).

\subsection{Standortfaktoren und deren Entwicklung}

Standortfaktoren sind als Kriterien für die Wahl eines Standorts und folgedessen für den Wert der Lage maßgeblich. Der wichtigste Standortfaktor wurde erwähnt: die Verkehrsanbindung bzw. die Nähe zu einem Zentrum. Dabei handelt es sich um einen ,harten“ Standortfaktor, er ist sichtbar, messbar und vergleichbar. Andere wichtige Standortfaktoren sind: Energiepreise, Nähe zu Produktionsfaktormärkten (Arbeit, Rohstoffe), Kaufkraft, Markteintrittsbarrieren, Arbeitslosenquote, Bodenpreise, usw.

\subsubsection{Harte Standortfaktoren}

Die wichtigsten harten Standortfaktoren sollen hier lediglich aufgezählt werden. ${ }^{36}$ Determinierend für die Miethöhe in einem Stadtwohnungsmarkt wie Wien dürften nur einige davon sein (sie sind hervorgehoben).

- Infrastruktur

- Verkehrsanbindung

- Transportkosten, Transportarten, Umladung (gebrochener Verkehr), Container

- Energiepreise

- Kommunikationsnetz (Breitbandverfügbarkeit, Ausfallsicherheit)

- Energieversorgung (Stromnetz)

- Abfallbeseitigung

- staatliche Förderung (Subventionen)

- Höhe der Steuern und Abgaben

- Nähe, Größe und Zugang zu Produktionsfaktormärkten

- Verfügbarkeit von Rohstoffen (Gewichtsverlust-/Reinmaterialien)

- Verfügbarkeit von erschlossenen Flächen

- Transaktionskosten

- Grundstückspreise/Mietkosten

- Zugang zum Kapitalmarkt

- Arbeitskräfte: Arbeitskosten (Lohnniveau)

- Arbeitskräfte: Quantitative Verfügbarkeit

- Arbeitskräfte: Qualitative Verfügbarkeit 
- Arbeitslosenquote

- Einfuhrzölle

- Kaufkraft

- Kündigungsschutz

- gesetzliche und tarifliche Rahmenbedingungen (Arbeitszeiten, Sozialversicherungen, Genehmigungsverfahren)

- Lohnkosten

- Nähe, Größe und Zugang zum relevanten Absatzmarkt (des Betriebes)

- Markttransparenz

- Markteintrittsbarrieren

- Wettbewerbsintensität

- Nähe zu Zulieferbetrieben

- Nähe zu Forschungs-, Bildungs- und Entwicklungseinrichtungen

- Umweltschutzauflagen

- Klima

- Ver- und Entsorgung

\subsubsection{Weiche Standortfaktoren}

Harte Standortfaktoren sind wichtig. Dennoch können sie nicht immer die ganze Wahrheit erklären. Wieso werden einzelne Stadtgebiete ohne zusätzlichen Ausbau der Verkehrsinfrastruktur attraktiv, während andere Teile einer Stadt stagnieren?

Ins Treffen könnten „weiche Standortfaktoren“ geführt werden. Das sind schwer fassbare und schwer quantifizierbare Faktoren, die einen maßgeblichen Einfluss auf die Standortwahl haben:

- Das Image einer Region,

- die Bildungsinfrastruktur,

- der Akademiker- und Ausländeranteil, also eine bestimmte Segregation am Standort, aber auch das Vorhandensein von

- Sackgassen, Rotlichtmilieu, und zersprungenen Fensterscheiben.

„Harte und weiche Faktoren verschwimmen“, und auch können weiche Standortfaktoren harte maßgeblich beeinflussen (Thießen 2005, 30). „The closer we get to forming coherent policies that can be effectively implemented, the more soft factors come into play" (Gibson 2000, 37). Im Übrigen argumentiert Thießen, dass die Trennung in harte und weiche Standortfaktoren überholt sei, denn Wirtschaftssubjekte denken ganzheitlich und entscheiden ,aufgrund eines Bündels von Faktoren“ (Thießen 2005, 31). 
Insbesondere die Rolle von Images und „Bildern“ für Standorte ist bedeutend (Grabow 2005, 47f). In frühen Phasen der Standortwahl kann es der bestimmende Faktor sein, ob ein Standort überhaupt in Erwägung gezogen wird oder nicht. Das Image ganzer Städte wirkt besonders langfristig und lässt sich auch nicht „uminszenieren“ (Grabow 2005, 50).

Weiche Standortfaktoren können jedenfalls sein: ${ }^{37}$

- Forschungs- und Entwicklungseinrichtungen

- Bürokratie

- Kooperationsbereitschaft der Behörden

- Politische Verhältnisse

- Etablierung von Demokratie und Rechtsstaatlichkeit

- Menschenrechtsachtung

- Unternehmensbezogene Faktoren

- Wirtschaftsklima am Standort

- Image des Standortes und der Region (Standortprestige)

- Konkurrenz bzw. Fühlungsvorteile (Beziehungsgeflecht, Agglomeration)

- Wirtschaftsblöcke

- Personenbezogene Standortfaktoren

- Wohnumfeld, Mentalität der ansässigen Bevölkerung

- Umweltqualität

- Medizinische Versorgung, Fürsorgeeinrichtungen

- Bildungsangebot

- Erholungs-, Kultur- und Freizeitangebot

- Einkaufsmöglichkeiten

- Wohnmöglichkeiten

- Vergnügungsmöglichkeiten

\subsection{Stadtentwicklung durch Regionale Polarisation}

Wenn einzelne Stadtteile aufblühen, während andere verfallen, dann wird diese Eigendynamik gerne mit der „Theorie der regionalen Polarisation“ nach Gunnar Myrdal (1957) begründet. Myrdals Antithese zu den Gleichgewichtsmodellen sieht die ,zirkuläre Verursachung eines kumulativen sozioökonomischen Prozesses“ als Grund (Staudacher 2005, 421): Ähnlich einer makroökonomischen Konjunkturspirale kann etwa die Verschönerung einer Gemeinde zu mehr Zuzug

37 http://de.wikipedia.org/wiki/Standortfaktor abgerufen am 10.03.2010. 
führen, wodurch mehr Steuereinnahmen für weitere Verschönerungen lukrierbar sind, was wiederum zu mehr Zuzug führt, usw.

Myrdals Aspekt der Eigendynamik liefert einen positiven externen Effekt als Anreiz für den Einzelnen, etwas für diese Dynamik beizutragen. Diese Eigendynamik kann genauso blockiert werden: wie beim spieltheoretischen „Prisoner's Dilemma“ unterbleiben private Investitionen in Häuser in schlechten Vierteln. Dort rentieren sich Investitionen eines Einzelnen für das Allgemeinwohl nicht (Maier/Tödtling 2006b, 83f). Die Mieten, und damit die Renditen und Bodenpreise, würden nur steigen, wenn es zu kollektiven Bemühungen kommt.

Konsequenterweise müsste die Polarisationstheorie in immer größeren Gegensätzen zwischen verschiedenen Stadtvierteln enden. Dass es dazu nicht kommt, führen die Vertreter der Polarisationstheorie auf „Ausbreitungseffekte“ zurück. Dazu zählen Nachbarschafts- und räumliche Spill-Over-Effekte zwischen Regionen.

Wie dynamisch sich einzelne Wiener Stadtgebiete in den vergangenen Jahren entwickelt haben, zeigen Längsschnittdaten des Immobilienpreisspiegels. Die Mietspreise bei Neuvermietungen haben sich besonders in Innenstadtlagen deutlich erhöht (Blaas/Wieser 2004, 10, 13f; Lugger 2010, 43; WKO 2010, usw.).

Die Wirkung von Agglomerationseffekten ist nicht auf den eigentlichen Ballungsraum beschränkt, sondern beeinflusst ebenfalls die wirtschaftlichen Aktivitäten im Umland. Dabei ist die Stärke dieser Effekte von der Entfernung und Erreichbarkeit zwischen Ballungsraum und Umland abhängig (Steil 1999) - ein wichtiger, harter Standortfaktor.

\subsection{Empirische Standortuntersuchungen mit hedonischen Modellen}

Mehrere Studien untersuchten die implizierte Wertigkeit von (Standort-) Faktoren mit Hilfe hedonischer Preismodelle. Mit hedonischen Regressionsmodellen können Mietpreise in messbare Komponenten zerlegt werden (Malpezzi 2002, 2). Über die Regressionskoeffizienten in Bezug auf die Charakteristika einer Wohnung können so die impliziten Preise dieser Charakteristika errechnet werden, etwa der Preis für den Standort. 


\subsubsection{Einfluss von Luftverschmutzung}

Li/Brown (1980) untersuchten auf Basis von 781 Datensätzen in Bosten den Einfluss von Luftverschmutzung, Qualität der Aussicht, Lärm und die Nähe zu Schulen, Meer, Flüssen, Erholungsgebieten, öffentlichen Verkehrsanbindungen, Industrie und Einkaufszentren. Schulen und Luftverschmutzung sollen keinen signifikanten Effekt auf Häuserpreise haben. Dubin/Sung (1987) zeigten, dass gerade in polyzentrischen Städten die Nähe zum Stadtzentrum (CBD) kein dominanter Preisfaktor ist, weil Haushalte eher die Nähe zu anderen Plätzen valorisieren. Correll et al. (1978) leiteten hohe Werte von Annehmlichkeiten durch die Nähe von „Greenbelts“ ab.

\subsubsection{Nähe zu Uni und Schnellstraße als Mietentreiber}

Jaffa/Bussa (1975) zeigten hingegen, dass die Miethöhe mit Entfernung von universitären Einrichtungen abnimmt (Guntermann/Norrbin 1987, 322). Guntermann/Norrbin argumentieren (1987, 323), dass es schwierig ist, hedonische Preismodelle auf Eigenheime anzuwenden, da etwa die Bewertung für ,pride of ownership“ problematisch ist. Besser ließen sich Einflüsse der Standortfaktoren (wie z.B. eine günstige Verkehrsanbindung) auf die Miethöhe erklären. Eine Meile mehr Distanz zu einer Schnellstraße wird bei einem Durchschnittsheim mit \$ 5,50 weniger Miete abgegolten.

\subsubsection{Wien im hedonischen Modell}

Für den Wiener Wohnungsmarkt hat Wolfgang Feilmayr mit hedonischen Preismodellen errechnet, welchen Einfluss gewisse einzelne externe Faktoren auf die Preise haben. Ein um zehn Prozent über dem Durchschnitt liegender Akademikeranteil im Wohngebiet erhöht etwa den Preis um 50 Prozent. Die Nähe zu Industriegebieten mindert den Preis um vier Prozent (vgl. Feilmayr 2007, 63, 68). Genauso lassen sich alle anderen Eigenschaften einer Immobilie gewichten und berechnen. Der Preis (bzw. der Logarihmus davon) setzt sich aus den einzelnen Eigenschaften $\left(E_{i}\right)$ zusammen, die in der Natur nie voneinander getrennt werden, und nur in einem hedonischen Modell isoliert gewichtet $\left(\alpha_{i}\right)$ werden können:

$$
\begin{array}{ll}
\operatorname{Ln}(\mathrm{P})=\mathrm{C}+\alpha_{1} \mathrm{E}_{1}+\alpha_{2} \mathrm{E}_{2}+\ldots+\alpha_{\mathrm{n}} \mathrm{E}_{\mathrm{n}} \\
\mathrm{P}: \quad \text { Preis } \\
\mathrm{E}_{\mathrm{i}}: \quad \text { Eigenschaften } \\
\alpha_{\mathrm{i}}: \quad \text { zu schätzende Parameter (Preisanteile der Eigenschaften) }
\end{array}
$$




\section{C: $\quad$ Modellkonstante}

Feilmayr untersucht auch Lagefaktoren: Naturraum (Höhenlage, Weingärten, etc.), Infrastruktur (Erreichbarkeit CBD), Soziales Milieu (Pensionistenanteil), Ökologie (Lärmbelastung etc.), Stadtgestalt (Nähe zu Denkmälern etc.). Eine gebrauchte Eigentumswohnung ist um 56 Prozent teurer, wenn in der Nachbarschaft 60 Prozent Akademiker und Maturanten wohnen, als eine sonst gleiche Wohnung, die in einer Gegend mit nur 0,6 Prozent Akademikern ist.

Auch Wolfgang Brunauer (2008) führt hedonische Analysen auf Basis der Immobilien.NET-Maklerdaten ${ }^{38}$ durch: Die räumliche Lage hat massiven Einfluss auf Mietpreise. Geographisch muss sich Brunauer aufgrund der Datenbasis auf sehr grobe Einheiten, nämlich Bezirke, beschränken, was die Mikrolagen ausklammert.

\subsubsection{Polyzentren: Mieter sind auf Nähe von Einkaufsmöglichkeiten angewiesen}

Um den Bias zu minimieren, der sich durch die reine Analyse von Angebotsdaten ergibt (tatsächliche Abschlüsse dürften preislich darunter ausfallen), haben Dökmeci et al. (2003) auf dem Wohnmarkt in Istanbul 1126 Haushalte befragt. Die Befragung von Mietern bietet einige Vorteile gegenüber herkömmlichen Datenerhebungen bei Maklern. Etwa in Bezug auf die Erreichbarkeit: In Istanbul gibt es mehrere Stadtzentren (CBD), aber welches ist relevant? Es zählt nicht die räumliche Entfernung, sondern die Erreichbarkeit in Zeiteinheiten. Die Grünlage hat als einziger Faktor hohen Einfluss auf Hauspreise (Dökmeci et al. 2003, 93). Am meisten Einfluss auf Mieten haben Transport- und Einkaufsmöglichkeiten. Vermutlich, so Dökmeci et al., weil Hauseigentümer wohlhabender sind und über ein Auto verfügen, Mieter hingegen mehr auf die Nähe von „Facilities“ angewiesen sind (Dökmeci et al. 2003, 96f).

Auch Cheshire/Sheppard (1995) hinterfragen die monozentristische Ansicht der Theorie Alonsos (Cheshire/Sheppard 1995, 248). Sie zeigen, dass es problematisch ist, Land entkoppelt von seiner Umgebung zu bewerten. ${ }^{39}$

38 Immobilien.NET ist die größte Immobilien-Onlineplattform Österreichs, hier inserieren nahezu alle Makler.

39 "The price of land as conceputally treatet in urban land theory is the price of pure land [...] Observed Prices of vacant or recently redeveloped plots of urban land cannot (sic!) be used to estimate land rent surfaces in the sense in which such surfaces exist in urban rent models. Vacant plots or urban land are seething with location-specific and valuable characteristics, in addition to their area of ,pure' land" (Cheshire/Sheppard 1995, 248). 


\subsection{Der zulässige Lagezuschlag}

Bessere Lagen sollen auch bei den geschützten Altbauwohnungen zu höheren Mieten berechtigen, so sieht es auch das MRG vor. Vermieter können diese „bessere Lage“ in Form eines Lagezuschlags zum Richtwertmietzins einpreisen. So die Theorie, doch: „Selbst für den intellektuell überdurchschnittlich begabten Laien scheint es unmöglich, den Lagezuschlag korrekt (i.S. von unanfechtbar) zu ermitteln“ (Dirnbacher et al. 1994, 95). Mehr ist als Einleitung zu diesem Thema nicht zu sagen. Im folgenden Kapitel wird das Instrument Lagezuschlag theoretisch erörtert und mit praktischen Berechnungsbeispielen unterlegt.

Wir haben es, wie später gezeigt wird, mit einem Mietbegrenzungsinstrument zu tun, das u.U. einen Sachverständigen benötigt, um die Höhe der Mietbegrenzung bzw. des „Mietenfreibetrages“ festzustellen. In der Regel greifen die Marktteilnehmer und Gerichte auf die Lagezuschlags-Empfehlungen der Stadt Wien zurück.

\subsubsection{Rechtliche Grundlagen der Zulässigkeit eines Lagezuschlags}

Ein Lagezuschlag zum Richtwert ist nur dann zulässig, „wenn die Liegenschaft, auf der sich die Wohnung befindet, eine Lage aufweist, die besser ist als die durchschnittliche Lage (§2 Abs 3 RichtWG)“ (§16 Abs 4 MRG) ${ }^{40}$. Das Mietrecht bezieht sich damit auf das Richtwertgesetz:

„Die durchschnittliche Lage (Wohnumgebung) ist nach der allgemeinen Verkehrsauffassung und der Erfahrung des täglichen Lebens zu beurteilen ...“ ( $\$ 2$ Abs 3 RichtWG) - dafür wird der Grundkostenanteil, also der an der Wohnnutzfläche anteilige Preis des Bodens, zur Berechnung zugezogen. Dazu später, denn nicht jede Wohnumgebung berechtigt überhaupt zu diesem Zuschlag „... wobei eine Lage (Wohnumgebung) mit einem überwiegenden Gebäudebestand, der in der Zeit von 1870 bis $1917^{41}$ errichtet wurde und im Zeitpunkt der Errichtung überwiegend kleine, mangelhaft ausgestattete Wohnungen (Woh-

40 Bis zum 3. Wohnrechtsänderungsgesetz, das 1993 den neuen Richtwertmietzins hervorbrachte, nahm das Mietrecht überhaupt keine Rücksicht auf den Wohnungsstandort: Eine Wohnung am noblen Graben hatte dieselbe Kategoriezins-Obergrenze wie jene in Simmering.

41 Mit Gründerzeit werden manchmal unterschiedliche Zeiträume bezeichnet, beispielsweise 1850 (nach Biedermeier) bis 1873 (Jahr des Börsenkrachs), manchmal auch 1850 bis zum Ersten Weltkrieg 1914. Gemeint ist damit jedenfalls die Zeit des Wirtschaftsaufschwungs um 1870. Bauhistorisch wurden die meisten Gründerzeit-Häuser von 1870 bis 1914 gebaut. 
nungen der Ausstattungskategorie D) aufgewiesen hat, höchstens als durchschnittlich einzustufen ist" ( $\$ 2$ Abs 3 RichtWG). Damit definiert das Richtwertgesetz die sogenannten „Gründerzeitviertel“ (GZV), in denen ein Lagezuschlag verboten ist.

Diese Definition von Gründerzeitvierteln bereitet Juristen Kopfzerbrechen, da sie auf den Zustand eines Gebäudebestands abstellt, wie er vermutlich vor mehr als hundert Jahren existiert hatte. Tatsächlich heißt das: steht das Haus in einem Gebiet, wo seinerzeit der Anteil an Substandardhäusern höher war, dann darf auch heute kein Lagezuschlag verrechnet werden. „Heftig zu kritisieren ist jedoch die Definition der durchschnittlichen Lage in $\$ 2$ Abs 3 RichtWG, weil sich darin der rechtssystematische Ungeist des Gesetzes in besonders schillernder Weise widerspiegelt“" (Tades/Stabentheiner 1994, 8 in: Müller 2007, 34). Der „Lage“ in all ihrer Komplexität wird damit die Dynamik abgesprochen.

Welche Viertel die zuschlagsfreien „Gründerzeitviertel“ sind, sollte später in Stein gemeißelt werden, ungeachtet einer etwaigen künftigen Verbesserung der Lage.

Wie der Markt auf die scharfe Abgrenzung der Gründerzeitviertel reagiert, wurde noch nicht empirisch erhoben. „Besonders deutlich tritt die Problematik des Ausschlusses jeglichen Lagezuschlags für Gründerzeitviertel dort in Erscheinung, wo solche unmittelbar an relativ hochpreisige Wohnzonen angrenzen. Die Frage, ob und in welcher Höhe Lagezuschläge zulässig sind, orientiert sich dann vielfach daran, auf welcher Straßenseite die Liegenschaft (zufällig) liegt"“ (Kothbauer et al. 2006, 54).

\subsubsection{Festsetzung der ,Gründerzeitviertel ${ }^{6}$}

Der Gesetzestext wurde durch die Wiener Magistratsabteilung 25 und den Bautenausschuss der Stadt Wien mithilfe von Archivmaterial in die städtische Geographie übersetzt. Grundlage war die Bebauung zur Jahrhundertwende sowie Daten aus der Gebäudezählung 1961 bzw. 1971. Jene Zählsprengel, die zur Gründerzeit anno 1900 einen mehr als 50-prozentigen Anteil an Substandardwohnungen mit WC am Gang hatten - die historischen Aufzeichnungen dienten hier als Grundlage - wurden fortan als Gründerzeitviertel geführt und berechtigen nicht zu einem Lagezuschlag, ungeachtet der heutigen Entwicklung der Grundstückspreise. Was ein Gründerzeitviertel ist, wurde somit in Stein gemeiBelt.

Ob dies mit der tatsächlichen Qualität der Lage in Verhältnis steht, ist fraglich. Auch Teile der „Gründerzeitviertel“ zählen heute zu begehrten Wohngegenden. Der Substandardbestand, der als Kriterium für die Festlegung als Grün- 
derzeitviertel hinzugezogen wurde, ist inzwischen geschrumpft: 89,33 Prozent der Hauptmietwohnungen in Wien entsprechen laut Statistik Austria 2009 der Ausstattungskategorie A, nur 6,56 Prozent der Kategorie D mit WC am Gang. Wobei es wahrscheinlich ist, dass der Substandard-Anteil noch geringer ist. Nicht alle einbezogenen WCs wurden statistisch erhoben, ${ }^{42}$ zumal die Datenbasis der letzten Volks- und Gebäudezählung zehn Jahre alt ist.

Immerhin sind Immobilien in Gründerzeitvierteln - und freilich bei weitem nicht alle davon sind 100 Jahre alt und aus der Gründerzeit stammend - für heutige Verhältnisse relativ zentral gelegen. „,Die meisten Gründerzeithäuser", so Wohnbaustadtrat Faymann (Anm. nunmehr Bundeskanzler der Republik Österreich), ,besitzen aufgrund ihrer Lage beträchtliche Standortvorteile. Der gute Anschluß an den öffentlichen Verkehr, funktionierende Nahversorgung, das Vorhandensein von Schulen und Kindergärten, aber auch die kleinräumige Durchmischung mit Arbeitsstätten sind wesentliche Elemente der Wohnqualität in den Gründerzeitvierteln. ““ ${ }^{43}$ Wiewohl Faymann auch feststellt, dass es Gründerzeitvierteln an wohnungsnahen Grün- und Erholungsflächen mangle. Ein Mangel, den so gut wie jede Innenstadtlage mit sich bringt.

Die Umsetzung der Gesetzesvorgabe erfolgte dazumal über den Ausschussbericht des Bautenausschusses der Stadt Wien. Demnach wird der Begriff „Lage“ nicht auf ganze Bezirke oder Stadtteile, sondern auf ein „Gebiet" abgestellt, das mehrere Wohnblöcke oder Straßenzüge umfasst, die eine gleichartige Gebäudecharakteristik aufweisen, da es ansonsten ,ein noch schwerer zu lösendes ,Abgrenzungsproblem" ergäbe“" (Dirnbacher et al. 1994, 56). Wohngebiete wurden somit in Zählbezirke und innerhalb dieser in Zählgebiete eingeteilt, die sich nahezu mit den Zählsprengeln der Statistik Austria decken.

Da das Gesetz vorsieht, dass jenes Gebiet ein Gründerzeitviertel sei, das ,im Zeitpunkt der Errichtung überwiegend kleine, mangelhaft ausgestattete Wohnungen $[\ldots]$ aufgewiesen hat", musste für die räumliche Festsetzung in die Stadtarchäologie vorgedrungen werden. Das älteste Datenmaterial dazu findet sich in der Häuser- und Wohnungszählung von 1961. Zusätzlich flossen die Wohnungszählung 1971 und die Arbeit von Bobek und Lichtenberger (1978)

42 Statistik Austria, Hauptwohnsitzwohnungen 2009 nach Ausstattungskategorie und Bundesland. Online unter http://www.statistik.at/web_de/static/hauptwohnsitzwohnungen_ 2009_nach_ausstattungskategorie_rechtsverhaeltnis_u_023006.pdf, abgerufen am 15.04.2010.

43 Pressemeldung im Internet. Online: http://www.ots.at/presseaussendung/OTS_ 19990518_OTS0133, abgerufen am 15.03.2010. 
über die „Bauliche Gestalt und Entwicklung Wiens“ seit der Mitte des 19. Jahrhunderts ein. ${ }^{44}$

„Der Plan wurde unter der Annahme erstellt, daß sich die Anzahl der Substandardwohnungen in den vom Errichtungszeitraum her (1870-1917) relevanten Häusern zwischen dem Zeitpunkt der Erbauung und dem Jahr 1961 (bzw. 1971) nicht vermehrt hat" (Dirnbacher et al. 1994, 57). Wies ein bestimmtes Zählgebiet eine Mehrzahl an kleinen Substandardwohnungen auf, so wurde dieses für alle Zeit als „Gründerzeitviertel“ definiert.

\subsubsection{Geographischer Überblick von Lagezuschlagszonen}

Wie groß die Einheit des nach dem Gesetz definierten „Wohngebiets“ ist, steht nirgends klar definiert. Ein Baublock? Ein Zählsprengel oder eine Straße? Die Stadt Wien hat dazu eine Empfehlung abgegeben, die in der Praxis anerkannt ist. Als kleinste Einheit eines „Gebiets“ für dessen Häuser ein gemeinsamer zulässiger Lagezuschlag festgelegt ist, gilt ein Zählgebiet (Zählsprengel) innerhalb der Wiener Zählbezirke. So wurden auf Basis der Wiener Häuser- und Wohnungszählungen 1961 und 1971 in Summe 1364 Zählgebiete festgelegt, die jeweils als mögliche Zuschlagszone oder Gründerzeitviertel eingestuft wurden.

Abbildung 10 zeigt eine Wien-Karte, in der die Zonen mit unterschiedlichen Lagezuschlägen je nach Zuschlagszone eingefärbt sind. Vorweg: es handelt sich um Empfehlungen der Stadt Wien, eine Art „Norm“, die kein Gesetz ist. Die Karte zerlegt die Stadt in Zählgebiete anhand der Zählsprengel-Statistik, deren Einwohnerzahlen in derselben Größenordnung liegen. So zeigt sich, dass sehr dünn besiedelte Zählsprengel, wie etwa die Lobau im Südosten der Stadt oder die bewaldete Gegend im äußersten vierzehnten Bezirk, große Flächen aufweisen, während innerstädtische Zahlsprengel nur aus wenigen Baublöcken bestehen.

44 Bobek, Hans/Lichtenberger, Elisabeth (1978): „Wien - Bauliche Gestalt und Entwicklung Wiens seit der Mitte des 19. Jahrhunderts“, Wien-Köln; ausgestattet mit der Karte: Wien II. Verbauungs- und Wohnungsstruktur 1:25.000. 


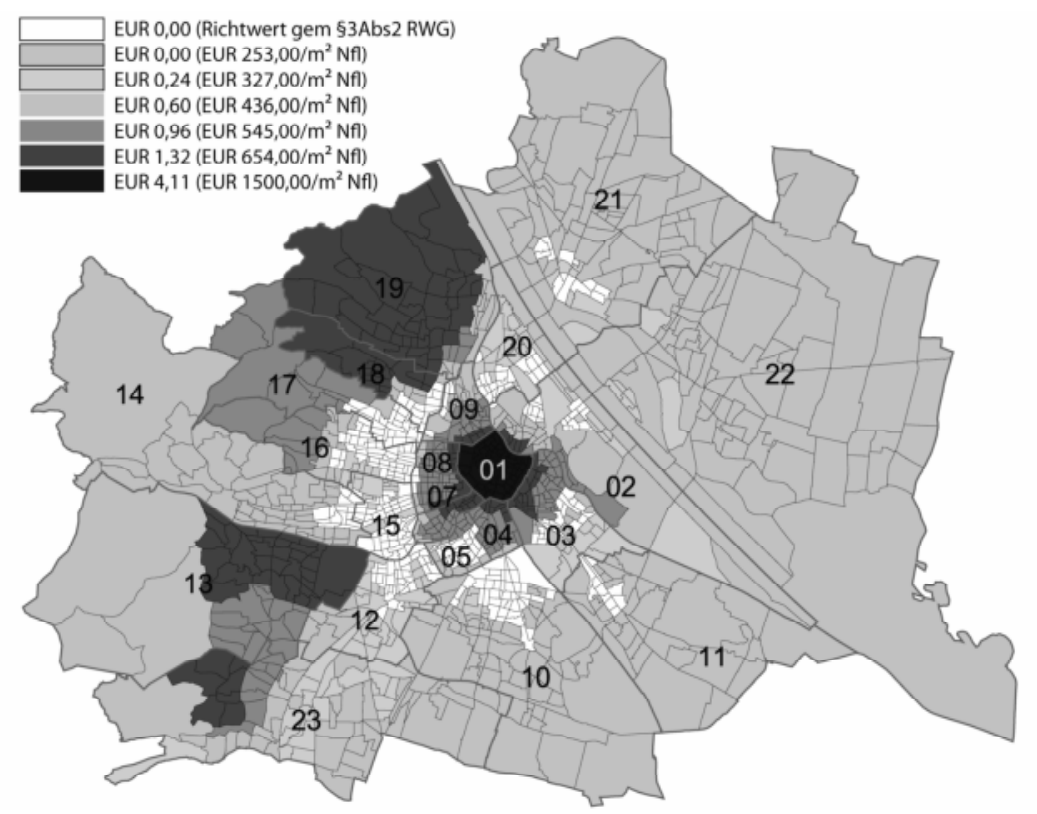

Quelle: Angelehnt an Magistrat der Stadt Wien, MA 25, 2010

Abbildung 10: Lagezuschläge in Wien nach Zählbezirken ab 1. April 2010

Den höchsten Lagezuschlag erlaubt der erste Bezirk, die Innenstadt, wo pro Quadratmeter Wohnfläche ein Zuschlag von 4,11 Euro im Monat möglich ist. In diesem Bezirk wird von einem Grundkostenanteil von mehr als 1.500 Euro pro Quadratmeter Wohnfläche ausgegangen. Ein derartiger Lagezuschlag ist zum Beispiel in der Operngasse 16 möglich. Gleich auf der anderen Straßenseite (des Karlsplatzes) - etwa in der Operngasse 18 - beträgt der Lagezuschlag lediglich noch 1,32 Euro, um mehr als zwei Drittel weniger. Die Grenzen zwischen den verschiedenen Zuschlagszonen verlaufen oft scharf.

Auf Zählgebietsebene wurde auch festgelegt, welche Teile der Stadt zu „Gründerzeitvierteln“ zählen. Für diese Gegenden ist ein Lagezuschlag von vornherein gesetzlich ausgeschlossen. Auch hier kommt es zu scharfen Abgrenzungen zwischen Lagezuschlagszonen innerhalb oder außerhalb des betroffenen Zählbezirks.

Besonders ,teure“ Zuschlags-Stadtgebiete erstrecken sich neben dem ersten Bezirk auch über den 18., 19., den dichter besiedelten 13. Bezirk sowie die inneren Bezirke zwei bis neun - mit Ausnahme des fünften Bezirks, der zum Groß- 
teil aus Gründerzeitvierteln besteht, sowie einzelnen Zählsprengeln im zweiten, dritten, aber auch im siebenten und neunten Bezirk (vgl. Abbildung 11).

Die Gebiete außerhalb des „Gürtels“, der die Innenbezirke von den äußeren Bezirken trennt, sind fast gänzlich Gründerzeitviertel, genauso wie der zehnte und elfte Bezirk. Erst noch weiter außerhalb, wo der Substandardanteil zur Zeit der Titulierung der Gründerzeitviertel gering gewesen war, finden sich grün schattierte Gebiete (vgl. Abbildung 10). Sie zeigen die Zuschlagszone 1 an, und deuten darauf hin, dass die Grundkostenanteile in dortigen Gegenden nur durchschnittlich sind. Fast der gesamte 21. und 22. Bezirk - mit Ausnahme der Standorte an den Hauptverkehrsadern - erlauben keine Lagezuschläge, weil die relativ niedrigen Immobilienpreise dies nicht zulassen. Zumindest geht die Empfehlung der Stadt Wien davon aus.

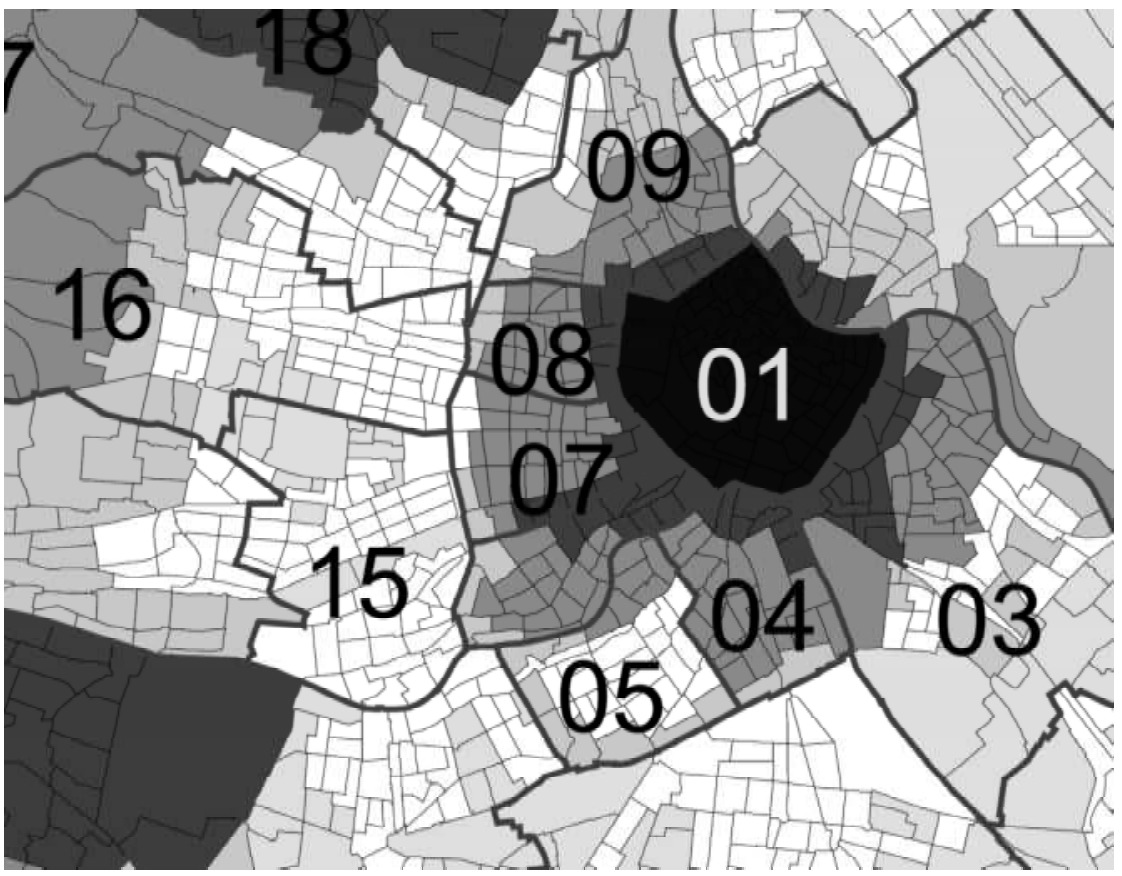

Quelle: eigene Darstellung. Daten: Magistrat der Stadt Wien, MA 25 Abbildung 11: Lagezuschlagszonen (farbig schattiert) rund um Gründerzeitviertel (weiß) 


\subsubsection{Rechtliche Grundlage zur Berechnung des Lagezuschlags}

Ist die Lage einer Wohnung besser als eine durchschnittliche Lage, so berechtigt dies zu einem Lagezuschlag. Im MRG wird dies so geregelt, dass ein etwaiger Zuschlag „,bis zur Höhe von 0,33 vH der Differenz zwischen dem der Richtwertermittlung zugrunde gelegten Grundkostenanteil ( $\$ 3$ Abs 2 und 5 und $\S 6$ RichtWG) ${ }^{45}$ und den der Lage des Hauses entsprechenden Grundkostenanteilen je Quadratmeter der Nutzfläche zulässig [ist], die unter Berücksichtigung der nach der Bauordnung zulässigen Bebaubarkeit für die Anschaffung von bebauten Liegenschaften, die überwiegend Wohnzwecken dienen, in dieser Lage (Wohnumgebung) üblicherweise aufgewendet werden“ ( 116 Abs 3 MRG). In einer Formel ausgedrückt heißt dies:

$$
L Z=\left(G K_{w}-G K_{\text {Normw }}\right) * E A
$$

LZ: $\quad$ Lagezuschlag

GKW: Grundkostenanteil der gegenständlichen Wohnung

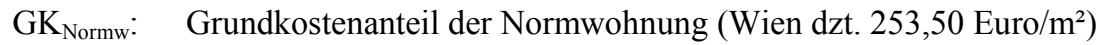

EA: $\quad$ Ertragsanteil (0,33\%/Monat)

Der derzeit (2010) dem Richtwert inhärente Grundkostenanteil beträgt 253,50 Euro pro Quadratmeter Wohnnutzfläche ${ }^{46}$. Eine durchschnittliche Wiener Wohnung hat - zumindest laut Gesetz - einen Grundkostenanteil in dieser Höhe. Liegt der wahre Grundkostenanteil höher, so kann die Differenz als Lagezuschlag auf den Richtwert aufgeschlagen werden. Derzeit beträgt der Richtwert 4,91 Euro pro Quadratmeter für das Bundesland Wien, wovon 17,21 Prozent ${ }^{47}$ die Grundkostenkomponente sind. Dieser prozentuale Bodenzinsanteil an der Miete wurde 1993 festgestellt.

$45 \S 2$ Abs 3 RichtWG stellt auf die erwähnten Gründerzeitviertel ab (,Erfahrungen des täglichen Lebens“, ,im Zeitpunkt der Errichtung überwiegend kleine, mangelhaft ausgestattete Wohnungen“; $§ 2$ Abs 5 erläutert den Grundkosten- und Baukostenanteil, der sich auf einen Durchschnittswert eines Bundeslandes beziehen soll; §6 RichtWG wurde mit BGB1. 113/2006 aufgehoben, er regelte die Neufestsetzung der Richtwerte.

46 Richtlinien für die Ermittlung des Richtwertzinses ab 1. April 2010, hg. durch die MA 25 der Stadt Wien, online unter http://www.wien.gv.at/wohnen/wohnbautechnik/ pdf/richtwert.pdf

47 93. Kundmachung, Änderung der Richtwerte nach dem Richtwertgesetz, online abrufbar etwa unter http://portal.wko.at/wk/dok_detail_file.wk?AngID=1\&DocID=13005 $06 \&$ ConID $=463485$ 


\subsubsection{Rechnerische Logik des Richtwert- und Zuschlagsystems}

Der Zusammenhang zwischen dem Grundkostenanteil einer Wohnung pro Quadratmeter Wohnnutzfläche und dem Richtwert lässt sich in folgender Formel darstellen:

$G K A_{\epsilon / m^{2}}=\frac{R W_{p m / m^{2}} * G K A \cdot R W_{\%} * M}{E A_{\%}}$

$\mathrm{GKA}_{\epsilon / \mathrm{m}^{2}} \quad$ Grundkostenanteil pro Quadratmeter Nutzfläche

$\mathrm{RW}_{\mathrm{pm} / \mathrm{m}^{2}}$ Richtwert lt BM für Justiz pro Monat

GKA.RW $\%$ Prozentualer Grundkostenanteil (konstant 17,21 \%) am RW

M Abgrenzung auf ein Jahr (12 Monate)

EA\% $\quad$ Ertragsanteil (konstant 0,04)

Steigt der Richtwert, so erhöht sich auch der inhärente Grundkostenanteil. Geht man daher von konstanten Grundwerten in bestimmten Lagen aus, wie es die Stadt Wien in ihren Empfehlungen tut - der empfohlene Grundkostenanteil (GKA) von 1.500 Euro/ $\mathrm{m}^{2}$ in der Innenstadt ist seit Jahren konstant, weil es kaum Transaktionen gibt, siehe weiter unten - dann führt das zwangsläufig zu scheinbar „fallenden“ Lagezuschlägen.

Eine „mietrechtliche Normwohnung“ sieht für den Mietzins von 4,91 Euro einen Anteil für die Abgeltung des GKA von 0,85 Euro vor. Dies entspricht 17,21 Prozent am Richtwert der gegenständlichen Wohnung. Die restlichen 82,79 Prozent müssen somit auf den durchschnittlichen, zum Teil abgeschriebenen Bauwert fallen. Da der inhärente Grundkostenanteil der Normwohnung 253 Euro pro Quadratmeter beträgt, geht der Gesetzgeber folglich von einem Wert für eine gebrauchte Mietwohnung von 1470,-- Euro pro Quadratmeter aus, für die der Vermieter (theoretisch) eine jährliche Rente von 4 Prozent erhalten darf.

Tabelle 4: Richtwertzinse und inhärente Lageanteile bei entsprechenden Grundkosten

\begin{tabular}{|r|r|r|r|}
\hline Grundkostenanteil & \multicolumn{2}{c}{ Lageanteil } & \multicolumn{2}{r|}{ Richtwert } & $\begin{array}{r}\text { davon } \\
\text { Lagezuschlag }\end{array}$ \\
\hline 253 & $0,8450 €$ & $4,9100 €$ & $0,0000 €$ \\
\hline 400 & $1,3360 €$ & $5,4010 €$ & $0,4910 €$ \\
\hline 600 & $2,0040 €$ & $6,0690 €$ & $1,1590 €$ \\
\hline 800 & $2,6720 €$ & $6,7370 €$ & $1,8270 €$ \\
\hline 1000 & $3,3400 €$ & $7,4050 €$ & $2,4950 €$ \\
\hline
\end{tabular}




\begin{tabular}{|r|r|r|r|}
\hline 1200 & $4,0080 €$ & $8,0729 €$ & $3,1629 €$ \\
\hline 1400 & $4,6760 €$ & $8,7409 €$ & $3,8309 €$ \\
\hline 1600 & $5,3439 €$ & $9,4089 €$ & $4,4989 €$ \\
\hline
\end{tabular}

Tabelle 4 zeigt Beispiele für die Systematik des Lagezuschlagssystems. Bei einem Grundkostenanteil (GKA) von 1000 Euro $/ \mathrm{m}^{2}$ liegen der Lagezuschlag bei 2,50 Euro und der Richtwertmietzins für diese Wohnung bei 7,40 Euro. Die in diesem Richtwert den Grundkosten zugeordnete Rente beträgt 3,34 Euro pro Quadratmeter und Monat, was über das Jahr gerechnet auch einer 4-prozentigen Rendite auf den Grundkostenanteil entspricht.

\subsubsection{Residualwertverfahren zur Berechnung des Grundkostenanteils}

Die Berechnung des Grundkostenanteils birgt rechtliche Unschärfen. Es sollen unbebaute Vergleichsobjekte ${ }^{48}$ herangezogen werden, so steht es im Gesetz. Unbebaute Grundstücke in Innenstadtlagen gibt es allerding de facto nicht. In der Praxis wird zur Berechnung des Grundkostenanteils (GKA) daher das Residualwertverfahren angewandt. Damit kann auch anhand von bebauten Grundstücken der GKA errechnet werden, schließlich entspricht dieser dem inhärenten Kostenanteil für den Grund bei bereits bebauten Liegenschaften. Die Kalkulation geht von einem Vergleichswert einer Liegenschaft aus, bzw. von einem Ertragswert, den ein bestimmtes Projekt birgt. Von diesem ermittelten Verkehrswert zieht man die Baukosten (aktiviert auf die Restnutzungsdauer des Gebäudes) ab und erhält quasi als Residuum den anteiligen Bodenwert - den maximalen Bodenkaufpreis, zu dem sich ein Projekt rechnet (Stabentheiner 2005, 211f), siehe nachstehende Aufstellung, angelehnt an Stabentheiner (2005, 214):

48 OGB 27.06.2006, 5 Ob 78/06s (WoBl 2007, Heft 5, S. 134, Nr. 51, online unter http://www.springerlink.com/content/v1hkp021085p1665/fulltext.pdf, abgerufen 15.04.2010. Diese Entscheidung des OGH wird von Sachverständigen als praxisfeindlich kritisiert. Schließlich lässt sich der Grundkostenanteil eines Wohngebiets nicht über die nur spärlich verkauften unbebauten, aber bebaubaren Grundstücke feststellen. Gerade im innerstädtischen Bereich werden fast ausschließlich bebaute Grundstücke verkauft, zumal ein Abriss in vielen Fällen schon alleine aus Denkmalschutzgründen nicht möglich ist. In der Praxis hilft man sich somit mit dem Residualwertverfahren, das würde man das Gesetz streng befolgen - eigentlich nicht zulässig wäre. Es wird allerdings angezweifelt, dass dies der Gesetzgeber so wörtlich gemeint haben könnte, wenngleich ein Gesetzprüfungsverfahren bisher nicht durchgeführt wurde. 


$$
\begin{aligned}
& R=\mathrm{M}_{\mathrm{BB}}-\mathrm{B}_{\mathrm{BEV}}-\mathrm{NK}_{\mathrm{GST}}-\mathrm{UG} \\
& R \quad \text { Residuum (wirtschaftlich tragfähiger Grundstückswert) } \\
& \mathrm{M}_{\mathrm{BB}} \quad \text { Marktwert bzw. Verkehrswert nach Bebauung, aus Vergleichswert- }
\end{aligned}
$$

Das Resultat sollte der jeweilige Verkehrswert der unbebauten Liegenschaft sein. Daraus sollte sich der Wert der für die Lagezuschlagsberechnung nötigen bebaubaren Liegenschaft ${ }^{49}$ ergeben. Der Wert für einen bebaubaren Quadratmeter Wohnnutzfläche hängt maßgeblich von einem weiteren Faktor ab, von der Bebaubarkeit eines Grundstücks.

Bei der Erhebung der (fiktiven) Bebaubarkeit sind grundsätzlich die aktuellen Bauvorschriften heranzuziehen. Auch das kann zu willkürlichen Ergebnissen führen, etwa dann, wenn infolge einer Widmungsänderung die Bebaubarkeit überhaupt nicht mehr möglich sein sollte. In diesem Fall schlagen Dirnbacher et al. $(1994,97)$ vor, den Ist-Zustand der Bebauung heranzuziehen.

Konkret gibt es mehrere Möglichkeiten, den Residualwert zu schätzen:

1) Man nehme den Verkehrswert einer Neubaueigentumswohnung in vergleichbarer Lage (etwa Euro 2.350,--/ $\mathrm{m}^{2}$ Nutzfläche) und ziehe lediglich die geschätzten Baukosten (je nach Ausstattung zwischen Euro 1.500,-- und 1.900,-) ab. Die dabei erhaltenen Grundkosten (z.B. Euro 453,--) werden um den im Richtwert eingepreisten Grundkostenanteil (Euro 253,--) vermindert, und die Differenz (Euro 200,--) mit der dem Vermieter zugestanden Verzinsung der überdurchschnittlichen Grundkosten (4\%/Jahr bzw. Faktor 0,33/Monat) multipliziert. Das ergibt den Lagezuschlag pro Quadratmeter Nutzfläche pro Monat (0,66 Euro).

Diese Methode ist freilich mit Ungenauigkeiten belastet, zumal sowohl der Verkehrswert als auch die zugrundeliegenden Baukosten geschätzt werden und der Gewinn des Wohnungseigentumsorganisators bzw. Bauträgers nicht berücksichtigt wird (Dirnbacher et al. 1994, 114).

2) Ist der Verkehrswert der bebaubaren Liegenschaft bekannt, etwa bei einem unbebauten Grundstück oder Abbruchhaus, so liefert dieser die Berech-

49 Die im Gesetzestext ( $\$ 3$ Abs 2 RichtWG) eigentlich zitierten „,bebauten“ Grundstücke würden zu rein willkürlichen, zufälligen Ergebnissen führen Dirnbacher et al. 1994, 97. 
nungsgrundlage (Quadratmeterpreis*Nutzfläche). Dazu wird die zulässige Bebaubarkeit der Liegeschaft geschätzt. Sie ergibt sich aus der Frontlänge und Bebauungstiefe des Grundstücks sowie der Bauklasse, aus der sich nach $\S 75$ der Wiener Bauordnung ${ }^{50}$ die maximale Geschoßzahl ergibt:

$\begin{array}{lll}\text { Bauklasse 1 } & \text { Höhe bis } 9 \mathrm{~m} & \max .3 \text { Geschoße } \\ \text { Bauklasse 2 } & \text { Höhe bis } 12 \mathrm{~m} & \max .4 \text { Geschoße } \\ \text { Bauklasse 3 } & \text { Höhe bis } 16 \mathrm{~m} & \max .5 \text { Geschoße } \\ \text { Bauklasse } 4 & \text { Höhe bis } 21 \mathrm{~m} & \max .7 \text { Geschoße } \\ \text { Bauklasse 5 } & \text { Höhe bis } 26 \mathrm{~m} & \max .8 \text { Geschoße } \\ \text { Bauklasse } 6 & \text { mindestens } 26 \mathrm{~m} & \end{array}$

Abzuziehen ist jedenfalls die Fläche für Allgemeinteile des Hauses (Gangflächen, Treppen, Hausbesorgerwohnungen, etc.), die etwa 25 Prozent der Bruttogeschoßflächen ausmachen. Der Verkehrswert dividiert durch die bebaubare Fläche ergibt den Grundkostenanteil je Quadratmeter bebaubarer Wohnnutzfläche und sohin den Lagezuschlag.

\subsubsection{Beispielrechnung für den Lagezuschlag}

Rechtlich stellt die Berechnung des Lagezuschlags auf das Einzelobjekt ab. Wenn nachgewiesen werden kann, dass der jeweilige Grundkostenanteil höher ist als der durchschnittliche Grundkostenanteil in Wien, dann berechtigt dies zu einem Lagezuschlag. Die Berechnung würde anhand eines Beispiels so aussehen:

Grundkostenanteil des Hauses, in dem sich

die Wohnung befindet 530,00 Euro

Grundkostenanteil gem. §3 Abs 5 RichtWG 253,50 Euro

Differenz

294,50 Euro

0,33 Prozent der Differenz

0,97 Euro

Lagezuschlag daher pro Quadratmeter und Monat

0,97 Euro

Auf alle Berechnungen kann verzichtet werden, wenn die pauschale Lagezuschlagseinteilung der Stadt Wien verwendet wird.

50 Die Bauordnung ist Ländersache, die Bebaubarkeiten hängen von den Bestimmungen der einzelnen Bundesländer ab. Auf Rest-Österreich soll hier nicht näher eingegangen werden, zumal der Lagezuschlag ohnehin ein Wiener Spezifikum ist. 


\subsubsection{Empfehlungen der Stadt Wien für den Lagezuschlag}

Um mehr Transparenz in die mietrechtliche Lageregulierung zu bringen, hat die Magistratsabteilung 25 der Stadt Wien eine Empfehlung für den höchstzulässigen Lagezuschlag erstellt (siehe geographischen Überblick, Kap. 4.5.3). Diese „Empfehlung“ ist weithin akzeptiert und wird bei Schlichtungsstellen-Verfahren - also quasi in erster Instanz - zur Überprüfung des Mietzinses herangezogen. In den meisten Fällen kommt der Empfehlung damit eine Gesetzeswirkung zu.

Bei den MA 25-Empfehlungen wurden sieben verschiedene Lagezuschlagszonen für Wien definiert und jedes einzelne Zählgebiet einer bestimmten $\mathrm{Zu}$ schlagszone zugeteilt. Die Datengrundlage für die Feststellung der ortsmäßigen Grundkosten liefert in Wien die MA 69, das Liegeschaftsmanagement der Stadt Wien. ${ }^{51}$ Die MA 69 erhält jeden Kaufvertrag und extrahiert die Kaufpreisdaten. Für die Feststellung der örtlichen Grundkosten werden lediglich unbebaute Grundstücke und Abrisshäuser berücksichtigt. Nur Transaktionen derartiger, immer seltener gehandelten Immobilien können statistisch die von der Stadt Wien angenommenen Grundkosten beeinflussen - ganz so, wie es wörtlich auch im Gesetz vorgesehen ist.

Dirnbacher/Rustler (1994) kritisieren im Übrigen die Einteilung in Zuschlagszonen nach Zählgebieten. Diese werde zu pauschal getroffen. Schließlich sei auf die Grundkostenanteile der Wohnung, die „der Lage des Hauses“ entsprechen, abzustellen. Von gleichen Grundkostenanteilen aller Häuser innerhalb einer Zone (Zählgebiet) auszugehen, sei zu weit gefasst (Dirnbacher et al. 1994, 118), zumal die Grenzen der Zählsprengel entlang von Straßenzügen verlaufen, und so die andere Straßenseite oft zu einem anderen Lagezuschlag berechtigen würde.

\subsubsection{Empfohlene sieben Zuschlagszonen}

Ein Zählgebiet kann nach Empfehlung der MA 25 zu einer von sieben Zuschlagszonen zugeteilt sein. Die jeweiligen Grundkostengrößen sind ordinal skaliert (von 1 - 7). Für die 3. Lage wurde etwa ein Grundkostenanteil von 327,-Euro angenommen, der rechnerisch einen Lagezuschlag von 0,24 Euro zulassen würde.
LZ-Zone
Grundkostenanteil
1. Durchschnittslage (Gründerzeitviertel)
2. Lage mit Grundkostenanteil
EUR 253,--
Lagezuschlag
3. Lage mit Grundkostenanteil
EUR 327,--
EUR 0,00
EUR 0,00
EUR 0,24

51 Reithofer 3.-5. Mai, 6, Gespräch mit DI Wilfried Doppler, MA 69 Liegenschaftsmanagement der Stadt Wien. 
4. Lage mit Grundkostenanteil

5. Lage mit Grundkostenanteil

6. Lage mit Grundkostenanteil

7. Lage mit Grundkostenanteil
EUR 436,-- $\quad$ EUR 0,60

EUR 545,-- $\quad$ EUR 0,96

EUR 654,-- $\quad$ EUR 1,32

EUR 1.500,-- $\quad$ EUR 4,11

\subsubsection{Das Phänomen der „fallenden“ Lagezuschläge}

Mit jeder Neuverlautbarung der Richtwerte untersucht die MA 69, ob es zu Verschiebungen der Grundkosten eines bestimmten Zählgebietes gekommen ist. Passiert dies, so kann ein Zählgebiet von einer Zuschlagszone in die nächsthöhere rutschen. Mit der letzten Verlautbarung des Richtwerts im April 2010 sind insgesamt 5 Zählsprengel in Wien ,avanciert“. Was allerdings konstant bleibt, ist die nominelle Höhe der in der jeweiligen Zuschlagszone angenommenen Grundkosten. Das hat einen sonderbaren Effekt: die Lagezuschläge eines bestimmten Zählgebiets sinken ständig. Denn wenn der Richtwert mit dem Verbraucherpreisindex steigt, und somit auch die anteiligen Durchschnittsgrundkosten steigen, sinkt die Differenz auf die nominell eingefrorenen Grundkosten der jeweiligen Zuschlagszone - und damit auch der Lagezuschlag:

Tabelle 5: Die von der Stadt Wien empfohlenen Lagezuschläge sinken alljährlich

Lagezuschlag für gewählte Adresse: 9. Bezirk, Althanstraße 10:

\begin{tabular}{|l|l|r|}
\hline gültig von & gültig bis & EUR je m2 \\
\hline 01.03 .1994 & 31.03 .1995 & 0,81 \\
\hline 01.04 .1995 & 31.03 .1996 & 0,80 \\
\hline 01.04 .1996 & 31.03 .1997 & 0,79 \\
\hline 01.04 .1997 & 31.03 .1998 & 0,77 \\
\hline 01.04 .1999 & 31.03 .2000 & 0,76 \\
\hline 01.04 .1998 & 31.03 .1999 & 0,76 \\
\hline 01.04 .2000 & 31.03 .2001 & 0,75 \\
\hline 01.01 .2002 & 31.03 .2002 & 0,73 \\
\hline 01.04 .2001 & 31.12 .2001 & 0,73 \\
\hline 01.04 .2002 & 31.03 .2003 & 0,72 \\
\hline 01.04 .2003 & 31.03 .2004 & 0,70 \\
\hline 01.04 .2004 & 28.02 .2005 & 0,69 \\
\hline 01.03 .2005 & 31.03 .2006 & 0,67 \\
\hline 01.04 .2006 & 31.03 .2007 & 0,66 \\
\hline 01.04 .2007 & 31.03 .2008 & 0,65 \\
\hline 01.04 .2008 & 31.03 .2010 & 0,63 \\
\hline 01.04 .2010 & 31.03 .2012 & 0,60 \\
\hline
\end{tabular}

Quelle: MA 25, Stadt Wien 


\subsubsection{Vertragliche Voraussetzungen für den Lagezuschlag}

Wird einem Mieter ein Lagezuschlag verrechnet, muss dies schriftlich festgelegt und auch begründet werden. Rein der Hinweis, die Wohnung befinde sich ,außerhalb des Gründerzeitviertels“ genügt nicht. Wohl aber ,zentrale Verkehrslage“, oder „Grünblick“, sofern dies den Tagsachen entspricht. Die Formvorschrift für den Lagezuschlag werten viele Vermieter als „Falle“. Immerhin erfüllt sie eine gewisse Informationsfunktion, und falls die Angaben nicht stimmen sollten, würde der Mieter eher Verdacht schöpfen, dass die Mietzinsbildung fehlerhaft ist.

Böhm (2003) kritisiert die komplizierte und zugleich unscharfe Definition der Lagezuschläge. In der Praxis würde für viele Wohnungen rein ,prophylaktisch“ ein Lagezuschlag verrechnet: „Soweit die sich grundsätzlich mit ,Allerweltsangaben' begnügende Judikatur in Vermieterkreisen allgemein bekannt ist, wird sie angesichts der Tatsache, dass die genaue Mietzinsbildung ohnehin nicht nachvollziehbar ist, tendenziell wohl dazu führen, dass ein stereotyper Hinweis auf irgendwelche angeblich vorteilhaften Lagekriterien und darauf, dass der Mietzins deshalb einen Lagezuschlag enthält, in den Vertrag aufgenommen wird, um so im Überprüfungsfall wenigstens erweiterten ,Argumentationsspielraum‘ zu haben“"(Böhm 2003, 35).

\subsection{Lageregulierung im Marktkontext}

Würde man die Begriffe „Lage“ und „Wohnumgebung“ gleich setzen - im österreichischen Richtwertgesetz werden sie synonym verwendet - dann müsste man sich die Frage stellen, inwieweit eine bestimmte Wohnumgebung als „,besser" anzusehen ist als eine andere. Das würde unmittelbar auf ein subjektives Kriterium abstellen. Beispielsweise mag für den einen Mieter die ruhige Grünlage am Stadtrand mehr Wert haben als für den anderen, der den Stadtrand wegen seiner Entfernung von der innerstädtischen Infrastruktur als nachteilig ansehen würde. „Der Versuch [...], das Kriterium der Lage durch Bezugnahme auf den Grundkostenanteil zu objektivieren, ist im Ansatz durchaus richtig“" (Dirnbacher et al. 1994, 95f). Werden individuelle Präferenzen nämlich ausgeblendet, bleibt der Marktwert als einzig entscheidendes Kriterium für die Einschätzung der Lage. Für Grundstücke gibt es einen freien Markt.

Steigen die Grundstückspreise in einem bestimmten Gebiet, so erhöht dies den möglichen Lagezuschlag für die Vermietung in diesen Lagen bei jenen Wohnungen, die bereits seit Jahrzehnten bestehen. Steigende Grundkostenanteile erhöhen den Zuschlag. Hier setzt ein maßgeblicher Kritikpunkt der Mieter- 
schützer ein. Der Hauseigentümer profitiere davon, dass die Infrastruktur in der Wohnumgebung unter Zuhilfenahme von Steuermitteln verbessert werde, ohne selbst etwas für diese Verbesserung zu leisten. „Das sind Windfall-Profits. Die Mieter zahlen doppelt, einerseits über die Steuer für die U-Bahn, andererseits den Lagezuschlag in ihrer Miete ${ }^{6.52}$.

Ein zumindest theoretisches Problem ergibt sich aus einem Rückkopplungseffekt. Der Lagezuschlag erhöht sich ja mit steigenden Grundkosten. Die Grundkosten wiederum ergeben sich aus den Mietpreissteigerungen bei Neuvermietungen, da diese die Beliebtheit einer Lage ausdrücken und auf den Ertragswert der Häuser wirken. Steigt nun der Ertragswert, und über ein Residualwertverfahren somit der Grundkostenanteil eines Hauses, so führt dieser Effekt wieder zu steigenden Lagezuschlägen. Die Konsequenz: Steigende Grundpreise bewirken - auf lange Sicht und bei anhaltendem Nachfrageüberhang, der zu steigenden Ertragswerten und weiter steigenden Lagezuschlägen führt - steigende Grundpreise.

Ein weiterer Einflussfaktor auf den Lagezuschlag ist die Bebaubarkeit der Liegenschaften. Wie oben ausgeführt spielt die Bauklasse eine bedeutende Rolle. Wird etwa die Bauklasse in einem innerstädtischen Gebiet plötzlich drastisch gesenkt, sodass die Bebaubarkeit eingeschränkt wird, hätte das einen Anstieg der Grundkostenanteile zur Folge. Vielleicht würde der Wert der Grundstücke unmittelbar ein wenig einknicken, da die Be- und Zubaubarkeit eine wesentliche Wertkomponente ist. Aber da Bebauungsfläche ein knappes Gut ist, das sich durch eine Herabsetzung der Bebaubarkeit weiter verknappt, steigen die anteiligen Grundkostenpreise im Bestand. Ähnlich wie eine Herabsetzung der Bauklasse ist de facto eine Verschärfung der Bauordnung zu verstehen, die ja genauso die Bestandserweiterung erschwert oder verhindert.

In der Praxis der Immobilienbewertung ist die Bebaubarkeit ein wesentliches Kriterium. Wird sie in einem konkreten Beispiel nicht ausgenutzt, so mindert das den Wert des Bodens, denn ein zweigeschoßiges Haus in einer Bauklasse, die drei Geschoße zulassen würde, kann nicht einfach aufgestockt werden. Der Abschlag für den Bodenpreis aufgrund einer Minderausnutzung hängt allerdings von der Restnutzungsdauer des Gebäudes ab. Kranewitter (2007) schlägt dazu folgende Formel vor: Ertragsminderung (in Prozent) mal Restnutzungsdauer. Ein Haus, das um ein Drittel (33\%) kleiner als erlaubt ist, aber nur noch zehn Jahre Restnutzungsdauer aufweist, mindert den Wert der Immobilie um 3,3 Prozent (Kranewitter 2007, 57).

Grundsätzlich ist auch ein Lageabschlag möglich (Dirnbacher et al. 1994, 99), etwa wenn der Grundkostenanteil einer Wohnung geringer ist als der der

52 Gespräch mit AK-Wohnrechtsexperten Franz Köppl am 20.04.2010. 
durchschnittlichen Lage in Wien (dzt. Euro 253,-- $/ \mathrm{m}^{2}$ ). Für diesen extrem unwahrscheinlichen Fall wäre dann die Differenz des Grundkostenanteils herauszurechnen.

\subsection{Exkurs: „Marktpräferenzen“" als Regulierungsvorschlag}

Zur Berechnung eines Lagezuschlags schlägt Moser (2007) in ihrer FH-Arbeit ein alternatives Modell vor, bei dem nicht von einem Grundkostenanteil ausgegangen würde, der dem Eigentumsmarkt entstammt, sondern bei dem die einzelnen „Lagekriterien“ berücksichtigt würden. Moser erhebt dazu bei 284 befragten Mietern die ihnen wichtigen Standortfaktoren; Etwa „Verkehrsanbindung“, „Unterhaltungseinrichtungen“, „Einkaufsmöglichkeiten“, etc. Diese insgesamt 10 Lagekriterien haben auch Detailausprägungen („Einkaufsmöglichkeiten“ etwa ergeben sich aus Nachversorgung, Einkaufsstraßen, Einkaufszentren und Gewerbeparks).

Ließe man die Mieter abstimmen, welches Kriterium mit einer Reihung von 1 bis 10 ihnen wichtig ist, so würde die Präferenzliste so aussehen:

Tabelle 6: Präferenzen der Mieter bez. Lagekriterien ( $n=284)$

\begin{tabular}{|l|l|l|}
\hline Rang & Lagekriterium & Prozent Gewicht \\
\hline 1 & Verkehrsanbindung & $12,47 \%$ \\
\hline 2 & Wohnlage, Wohnumgebung & $12,31 \%$ \\
\hline 3 & Einkaufsmöglichkeiten & $11,59 \%$ \\
\hline 4 & Medizinische Einrichtungen & $10,10 \%$ \\
\hline 5 & Freizeiteinrichtungen & $9,67 \%$ \\
\hline 6 & Bildungseinrichtungen & $9,38 \%$ \\
\hline 7 & Gastronomische Einrichtungen & $9,01 \%$ \\
\hline 8 & Unterhaltungseinrichtungen & $8,73 \%$ \\
\hline 9 & Kulturelle Einrichtungen & $8,42 \%$ \\
\hline 10 & Kommunale Einrichtungen & $8,32 \%$ \\
\hline
\end{tabular}

Quelle: Moser 2007, 95.

Moser versucht richtigerweise auch die Distanz von diesen durch Mieter nachgefragten Lagekriterien in Bezug zu setzen, wobei sie vier verschiedene Distanzklassen definiert. „Nahe“ ist alles im Umkreis von 300 Metern, ,gut erreichbar" sind Annehmlichkeit in maximal 700 Meter Entfernung, und zu Fuß 
„noch erreichbar“ soll eine Distanz bis 1400 Meter sein. Jede Abstufung in der Distanzklasse verringert den Wert des Lagekriteriums (und somit des Zuschlags) um weitere 33 Prozent. Sind jedoch alle Einrichtungen in kurzer Distanz erreichbar, würde dies den höchsten Lagezuschlag von 5,27 Euro/m²/Monat zulassen. Entsprechende weitere Distanzen oder das Fehlen etwa von Kultur- oder Bildungseinrichtungen führen zu Abschlägen.

Leider verabsäumt es Moser, ihr Lagebewertungsmodell anhand von praxistauglichen Beispielen vorzuführen oder der Marktlage anzupassen. Es kann erwartet werden, dass etliche einen hohen Lagezuschlag determinierende Faktoren sogar in bewertungstechnisch „schlechteren“ Lagen vorhanden wären. Zudem vernachlässigt Moser weiche Standortfaktoren. Diese determinieren nämlich das „Image“ einer Wohngegend, das wiederum einen gehörigen Einfluss auf die Beliebtheit und die Marktpreise hat. Eine Standortbetrachtung lediglich auf diese vereinfachte Analyseform herunter zu brechen, ist für die Beurteilung eines „fairen" Lagezuschlags nicht geeignet. Schließlich baut das gesamte Richtwertsystem darauf auf, eine Marktabschöpfung der Vermieter über Gebühr zu verhindern. Sie sollen nur eine Kostenmiete erhalten, so das Credo, und diese orientiert sich die Lage betreffend klarerweise an den Grundkosten. Jedes andere Modell führt die Philosophie des Kostenmietensystems ad absurdum. Die Frage, wozu es dann überhaupt einer Mietregulierung bedarf, wäre berechtigt. 


\section{Befunde zum heutigen Wiener Wohnmarkt}

In diesem Abschnitt beleuchten einige Studien das Spektrum des Wiener Mietwohnungsmarktes. Vorweg muss relativiert werden: Viele Studien wurden im Auftrag politischer Interessensträger erstellt und weisen deshalb zumindest eine entsprechend wertbehaftete Fragestellung auf. Besonders die Arbeiterkammer beauftragt sehr aktiv Studien zum Wohnmarkt, die zumeist belegen (sollen?), dass die Mieten zu hoch sind. Dieser Abschnitt soll möglichst wertfrei einen Überblick schaffen.

\subsection{Statistische Auswertungen zum Wohnmarkt}

\subsubsection{Wohnungs- und Eigenheimbestand in Österreich und Wien}

Österreich ist grundsätzlich ein eigentumsfreundliches Land. Zwei Drittel der Österreicher besitzen die Wohnung bzw. das Haus, das sie bewohnen, oder es gehört Verwandten. Im Gegensatz dazu ist die Eigentumsquote in Wien sehr gering. In der Bundeshauptstadt gibt es einen beachtlichen Mietenmarkt, hier ist es „normal“ das ganze Leben lang eine Wohnung zu mieten, wohingegen auf dem Lande stets der Wunsch nach Eigentum vorherrscht. Dennoch: „Der Eigentumsanteil liegt in Österreich leicht unter dem europäischen Durchschnitt“ (Lugger 2010, 27), wenn als Basis der Anteil an Eigentumswohnungen und Eigenheimen angenommen wird. Länder wie Spanien, Irland, Italien und Griechenland haben struktur- und traditionsbedingt einen noch höheren Eigentumsanteil von ca. 80 Prozent. Dennoch, die Eigentumsquote über Gesamt-Österreich gesehen ist beachtlich. Die folgenden Tabellen geben einen Überblick. 
Tabelle 7: Hauptwohnsitzwohnungen in 1.000 in Österreich nach Baujahr

\begin{tabular}{|c|c|c|c|c|c|c|c|c|c|}
\hline Rechtsverhältnisse & $\begin{array}{r}\text { Hauptwohnsitze } \\
\text { gesamt }\end{array}$ & $\begin{array}{r}\text { vor } \\
1919\end{array}$ & $\begin{array}{r}1919- \\
1944\end{array}$ & $\begin{array}{r}1945- \\
1960\end{array}$ & $\begin{array}{r}1961- \\
1970\end{array}$ & $\begin{array}{r}1971- \\
1980\end{array}$ & $\begin{array}{r}1981- \\
1990\end{array}$ & $\begin{array}{r}1991- \\
2000\end{array}$ & $\begin{array}{l}\text { 2001- } \\
\text { heute }\end{array}$ \\
\hline Insgesamt & $3.598,30$ & 545,30 & 294,70 & 450,10 & 559,30 & 548,30 & 413,10 & 489,50 & 298,10 \\
\hline Hauseigentümer & $1.448,50$ & 170,70 & 97,30 & 170,60 & 208,70 & 250,90 & 203,90 & 216,40 & 130,20 \\
\hline Verwandte & 183,10 & 34,40 & 15,10 & 35,40 & 36,70 & 31,00 & 15,10 & 10,90 & 4,30 \\
\hline Wohnungseigent. & 389,20 & 30,60 & 7,70 & 26,20 & 72,30 & 83,50 & 60,20 & 70,30 & 38,30 \\
\hline Hauptmieter & $1.424,50$ & 272,10 & 157,90 & 195,00 & 213,90 & 161,50 & 121,60 & 182,10 & 120,50 \\
\hline Untermieter & 34,40 & 8,60 & 4,10 & 4,50 & 5,50 & 5,00 & 2,40 & 2,90 & 1,30 \\
\hline Sonstige Rechtsvh & 118,60 & 28,80 & 12,60 & 18,40 & 22,20 & 16,40 & 9,80 & 6,90 & 3,50 \\
\hline
\end{tabular}

Quelle: Statistik Austria Jahrbuch 2009

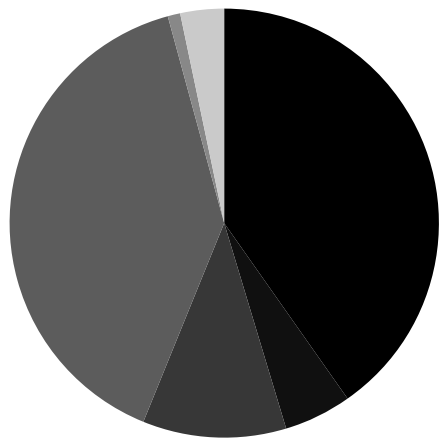

- Hauseigentümer

Verwandte

Wohnungseigent.

Hauptmieter

Untermieter

Sonstiges Rechtsvh

Abbildung 12: Gesamt-Österreich hat eine Eigentumsquote von Zwei Drittel

Während auch in Gesamt-Österreich der Altbaubestand sehr gering ist - nur jedes sechste Rechtsverhältnis bezieht sich auf ein Gebäude mit Baujahr in der Gründerzeit bis 1919 oder davor - so ist der Altbau in Wien geradezu ein dominierendes Element. 30 Prozent der Wohnungen bzw. Rechtsverhältnisse befinden sich in „klassischen“ Altbauten. Klassisch deshalb, weil in Wien zwar sämtliche Häuser, die vor 1945 gebaut wurden, de jure als Altbauten gelten, allerdings nur jene aus der Gründerzeit die markante, typische Altbauarchitektur ${ }^{53}$ aufweisen. In der Zwischenkriegszeit wurden wenige Häuser gebaut, die heute zum privaten Immobilienmarkt zählen.

53 Am einfachsten sind Gründerzeithäuser neben deren oft prunkvollen Fassaden und großzügigen Geschoßhöhen wohl an den Fenstern zu erkennen. Sie sind hochformatig und ca. $100 * 180 \mathrm{~cm}$ groß - mit 99-prozentiger Wahrscheinlichkeit ist ein solches Haus vor 1919 gebaut worden. Erst danach kamen kleinere Fenster in Mode. 
Tabelle 8: In Wien sind 30 Prozent der Liegenschaften Gründerzeitbauten (BJ. vor 1919)

\begin{tabular}{|lrrrrr|r|r|r|r|r|r|}
\hline & Hauptwohns. & vor & $1919-$ & $1945-$ & $1961-$ & $1971-$ & $1981-$ & $1991-$ & $2001-$ \\
Rechtsverhältnisse & gesamt & 1919 & 1944 & 1960 & 1970 & 1980 & 1990 & 2000 & heute \\
\hline Zusammen & 838,40 & 238,10 & 96,70 & 99,50 & 129,80 & 86,60 & 65,40 & 73,00 & 49,40 \\
\hline \hline Hauseigentümer & 57,60 & 8,00 & 9,00 & 5,40 & 4,40 & 7,30 & 6,90 & 8,50 & 8,10 \\
\hline Verwandte & 3,00 & 0,40 & 0,40 & 0,30 & 0,70 & 0,80 & 0,10 & 0,30 & 0,10 \\
\hline Wohnungseigent. & 107,40 & 22,10 & 2,90 & 11,20 & 28,30 & 18,50 & 8,90 & 8,80 & 6,90 \\
\hline Hauptmieter & 639,00 & 195,20 & 79,50 & 78,20 & 92,30 & 58,10 & 47,70 & 53,90 & 34,20 \\
\hline Untermieter & 11,70 & 5,70 & 1,90 & 0,70 & 1,30 & 0,70 & 0,90 & 0,50 & - \\
\hline Sonstiges Rechtsvh & 19,70 & 6,80 & 3,00 & 3,80 & 2,80 & 1,10 & 1,10 & 1,00 & 0,10 \\
\hline
\end{tabular}

Quelle: Statistik Austria Jahrbuch 2009

Beachtlich ist vor allem, dass der Mietenanteil gerade in Wien (76 Prozent) und gerade im Altbaubereich (82 Prozent) sehr hoch ist. Hier gilt grundsätzlich das Mietrechtsgesetz im Vollanwendungsbereich, bei Neuvermietungen zählt der Richtwert.

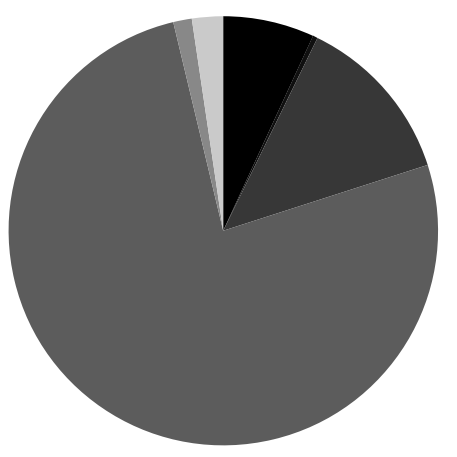

- Hauseigentümer

- Verwandte

Wohnungseigent.

Hauptmieter

Untermieter

Sonstiges Rechtsvh

Abbildung 13: Drei Viertel der Wiener sind Mieter

Viele Mietwohnungen - und zwar österreichweit - sind durch gemeinnützige Bauträger errichtet worden. Für sie gelten in vielerlei Hinsicht ,eigene Gesetze“, etwa das WGG (Wohnungsgemeinnützigkeitsgesetz), auf das in dieser Arbeit nicht eingegangen wird. Grundsätzlich orientieren sich gemeinnützig errichtete Mietwohnungen noch stärker an der Kostenmiete. Der günstige Mietzins ist stets eine Förderbedingung. Auf dem Mietmarkt sind gemeinnützige/kommunale und private Vermieter in etwa gleich stark, wie Tabelle 9 zeigt. 
Tabelle 9: Bestand an Miet-, Eigentumswohnungen und Eigenheimen im Jahr 2001

\begin{tabular}{|l|r|r|}
\hline Gewerblich errichtete Eigentumswohnungen & 266.000 & $7 \%$ \\
\hline von GBV errichtete Eigentumswohnungen & 228.000 & $6 \%$ \\
\hline Zwischensumme Eigentumswohnungen & 494.000 & $13 \%$ \\
\hline \hline GBV Mietwohnungen & 494.000 & $13 \%$ \\
\hline kommunale Mietwohnungen & 342.000 & $9 \%$ \\
\hline private Mietwohnungen errichtet vor 1945 & 494.000 & $13 \%$ \\
\hline private Mietwohnungen errichtet nach 1945 & 342.000 & $9 \%$ \\
\hline Zwischensumme Mietwohnungen & 1.672 .000 & $44 \%$ \\
\hline \hline Eigenheime & 1.634 .000 & $43 \%$ \\
\hline \hline Summe & 3.800 .000 & $100 \%$ \\
\hline \hline
\end{tabular}

Quelle: Lugger 2010, 28

Diese Bestandszahl an Mietwohnungen ist in den letzten Jahren gestiegen, vor allem in Ballungszentren. Tabelle 10 zeigt die Entwicklung der Jahre 2007 bis 2009, umfasst jedoch nur Hauptmietverhältnisse. Davor zitierte Quellen (Lugger 2010) schließen in ihren Schätzungen auch QuasiHauptmietverhältnisse ein.

Tabelle 10: Anzahl der Mietwohnungen nach Bundesländern

\begin{tabular}{|c|c|c|c|}
\hline Mietwohnungen & 2007 & 2008 & 2009 \\
\hline Österreich & 1.360 .400 & 1.389 .800 & 1.423 .800 \\
\hline Burgenland & 14.800 & 14.900 & 16.500 \\
\hline Kärnten & 71.100 & 76.200 & 76.300 \\
\hline Niederösterreich & 150.200 & 150.400 & 151.000 \\
\hline Oberösterreich & 177.800 & 184.200 & 194.200 \\
\hline Salzburg & 68.100 & 69.000 & 69.000 \\
\hline Steiermark & 137.700 & 145.500 & 150.700 \\
\hline Tirol & 79.500 & 83.700 & 82.900 \\
\hline Vorarlberg & 41.600 & 42.500 & 44.300 \\
\hline Wien & 619.600 & 623.300 & 638.900 \\
\hline
\end{tabular}

Quelle: Statistik Austria Mikrozensus 2009 


\subsubsection{Gebäudebestand in Wien}

Nach der letzten Vollerhebung der Statistik Austria 2001 gibt es 165.886 Gebäude in Wien. Das Diagramm in Abbildung 14 zeigt die Anzahl der Gebäude je nach Nutzungsart, Ein- und Zweifamilienhäuser vor 1945 (Altbau $=A B$ ) und nach $1945($ Neubau = NB) sowie Mehrparteienhäuser AB und NB und Sonstige Gebäude (Industrieliegenschaften, Büros, Hoheitsgebäude, etc.). Jedes zweite Gebäude ist ein Ein- oder Zweifamilienhaus. Diese Häuser finden sich seltener im innerstädtischen, verdichteten Gebiet.

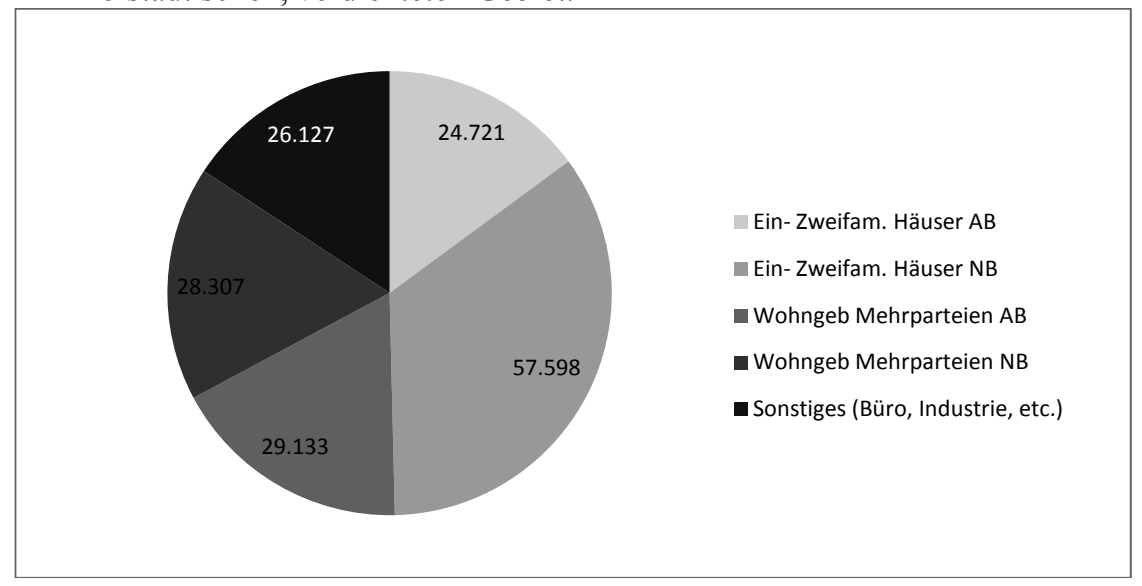

Abbildung 14: Aufteilung des Wiener Gebäudebestands

\subsubsection{Größe und Bedeutung der Gründerzeitviertel}

In Wien gibt es rund 280.000 Altbauwohnungen in Gründerzeitvierteln ${ }^{54}$, das sind 32 Prozent des Wohnungsbestands. Zur Erinnerung: in Gründerzeitvierteln darf kein Lagezuschlag verlangt werden. Nach der letzten „Gebäude und Wohnungszählung 2001“ gibt es insgesamt 168.167 Häuser, davon

35.014 Gebäude mit Wohnungen vor 1919 errichtet, und 27.144 Gebäude mit Wohnungen von 1919 bis 1944 errichtet, also gesamt $\underline{\text { 62.158 Altbauten in Wien }}$

Der Anteil der in einem Gründerzeitviertel gelegenen Altbauten sollte bei 52,34 Prozent liegen, denn 32.465 betroffene Altbauten weist das Straßenver-

54 Ausstellung „Wohnqualität der Gründerzeitviertel“ vom 18.05-30.06.1999 (Müller 2007, 85). 
zeichnis von Dirnbacher/Heindl/Rustler (1994) auf (Dirnbacher et al. 1994, 253ff). Inzwischen dürften ihr Anteil gesunken sein: gerade in Gründerzeitvierteln stehen Häuser mit schlechter Bausubstanz. Werden sie abgerissen so wird die Baulücke rasch mit einem Neubau (ohne Mietregulierung) gefüllt.

Eine Bestandsanalyse der Wiener Zinshäuser (diese wurden per Definition vor 1919 gebaut) ergibt, dass lediglich noch 15.529 der vermutlich 29.133 Wiener Zinshäuser in klassischem Alleineigentum stehen. Die übrigen Zinshäuser gingen bereits in Form von Wohnungseigentumsobjekten ,verloren“ (Otto Immobiliengruppe 2010, 6f).

\subsubsection{Mietwohnkosten in Österreich und Wien}

Gerne werden sowohl von Mieterschützern als auch von deren Gegnern die Wohnkosten ins Treffen gebracht, wenn sie für die jeweilige Ideologie werben. Dabei werden auch Statistiken geschönt. ${ }^{55}$ Hier sollen lediglich die neutralen Daten der Statistik Austria Platz finden, auf eine longitudinale Betrachtung wird verzichtet.

Die durchschnittliche Miete pro Quadratmeter liegt im Österreichschnitt bei 6,01 Euro. Wien liegt dabei genau im Durchschnitt. Besonders teuer sind die Bundesländer Salzburg, Tirol und Vorarlberg, der Osten und Süden Österreichs ist naturgemäß günstig (Burgenland, Steiermark, Kärnten, Niederösterreich).

Tabelle 11: Miete inkl. Betriebskosten und Umsatzsteuer pro Quadratmeter und Monat

\begin{tabular}{|l|r|r|r|}
\hline Miete $/ \mathrm{m}^{2}$ & 2007 & 2008 & 2009 \\
\hline Österreich & 5,63 & 5,80 & 6,01 \\
\hline \hline Burgenland & 3,96 & 4,29 & 4,47 \\
\hline
\end{tabular}

55 Die Arbeiterkammer proklamiert ständig, dass die Wohnkosten überproportional steigen, und dass daher eine strengere Mietenkontrolle eingerichtet gehöre. Die Mietkosten seien seit 1994 inflationsbereinigt um das Doppelte gestiegen. Das ist richtig, schließlich „steigt“ jede Altbaumiete, die zuvor an den niedrigen Kategoriezins oder gar an den extrem billigen Friedenskronenzins gebunden war, bei Neuvermietung stark an. Die Mietpreiserhöhungen ergeben sich zum Gutteil bereits aus der Mieterfluktuation und dem Auszug von Altmietern, die oft nur 1,5 Euro/ $\mathrm{m}^{2}$ Nutzfläche an Miete bezahlen.

Die Haus- und Grundbesitzer wiederum kontern derartige Wuchervorwürfe mit folgendem Argument: Die Mietpreise für Wohnungen lägen ohnedies zwischen 10 und 15 Prozent unterhalb der Richtwerte und werden zum Vorteil der Mieter nicht ausgenutzt. Das mag sogar stimmen, allerdings nur im gesamtösterreichischen Vergleich. In Wien gleicht der Richtwert einer Geschwindigkeitsbeschränkung auf einer leeren Autobahn diese wird in der Regel als Mindest- und nicht als Höchstgeschwindigkeit angesehen. 


\begin{tabular}{|l|r|r|r|}
\hline Kärnten & 4,92 & 5,05 & 5,12 \\
\hline Niederösterreich & 4,98 & 5,15 & 5,37 \\
\hline Oberösterreich & 5,49 & 5,72 & 5,92 \\
\hline Salzburg & 7,30 & 7,35 & 7,46 \\
\hline Steiermark & 5,55 & 5,76 & 6,01 \\
\hline Tirol & 6,26 & 6,33 & 6,54 \\
\hline Vorarlberg & 7,01 & 7,02 & 7,22 \\
\hline Wien & 5,62 & 5,80 & 6,05 \\
\hline
\end{tabular}

Quelle: Statistik Austria Mikrozensus 2009

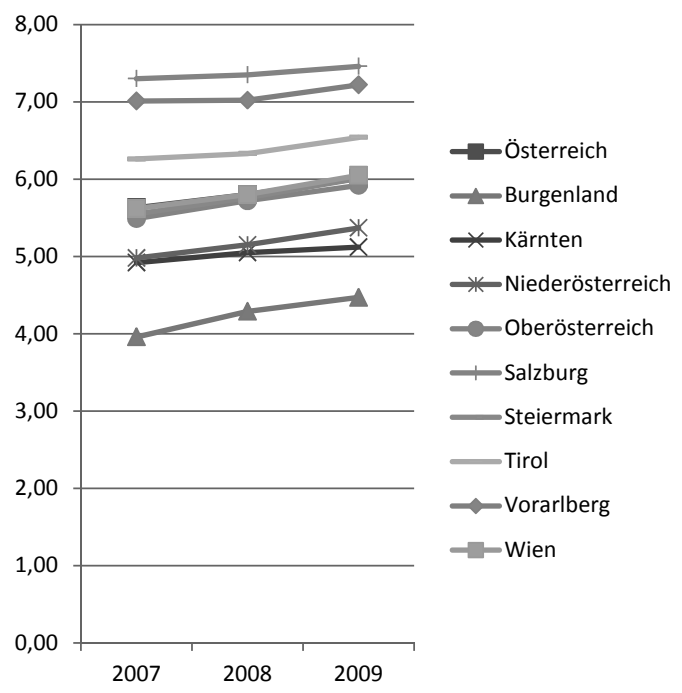

Quelle: Statistik Austria Mikrozensus 2009

Abbildung 15: Entwicklung der Quadratmetermiete in Österreich

Analog zum Mietmarkt lohnt sich ein langfristiger Blick auf die Entwicklung des Wohnaufwands laut Mikrozensus. Die Kurven ähneln sich. Tatsächlich haben sich die Wohn- und Mietkosten, aber vor allem die Betriebskostenkomponente, in den vergangenen 25 Jahren sehr stark von den Verbraucherpreisen abgekoppelt. 


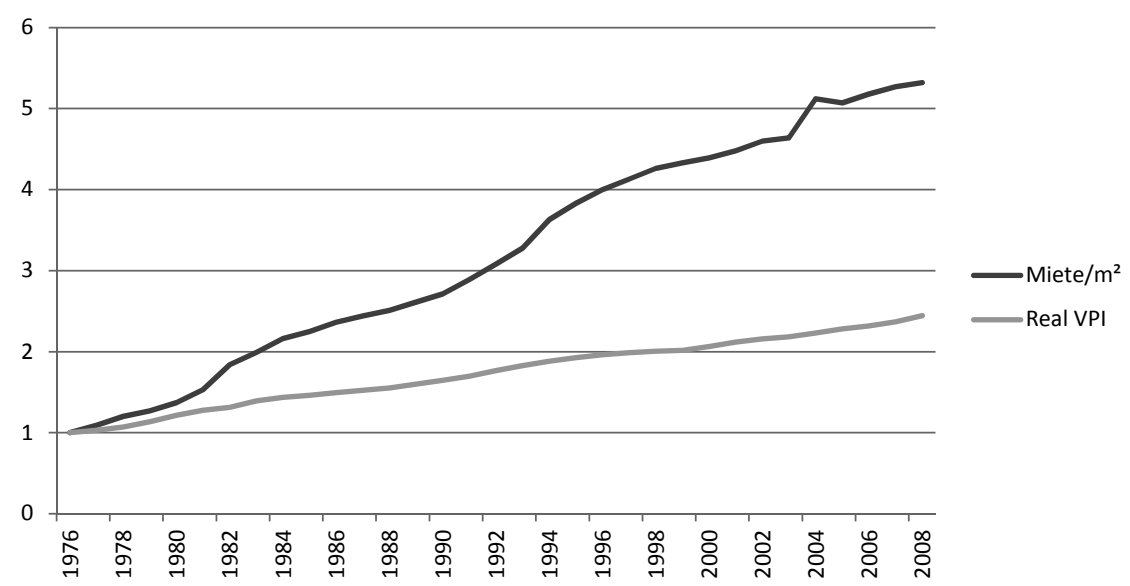

Quelle: Statistische Nachrichten 2007, 500; Statistische Nachrichten 2008, 477;

Statistische Nachrichten 2009, 481, Lugger 2010, 36, Eigene Darstellung

Abbildung 16: Mietensteigerungen seit den 70er Jahren - ,real “ oder nur bereinigt?

Die Grafik ist freilich mit Vorsicht zu genießen. Das reale Mieten- bzw. Wohnkostenniveau in den 70er und 80er-Jahren ist dermaßen niedrig gewesen, dass bei dem Anstieg noch keine vorschnellen Schlüsse gezogen werden können. Die Häuser und Grundstückspreise haben sich seither v.a. in Ballungszentren real vervielfacht.

Betrachtet man die einzelnen Jahre, in denen sich eine Preissteigerungsdifferenz zwischen Geldwert und Wohnaufwand zeigt, ergibt dies folgendes Bild:

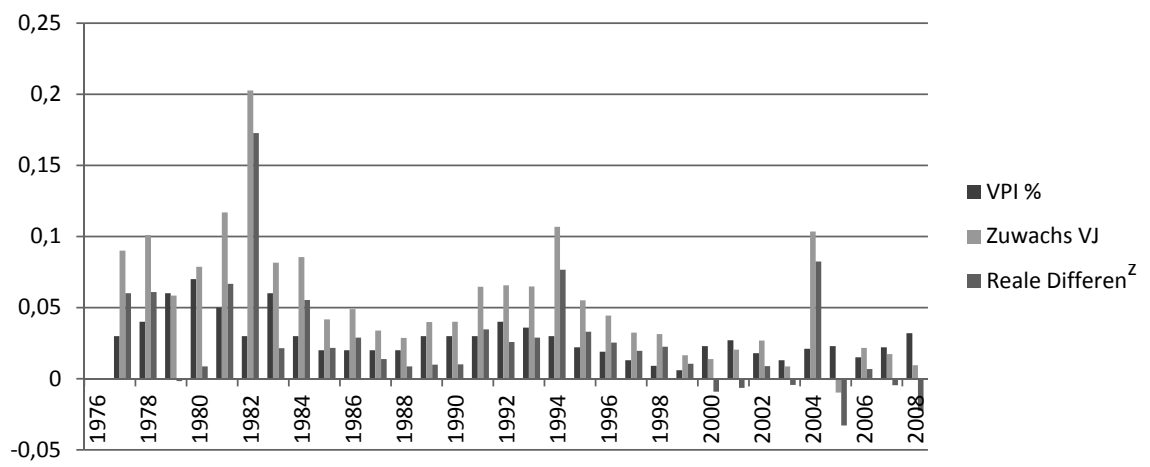

Quelle: s.o.; Lugger 2010, 38; eigene Darstellung Abbildung 17: Differenz VPI-Erhöhung und Wohnungsaufwand 
VPI und Mieten klaffen zusehends stärker auseinander in den Jahren 1982, aber v.a. auch 1994 und 2004. Die Differenz 2004 ist auf einen statistischen Fehler $^{56}$ zurückzuführen. In den Jahren 1982 und 1994 gab es allerdings Mietrechtsänderungen, die Erklärungspotenzial für eine Abweichung von Marktmieten und VPI bieten. Die Mietrechtsreform 1994 bedeutete einen markanten Liberalisierungsschritt. Davor galt seit 1982 der Kategoriezins (heute inflationiert 3,08 Euro/m² Nutzfläche bei Kategorie A).

\subsection{Richtwertmieten und freie Mieten in Wien im Jahr 2004}

(Feilmayr, 2005)

Im Auftrag der Arbeiterkammer untersucht Feilmayr (2005) im Wesentlichen die Miethöhen-Differenz zwischen Richtwert-Wohnungen und frei vermietbaren Neubauwohnungen. Das Datenmaterial stammt von 20 unabhängigen Maklern, die es über ihre gemeinsame Austria Immobilienbörse (A!B) gesammelt haben. Der gegenständliche Datensatz aus 2004 basiert auf 1251 Fällen, wobei zwei Drittel davon auf frei vermietbare Wohnungen entfallen (Feilmayr 2005, 2ff).

Freie Mieten sind demnach um mindestens 15 Prozent höher als Richtwertmieten. Am geringsten sind die Unterschiede zwischen freien und RichtwertMieten im Ersten Bezirk (5 Prozent). Der Erhebung zufolge liegt die Durchschnittsmiete der Richtwertwohnungen bei 8,16 Euro $/ \mathrm{m}^{2}$ (exklusive des 1 . Bezirks), wobei Richtwertmieten in den Außenbezirken (10.-12., 15.-17., 21.-23. Bezirk) mit durchschnittlich 7,09 noch einmal um 15 Prozent geringer sind. In den Außenbezirken - bei vielen handelt es sich um Gründerzeitviertel - ist auch die Differenz zu den Freien Mieten höher und liegt bei mehr als 20 Prozent (siehe Tabelle 12).

56 „Im Jahr 2004 gab es eine neue Erhebungsart der Statistik Austria, das Ergebnis gibt kein realistisches Bild“" (Lugger 2010, 38). 
Tabelle 12: Freie Mieten sind um 15 Prozent höher als Richtwertmieten (Jahr 2004)

Durchschnittsmieten 2004 für Kat A in Wien

ohne Hausbetriebskosten* und MwSt

\begin{tabular}{l|r|r}
\hline & Richtwertmieten & freie Mieten \\
\hline Bezirke 2. bis 9., und 20. (.Innenbezirke") & 8,32 & 9,31 \\
Bezirke 13.,14.,18.,19 („Außenbezirke 1") & 8,43 & 10,46 \\
Bezirke 10.,11.,12., 15., 16.,17.,21.,22.,23., (Außenbezirke 2") & 7,09 & 8,60 \\
1.Bezirk & 12,25 & 12,84 \\
& & \\
Alle Bezirke & 8,77 & 10,13 \\
Bezirke ohne 1.Bezirk & 8,16 & 9,73 \\
\hline
\end{tabular}

" Zu den Hausbetriebskosten zăhlen die Kosten fur die Hausverwaltung, Haus-und Gehsteigreinigung bzw Hausbesorger, Hausversicherung, Mallgebahren, Wassergebahren etc

Quelle: Feilmayr 2005, 5

\subsection{Hohe Zuschläge im Richtwertsystem}

(Moser/Schöffmann/Stocker 2002)

Bei Vermietungen nach dem Richtwertsystem (unter Vollanwendung des MRG) dürfen Zuschläge zum Hauptmietzins für Lage und Ausstattung verlangt werden. Eine Studie im Auftrag der Arbeiterkammer Wien (AK-Wien) erhebt die Ausgestaltung dieses Zu- und Abschlagssystems in der Praxis. Dazu werden 300 in Zeitungen inserierte Altbauwohnungen in Wien nach ihrer Preisgestaltung untersucht. Die Autoren erheben Wohnungsgröße, Ausstattung, Stockwerkslage, Dauer des Mietvertrags, Lage, Raumanzahl und Höhe der Brutto- bzw. Nettomiete. Die Miethöhe pro Quadratmeter divergiert dabei drastisch zwischen 3,90 und 25,60 Euro inklusive Betriebskosten und Umsatzsteuer (Moser et al. 2002, 12). Nach RichtWG darf die mietrechtliche Standardwohnung derzeit zu 4,91 Euro exklusive $\mathrm{Zu}$ - und Abschläge für Lage und Ausstattung vermietet werden. Im Durchschnitt beträgt der Nettomietzins (ohne BK) 6,70 Euro/m² (Moser et al. 2002, 17).

\subsection{1 „Lagezuschläge“, eine rechtliche Grauzone?}

Brisant sind die Ergebnisse über die räumliche Verteilung der Miethöhe. Moser et al. (2002) teilen die Lage sehr grob in vier Regionen für Lagezuschläge ein: Zentrum (1. Bezirk, Z.5), Innenbezirke (Bezirke 2-9 sowie 20, Z.4), Außenbezirke 1 (13., 14., 18., 19. Bezirk, Z.3) und Außenbezirke 2 (10.-12., 15.-17. sowie 21. Bezirk, Z.2). Erwartungsgemäß liegt die Durchschnitts-Nettomiete im 1. 
Bezirk (höchster Lagezuschlag) bedeutend über den anderen Bezirksgruppen. Die Autoren versuchten allerdings auch, die Adresse der Liegenschaften grob nach den erlaubten (bzw. „empfohlenen“) Lagezuschlägen der Stadt Wien (MA 25) einzuteilen. Hier zeigt sich das „Phänomen ““57, dass offenbar in Zonen, wo kein Lagezuschlag möglich ist („Gründerzeitviertel“, ohne Z.), die Miethöhe durch andere Zuschläge kompensiert zu werden versucht (vgl. Abbildung 18).

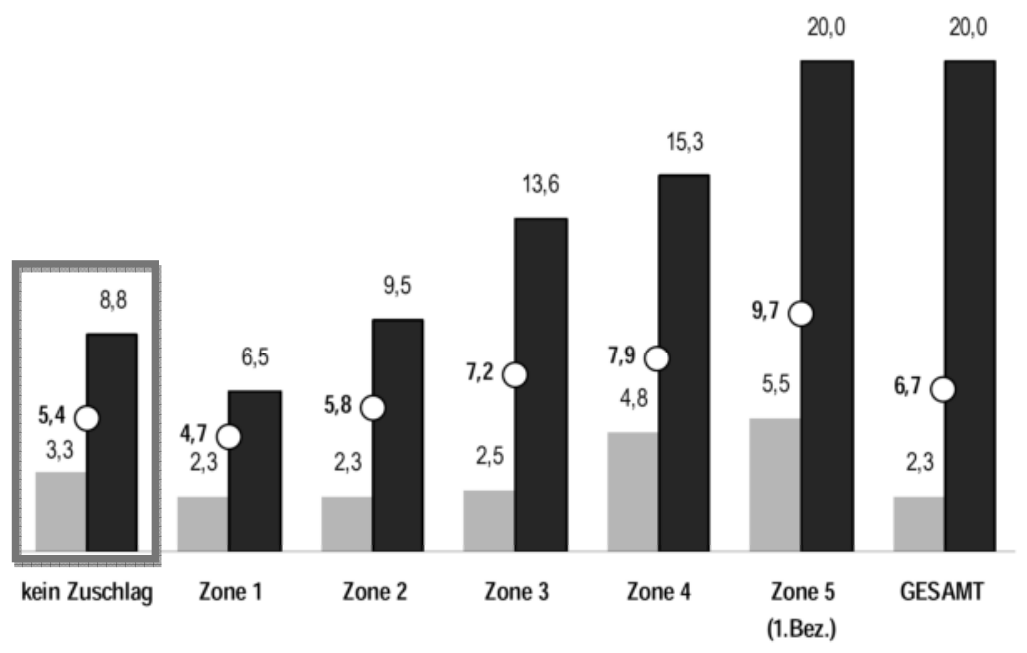

niedrigste Miete $\square$ höchste Miete Odurchschnittliche Miete

Quelle: Moser/Schöffmann/Stocker 2002, 20

Abbildung 18: Nettomiete pro Quadratmeter in Euro je Zuschlagszone

In den lagezuschlagsfreien GZV liegt der Mittelwert bei 5,4 Euro pro Quadratmeter Wohnnutzfläche, also deutlich (27 Prozent) über dem damals aktuellen Richtwertmietzins von Kategorie-A-Wohnungen (4,24 Euro/ $\left.\mathrm{m}^{2}\right)$. In Zone 3, die sich über relativ gute Innenstadtlagen erstreckt, und wo der erlaubte Lagezuschlag bei 1,08 Euro liegt, sind die Durchschnittsmieten um 35 Prozent über

57 Hier setzt sich der Markt durch. Auch wenn es so nicht in der AK-Studie gedeutet wird: Die Gründerzeitviertel weisen zum Teil offenbar eine bessere Lage auf als jene der „Zone 1“, die sich tatsächlich über die billigen Randlagen der Stadt erstreckt. Die gute und zentrale Lage der Gründerzeitviertel wird hier „,illegal“ eingepreist. Würde es kein kategorisches Zuschlagsverbot geben, würden Teile der Gründerzeitviertel vermutlich noch teurere Mieten erwirken. 
dem ,normalen“ Ausmaß. Das heißt, dass die erlaubte Standard-Miethöhe durch etwaige andere Zuschläge im Schnitt um 35 Prozent gehoben wird. Durch derartige Zuschlagspraktiken übersteigt die Durchschnittsmiete in allen Lagen das gesetzliche Ausmaß (vgl. Tabelle 13).

Tabelle 13: Zuschlagszonen, Miethöhe und deren Überschreitung zum Richtwert

\begin{tabular}{|l|c|c|c|c|c|c|c|}
\hline \multicolumn{9}{c}{$\begin{array}{c}\text { kein Zu- } \\
\text { schlag }\end{array}$} & Zone 1 & \multicolumn{2}{c|}{ Zone 2 Zone 3 } & Zone 4 Zone 5 & Gesamt \\
\hline Spitzenmiete & 8,80 & 6,50 & 9,50 & 13,60 & 15,30 & 20,00 & 20,00 \\
\hline niedrigste Miete & 3,30 & 2,30 & 2,30 & 2,50 & 4,80 & 5,50 & 2,30 \\
\hline Durchschnittsmiete & 5,40 & $4,70^{58}$ & 5,80 & 7,20 & 7,90 & 9,70 & 6,70 \\
\hline $\begin{array}{l}\text { Erlaubter Lagezu- } \\
\text { schlag zum Kateg.- } \\
\text { A-Miete (4,24 €) }\end{array}$ & 0,00 & 0,36 & 0,72 & 1,08 & 1,44 & 4,07 & \\
\hline Überschreitung & $27 \%$ & $2 \%$ & $17 \%$ & $35 \%$ & $39 \%$ & $17 \%$ & \\
\hline
\end{tabular}

Quelle: eigene Darstellung nach Moser/Schöffmann/Stocker 2002, 20

Eine „Überschreitung“ ist per se nicht ungerechtfertigt. Zu- und Abschläge ergeben sich auch aus den Faktoren Stockwerkslage, Lift, Balkon, Garten, Ausstattung, Möblierung, Himmelsrichtung, etc. Eine Obergrenze für derartige Zuschläge ist nicht gesetzlich definiert. Allerdings zeigen Entscheidungen der zuständigen Schlichtungsstellen regelmäßig, dass von Rechts wegen ein Zuschlag über 30 Prozent kaum noch akzeptiert wird - möge die Wohnung noch so herausragend ausgestattet sein. Es darf angenommen werden, dass die obigen MietObergrenzen je Zuschlagszone (etwa 8,80 Euro Nettomiete in der zuschlagsfreien Zone oder 15,30 Euro Nettomiete in Zone 4) deutlich in eine rechtliche Grauzone hineinragen.

Die Ergebnisse, auch wenn sie nicht repräsentativ sind, legen nahe, dass es „Umgehungsmechanismen“ gibt, vor allem, wenn die Liegenschaft in der zuschlagsfreien Zone liegt. Vermieter versuchen möglicherweise, die fehlende Zuschlagsmöglichkeit in Gründerzeitvierteln durch andere Zuschläge zu kompensieren. Wie dies vonstattengehen könnte, zeigt der zweite Teil der AK-Studie (Moser et al. 2002, 27).

Im zweiten Schritt untersuchten Moser et al. (2002) 57 Mietverträge von Hausverwaltungen. Nur bei 36 Verträgen hätte ein Lagezuschlag eingehoben werden dürfen; tatsächlich wurde ein ,Zuschlag für die gute Lage“ bei 47 Miet-

58 Dass die Zone 1 eine vergleichsweise geringe Miethöhe aufweist dürfte am geringen Sample dieser Gruppe $(n=5)$ liegen. 
verträgen erwähnt und auch eingehoben. Allerdings mangelt es bei 91,5 Prozent aller Verträge, die einen Lagezuschlag vorschreiben, an einer Begründung (und der Angabe der Höhe dieses Zuschlags), wie dies gesetzlich vorgesehen wäre (Moser et al. 2002, 27).

\subsubsection{Ignorierte Befristungsabschläge}

Diese „rechtliche Grauzone“ bei den verlangten Zuschlägen erstreckt sich auch auf die Preispolitik bei Befristungen. Nach dem RichtWG muss bei befristeten Mietverträgen ein Abschlag von 25 Prozent vom Hauptmietzins gewährt werden. In der Erhebung im Auftrag der AK-Wien liegt die Nettomiete bei unbefristeten Mietverhältnissen bei $6,51 \mathrm{Euro} / \mathrm{m}^{2}$; bei befristeten Mietverträgen ist die verlangte Miete sogar höher (6,89 Euro pro Quadratmeter). „Dieses Ergebnis ist nicht auf eine ,schiefe" Verteilung der Stichprobe zurückzuführen“ (Moser et al. 2002, 21), denn in fast allen Lagezuschlags-Zonen - vor allem in der zuschlagsfreien Zone - sind befristete Mietverhältnisse ,teurer“ als unbefristete. In Gründerzeitvierteln liegt der Nettomietzins bei Befristung bei 5,70 Euro pro Quadratmeter, ohne Befristung werden 5,30 Euro verlangt (Moser et al. 2002, 21).

Diese Praxis ist m.E. erklärbar: Wenn Vermieter schon die rechtliche Unsicherheit der Beeinspruchung der Miethöhe auf sich nehmen, dann möchten sie dieses erhöhte Risiko durch höhere Mieteinnahmen kompensieren. Dass heute nur wenige Mietverträge unbefristet begeben werden liegt daran, dass die Befristung oft die einzige Möglichkeit ist, einen aus welchen Gründen auch immer unangenehmen Mieter loszuwerden.

\subsubsection{Kritische Anmerkung}

Die vorliegende Untersuchung fußt auf wenigen Beobachtungen, die keinesfalls einen repräsentativen Anspruch erheben können. Die 300 Mietangebote wurden aus drei Tageszeitungen gewonnen („Kurier“, „Standard“, „Presse“). Auch die untersuchten Mietverträge sammelten die Autoren als „Convenience Sample“ von ihnen gut gesonnenen Hausverwaltungen, abgesehen davon, dass diese Stichprobe nur tendenzielle Aussagen zulassen. Überdies kommt die wohnpolitische Färbung des Auftraggebers der Studie, der AK-Wien, klar zum Ausdruck, werden doch Zahlen und Fakten undifferenziert so ausgelegt, dass sie das unterschwellige politische Argument - „Vermieter verlangen zu viel Miete“ - bekräftigen, ob nun klar gerechtfertigt oder nicht. 


\subsection{Erste Bewertung der Mietrechtsreform}

(Czasny/Köppl/Rosifka 1996)

Auf dieses Studienwerk aus 1996 soll am Rande eingegangen werden. Die Autoren untersuchten 152 Mietverträge, um den Umgang mit der neuen Mietzinsberechnung (Richtwertzins) zu dokumentieren. Die rein deskriptive Erhebung ergab, dass Mietverträge „unpräzise“ gehandhabt werden (Czasny et al. 1995, 6ff).

- Jedes fünfte Dokument lässt nicht erkennen, ob es sich um eine RichtwertWohnung handelt oder nicht.

- 71 Prozent der Verträge verschweigen wichtige Abschläge vom Mietzins (Stockwerkslage, schlechter Zustand des Hauses oder Lärm).

- Die Vermieter praktizieren die „Strategie der Präzisionsverweigerung“.

- Der Befristungsabschlag (damals 20\%) wird bei jedem vierten Mietverhältnis bewusst untergraben, bei einem weiteren Drittel lässt sich nicht eruieren, ob der Abschlag abgezogen wurde oder nicht.

- In 30 Prozent der Mietverhältnisse, bei denen ein Lagezuschlag vereinbart wurde, ist dies unrechtmäßig geschehen.

- 41 Prozent der Wiener Altbauwohnungen liegen 1996 in einem Gebiet, das keinen Lagezuschlag zulässt (Czasny et al. 1995, 44). Dazu haben die Autoren aber offenbar - vielleicht ebenfalls aus Präzisionsverweigerung - Gründerzeitviertel und jene Gebiete, die aufgrund des geringen Grundkostenanteils nach den Empfehlungen der MA 25 keinen Lagezuschlag zulassen, zusammengezählt.

- In 42 Interviews mit Mietern stellt sich heraus, dass sich der Mietvertragstext nicht immer mit der Realität deckt. Die positiven Ausstattungsmerkmale wurden in 44 Prozent der Fälle genannt und waren auch vorhanden. Im gleichen Ausmaße wurden sie aber auch nicht genannt - obwohl sie vorhanden waren. Dafür wurden negative Ausstattungsmerkmale in 79 Prozent der Fälle im Mietvertrag ,verheimlicht“.

\subsection{Einfluss des Richtwertsystems auf die Mietenentwicklung in Österreich}

(Blaas/Wieser, 2004)

Welchen Effekt hat die „Liberalisierung“ 1993 auf die reale Miethöhe gehabt? Welchen Einfluss hat der geförderte Neubau auf das Mietniveau? Diesen Fragen versuchen Blaas/Wieser (2004) nachzugehen. Zur Erinnerung: die Einführung des Richtwertmietzinses ab dem Jahr 1994 löste den zuvor geltenden Kategorie- 
zins ab, der keinerlei Zuschläge für eine besondere Lage oder Ausstattung zuließ und heute im Verhältnis zur Marktmiete noch weit niedriger liegen würde.

Blaas/Wieser verwenden dazu ein ökonometrisches Modell unter Einbeziehung verfügbarer volkswirtschaftlicher Zeitreihen-Daten: die Marktmieten (Quelle: Immobilienpreisspiegel der Wirtschaftskammer), Anzahl der Haushalte (Statistik Austria), Netto-Haushaltseinkommen (Mikrozensus Statistik Austria), Baukosten pro $\mathrm{m}^{2}$ (Statistik Austria), Wohnbauobjektförderung (Summe aus Darlehen, Eigenmittelzusatzdarlehen, Annuitätenzuschüssen bzw. Anzahl der Förderungszusagen, Quelle: GBV), Wohnbeihilfen (GBV), Fertigstellungen von Mietwohnungen, Eigentumswohnungen und Eigenheimen (GBV), Hypothekarzins (Nationalbank) sowie die Mietrechtsreform als Dummy-Variable.

Alle diese Variablen wurden - mit Ausnahme des Hypothekarzinses und der Dummy-Variable - in Logarithmen transformiert. Die geschätzten Koeffizienten sind daher als Elastizitäten zu interpretieren. Die Ergebnisse: Kurzfristig wirkt vor allem ein Wachstum der Haushalte entscheidend auf das reale Mietniveau. Langfristig beeinflussen vor allem die Baukosten (Blaas, Wieser 2004, 23).

\subsubsection{Förderrückgang erhöht Marktmieten}

Eine Erhöhung des Mietangebots drückt unter sonst gleich bleibenden Bedingungen das Mietniveau. Würde um 10 Prozent mehr fertiggestellt, sänke die Miete um 1 Prozent. Derzeit gibt es 47.000 Fertigstellungen an Eigenheimen, Miet- und Eigentumswohnungen pro Jahr.

Die Fertigstellungen hängen freilich von der Intensität der Förderungen ab. Wieser/Blaas errechnen über eine geschätzte Elastizität der Mieten in Bezug auf die Wohnbauförderung das Mieteniveau der Zukunft. Sie gehen von einer steigenden Elastizität zwischen 0,1 und 0,15 aus (bedingt durch eine allgemeine Preissteigerung von $2 \%$ pa). Somit würde sich bei nominell gleichbleibendem Förderniveau ein Mietpreisanstieg von jährlich durchschnittlich 1,4 Prozent über die nächsten zehn Jahre ergeben. Würde die Wohnbauförderung um 25 Prozent gesenkt werden und auf diesem nominellen Niveau verharren, würden die Mieten real um durchschnittlich 4,5 Prozent pro Jahr steigen (bis zum Jahr 2014) (Blaas, Wieser 2004, 24).

Bei Förderungen ist allerdings bekannt, dass es Mitnahmeeffekte gibt. Vieles würde auch dann gebaut, wenn die Baukosten nicht gefördert werden würden. 


\subsubsection{Einfluss des Richtwertsystems auf das Mietniveau}

Die Ergebnisse in Bezug auf den Einfluss der Einführung des Richtwertmietzinses 1993 auf das Mietniveau sind nicht signifikant. Es ist schwierig, diesen Einfluss nachzuweisen, zumal die Marktmieten nicht dem MRG unterliegen und somit „ein Zusammenhang nur indirekt hergestellt werden“ kann. Über Rückkopplungen wirken die Maßnahmen, die zunächst nur den Altbau-Sektor betreffen, auch auf den freien Mietwohnungsmarkt. Wenngleich die Höhe des vermuteten Einflusses nicht gewiss ist, darf angenommen werden, dass das Jahr 1993 einen starken Effekt auf das davor unvergleichbar niedrige Mietniveau bei Neuvermietungen hatte.

Insbesondere der Altbau-Mietmarkt hat sich von 1986 bis 2002 sehr stark verändert. Die Mieten in Wohnungen, die vor 1945 gebaut wurden, stiegen in diesem Zeitraum um ca. 135 Prozent (Blaas, Wieser 2004, 11). Diese Entwicklung ist auf drei Ursachen zurückzuführen: 1) Extrem günstige Altmietverträge laufen aus, die Wohnungen werden zur Richtwert- bzw. Marktmiete neu vermietet. 2) Der „Erhaltungs- und Verbesserungsbeitrag“ (EVB), der bei Altmieten verlangt werden konnte, wurde wie eine „Mieterhöhung“ (Blaas, Wieser 2004, 12) zweckungebunden verlängert, aber vor allem 3) sind durch den ,Wiedervermietungseffekt" viele Wohnungen in ihrem Standard angehoben und zu einer höheren Miete neu vermietet worden. ${ }^{59}$

Dass eine Teil-Deregulierung wie die Einführung des Richtwertzinses auf das Mietniveau wirkt, ist zu erwarten. Blaas/Wieser schätzen die reale Mieterhöhung durch diese Reform auf nachhaltig 6 Prozent ein. Es wirken nicht abschätzbare Wechselbeziehungen: „Für die Wohnungsnachfrager besteht eine Substitutionsbeziehung zwischen der bisherigen und einer neuen, nicht mietzinsregulierten Wohnung. Ist die neue Wohnung zu teuer, wird der Mieter - unter sonst gleichbleibenden Umständen (etwa betreffend die familiäre oder berufliche Situation) - länger mit einem Umzug warten. Dies wirkt dämpfend auf die Marktmieten“ (Blaas, Wieser 2004, 25). Dennoch sei die Mietrechtsreform preistreibend gewesen. Ohne Gegensteuerung durch den geförderten Wohnbau würden Mieten heute um fünf Prozent teurer sein.

59 Der Wiedervermietungseffekt wirkt sogar bei sinkenden Mietniveaus, dies sei anhand eines Beispiels beschrieben: es sind im Ausgangsjahr 0 von 100 Wohnungen 25 der Kategorie D und 75 der Kategorie A vermietet. Die Miete beträgt für die D-Wohnungen 3 Euro $/ \mathrm{m}^{2}$, für die A-Wohnungen 7 Euro/ $\mathrm{m}^{2}$. Im Jahr 1 sinkt - aus welchem Grund auch immer - die Kategorie-A-Miete von 7 auf 6,5 Euro bei Neuvermietungen. Es werden 4 der 75 Kat-A-Wohnungen (5\%) neu vermietet. Zugleich wir eine D-Wohnung auf Kategorie A angehoben und ebenfalls zu 6,5 Euro $/ \mathrm{m}^{2}$ vermietet. Trotz des Mietenrückgangs steigt die Durchschnittsmiete aufgrund der Standardanhebung von 6,0 auf 6,025 Euro/m² oder um 0,4 Prozent (Blaas, Wieser 2004, 12f). 


\section{Hypothesen zu Effekten der Lageregulierung}

Die vorangegangene Erörterung des Themas legt nahe, dass es in Teilbereichen des Wohnmarktes eine Lücke zwischen erlaubter Miethöhe und ökonomisch möglicher Miethöhe gibt. Das muss in der Theorie zu einem Graubereich führen, auf den der Markt und seine Teilnehmer reagieren.

Dieses Kapitel erörtert, wo ein derartiger Graubereich zu erwarten ist, und welche Effekte dieser Graubereich auf den Markt haben kann. In einem ersten Schritt werden grundsätzliche Einflussfaktoren auf die Wertbemessung einer bestimmten Lage diskutiert. Dann wird die Problemdiskussion über die Gründerzeitviertel vertieft, und schließlich mögliche Auswirkungen der erwarteten „Grauzone“ in Form von Hypothesen formuliert.

\subsection{Einflussfaktoren auf den „Preis der Lage“}

Der Mietmarkt, der grundsätzlich einer Dynamik zwischen Angebot und Nachfrage unterliegt, wird von mehreren Parametern beeinflusst. Dazu zählen die Immobilienpreise, die Mieter, die Risikobereitschaft der Vermieter, verschiedene Standortfaktoren, makroökonomische Einflüsse, etc.

Geht man davon aus, dass ein auf dem Wohnungsmarkt gefundener Mietpreis eine Lage-Komponente beinhaltet, also eine „Miete für die Grundkosten“, so wird dieser Lagepreis von folgenden Faktoren geprägt:

- Standortfaktoren

Die U-Bahn-Nähe und das Image des Bezirks sowie unzählige andere harte und weiche Standortfaktoren beeinflussen die Lageeinpreisung.

- Nachbarschaftseffekte: Entfernung zu besserer/schlechterer Lage

Eine Wohnung innerhalb eines Wohngebiets, das unmittelbar neben einer teuren Wohnlage liegt, wird diese Nähe einpreisen können.

- Anwendbarkeit der Mietzinsobergrenzen des Mietrechts

In der Literatur wird der Mietregulierung stets ein zumindest dämpfender Preiseffekt zugeschrieben. Fällt eine Wohnung nicht in die mietengeschützte Kategorie, müsste der Mietpreis höher sein. Vorausgesetzt, die Mietzinsbegrenzung liegt unter der Marktmiete, was in Wien der Fall ist.

- Verbot von Zuschlägen: Feststellung eines Gründerzeitviertels

Liegt die Wohnung in einem Gründerzeitviertel, so darf grundsätzlich kein Lagezuschlag verlangt werden, ungeachtet der Wohnqualität. Das kann den Preis der "Grundkostenmiete“ beeinflussen, sofern der Lagezuschlag ein wirksames Regulativ ist (dies gilt auch für die folgenden Punkte). 
- Höhe der Grundkosten

Liegt ein Objekt außerhalb eines Gründerzeitviertels, dann errechnet sich der Lagezuschlag aus den Grundkosten. Diese ergeben sich auf dem Eigentumsmarkt und preisen die Standortqualität und die Bebaubarkeit ein, was wiederum mit den Standortfaktoren zusammenhängt.

- Abverkaufsrenditen bzw. „Liegenschaftszins“

Renditeerwartungen können einen Einfluss haben: Je geringer der Mietertrag aufgrund des MRG im Verhältnis zu einem möglichen erzielbaren Abverkaufspreis einer Einzelwohnung ist, desto eher würde ein Haus parifiziert werden und die Einzelwohnungen abverkauft. Kann ein Objekt etwa nur einen derart geringen Ertrag erwirtschaften, dass dieser nur zwei Prozent des möglichen Verkaufspreises auf dem Eigentumsmarkt ausmacht, so würde sich - je nach Renditeerwartung und Zinsniveau - ein Verkauf lohnen. Eigentumswohnungen werden teilweise wieder vermietet, oft genug jedoch (allenfalls als Zweitwohnsitz) von den Eigentümern selbst genutzt.

- Kontrolle der mietrechtlichen Ordnung Auch wenn es eine Regulierung gibt, wird ihre Durchsetzbarkeit davon abhängen, ob die Kontrolle auf dem Markt effektiv ist oder nicht. Einfluss darauf hat auch der Grad der Rechtssicherheit. Gibt es rechtliche Unschärfen, was aufgrund der komplexen rechtlichen Mietzinsberechnung zu erwarten ist, haben Kläger und Beklagte in Mietrechtsstreitigkeiten ein Klagsrisiko $^{60}$.

- Behavioristische Einflüsse

- Renditeerwartungen der Vermieter

Vermieter können gewisse Renditeerwartungen haben, um einen bestimmten prozentualen Ertrag auf das eingesetzte Kapital zu erwirtschaften.

- Risikobereitschaft der Vermieter In Zusammenhang mit der Kontrolle der mietrechtlichen Ordnung werden risikoaverse Vermieter die Klagsgefahr geringer halten, indem sie Abstriche von ihren Renditeerwartungen machen.

Zugleich können Vermieter rechtliche Lücken ausnutzen um eine fehlende rechtswirksame Durchsetzung ihrer Renditeerwartungen zu umgehen, und so etwa bei Fehlen einer Lagezuschlagsmöglichkeit andere Zuschläge verrechnen.

- Klagsaffinität der Mieter

60 In Außerstreitverfahren trägt jede Partei ihre Kosten selbst. Die Richtwertberechnung muss im Streitfall durch Sachverständige - also Menschen, die nach eigenem Ermessen urteilen - überprüft werden. 
Haben die Mieter ein ausgeprägtes Rechtsdurchsetzungs-Bewusstsein und scheuen sie vor einer Klage nicht zurück, so würde das die Kontrolle der mietrechtlichen Ordnung erhöhen und die Mieten in Grauzonen in Schranken weisen. Mieter sehen sich eher zu einer Rechtsdurchsetzung gezwungen, wenn die Mieten schwer leistbar sind. Das hängt nicht zuletzt mit der absoluten Höhe der Miete zusammen. Kleine Wohnungen sind selbst bei ungünstigen sozioökonomischen Voraussetzungen leichter leistbar, als große und entsprechend teurere Wohnungen. Bei kleineren Wohnungen sinkt somit auch das Klagsrisiko.

- Ökonomische Faktoren

Inflation erhöht die Mieten, und das Zinsniveau determiniert maßgeblich die Immobilienpreise. Die Preise steigen, wenn das Zinsniveau niedrig ist, und fallen, wenn die Zinsen nach oben klettern. Steigende Immobilien preise führen allerdings zu steigenden Lagezuschlägen über den Grund kostenanteil.

Fokus der Arbeit ist die Auswirkung der Mietregulierung. Wie viele Studien und Beobachtungen belegen, liegt in Wien der gesetzlich höchstzulässige Mietzins für mietengeschützte Wohnungen unter der freien "Marktmiete“ (Czasny/Köppl/Rosifka 1995; Abele 2007; Blaas/Wieser 2004; Böhm 2003; Feilmayr 2005; Moser/Schöffmann/Stocker 2002). Oder anders formuliert: wird die Regulierung bei einer bestimmten mietengeschützten Wohnung eingehalten, so liegt der Mietpreis unter jenem Preis, der auf dem freien Mietmarkt für die gegenständliche Wohnung erzielbar wäre. Wird die Mietregulierung zumindest teilweise eingehalten, so muss das die Miete im regulierten Segment dämpfen.

Hypothese 1: Die Miethöhe ist im mietengeschützten Segment geringer als im unregulierten Neubausegment.

\subsection{Vermutete Probleme bei der Lagezuschlagsbegrenzung}

Neben der Begrenzung der Miete für eine durchschnittliche Standardwohnung reguliert das Mietrecht auch den jeweiligen Mietzuschlag, zu dem eine besondere Lage berechtigt. Insbesondere setzt das Mietrecht Bereiche fest (Gründerzeitviertel), in denen ein derartiger Lagezuschlag verboten ist, ungeachtet der zwischenzeitlichen Attraktivität, die diese Gegenden erfahren haben können. Auch dieses Regulativ muss den Preis senken:

Hypothese 2: Das Verbot des Lagezuschlags hat einen Einfluss auf die Miethöhe im betroffenen Segment und Gebiet (Gründerzeitviertel). 


\subsubsection{Problematik der Gründerzeitviertel}

Allerdings weiß man, dass Nachbarschaftseffekte auf die Attraktivität und den Marktpreis von Immobilien wirken. Ist eine Preisregulierung jedoch nur für eine von zwei benachbarten Gebieten gültig, führt das zwangsläufig zu Verzerrungen. Die Problematik soll in Abbildung 19 verdeutlicht werden, und zwar anhand eines typischen Beispiels für ein Gründerzeitviertel (kein Lagezuschlag), das zwischen Gebieten, die einen (höheren) Lagezuschlag zuließen, liegt. Es handelt sich um den Zählbezirk 90901032 (kleiner Kreis in der Abb.) zwischen Borschkegasse und Lazarettgasse im 9. Bezirk.

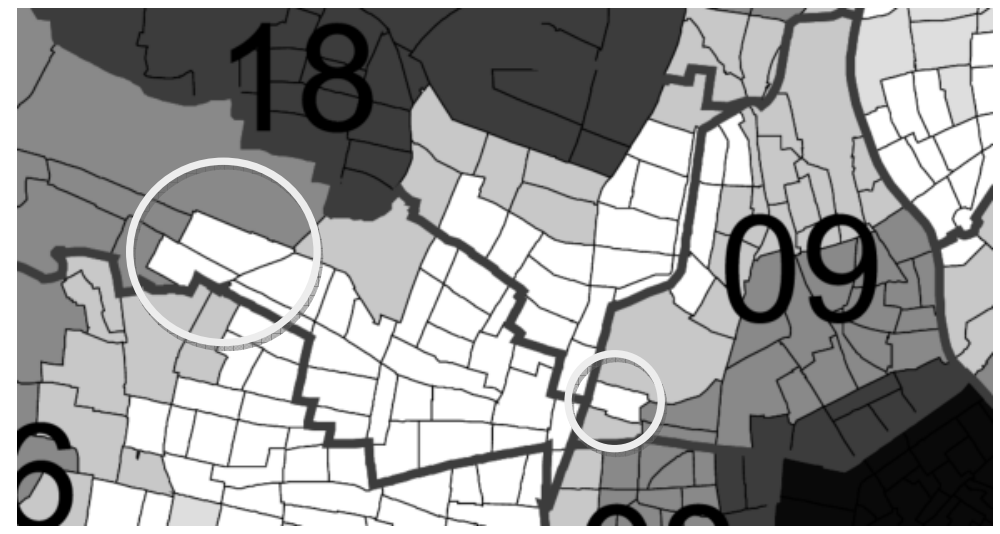

Legende: $₫$ Zone $3\left(€ 0,24 / \mathrm{m}^{2}\right)$, $₫$ Zone $4\left(€ 0,60 / \mathrm{m}^{2}\right)$, $\square$ Zone $5\left(€ 0,96 / \mathrm{m}^{2}\right)$, versus $\square$ Zone $1=$ Gründerzeitviertel $\left(€ 0,00 / \mathrm{m}^{2}\right)$. Auch $\square$ Zone $6\left(€ 1,35 / \mathrm{m}^{2}\right)$ grenzt direkt an Gründerzeitviertel an

Abbildung 19: Beispiele für "Grauzonen" im Lagezuschlagsplan

Dieses zuschlagsfreie Gründerzeitviertel liegt zwischen zwei Gebieten, die nach den Empfehlungen der Stadt Wien immerhin zwischen 60 und 96 Cent pro Quadratmeter an Lagezuschlag zuließen (womöglich mehr, über ein Gutachten zum Grundkostenanteil der jeweiligen Objekte).

Die Trennlinien verlaufen scharf. In der Borschkegasse trennt die Fahrbahn die Zuschlagszonen mit einer Differenz von $60 \mathrm{Cent} / \mathrm{m}^{2}$ (bzw. $96 \mathrm{Cent} / \mathrm{m}^{2}$ Richtung Osten). Es ist zu bezweifeln, ob auch die regionale Marktmiete, die ja die ökonomisierte Lebensqualität in einem Wohngebiet abbildet, einen derartig scharfen Knick mitmacht.

Abbildung 20 verdeutlicht, dass dies insbesondere in Gründerzeitvierteln zu einer angespannten Situation führen muss. Auch der vom Stadtzentrum fallende 
Rentengradient verläuft kontinuierlich über das Gründerzeit-Einschlussgebiet hinweg.

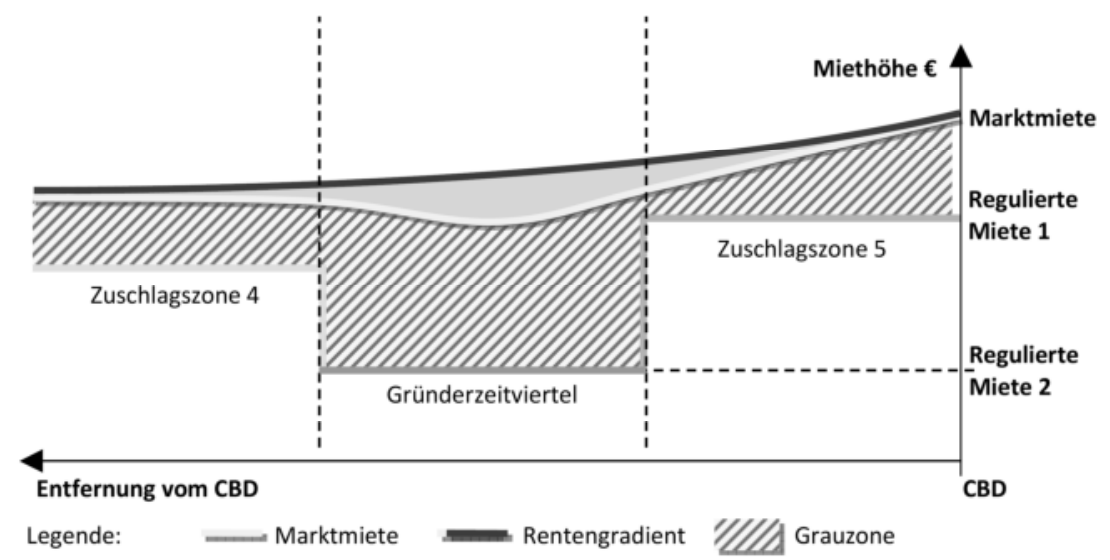

Abbildung 20: Rentengradient, Marktmiete und die entstehende Grauzone

In der obigen Darstellung (Abbildung 20) wird unterstellt, dass es auch in den Zonen, wo ein Lagezuschlag zulässig ist, zu Anspannungen kommen würde (Hypothese 1). Es soll graphisch verdeutlicht werden, dass diese Anspannung in Gründerzeitvierteln noch größer sein muss. Zwar würde die Marktmiete möglicherweise über diesen Vierteln, deren Substandardanteil früher höher gewesen, und deren Beliebtheit in Folge entsprechend geringer ist, eine „Delle“ beschreiben. Dass diese Delle aber ähnlich ausgeprägt und scharfkantig ist wie es die Mietregulierung vorsieht, darf bezweifelt werden.

\subsubsection{Problematik der scharfen Abgrenzung der Zuschlagszonen}

In manchen „Gründerzeitvierteln“ kann mittlerweile nicht mehr von einer unbeliebten Wohngegend die Rede sein, zumal diese Viertel auch in sehr attraktiven, innerstädtischen Gebieten vorkommen. Gemeint sind etwa einzelne Lagen im 7. und 9. Bezirk, der nahezu gesamte 5. Bezirk (somit auch das beliebte „Schloßquadrat"), ein Gutteil des 12. Bezirks und auch die beliebte Fußgängerzone in der Meidlinger Hauptstraße, das immer begehrtere Stuwerviertel im 2. Bezirk, das durch den bevorstehenden Zuzug der Wirtschaftsuniversität bereits einen massiven Aufschwung eingepreist hat, sowie nicht zuletzt der populäre Brun- 
nenmarkt im 16. Bezirk. Dem Vermieter bleibt letztlich ein Lagezuschlag verwehrt (vgl. den geographische Überblick Kap. 4.5.3).

Die Zuschlagszonen, wie sie die Stadt Wien veröffentlicht, sind zwar nicht rechtsverbindlich. In der Praxis kann durch Sachverständigengutachten bewiesen werden, dass der Lagezuschlag eines bestimmten Hauses doch höher wäre als der öffentlich verlautbarte. Allerdings entscheidet diese Zuschlagskarte bei mietrechtlichen Schlichtungsstellenverfahren sozusagen ,in erster Instanz“, und es ist zu bezweifeln, dass sich viele Vermieter ein Sachverständigengutachten leisten möchten. Die Zuschlagskarte der Stadt Wien ist immerhin praktisch. Allerdings verlaufen dabei die Grenzen zwischen den Zuschlagszonen sehr scharf, und womöglich an der Realität vorbei: Darf etwa am Schwarzenbergplatz 15 ein Lagezuschlag von 4,11 Euro verlangt werden, lässt die Adresse Schwarzenbergplatz 14 ,nur“ 1,32 Euro pro Quadratmeter und Monat zu. Dazwischen liegt eine Querstraße. Es ist zu bezweifeln, dass der Bodenpreisgradient genauso drastisch abfällt. Der Theorie zufolge sollte er loglinear mit Entfernung vom Zentrum abnehmen. Die zusätzlichen 50 Meter im vorliegenden Beispiel können unmöglich einen dermaßen drastischen Knick in der Nutzenfunktion bzw. Lagebepreisung verursachen.

Die obige Argumentation führt zu folgenden Hypothesen:

Hypothese 3: Die Mietregulierung wird in Gebieten, wo es eine Lagezuschlagsmöglichkeit gibt, eher eingehalten als in Gebieten, wo ein Lagezuschlag verboten ist (Gründerzeitviertel).

Hypothese 4: Die schärfsten Abstufungen von höheren zu niedrigeren Lagezuschlagsmöglichkeiten gibt es in ,guten“ Bezirken, in denen Gründerzeitviertel definiert sind. Dort wird die Mietregulierung weniger eingehalten.

Hypothese 5: Je weiter eine angebotene Wohnung vom CBD entfernt ist, desto günstiger das Mietangebot. Dieser Zusammenhang ist besser im Neubau zu sehen bzw. unter Ausblendung der Gründerzeitviertel (GZV).

\subsection{Auswirkungen einer, ,Grauzone“6}

Obige Ausführungen zeigen, dass es unter dem vorliegenden mietrechtlichen Lagezuschlags-Regime zu Grauzonen kommen muss. Wie gehen Marktteilnehmer mit der Deckelung der Lagezuschläge um? Gibt es Umgehungsmechanismen? Die bisherigen Studien - hauptsächlich im Auftrag der Arbeiterkammer belegen, dass Vermieter mehr Miete verlangen als sie verlangen dürften. 


\subsubsection{Umgehungsmechanismen des Lagezuschlags-Regimes}

Liegt die mögliche Marktmiete in bestimmten Gebieten über der nach MRG erlaubten Miethöhe, so haben die Vermieter einerseits die Möglichkeit sich der Regulierung $\mathrm{zu}$ beugen. Andererseits kann es $\mathrm{zu}$ Umgehungsmechanismen kommen, wenn das enge Reglement des Lagezuschlags nicht ausreicht, den tatsächlichen „Wert“ einer Wohnlage als Mietzinsbestandteil abzubilden.

Ein Umgehungsmechanismus einer Regulierung wird durch eine Tatsache befeuert, die schon mehrmals angesprochen wurde: die Rechtsunsicherheit in der gesamten Richtwertgesetzgebung. Stets wird bei Regelungen, die sich in wesentlichen Teilbereichen der praktischen Umsetzung entziehen, auch in jenen Bereichen, die durchaus faktisch nachvollziehbar wären, die strikte Auslegung tendenziell nicht befolgt. Vor allem dann nicht, wenn sie für jene Partei nachteilig ist, die das Vertragsabschlussgeschehen typischerweise dominiert (Böhm 2003, 42). Ist etwa der Lagezuschlag nicht einfach berechenbar, könnte der Vermieter (als dominierende Vertragspartei) andere Zuschläge verrechnen und einzelne Abschläge je nach persönlicher Auslegung vernachlässigen.

Ist eine Regel unverständlich, so würden Parteien auf den ,nächstverständlichen" Regelungsbereich ausweichen, im konkreten Fall den des Angemessenen Hauptmietzinses. „Diesbezüglich kann dem Gesetzgeber zugute gehalten werden, dass er mit seiner Regelung dadurch zumindest einen gewissen Dämpfungseffekt hinsichtlich des Mietzinsniveaus erzielt.“(Böhm 2003, 42)

Ein Vermieter wird zumindest zurückhaltender bei seinen Mietzinsforderungen sein, wenn er weiß, dass die Mietvereinbarung nachgeprüft werden kann. Das Richtwertzins-System geht „,von starren Größen“ aus, ,während der Angemessene Mietzins - jedenfalls auf Basis der [...], Vergleichswertmethode " - auf die Marktverhältnisse reagiert" (Böhm 2003, 42). Böhm geht so weit, dass er den Richtwertmietzins aufgrund der in der Praxis zum Teil willkürlichen Auslegung für ,totes“ Recht hält.

Hypothese 6: Eine fehlende Lagezuschlagsmöglichkeit wird bei Mietverhältnissen durch andere Zuschläge substituiert.

Andere Umgehungsmechanismen können sein: 1) Verbotene, überteuerte Ablösen, 2) Mietvertragsgestaltung über Scheinuntermieten, überteuerte Möbelmieten, vertragliches Ausweichen auf Ausnahmen vom Mietrecht („Ferienwohnung“, etc.) oder ähnliche rechtliche Konstrukte, die eine Überprüfung der Miethöhe erschweren. 


\subsubsection{Mietrecht und Erhaltungszustand der Häuser}

Als direkter Effekt von „Rent-Control“ wird stets genannt, dass Vermieter durch die Mindereinnahmen weniger in die Instandsetzung der Häuser investieren (vgl. 2.4.2), und dass ein strenges Mietrecht zwangsläufig zur Bestands-Deterioration führt. Geht man davon aus, dass es sich bei der Vermietung von Altbauwohnungen zum Marktpreis um eine mietrechtliche Grauzone handelt, so müssen die Vermieter auch ein Risiko für mögliche Mietzinsherabsetzungen einpreisen. In Anbetracht der Unsicherheit über zukünftige Mieterträge, die von der Klagsaffinität der Mieter abhängen, wird die Investitionsstimmung weiter eingetrübt, auch wenn sich Erhaltungsinvestitionen im Verhältnis zum (tatsächlich verlangten, aber rechtlich überhöhten) Mietertrag rechnen würden. In Bezug auf den Lagezuschlag heißt das:

Hypothese 7: Je geringer der Lagezuschlag ist, desto schlechter ist auch der Erhaltungszustand der angebotenen Wohnungen.

\subsubsection{Selektionseffekte als Ursache für Segregation}

Der Vermieter hat als dominierende Vertragspartei auch eine weitere Möglichkeit, mietrechtliche Konfrontationen zu vermeiden: Er kann sein Gegenüber aussuchen. Das wiederum kann zu Selektionseffekten führen. Ist der Markt bereit, mehr als die mietrechtlich höchstzulässige Miete zu zahlen, so kann dies der Vermieter nur unter dem Risiko ausnutzen, dass der Mieter die Miethöhe beeinsprucht und den Mietzins gerichtlich herabsetzen lässt. Dieses Risiko kann dadurch verringert werden, dass ein Mieter ausgesucht wird, der mit dem österreichischen Rechtssystem weniger vertraut ist (Ausländer, Migranten ohne Aufenthaltstitel, etc.), oder der aufgrund seiner schlechten Ausbildung nicht über seine Rechte aufgeklärt ist. Der Ausländeranteil und das Bildungsniveau sind dafür Indikatoren.

Hypothese 8: In Gründerzeitvierteln (in guten Lagen) kommt es zu einer Mieterselektion: der Anteil an Ausländern ist höher und das Bildungsniveau niedriger als in Nachbar-Sprengeln, wo ein LZ erlaubt ist.

Ein weiterer Effekt der Risikobegrenzungspolitik könnte die zeitliche Befristung der Mietverhältnisse sein. Kommt es zu einer rechtlichen Auseinandersetzung mit dem Mieter in Bezug auf die Miethöhe, so ist dieses Problem damit für den Vermieter zumindest zeitlich auf die befristete Mietdauer begrenzt. 


\subsubsection{Flucht aus dem Markt}

In der Literatur wird als ein maßgeblicher Effekt von „Rent-Control“ stets der Rückgang des Angebots genannt (vgl. Kapitel 2.4.5; Arnott 2002, 4f, Albon/Stafford 1987, 18f). Rent-Control müsste in der lagezuschlagsfreien Grauzone diesen Effekt verstärkt hervorrufen. Der Rückgang des Angebots bedeutet nicht unbedingt eine Reduktion der Wohnungen, sondern womöglich lediglich eine Reduktion der Mietwohnungen. Da die Mietregulierung vor allem den Altbaubereich - das klassische Zinshaus - betrifft, haben die Vermieter die Möglichkeit, ihre Häuser in Wohnungseigentum zu parifizieren und zu verkaufen. Auf einen Rückgang der Neubautätigkeit dürfte die Einordnung als Gründerzeitviertel bzw. „Grauzone“ keinen mittelbaren Einfluss haben, denn Neubauten unterliegen grundsätzlich keiner Mietregulierung. Abbildung 21 soll die soeben erörterten Faktoren in einer Gedankenkarte zusammenfassen.

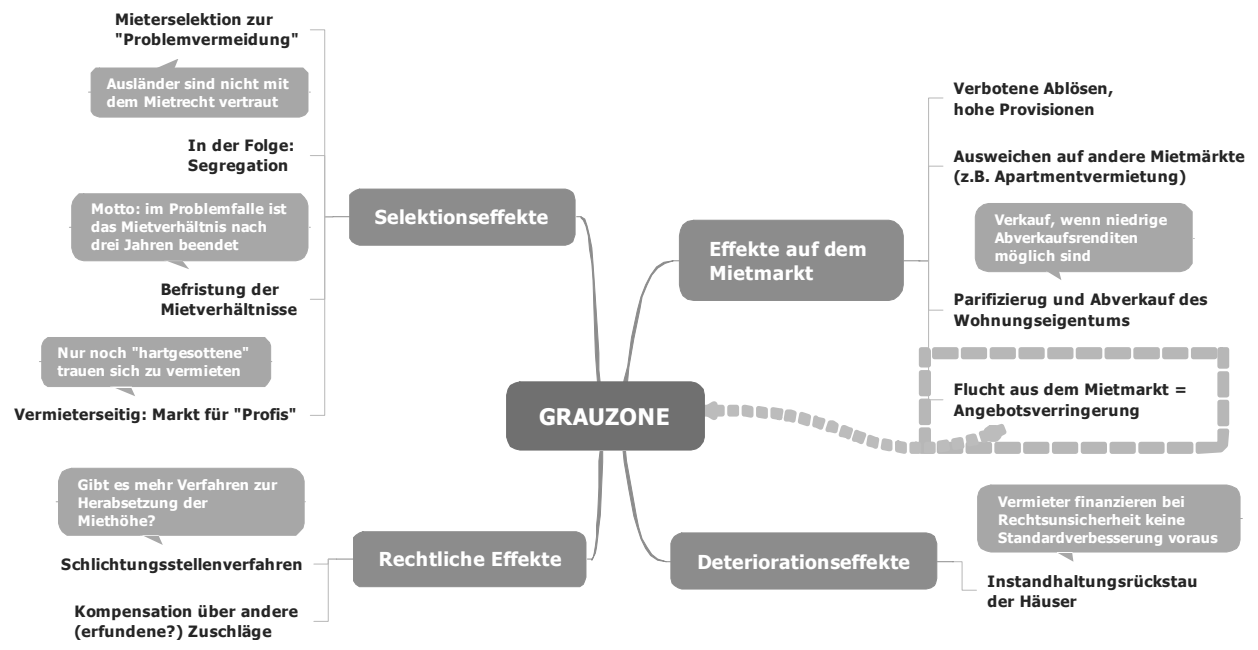

Abbildung 21: Theoretische Effekte einer mietrechtlich-ökonomischen Grauzone 
Je stärker der mietrechtlich bedingte „Knick“ in der erlaubten Miethöhe ist, desto stärker muss dies Abverkäufe provozieren. Das fassen folgende Hypothesen zusammen:

Hypothese 9: In Gründerzeitvierteln in guten Lagen ist das Mietangebot geringer bzw. rückläufig, da der „Graubereich“ höher ist.

Dies rührt auch aus der beobachtbaren Entwicklung, dass Mietshäuser zunehmend parifiziert und als Eigentumswohnungen abverkauft werden. Diese Wohnungen werden zwar zum Teil wieder vermietet, zum Teil jedoch von den Eigentümern selbst genutzt, egal ob als Hauptwohnsitz oder als Zweitwohnung für Freizeitzwecke in der Bundeshauptstadt. Jedenfalls führt dies zu einer Verkleinerung des Mietmarktes. Ist der Graubereich des Mietrechts in Gründerzeitvierteln höher, aber zugleich die Abverkaufsrenditen in Bezug auf die legale Marktmiete geringer ${ }^{61}$ so müssen rational handelnde Vermieter ihre Häuser tatsächlich parifizieren und einzeln verkaufen:

Hypothese 10: In Gründerzeitvierteln in guten Lagen kommt es verstärkt zu Parifizierungen und Abverkäufen von Wohnungen.

61 Zur Abverkaufsrendite: erwirtschaftet ein Zinshaus 100.000 Euro pro Jahr, so kann es als „Ertragshaus mit 5 Prozent Rendite“ für 2 Mio. Euro verkauft werden. Ist von diesem Mietertrag aber nur die Hälfte nachhaltig und mietrechtlich durchsetzbar, weil das Haus in einem Gründerzeitviertel überteuert vermietet wird, so verringert das die „legale“ Rendite entsprechend auf 2,5 Prozent. Wäre das Haus aber frei vermietbar, würde es möglicherweise ohnehin teurer verkauft werden können, als „4-Prozenter“ für 2,5 Mio. Euro. Der Anlegerhunger nach Zinshäusern führt m.E. dazu, dass die Kaufinteressenten zunehmend das Risiko der Mietzinsherabsetzungen geringschätzen. 


\section{Empirischer Teil}

Der folgende Abschnitt bildet den Kern der Dissertation. Die theoretischen Modelle über die Effekte und Sinnhaftigkeit einer Preisregulierung können lediglich Ansätze für die Hypothesenbildung liefern. Die Nagelprobe der Modelle über Regulierungseffekte muss empirisch erfolgen. Die Daten dafür liefert im vorliegenden Fall der Markt. Zuerst soll nach einer Methodendiskussion auf erwartete Probleme bei der Erhebung eingegangen werden. Dann bildet eine erste deskriptive Auswertung des Materials den Mietmarkt ab. Es folgt die Hypothesenprüfung sowie deren Limitationen.

\subsection{Methode}

Die Suche nach den Effekten der Lageregulierung auf bestimmte Gebiete des Wohnmarktes erfordert im Grunde ein Experiment: Nur Experimente können einen kausalen Zusammenhang zwischen einer Intervention (Gesetz, Programm, Subvention, etc.) und einem Ergebnis (Preis, etc.) beweisen. Vergleichende, experimentelle Designs messen den Einfluss eines solchen Programms, das nur einen Teil der Gesamtheit betrifft (partial-coverage) (Rossi, Freeman 1993, 264ff).

Für das Testen einer Einflussvariablen ist neben der Messung der Versuchsgruppe auch eine Referenzmessung in einer Kontrollgruppe nötig. Dabei ist darauf zu achten, dass die Versuchs- und Kontrollgruppe möglichst gleichartig sind (Rossi, Freeman 1993, 264ff). Je gleichartiger, desto eher ist es die Einflussvariable, die das unterschiedliche Messergebnis bedingt - und nicht die gegebenen Unterschiede der beiden Versuchsgruppen. „Es ist immer möglich, dass es zwischen beiden [...] Gruppen Unterschiede gibt, und dass diese Unterschiede - nicht die Intervention - alles oder einen Teil des beobachteten Effekts verursachen“ (Rossi, Freeman 1993, 300).

Würde der Forscher die Versuchsgruppen ex ante zuteilen, also vor der Implementierung eines Programms, so würde das die Gruppen vergleichbarer machen (Rossi, Freeman 1993, 301). Viele Untersuchungen sind aber deswegen ex post-Designs, weil die Entscheidung für eine Evaluierung erst fällt, wenn ein Programm - in diesem Fall die Implementierung einer Mietregulierung mit Lagezuschlägen - bereits zu laufen begonnen hat.

Die vorliegende Untersuchung geht dem Einfluss des Lagezuschlags (= Einflussvariable) nach. Diese „Intervention“ ist ein wohnungspolitisches Programm, das seit 1994 in Kraft ist und auf die Preisgestaltung eines Gutteils der Wiener Mietwohnungen wirken kann. Die „Versuchsgruppe“ ist damit klar defi- 
niert, und die „Kontrollgruppe“ ergibt sich aus jenen Wohnungen, die nicht in die Kategorie der mietrechtlich geschützten Wohnungen fallen. Allerdings: diese Unterscheidung zwischen beiden Gruppen kann nicht „randomisiert“ erfolgen, ein echtes Experiment ist dabei somit nicht möglich. Die Alternative ist ein quasi-experimentelles Design.

\subsubsection{Quasi-experimentelle Designs}

„Quasi-experimentelle Designs werden meist benutzt, um den Einfluss eines Programms zu schätzen, wenn die zufällige Zuteilung (Anm. zu Versuchs- und Kontrollgruppe) nicht vorgenommen werden kann“ (Rossi, Freeman 1993, 298). Im Vergleich zum Experiment, das bereits Störvariablen aufweist [Err] hat ein Quasi-Experiment einen zusätzlichen Fehlerherd aus unkontrollierten Differenzen zwischen den Messgruppen (Rossi, Freeman 1993, 300).

Netto Effekt $=\left[O_{e}\right]-\left[O_{c}\right] \pm\left[S D_{e-c}\right] \pm[$ Err $]$

$O \quad$ Output der Versuchsgruppe (e) oder Kontrollgruppe (c)

Err Design Effekte und Stochastische Fehler

$S D$ Unkontrollierte Differenzen zwischen Versuchs- und Kontrollgruppe

Diese Unterschiede zwischen den beiden Versuchsgruppen drücken auf die interne Validität von Quasi-Experimenten im Vergleich $\mathrm{zu}$ anderen Methoden (vgl. Abbildung 22). Die Messung misst nicht das, was sie messen sollte, nämlich den Einfluss eines Treatments, sondern eben den Unterschied zwischen Versuchs- und Kontrollgruppe. Immerhin weisen Feldstudien, etwa die Evaluierung des realen Wohnungsmarktes, eine hohe externe Validität auf, die Ergebnisse der Studie sind stark gültig für den Markt. Es ist nötig, bei der vorliegenden quasi-experimentellen Feldstudie zusätzlich eine hohe interne Validität anzustreben. 


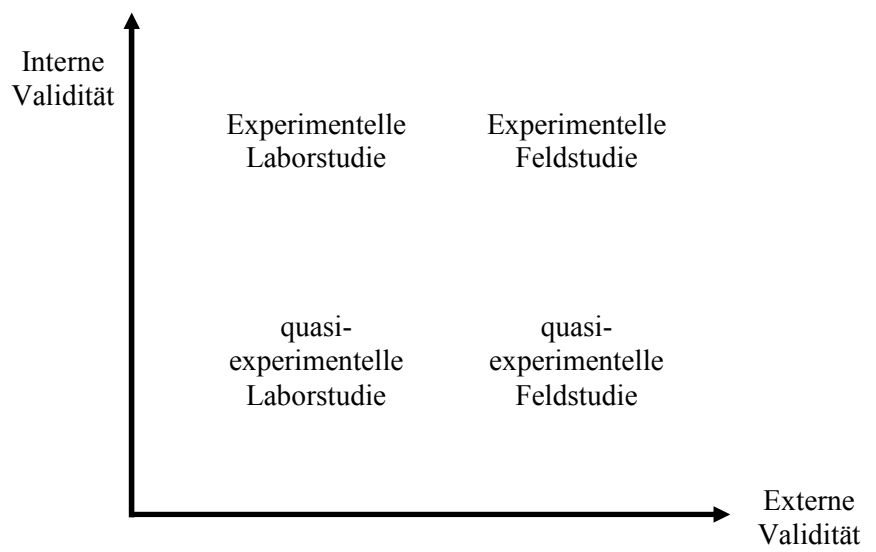

Abbildung 22: Validitäten von (Quasi-) Experimenten in Labor und Feld

\subsection{2 „Matching“" und Variablenkontrolle über ein hedonisches Modell}

Vergleichsgruppen müssen daher, wenn sie schon nicht ,gleich“ sind, nach den wesentlichen Charakteristika gleichgeschaltet werden. Das sind jene Eigenschaften, die ebenfalls einen Einfluss auf die abhängige Variable haben, aber unabhängig von der Intervention sind. Bei Tests mit Personen sind das üblicherweise das Alter, das Geschlecht und einige andere persönliche Charakteristika.

Unter „Matching“ wird eine Art „Partnersuche“ für die Versuchsgruppe verstanden. Jedem Individuum der Versuchsgruppe soll entweder ein zweites in der Kontrollgruppe gegeben sein, z.B. Mann, 29, Akademiker (,individual matching") oder es sollen zumindest die Anteile der Charakteristika an den beiden Gruppen gleich sein, etwa 45 Prozent Männer, 14 Prozent Akademiker (,aggregate matching"). Heute ist es allerdings üblicher, diese Charakteristika statistisch zu kontrollieren (Rossi, Freeman 1993, 310).

Mit statistischen Kontrollen können die Charakteristika von zwei Vergleichsgruppen angeglichen werden. $\mathrm{Zu}$ diesem Zweck ist eine Regressionsanalyse notwendig: So kann der Einfluss der Intervention gemessen werden, indem alle anderen (unabhängigen Variablen) gegen das Ergebnis modelliert werden. Erst danach wird die Interventionsvariable eingeschaltet und erhoben, wie viel Varianz sie erklärt (Rossi, Freeman 1993, 312ff). Die Regressionsanalyse gehört zu den komplexen multivariaten Methoden. Sie zeigt, welchen Einfluss (wel- 
chen „Netto-Effekt“) eine bestimmte Variable (das „Treatment“) auf das Ergebnis hat, wenn alle anderen Variablen gleich bleiben (Rossi, Freeman 1993, $315 f)$.

Derartige Regressionen sind auf dem Wohnungsmarkt vor allem in hedonischen Regressionsmodellen $\mathrm{zu}$ finden. Beispielsweise wird für das Merkmal „Balkon“ bei einer Durchschnittswohnung ein implizierter Mietzuschlag von 6,3 Prozent errechnet (Brunauer et al., 16).

Sind sämtliche Wohnungscharakteristika bekannt, so zeigt sich, dass insbesondere die folgenden kontrolliert werden müssen, da sie einen Einfluss auf die Miethöhe haben:

Tabelle 14: Charakteristika von Wohnungen und deren Skalenniveau

\begin{tabular}{|l|l|}
\hline Unabhängige Variable & Skalenniveau \\
\hline Wohnungsgröße & Absolut \\
\hline Lage (Adresse) & absolut x, y \\
\hline Zimmerzahl & Absolut \\
\hline Stockwerk & Ordinal \\
\hline Baujahr & Ordinal \\
\hline Bezirk & Nominal \\
\hline Ausstattungskategorie & (2) \\
\hline Zustand der Wohnung & ordinal (A bis D) \\
\hline Lift & Ordinal \\
\hline Garage & nominal (dichotomisch) \\
\hline Parkplatz & nominal (dichotomisch) \\
\hline Terrasse & nominal (dichotomisch) \\
\hline Balkon & nominal (dichotomisch) \\
\hline Entfernung zur U-Bahn & nominal (dichotomisch) \\
\hline Entfernung zum übrigen öff. Verkehrsnetz & Absolut \\
\hline Entfernung zum CBD & Absolut \\
\hline Entfernung Erholungspark & Absolut \\
\hline Gartenbenützung & Absolut \\
\hline Ausrichtung Himmelsrichtung & nominal (dichotomisch) \\
\hline
\end{tabular}

62 Die Ausstattungskategorie sollte viele Ausstattungsmerkmale subsummieren: Hat die Wohnung ein Bad, WC, Heizung, Vorraum, Kochgelegenheit, etc.?

63 Der ,Zustand“ sollte berücksichtigen, wie hochwertig und brauchbar die Ausstattungsmerkmale sind. Gibt es einen Parkettboden? Neue Fenster? Schönen Ausblick? 


\begin{tabular}{|l|l|}
\hline Energieeffizienzklasse & Ordinal \\
\hline & \\
\hline Abhängige Variable & Skalenniveau \\
\hline (Brutto-) Miete der Wohnung (kalt) & Absolut \\
\hline
\end{tabular}

\subsection{Datengenerierung und Datenbereinigung}

Die Daten für den empirischen Teil der Arbeit stammen aus vier verschiedenen Quellen:

- Mietangebotsdaten:

Der Maklersoftware-Anbieter Edi-Real stellt sämtlich Mietangebote der Jahre 2005 bis Juni 2010 für das Wiener Stadtgebiet zur Verfügung. Der Rohdatensatz wurde von Prof. Wolfgang Feilmayr (Stadt und Regionalforschung TU-Wien) aufbereitet. Neben diesen 32.732 Datensätzen, die größtenteils eine Adressangabe inkludieren und daher lokal exakt verortet werden können, liegen auch noch weitere ca. 8.000 Mietangebotsdaten der Firma EresnetConsulting vor. Eresnet ist Betreiber von Immobilien.NET, der größten Online-Immobilienplattform. Dieser Datensatz weist allerdings einen Manko auf, der ihn für die Arbeit unbrauchbar macht: nur sehr wenige Mietangebote beinhalten die genauen Adressangaben, die auf dem lokalen Markt verortet werden könnten.

- Grundbuchsdaten:

Das Bundesministerium für Justiz stellte für diese Dissertation einen vollständigen Grundbuchs-Datensatz der Stadt Wien zur Verfügung. Die 124.178 Grundbuchsauszüge sind im *.txt Format verfügbar und müssen einem Parsing unterzogen werden.

- Statistische Erhebungen:

Da die Mietangebotsdaten auf Zählsprengelebene genau verortet werden können, müssen sie mit demselben geographischen Genauigkeitsgrad mit soziodemographischen Daten unterlegt werden. Die Statistik Austria stellt Daten zu Wohnungs- und Gebäudebestand sowie Zahlen über Arbeitslosigkeit, Bildungsniveau und Hauptwohnsitzmeldungen auf Sprengelebene genau zur Verfügung. Datenbasis sind die Volkszählung und Gebäudezählung aus dem Jahr 2001 sowie der Mikrozensus der Statistik Austria aus 2010, somit eine Vollerhebung, die auch Ausländeranteile auf Zählsprengelebene ausweist.

- Sonstige Daten: 
Die Magistratsabteilung 25 der Stadt Wien stellt eine Liste aller Zählsprengel der Stadt zur Verfügung, mit Angabe über die jeweilige Höhe des empfohlenen Lagezuschlags (Zone 1 bis 7). Dies inkludiert auch eine Aufzählung der als Gründerzeitviertel geltenden Zählsprengel.

\subsubsection{Mietangebotsdaten und deren Operationalisierung}

Der umfangreiche Datensatz an Mietangeboten wurde von Juni 2005 bis März 2010 über die Maklerplattform Edi-Real generiert. Das ist eine Maklersoftware, die zugleich eine Ameta-Plattform von zahlreichen österreichischen Maklerunternehmen darstellt. In der Regel wird jede Mietwohnung, die ein Makler zur Vermittlung übernimmt, in das System gestellt, ungeachtet dessen, ob eine Ameta-Vermarktung $^{64}$ erwünscht ist oder nicht. In diesem Zeitraum wurden für das geographische Gebiet Wien insgesamt 32.732 Mietwohnungs-Angebote angelegt. Darunter befinden sich sehr luxuriös ausgestattete Dachgeschoßwohnungen genauso wie renovierungsbedürftige Garçonnièren in Außenbezirken.

Folgende Variable definieren die inserierenden Makler über die Mietwohnungen (vgl. Tabelle 15):

Tabelle 15: Variable, Skalenniveaus und Ausprägungen des Datenmaterials

\begin{tabular}{|l|l|}
\hline Variable & Ausprägung, Beispiele \\
\hline $\mathrm{Plz}$ & Postleitzahl, Gemeindebezirk \\
\hline Ort & Wien \\
\hline zaehlsp_id & $\begin{array}{l}\text { Zuordnung zu einem Zählsprengel } \\
077^{65} \text {, wobedeutet: 9=Wien, 15=Bezirk Rudolfsheim-, } 1501 \\
\text { Fünfhaus, 01=bedeutungslos, 07=Zählbezirk 7, 7=Sprengel } \\
7 \text { innerhalb des Zählbezirks. }\end{array}$ \\
\hline lat & Latitudinale Grade (z.B. 48,19938) \\
\hline lon & Longitudinale Grade (z.B. 16,31878) \\
\hline point_x & Geokoordinate X \\
\hline point_y & Geokoordinate Y \\
\hline date_veraend & Eingabedatum des Angebots \\
\hline area_low & Wohnnutzfläche des Objekts \\
\hline
\end{tabular}

64 Unter Ameta-Geschäften versteht man eine Abmachung zwischen zwei Maklern, nach der ein Gewinn bei einem Geschäft geteilt wird, etwa weil der eine das Objekt und der andere den Käufer/Mieter bringt.

65 Die Zuordnung zu Zählsprengeln wurde anhand der Adressangaben mit einem Python Geocoding Tool über Google Maps gemacht. 


\begin{tabular}{|l|l|}
\hline bj & Baujahr des Gebäudes/der Wohnung \\
\hline cond & Erhaltungszustand der Wohnung (,gut“') \\
\hline floor & Stockwerk, in dem sich die Wohnung befindet \\
\hline heiz_cost & Heizkosten pro Monat \\
\hline heiz_type & Art der Heizung (,Gasetagen“, ,Zentral“) \\
\hline betr_cost & Betriebskosten (nur teilw. erhoben) \\
\hline jahrerstell & Datum der erstmaligen Insertion \\
\hline kell & Kellerabteil vorhanden true/false \\
\hline lift & Lift vorhanden true/false \\
\hline month_veraend & Monat, in dem das Inserat geschaltet wurde \\
\hline year_veraend & $\begin{array}{l}\text { Jahr, in dem das Inserat geschaltet wurde, darunter befin- } \\
\text { den sich auch ältere Inserate, bei denen date_veraend nicht } \\
\text { kodiert wurde }\end{array}$ \\
\hline nettomiete & Gesamt-Nettomiete der Wohnung \\
\hline no_balc & Zahl der Balkone $(0,1,2, \ldots)$ \\
\hline no_bath & Zahl der Bäder $(0,1,2, \ldots)$ \\
\hline no_loggia & Zahl der Loggien $(0,1,2, \ldots)$ \\
\hline no_terr & Zahl der Terrassen $(0,1,2, \ldots)$ \\
\hline no_wc & Zahl der WCs $(0,1,2, \ldots)$ \\
\hline rooms & Anzahl der Zimmer \\
\hline ust & Summe Umsatzsteuer (i.d.R. 10\% der Nettomiete) \\
\hline
\end{tabular}

Das Datenset wurde mit Daten der MA 25 der Stadt Wien zur Höhe der Lagezuschläge in den einzelnen Zählsprengeln verschnitten und recodiert. Das Baujahr des Gebäudes (vor oder nach 1945) lässt Rückschlüsse auf die Anwendbarkeit des Mietrechtsgesetzes zu, was ebenfalls entsprechend kodiert wurde. Wohnungen nach 1945 können grundsätzlich frei vermietet werden. Freilich gibt es Ausnahmen, etwa wenn das Objekt nach einer Wohnbauförderung 1968 gefördert worden war, ein geförderter Wiederaufbau ist, wenn es sich um eine „Genossenschaftswohnung“ handelt, o.ä. Auf diese feinen Unterscheidungen wurde nicht Rücksicht genommen. Zumal es auch Altbauten gibt, die „frei vermietbar“ sind, weil sie nach dem Zweiten Weltkrieg gefördert wiederaufgebaut wurden und dieses Förderdarlehen nach den Rückzahlungsbegünstigungsgesetzen 1971 oder 1987 getilgt worden war. Auch könnten in den Datensatz der Altbauwohnungen einige Dachgeschoßausbauten von Gründerzeithäusern in die Baujahre vor 1945 
gelangt sein. Diesbezügliche Fehler im Datenmaterial können nicht bereinigt werden. Zusätzlich wurden folgende Variablen aus den Daten generiert:

Tabelle 16: Variable und Ausprägungen des generierter Variablen

\begin{tabular}{|l|l|}
\hline Variable & Ausprägung, Beispiele \\
\hline MRG & $\begin{array}{l}\text { Altbau (1) oder Neubau (2) im mietrechtlichen Sinne, wobei Dachge- } \\
\text { schoße und Wohnungen mit Nutzfläche }>130 \mathrm{~m}^{2} \text { zu den frei vermiet- } \\
\text { baren Objekten gezählt wurden }\end{array}$ \\
\hline miete_m & Miete pro Quadratmeter Wohnnutzfläche \\
\hline LZ & Lagezuschlagszone nach MA 25 Stadt Wien \\
\hline LZ_EURO & Höhe des Lagezuschlags nach MA 25 Stadt Wien \\
\hline miete_netto_m & Nettomiete nach Abzug der Betriebskosten (BK), s.u. \\
\hline ln_miete_m & Logarithmus der um BK bereinigten Nettomiete \\
\hline balc_terr_logg & $\begin{array}{l}\text { Dichotome Ausprägung, ob Terrasse, Balkon oder Loggia vorhanden } \\
\text { ist (0/1) }\end{array}$ \\
\hline dist_CBD & Errechnete Distanz zum CBD (Stephansplatz) in Kilometer \\
\hline floor & Stockwerk bereinigt \\
\hline cond_1_5 & Zustand der Wohnung nach Schulnoten recodiert (1-5) \\
\hline LZ & Lagezuschlagszone (1-7) lt. Empfehlung MA 25 \\
\hline GZV & Dichotome Ausprägung, ob es ZSP ein Gründerzeitviertel ist \\
\hline LZ_EURO & Absolute Höhe des LZ/m² \\
\hline miete_ohneZ & $\begin{array}{l}\text { Altbauten unter Bereinigung der Zuschlags- und Abschlagsmöglichkei- } \\
\text { ten nach Kriterienkatalog der Zentralen Schlichtungsstelle (s.u.) }\end{array}$ \\
\hline grenz_area & GZV, das an Zuschlagszone angrenzt oder umgekehrt (0/1) \\
\hline
\end{tabular}

Der Datensatz wurde von Ausreißern bereinigt. Zu geringe, aber auch zu hohe Nettomieten wurden entfernt (bei bis zu 45 Euro Miete pro Quadratmeter handelt es sich teilweise ganz offensichtlich um Fehleingaben). Derartige Tippfehler mussten bereinigt werden. Eine 147 Quadratmeter große Wohnung nahe der U4 im 6. Bezirk kann unmöglich nur 210 Euro Nettomiete kosten, außer es handelt sich etwa nur um ein Zimmer in einer entsprechend großen Wohngemeinschaft. Ausgeschieden wurden auch ,astronomische“ Mietangebote jenseits einer Nettomiete von 4.900 Euro pro Monat, sowie jene unter 50,00 Euro pro Monat. Die höchste Miete verzeichnete etwa eine 600 Quadratmeter Wohnung für 17.000 Euro Nettomiete pro Monat.

Das komplexeste Datenproblem verschafft die Geocodierung der Adressangaben. Diese erfolgte mithilfe eins Python-Tools über Google-Maps. Die Ad- 
ressangaben der Maklerangebote wurde online über Google in eine Koordinate umgewandelt. Was bei unvollständigen Eingaben passiert, ist in Tabelle 17 und Abbildung 23 ersichtlich: Einzelne geographische Punkte sind mit Angeboten künstlich überladen. Die Koordinate 48,15646 lat (Nord), 16,34786 lon (Ost) ${ }^{66}$ weist 667 Maklerangebote auf. Abgesehen davon, dass nicht an einer Adresse derartig viele Mietobjekte verfügbar sein können, ist der Bias offensichtlich. Wo Google keine Adresse zuordnen konnte, erfolgte die Geocodierung am Bezirksmittelpunkt, in diesem Fall dem des 8. Bezirks.

Bezirksmittelpunkte sind sämtliche Konglomerate, auf denen es mehr als 68 Mietangebote gibt. Die Zahl dieser Konglomerate ist ab dieser Grenze so hoch wie die Anzahl an Bezirken, die es in Wien gibt, nämlich 23. Abbildung 23 zeigt, wo sich diese Bezirksmittelpunkte und künstlichen Anhäufungen befinden. Sie müssen aus dem Datensatz ausgeschieden werden.

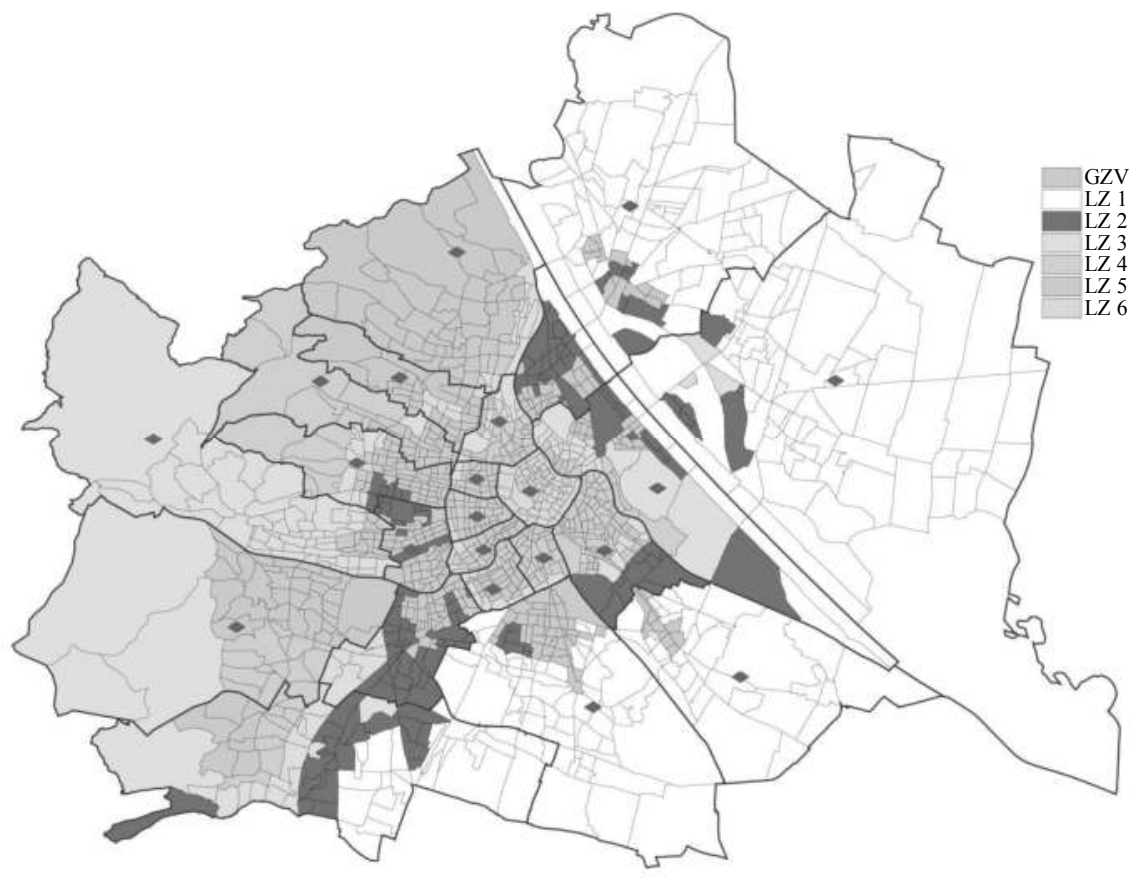

Abbildung 23: Statistische Datenkonglomerate in den Bezirksmittelpunkten. Ein Bias.

66 Google verwendet Grade und Dezimalminuten, eine Umrechnung auf Minuten und Sekunden ist nicht nötig. 
Nun verbleiben noch weitere geocodierte Konglomerate, die vermutlich ebenfalls Redundanzen aufweisen. Diese Konglomerate, an denen sich weniger als 68 Mietangebote verortet finden, sind Mittelpunkte von Straßen, bei denen es offenbar keine Hausnummernangaben gab, weshalb Google die nächstbeste Koordinate generierte. Dieser Daten-Bias bleibt in der Arbeit unberücksichtigt.

Tabelle 17: Dubletten an den einzelnen Bezirksmittelpunkten (Bez. 1 bis 23).

\begin{tabular}{|c|c|c|c|}
\hline PLZ & lon & lat & Dubletten \\
\hline 1010 & 16,36776 & 48,20835 & 2131 \\
\hline 1020 & 16,41505 & 48,20910 & 851 \\
\hline 1030 & 16,39536 & 48,19411 & 1809 \\
\hline 1040 & 16,37269 & 48,19232 & 1311 \\
\hline 1050 & 16,35388 & 48,18486 & 1012 \\
\hline 1060 & 16,35045 & 48,19429 & 654 \\
\hline 1070 & 16,34798 & 48,20230 & 836 \\
\hline 1080 & 16,34786 & 48,21126 & 667 \\
\hline 1090 & 16,35620 & 48,22536 & 1385 \\
\hline 1100 & 16,39107 & 48,15646 & 655 \\
\hline 1110 & 16,44580 & 48,16376 & 127 \\
\hline 1120 & 16,32099 & 48,17179 & 528 \\
\hline 1130 & 16,25863 & 48,17574 & 998 \\
\hline 1140 & 16,22771 & 48,22104 & 547 \\
\hline 1150 & 16,32351 & 48,19438 & 510 \\
\hline 1160 & 16,30338 & 48,21518 & 380 \\
\hline 1170 & 16,28986 & 48,23502 & 563 \\
\hline 1180 & 16,31916 & 48,23586 & 1456 \\
\hline 1190 & 16,34052 & 48,26597 & 2143 \\
\hline 1200 & 16,37310 & 48,23567 & 350 \\
\hline 1210 & 16,40480 & 48,27703 & 315 \\
\hline 1220 & 16,48106 & 48,23518 & 264 \\
\hline 1230 & 16,29115 & 48,14552 & 274 \\
\hline
\end{tabular}

Abgesehen von der teilweise fehlerhaften Geocodierung fehlen einzelne essenzielle Variablen. In 1.438 Fällen fehlt die Angabe der Nutzfläche, diese Datensätze sind für das Forschungsprojekt unbrauchbar und werden ausgeschieden. 
String-Variablen, die eine numerische Skalierung zulassen, wurden in eine solche umgewandelt, beispielsweise der Zustand (Condition): die fünf verbalen Einteilungsklassen wurden in ordinalskalierte Schulnoten eingeteilt. Damit wurde der Erhaltungszustand operationalisiert. Ebenso wurden Stockwerksangaben umgewandelt $(\mathrm{EG}=$ Stockwerk $0, \mathrm{HP}=$ Stockwerk $1, \mathrm{DG}=$ Stockwerk 8, alle Stockwerke über 15 wurden als 15 berichtigt).

Problematisch ist die unvollständige Angabe der einzelnen Mietkomponenten. Viele Datensätze haben keine Betriebskosten ausgewiesen, bei anderen Datensätzen gibt es gravierende Eingabefehler, offensichtlich sind die Kommastellen teilweise nach rechts verrutscht. Hausbetriebskosten sind laufende Ausgaben für Wasser, Kanal, Müllentsorgung, Hausversicherung, Hausverwaltung, Reinigung, Winterdienst, Schädlingsbekämpfung, etc. Bereinigt um die offensichtlichsten Mängel haben die Wohnungen im Schnitt Betriebskosten in Höhe von 1,82 Euro pro Quadratmeter. Das deckt sich mit vielen Studien und Erhebungen, bei denen durchschnittlich von Betriebskosten in Höhe von $1,80 \mathrm{Euro} / \mathrm{m}^{2}$ ausgegangen wird. Der Mikrozensus 2009 der Statistik Austria weist für Wiener Wohnungen inkl. 10\% USt 1,94 Euro pro Quadratmeter aus (Statistik Austria 2010, 87). Bei jenen mangelhaften Angeboten wird die fälschlicherweise als Bruttomiete (nicht im steuerlichen Sinn) ausgewiesene „Nettomiete“ um die inkludierten Betriebskosten von 1,80 Euro reduziert.

Für die mietrechtlichen Untersuchungen ist von Relevanz, welchen inhärenten Lagezuschlag eine Wohnung in einer bestimmten Lage hätte, wie hoch also unter Kontrolle der übrigen Ausstattungsmerkmale die Lage eingepreist ist. Dazu müssen Ausstattungsmerkmale bereinigt werden, die zu einem Zuschlag berechtigen, weil sie über das Normmaß hinausgehen. Die Bereinigung erfolgt auf Kriterienbasis des Zuschlagskatalogs der MA 25 (vgl. Kap. 3.4.1). Die relativen Zuschläge, z.B. ,+ $10 \%$ “ beziehen sich auf den Kategorie-A-Mietzins von derzeit 4,91 Euro. Ein Zuschlag von 10 Prozent entspricht also einer erhöhten Mietzinsberechtigung von 49 Cent pro Quadratmeter. Völlig unberücksichtigt muss leider mangels Angaben die Befristungsstruktur der Angebotsdaten bleiben. Befristete Mietverhältnisse erfordern bekanntlich einen Abschlag von 25 Prozent.

Tabelle 18: Bereinigung der Altbaumieten um zu- und abschlagsfähige Ausstattungsmerkmale

\begin{tabular}{|c|c|}
\hline Variable & Ausprägung, Beispiele \\
\hline cond & Erhaltungszustand der Wohnung \\
\hline floor & $\begin{array}{lr}\text { Stockwerk, in dem sich die Wohnung befindet } \\
\text { Erdgeschoß pauschal Abschlag } & -10 \% \\
\text { Geschoßzuschlag mit Lift: } & (\text { Geschoß-1)* }+4 \% \\
\text { Geschoßabschlag ohne Lift: } & (\text { Geschoß-1)* }-2,5 \%\end{array}$ \\
\hline
\end{tabular}




\begin{tabular}{|c|c|}
\hline heiz_cost & Heizkosten pro Monat \\
\hline heiz_type & Art der Heizung (,Gasetagen“, „Zentral“) \\
\hline betr_cost & Betriebskosten (nur teilw. erhoben) \\
\hline area_low & $\begin{array}{l}\text { Mini-Wohnung (keine Kategorie-A, aber Zuschlagsfähig- } \\
\text { keit von } 10 \% \text { ) } \\
\end{array}$ \\
\hline kell & Wenn kein Kellerabteil $^{67} \quad-5 \%$ \\
\hline lift & Lift vorhanden true/false (bei Stockwerk berücksichtigt) \\
\hline year_veraend & $\begin{array}{l}\text { Der Richtwert ist gestiegen. Entsprechend müsste er bei } \\
\text { älteren Inseraten geringer sein (etwa 4,73 statt 4,91 Eu- } \\
\text { ro/m²). Diese Geringfügigkeit wird nicht beglichen, inzwi- } \\
\text { schen wurde die Miete der } 2007 \text { vermieteten Wohnung } \\
\text { bereits indexiert. Auch bei den Neubauten bleibt das Jahr } \\
\text { der Insertion unberücksichtigt. }\end{array}$ \\
\hline $\begin{array}{l}\text { no_balc } \\
\text { no_terr } \\
\text { no_loggia }\end{array}$ & Balkon/Terrasse/Loggia vorhanden einmalig \\
\hline no_bath & if no_bath $>1 ;+7,5 \%$ \\
\hline no_wc & if no_wc $>1 ;+5,0 \%$ \\
\hline
\end{tabular}

Viele Zuschlags- und Abschlagsmöglichkeiten aus dem Katalog der Schlichtungsstelle können nicht einberechnet werden. Über die Ausrichtung der Wohnungen oder eine allfällige Lärm- und Geruchsbelästigung, über einen Grünblick oder die zusätzliche Nutzbarkeit von Allgemeinteilen (Dachboden, Gärten etc.) ist in den Angeboten nichts codiert. Zudem mag es sich bei den entsprechenden $\mathrm{Zu}$ - und Abschlägen zum Teil um subjektive Bewertungen handeln (etwa „schlechte Grundrisslösung“, die zu 10 Prozent Mietminderung führt: sind viel kleine Zimmer ein Vor- oder Nachteil?

\subsubsection{Operationalisierung der Grundbuchsdaten}

Mit Daten aus dem Wiener Grundbuch soll festgestellt werden, inwiefern bestimmte Wohngebiete einen höheren Anteil an Wohnungseigentumsbegründungen aufweisen. Die Hypothese dahinter postuliert, dass ein lokal angespannter Mietmarkt zu einem Abverkauf von Einzelwohnungen führt. Das Jahr der Parifizierung ist ein wesentliches Datenmerkmal, um festzustellen, ob sich die

67 Da die Mehrzahl der Inserate hier Eingabefehler aufweisen und nur für eine geringe Anzahl der Wohnungen Kellerabteile ausgewiesen werden, bleibt dieser Abschlag unberücksichtigt. 
Mietregulierung im Abverkaufsverhalten der Hauseigentümer manifestiert. Dieses Parifizierungsjahr findet sich ausschließlich im B-Blatt (Eigentumsblatt) des jeweiligen Grundbuchs. Für diese Arbeit stellte das Bundesministerium für Justiz (BMJ) Grundbuchsauszüge zur Verfügung. Ein Grundbuchsauszug, wie unten dargestellt, ist als *.txt Datei gespeichert. Diese unstrukturierten Daten müssen zuerst mittels eines Parsings in eine Datenbank übertragen werden.

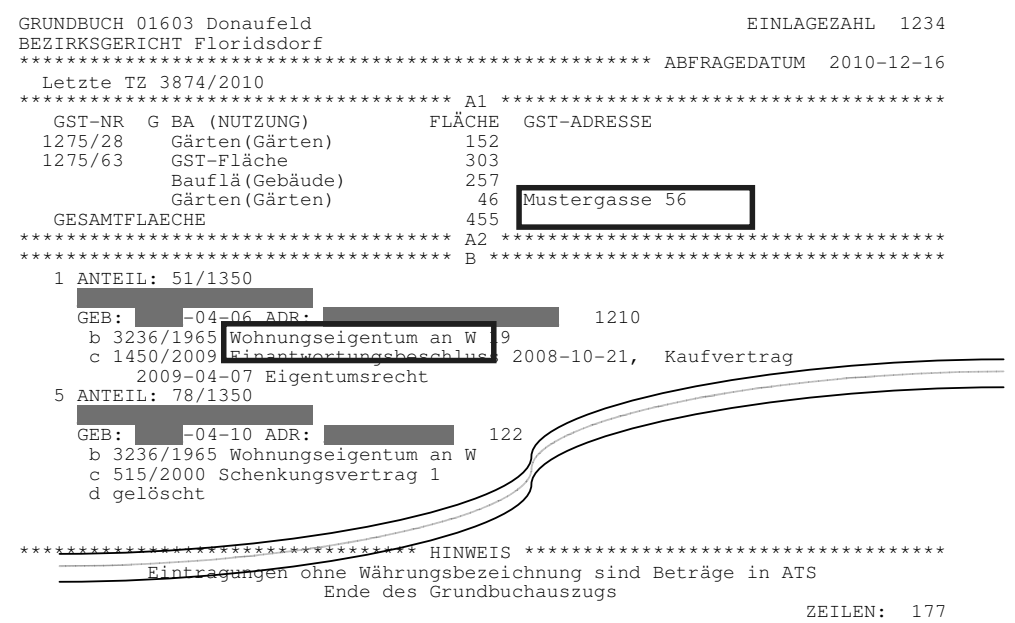

Abbildung 24: Grundbuchsauszug einer Wohnungseigentümergemeinschaft

Wesentlich sind vor allem das Jahr der Wohnungseigentumsbegründung sofern das Gebäude parifiziert ist - sowie die Adresse, mit der eine Geocodierung möglich ist.

Für das Parsing wurde ein einfaches Perl-Script programmiert. Die Adresse und das Jahr der WE-Begründung wurde folgendermaßen aus den Grundbuchsdaten destilliert:

Die Adresse steht im A1-Blatt, an der Position ab dem 43. Zeichen von links:

$$
\$ t 4=\operatorname{substr}(\$+43) ;
$$

Weiter unten wird die Ausgabe des Adressfelds definiert:

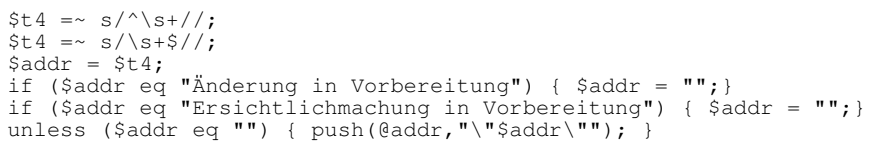


Das Jahr der WE-Begründung kommt im B-Blatt (Eigentumsblatt) des GBAuszugs vor, und zwar als Tagebuchzahl neben dem Wort „Wohnungseigentum an. .."

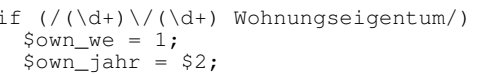

Das Ausgabeformat ist eine CSV-Datei, die in Excel lesbar ist und in SPSS weiterzuverarbeiten ist. Die Adressen werden wieder mit dem Python-Tool geocodiert und über die Geosoftware ArcGis Zählsprengeln zugeordnet. Aufgrund der Daten der Statistik Austria weiß man, wie viele Gebäude (neue und alte Wohnbauten sowie gewerbliche Häuser) es in jedem Zählsprengel gibt. Die Zahl der Parifizierungen, also jener Altbau-Objekte, die im GB Wohnungseigentum ausweisen, ergibt sich aus der über die Zahl der meist parifizierten neuen Wohnhäuser hinausgehenden Zahl der Parifikate.

Von den 124.178 Grundbuchsauszügen enthielten 22.137 keine Adressangaben. Weitere ca. 6.000 Adressangaben waren unbrauchbar, weil sie entweder Parzellen von Kleingärten waren (4.212 KLGs), oder etwa „A23 Südosttangente“ oder „Pfalzgasse KG 01652“ als Adresse enthielten. Die restlichen 95.708 Adressen wurden mit dem Python-Tool geocodiert. Dies gelang Google-Maps immerhin bei 95.680 Häusern.

\subsection{Erwartete Probleme bei der Datenerhebung}

Empirisch ergeben sich Schwierigkeiten durch die geographisch feine Ausgestaltung des Lagezuschlags. Es gibt in Wien 1402 Zählsprengel, in jedem können etwa zwischen 50 und 3.000 Menschen leben. Die Zuordnung zu diesen Zählsprengeln macht bei der Geocodierung des Adressbestands Probleme. Rund ein Drittel der Mietangebote enthält keine exakten Adressen, womit die genaue Sprengelzuordnung unmöglich ist. Wo lediglich der Straßenname angegeben wurde, hat das Python-Codierungstool oft den Straßenmittelpunkt codiert, der möglicherweise sogar in einem anderen Sprengel liegt. Das kann Verzerrungen bei der Zuordnung von Zuschlagszonen verursachen. Eine große Zahl an Mietangeboten bleibt somit unberücksichtigt, und auch jene Angebote, die kein Baujahr für die Wohnung nennen, lassen sich nicht in einen Anwendungsgrad des Mietrechts einteilen und werden damit für die meisten Auswertungen unbrauchbar.

Im Mittelpunkt der Betrachtung stehen die Lage der jeweiligen Wohnung und deren Preis. Dazu muss der ebenfalls preisbeeinflussende Zustand der Wohnung ,neutralisiert“ werden. Die Kontrolle des Ausstattungsmerkmals ist mit den für Wien verfügbaren Wohnungsdaten nicht einfach. Rückschlüsse auf den 
Ausstattungszustand sind nur mit der Variablen „Condition“ möglich, die für die meisten angebotenen Objekte das Attribut ,sehr gut" nennt, worin jedoch feinere Abstufungen enthalten sein dürften.

Langfristig kann jede Beobachtung wiederum eine Rückkopplung auf andere Variablen verursachen, entsprechend der Polarisationstheorie nach Myrdal. Wird der Marktdruck bei fehlender Lagezuschlagsmöglichkeit durch steigende Immobilienpreise erhöht, müsste das wiederum zu mehr Abverkauf, weniger Mietangebot und überproportionaler Mietnachfrage in einer bestimmten Gegend führen.

Für die Variablenkontrolle werden Querschnittsdaten (cross-sectional samples) benutzt, vornehmlich sollten das jene sein, die bereits vor der Intervention die Unterschiede der Gruppen definieren (Rossi, Freeman 1993, S. 327ff). Es muss angenommen werden, dass es zu einem "Selection Bias" kommt, einer Auswahlverzerrung, die den kausalen Zusammenhang zwischen Interventionsvariable und Ergebnis eintrübt (Rossi, Freeman 1993, S. 329). Das Auswahlkriterium von Gründerzeitvierteln setzt ja das Vorhandensein von Wohnungen schlechter Ausstattung zum Zeitpunkt ihrer Errichtung vor etwa 100 Jahren (Substandardwohnungen) voraus. Womöglich wurden noch nicht alle dieser Wohnungen auf einen modernen Standard gebracht, was wiederum die Miethöhe beeinflusst.

Zudem stammen die Daten von Immobilienmaklern, die gerade im Mietbereich nicht den gesamten Markt abdecken. Viele Wohnungen werden ,privat“ vermietet, deren Angebote gehen an einer automatisierten Erhebung vorbei. Auch konzentrieren sich viele dieser Makler-Angebote auf „bessere“ Gegenden, wodurch die Zuschlagszonen 5 bis 7 überrepräsentiert sind. Eine Aussage über die „Wiener Durchschnittsmiete“ auf Basis dieses Samples würde zu einer Überschätzung der tatsächlichen Miethöhe führen. Gerade günstige Mietobjekte bedürfen keiner Marketingmaßnahme durch einen Makler und finden sich nicht im Sample.

Es handelt sich außerdem um Querschnittsdaten, zumindest werden sie als solche verwendet und damit wird die Entwicklung der vergangenen vier Jahre ausgeblendet. Die Mieten sind indes weiter gestiegen, lediglich nach Ausbruch der Finanzkrise zeigen sie im teuren Neubausegment einen kleinen Einbruch. All dies wird bei den folgenden Auswertungen nicht berücksichtigt, was eine Verzerrung begründen kann. 


\subsection{Deskriptive Auswertung des Datenmaterials}

Auf den folgenden Seiten wird das Datenmaterial rein deskriptiv beschrieben, mit wenigen statistischen Tests. Diese folgen erst im Abschnitt „Hypothesenprüfung“. Entsprechend dürfen auf Basis der Diagramme keine vorschnellen Schlüsse gezogen werden.

\subsubsection{Datenbasis Maklerangebote}

Die vorliegenden Maklerdaten wurden seit dem Jahr 2004 aufgezeichnet. Offensichtlich gab es Jahr 2006 und 2007 bedeutend weniger Dateneingaben. Die verwendbare Datenbasis aus diesen Jahren ist nicht zuletzt deshalb geringer, weil die Adressangaben und damit die Geocodierung mangelhaft waren.

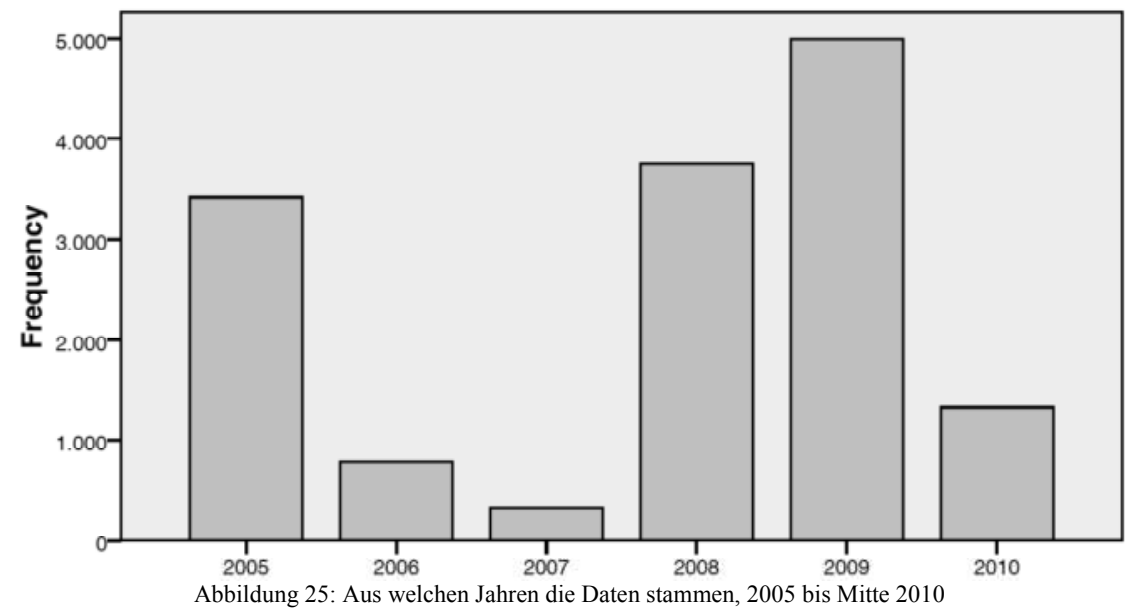

\subsubsection{Geographische Streuung}

Die Maklerangebote verteilen sich über das gesamte Wiener Stadtgebiet. Einige Bezirke sind stärker vertreten, manche Bezirke sind unterrepräsentiert. So liegen etwa 10,5 Prozent der angebotenen Wohnungen ${ }^{68}$ im 1. Bezirk, dessen Wohnungsbestand einen Anteil am Gesamtbestand der Stadt Wien von 1,26 Prozent hat, während der 11. Bezirk, der immerhin 4,5 Prozent des Wiener Wohnungs-

68 Für diese Aufstellung, Abbildung 26, wurden alle Mietangebote mit einbezogen, auch wenn die Zählsprengelzuordnung aufgrund einer fehlerhaften Geocodierung nicht möglich war. 
bestands zählt, nur 0,6 Prozent der Stichprobe ausmacht. Vergleiche dazu Abbildung 26: „Bessere“ Bezirke, vor allem die Innenstadtlagen sowie der 13., 18. und 19. Bezirk kommen in der „Stichprobe“ anteilig häufiger vor als auf dem Wohnungsbestandsmarkt. Dieser umfasst Eigentums- und Mietwohnungen nach der Gebäudezählung Statistik Austria 2001, sowie den beachtlichen Anteil der Wiener Gemeindewohnungen.

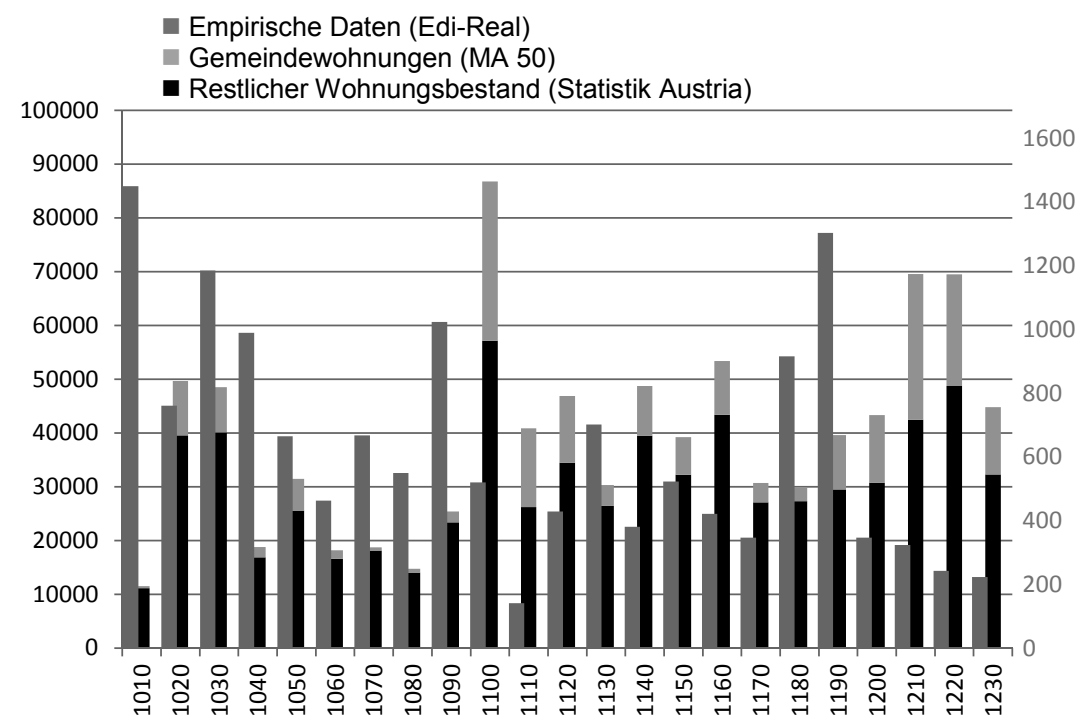

Abbildung 26: Datenmaterial nach Bezirken und Verhältnis zum Wohnungsbestand

Für diese Arbeit von Relevanz ist allerdings die geographische Aufteilung nach Lagezuschlagszonen. Zu diesem Zweck soll noch einmal die Lagezuschlagszone von Wien gezeigt werden. 


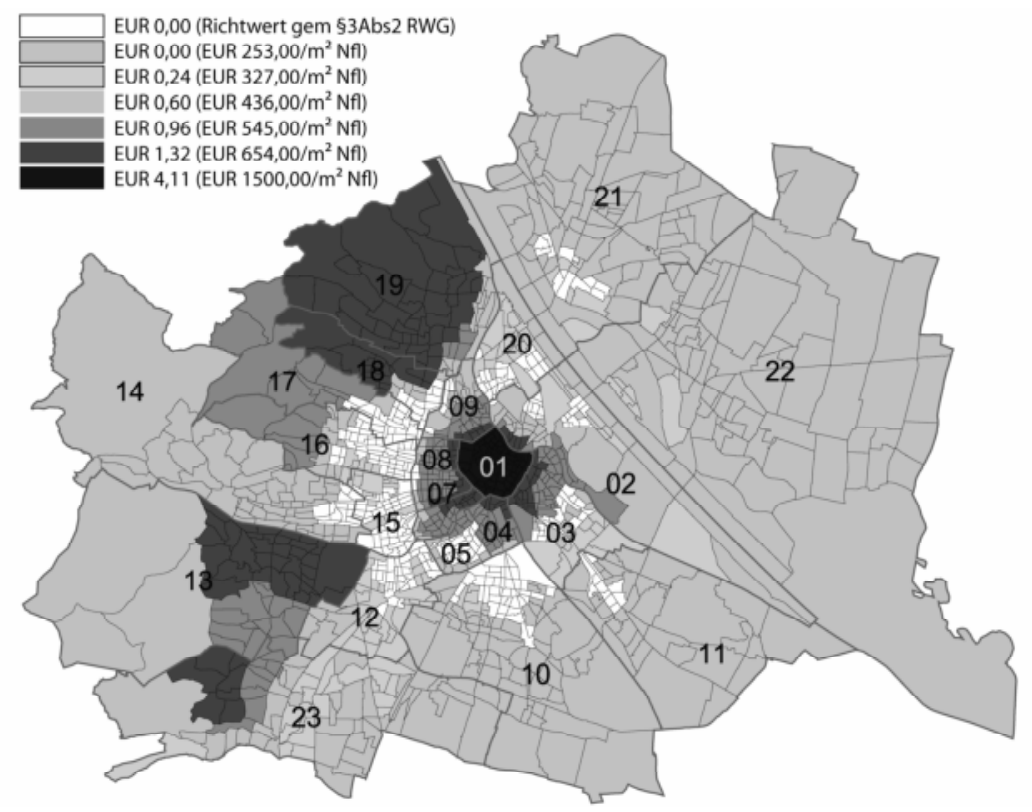

Abbildung 10: Lagezuschlagszonen von LZ 1 (GZ-Viertel, weiß) bis LZ 7 (Innenstadt, dunkel schraffiert)

Von allen Mietangeboten befindet sich ein relativ großer Prozentsatz, immerhin 23,3 Prozent, in Gründerzeitvierteln. Relativ wenige angebotene Wohnungen befinden sich in der Lagezuschlagszone 2 und 3. Zone 2 kommt nach Berechnungen der MA 69 auf einen durchschnittlichen Grundkostenanteil von weniger als 253 Euro pro Quadratmeter und berechtigt daher nicht zu einem Lagezuschlag. Zone 3 befindet sich in mittelmäßigen Vorstadtvierteln, oder zumindest überall, wo eine relativ gute öffentliche Verkehrsanbindung vorhanden ist (U-Bahn in Geh- oder kurzer Straßenbahndistanz entfernt).

Eine hohe Zahl an Angeboten stammt aus guten Innenstadtlagen oder traditionell beliebten Wohnvierteln nord- und südwestlich von der Innenstadt. Diese befinden sich in Zone 5 und 6. Die Wiener City umfasst deckungsgleich die Zone 7, die Innenstadtlage, mit einem durchschnittlichen Grundkostenanteil von 1500 Euro pro Quadratmeter und mehr. Wie Abbildung 27 zeigt, ist das Angebot in den Zuschlagszonen 5 bis 7 gegenüber dem Wohnungsbestand (nach Gebäudezählung Statistik Austria 2001, grau dargestellt) relativ hoch. Gerade der Erste Bezirk hat einen besonders hohen Umschlagsprozentsatz: Die Zahl der Mietangebote in den Jahren 2005 bis 2010 entspricht 12,78 Prozent des Woh- 
nungsbestands des Bezirks. Im Wiener Durchschnitt wurden in diesem Zeitraum nur 2,04 Prozent der Wohnungen inseriert. ${ }^{69}$

Der überproportionale Anteil der Toplage kann daran liegen, dass 1) auf der Maklerplattform überproportional teure und hochwertige Mietwohnungen landen, und dass 2) das Vermietungsgeschäft aufgrund des hohen Lagezuschlags und der guten Bonität des Mietklientels mehr Rechtssicherheit und damit Attraktivität bietet als außerhalb der Bestlage. Manche Hausherren dürften auch ein Gutachten über die Höhe ihres Grundkostenanteils beauftragt haben, wodurch die Rechtssicherheit eines hohen Lagezuschlags gewährleistet ist. Diese Investition in ein derartiges Gutachten rechnet sich bei hochpreisigen Vermietungsgeschäften freilich eher.

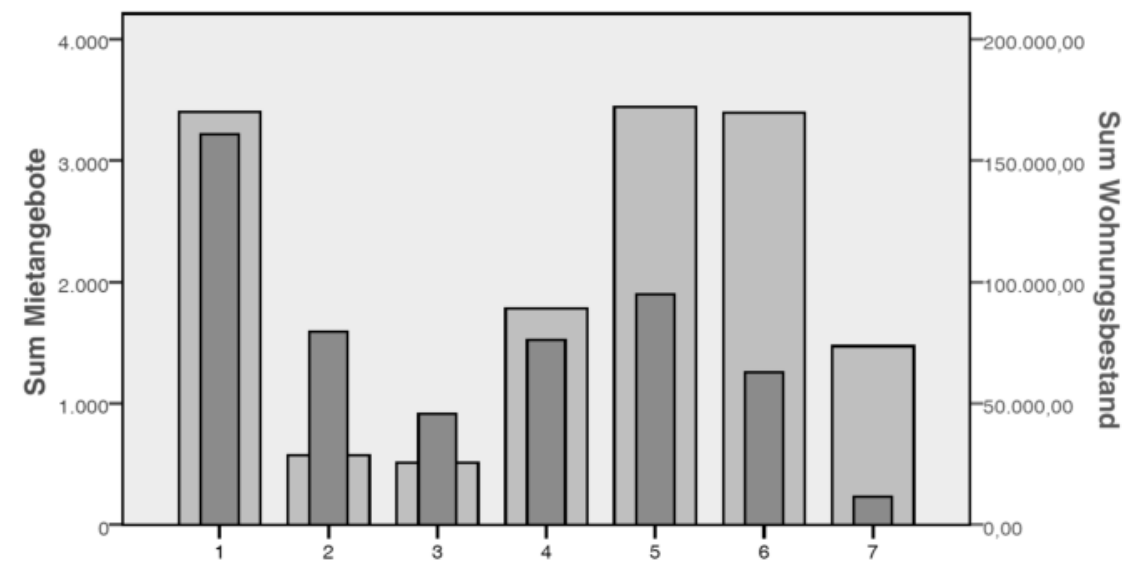

Abbildung 27: Mietangebotsdaten und Wohnungsbestand nach Lagezuschlagszone

In guten Lagen, ab Zuschlagszone 5, ist das Angebot an Altbauwohnungen relativ gering, zeigt ein Blick auf Abbildung 28. Tatsächlich ist das Angebot von mietregulierten Wohnungen gerade in Gründerzeitvierteln verhältnismäßig hoch. Das liegt auch an der Gebäudestruktur. In Gründerzeitvierteln gibt es viele Altbauten, und auch wenn einige über die Jahrzehnte dem Abriss unterzogen worden sind, verbleibt die Mehrzahl der Gebäude in der Kategorie „Althaus“. Im Gegensatz zu vorangegangener Grafik sind hier all jene Angebot ausgegliedert, bei denen die Zuteilung zu Alt- oder Neubau nicht exakt möglich ist.

69 Allerdings fließen sämtlich Angebote, die nicht exakt verortet werden konnten - immerhin mehr als die Hälfte der Wohnungen - nicht in diese Statistik ein, die im Übrigen nach dem Wohnungsbestand im jeweiligen Sprengel gewichtet ist. Der prozentuale Vermietungsanteil pro Sprengel wird damit im Verhältnis zu seiner Größe gesehen. 


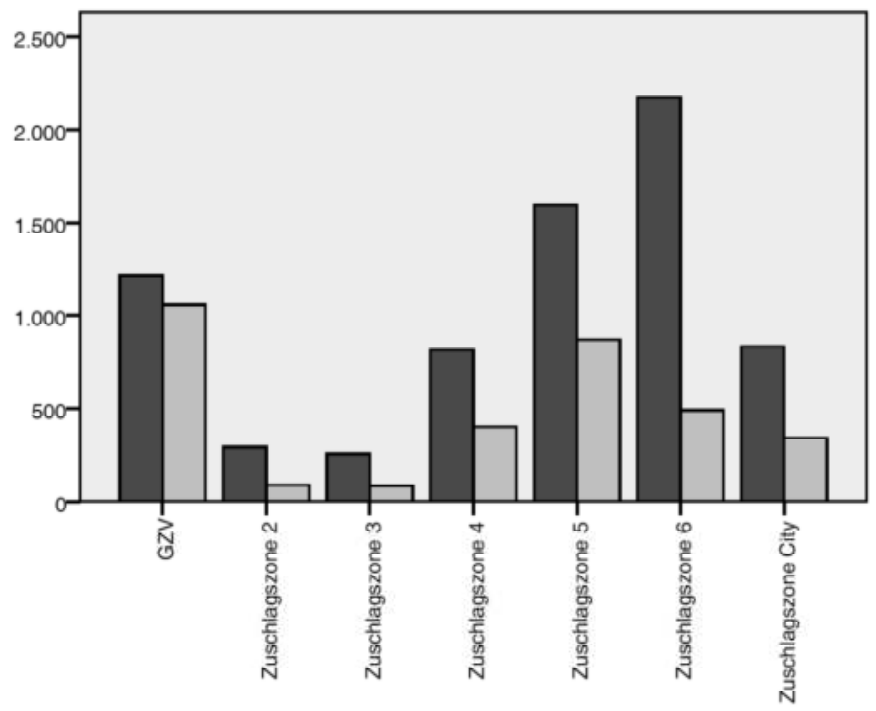

MRG anwendbar (AB_NB)

$\square$ Freie Miete $\square$ Richtwert

Abbildung 28: In Gründerzeitvierteln ist das Altbau-Angebot überproportional hoch

\subsubsection{Anteil mietengeschützter Wohnungen}

Fast die Hälfte der angebotenen Wohnungen befindet sich in Neubauten. Nahezu ein Viertel sind eindeutig Altbauten, bei etwa zwei Fünftel der Angebote lassen die Daten keinen Rückschluss auf das Baujahr und somit auch nicht auf die Anwendbarkeit des Mietrechts zu. 


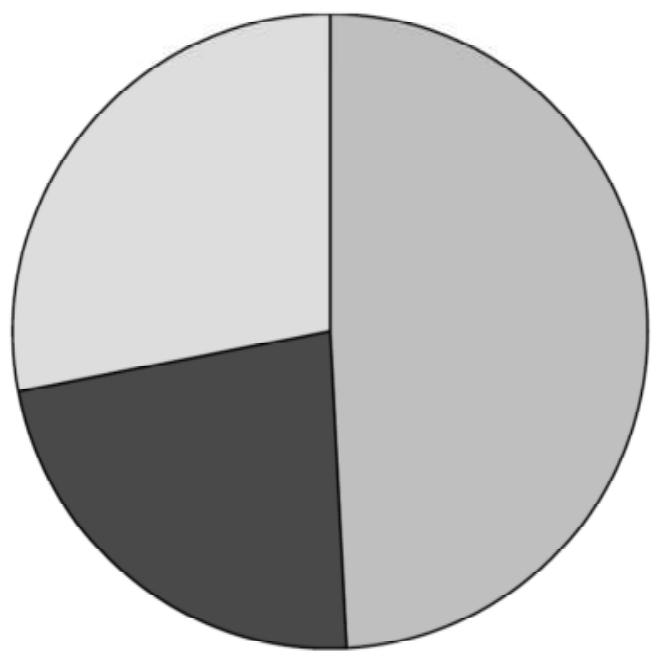

\section{MRG anwendbar} (AB_NB)

$\square$ Freie Miete

Richtwert

Dohne Angabe

Abbildung 29: Anteil Altbauten und Neubauten im Datensatz

\subsubsection{Verteilung der Miethöhe}

Die durchschnittliche Miethöhe für die vorliegenden, heterogenen Mietangebotsdaten liegt bei $8,97 \mathrm{Euro} / \mathrm{m}^{2}$, 68,3 Prozent der Fälle (Standardabweichung $+/-1$ ) liegen zwischen 5,74 und 12,20 Euro/ $\mathrm{m}^{2}$.

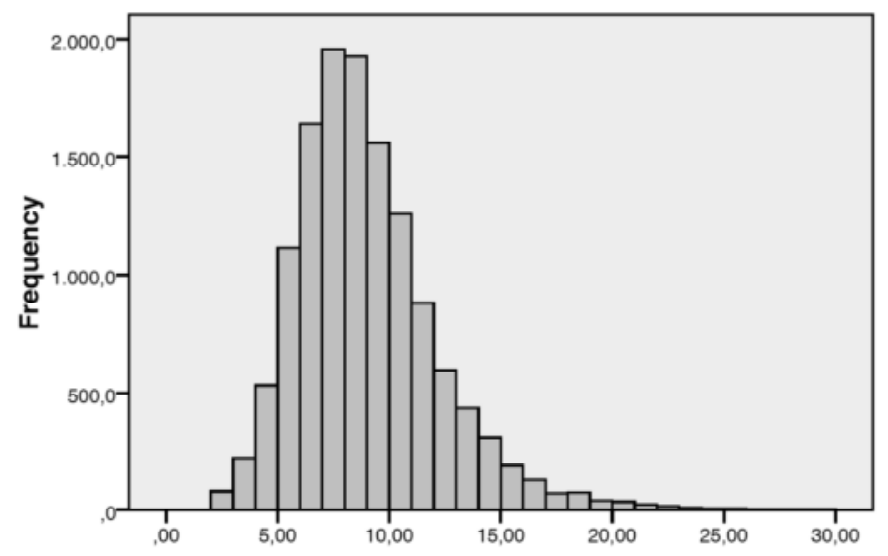

Mean $=8,9735$ Std. Dev. $=3,23236$ $\mathrm{N}=13.120$

Abbildung 30: Verteilung der Miethöhe der Angebotsdaten 


\subsubsection{Wohnungsgrößen, Zimmerzahlen und Ausstattungszustand}

Die Wohnungen des Samples sind überdurchschnittlich groß. Die Durchschnittsgröße liegt bei 90,36 Quadratmetern Wohnnutzfläche, die durchschnittliche Zimmeranzahl beträgt 2,81, vergleiche die folgenden Grafiken.
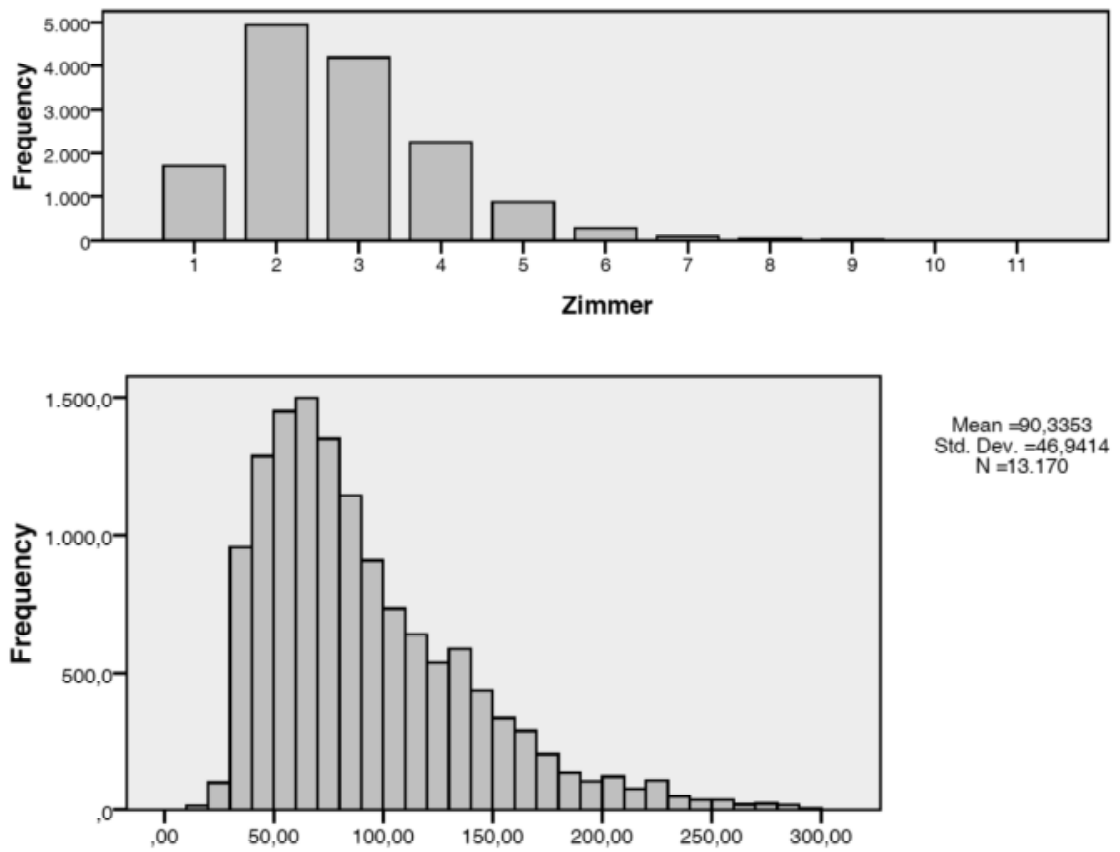

Abbildung 31: Verteilung der Wohnungsgröße und Zimmerzahl. Der Durchschnitt liegt bei 90,36m² bzw. 2,8 Zimmern.

Aus den Daten geht klar hervor, dass über die Maklerplattform überdurchschnittlich schöne, große und geräumige Wohnungen vermietet werden. Das liest sich insbesondere an den Angaben über den Erhaltungszustand der Wohnungen ab. 81,6 Prozent der Wohnungen mit einer Angabe über deren Erhaltungszustand wurden diesbezüglich von den Maklern als „sehr gut“ bewertet (exkl. „missing values“ 72,4 Prozent). Freilich kann man den Maklern unterstellen, dass die Eigenangaben der Geschäftsförderung dienen. Doch die Struktur der Daten lässt ein gehobenes Segment des Mietmarktes nicht abstreiten. 


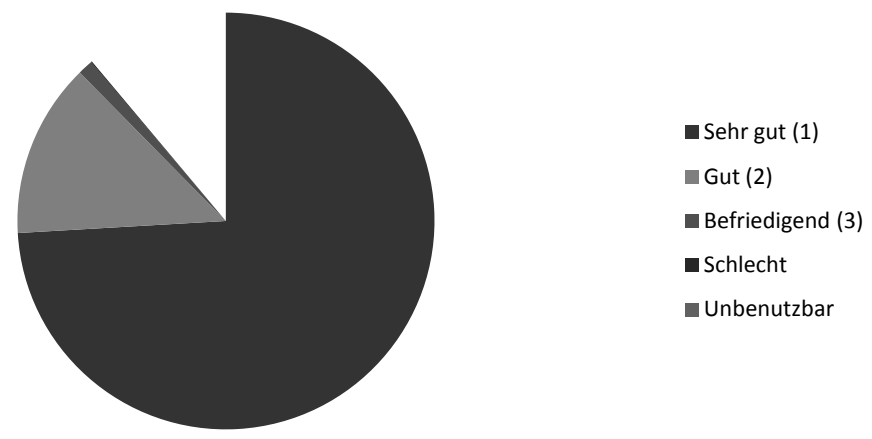

Abbildung 32: Die Wohnungen weisen einen guten Erhaltungszustand auf (weiß: o.A.)

Ein beachtlicher Teil der Wohnungen wird „komplett möbliert“ vermietet. Tatsächlich hat dies einen - wenn auch geringfügigen - Einfluss auf die Miethöhe: Eine möblierte Wohnung kostet im Schnitt 10,97 Euro/m² ${ }^{2}$ eine unmöblierte $10,65 \mathrm{Euro} / \mathrm{m}^{2}$. Der Unterschied ist signifikant.

\subsection{Hypothesenprüfung}

In diesem Abschnitt werden die Daten statistischen Tests unterzogen - Varianzanalysen, lineare Regressionen, Korrelationsanalysen, T-Tests, etc. - und teilweise als Diagramme oder ArgGis-Karten dargestellt. Die einzelnen Unterkapitel nehmen Bezug auf die Hypothesen, die sich in ihren Aussagen zum Teil überschneiden, weshalb in mehreren Kapiteln auf einzelne Hypothesen Bezug genommen wird.

\subsubsection{Miethöhe und Mietregulierung}

Hypothese 1: Die Miethöhe ist im mietengeschützten Segment geringer als im unregulierten Neubausegment.

Für diese Hypothesenprüfung ist die Verteilung der Miethöhe in Unterteilung nach Anwendbarkeit des Mietrechtsgesetzes von Interesse. Altbauten, die vor 1945 gebaut wurden, unterliegen grundsätzlich dem Richtwert. Neubauten hingegen nicht. Die Unterscheidung nach dem Baujahr ist jedoch ungenügend, da auch jene „Altbauwohnungen“ (Baujahr vor 1945), die entweder mehr als 130 Quadratmeter haben (und aufgrund dessen zumindest für den Angemessenen Mietzins qualifizieren), oder sich im ausgebauten Dachgeschoß eines Altbaus 
befinden, keiner Mietbegrenzung unterliegen. Der Angemessene Mietzins, der sich am Mietmarkt der Umgebung orientiert, wurde der freien Miete gleichgestellt, und alle diesbezüglichen Wohnungen zu den Neubauten gezählt.

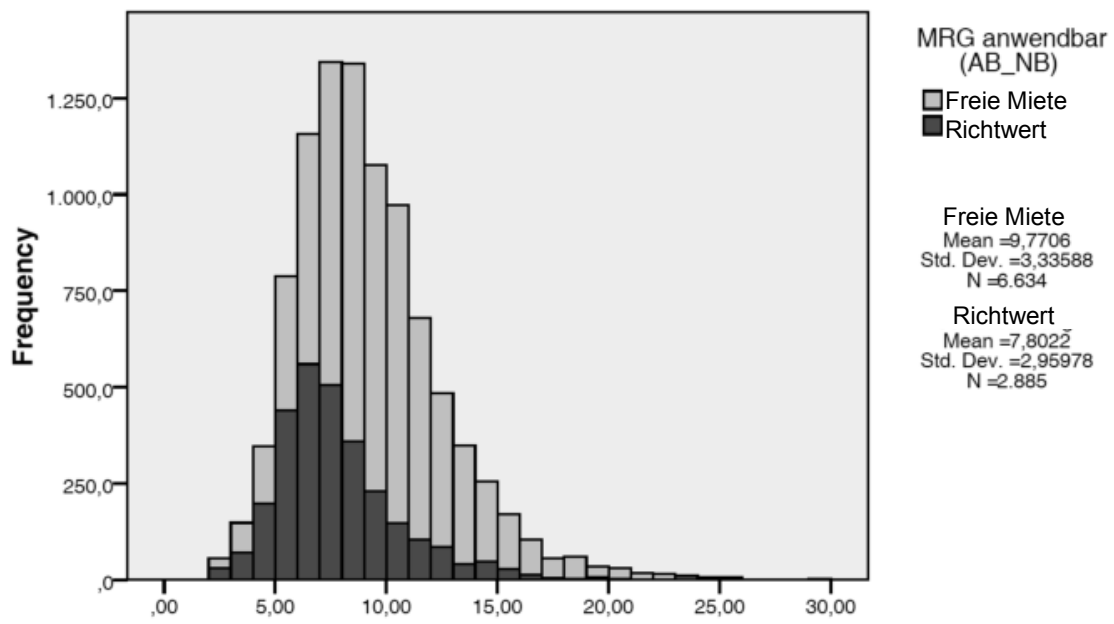

Abbildung 33: Häufigkeit und Verteilung der Miethöhe (x) nach Anwendungsgrad des $M R G(A B / N B)$

Im Durchschnitt liegt die Altbaumiete um 2,17 Euro unter der durchschnittlichen Neubaumiete. Objekte, die keiner Mietregulierung unterliegen, werden im Schnitt für 9,77 Euro/ $\mathrm{m}^{2}$ vermietet, Altbauwohnungen für $7,80 \mathrm{Euro} / \mathrm{m}^{2}$. Der Unterschied ist im Übrigen signifikant $(0,000)$, ergibt eine Varianzanalyse (ANOVA) nach einem Homogenitätstest. Die Mittelwertausprägungen und Standardabweichungen sind in Abbildung 34 zu sehen. 


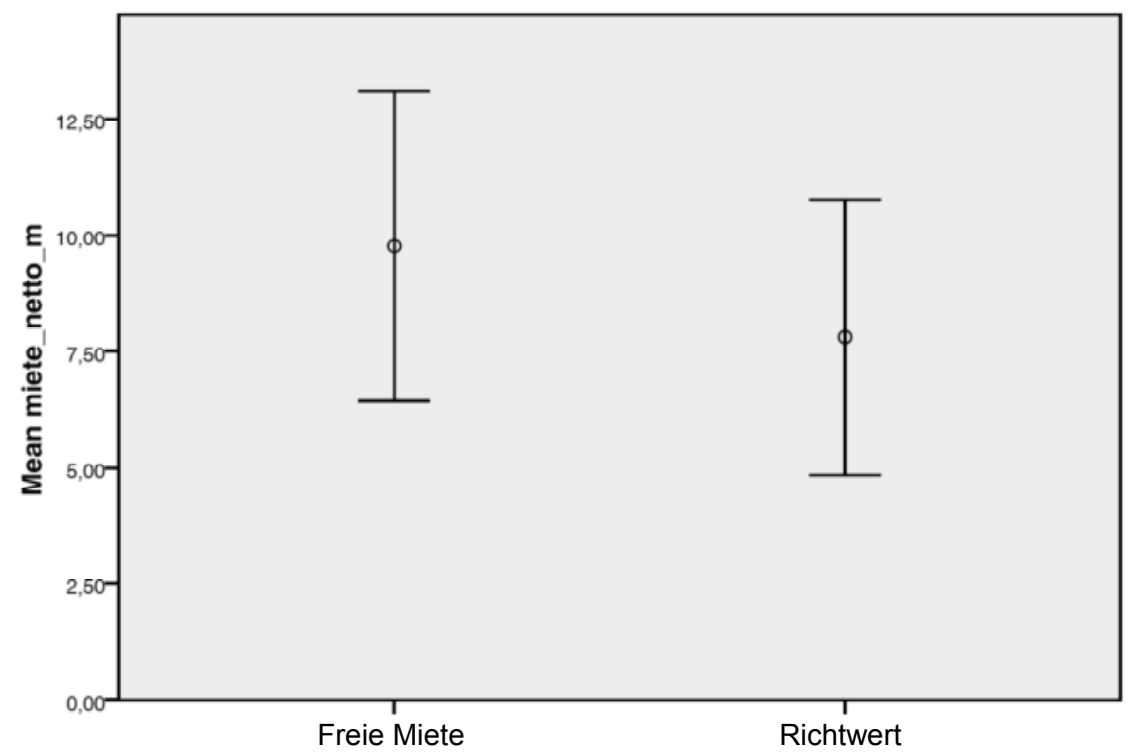

Abbildung 34: Standardabweichung der Durchschnittsmieten $/ m^{2}$ in AB und NB

\subsubsection{Miethöhe und Lage}

Welche Effekte hat die Mietregulierung auf lokale Mietmärkte? Wo wird die Regulierung eingehalten, wo setzt sich der Markt durch? Auf den folgenden Seiten sollen drei Hypothesen zur Lageabhängigkeit der Miethöhe getestet werden:

Hypothese 2: Das Verbot des Lagezuschlags hat einen Einfluss auf die Miethöhe im betroffenen Segment und Gebiet (Gründerzeitviertel).

Hypothese 3: Die Mietregulierung wird in Gebieten, wo es eine Lagezuschlagsmöglichkeit gibt, eher eingehalten als in Gebieten, wo ein Lagezuschlag verboten ist (Gründerzeitviertel).

Hypothese 4: Die schärfsten Abstufungen von höheren zu niedrigeren Lagezuschlagsmöglichkeiten gibt es in ,guten“ Bezirken, in denen Gründerzeitviertel definiert sind. Dort wird die Mietregulierung weniger eingehalten.

Zunächst wird das Mietangebot auf die regionale Aufteilung nach Lagezuschlagszonen betrachtet. Mieten von Neubauwohnungen sind vor allem auch in „schlechteren“ Lagen, in der Lagezuschlagszone 2 und 3, bedeutend höher als Altbaumieten. Relativ hohe Mieten erzielen Neubauwohnungen auch in den an- 
geblich „schlechten“ Gründerzeitvierteln. Dort sind auffallend auch Altbaumieten relativ hoch, noch höher als in höheren Lagezuschlagsklassen, wie Abbildung 35 und die folgenden Abbildungen zeigen.

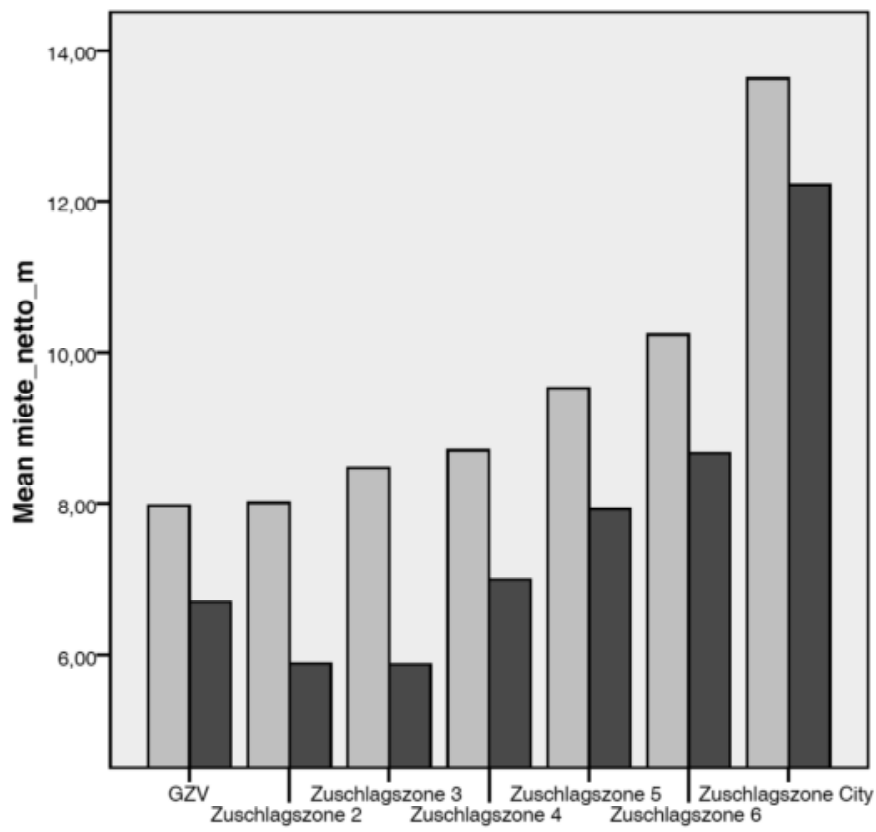

MRG anwendbar (AB_NB)

$\square$ Freie Miete

Richtwert

Abbildung 35: Miethöhe in Altbau und Neubau nach Zuschlagszone 1 bis 7

Um zu testen, ob die Mietregulierung einhalten wird, müssen zunächst sämtliche Zuschlagsmöglichkeiten für die Ausstattung der jeweiligen Wohnung (Balkone, Lift im Haus, etc.) berücksichtigt werden, unter Anwendung der Zuund Abschläge in Tabelle 18. Ein Balkon oder eine Terrasse berechtigt somit zum Zuschlag von 10\% des Richtwert-Mietzinses von 4,91 Euro $=49$ Cent.

\begin{tabular}{|c|c|c|}
\hline Variable & Ausprägung, Beispiele & \\
\hline Cond & $\begin{array}{r}\text { Erhaltungszustand der Wohnung ,sehr gut" } \\
+5 \%\end{array}$ & $\begin{array}{l}\text { If cond ="sehr gut" } \\
\text { zuschlag = zuschlag }+0,25\end{array}$ \\
\hline Floor & $\begin{array}{l}\text { Stockwerk, in dem sich die Wohnung be- } \\
\text { findet: } \\
\text { Erdgeschoß pauschal Abschlag }-10 \% \\
\text { Geschoßzuschlag mit Lift ab 2. OG: } \begin{array}{r}+4 \% \\
\text { Geschoßabschlag o. Lift ab 2. OG: }\end{array}-2,5 \%\end{array}$ & $\begin{array}{l}\text { If floor }=0 \rightarrow-0,49 \\
\text { Else } \\
\text { If lift }=1 \rightarrow(\text { floor }-1) * 0,2 \\
\text { If lift }=0 \rightarrow(\text { floor }-1) *(-0,11)\end{array}$ \\
\hline
\end{tabular}




\begin{tabular}{|c|c|c|}
\hline area_low & $\begin{array}{l}\text { Mini-Wohnung (keine Kategorie-A, aber } \\
\text { Zuschlagsfähigkeit von } 10 \% \text { ) }\end{array}$ & $\begin{array}{l}\text { If area_low }<30 \\
\text { zuschlag }-0,74\end{array}$ \\
\hline Kell & Wenn kein Kellerabteil $^{70}$ & $\begin{array}{l}\text { If keller }=0 \\
\text { zuschlag }-0,25\end{array}$ \\
\hline year_veraend & $\begin{array}{l}\text { Der Richtwert ist gestiegen. Entsprechend } \\
\text { muss er bei älteren Inseraten geringer sein } \\
\left(4,73 \text { bzw. } 4,59 \text { Euro statt } 4,91 \text { Euro } / \mathrm{m}^{2}\right) \text {. }\end{array}$ & $\begin{array}{l}\text { If year_veraend }<2009 \\
\text { Zuschlag }+0,30\end{array}$ \\
\hline $\begin{array}{l}\text { no_balc } \\
\text { no_terr } \\
\text { no_loggia }\end{array}$ & $\begin{array}{l}\text { Balkon/Terrasse/Loggia vorhanden } \\
\text { einmalig }+10 \%\end{array}$ & $+0,49$ \\
\hline no_bath & Zuschlag für 2. Bad if no_bath $>1 ;+7,5 \%$ & if no_bath $>1 ;+0,37$ \\
\hline no_wc & Zuschlag für 2 . WC if no_wc $>1 ;+5,0 \%$ & if $n o \_w c>1 ;+0,25$ \\
\hline
\end{tabular}

Die Zu- und Abschläge für die Ausstattung der angebotenen Wohnungen bewegen sich zwischen -0,94 Euro und 2,43 Euro pro Quadratmeter. Gemessen am Richtwert ist das eine Zuschlagsbandbreite zwischen -19\% (Abschlag) und + 49 \% (Zuschlag). Hinzu kommt der Lagezuschlag, der nach Empfehlungen der MA 25 bis zu 4,11 Euro ausmacht. Die Zuschlagsbandbereite reicht im Sample somit von -0,94 bis +6,54 Euro pro Quadratmeter. In der Realität können $\mathrm{Zu}-$ schläge und Abschläge größer sein, zumal viele zu- und abschlagsfähige Indikatoren (etwa Luftverschmutzung, oder auch Luxus-Ausstattungen) nicht bekannt sind. Es wird geschätzt, dass die Bandbreite nach unten wie oben um weitere 20 Prozent möglich ist.

Wird von der angebotenen Miethöhe pro Quadratmeter die Zuschlagsfähigkeit für Ausstattung und Lage abgezogen, so sollte dies - gesetzt den Fall die Mietregulierung wird eingehalten - im Vollanwendungsbereich (bei Altbauten) $\mathrm{zu}$ gleich hohen Mieten in allen Zuschlagslagen führen. Die Variable miete_ohneZ ist somit die Miete ohne Zuschlagskomponente. Das Mietrechtsgesetz würde vorsehen, dass diese Variable der ,mietrechtlichen Normwohnung“ entspricht und theoretisch für alle Objekte dieselbe Ausprägung haben muss. Das Liniendiagramm in Abbildung 36 zeigt die Häufigkeit der Angebote in der jeweiligen Zone. Die Skalierung beginnt aus Darstellungsgründen bei 4,50 Euro.

70 Da die Mehrzahl der Inserate hier Eingabefehler aufweisen und nur für eine geringe Anzahl der Wohnungen Kellerabteile ausgewiesen werden, bleibt dieser Abschlag unberücksichtigt. 


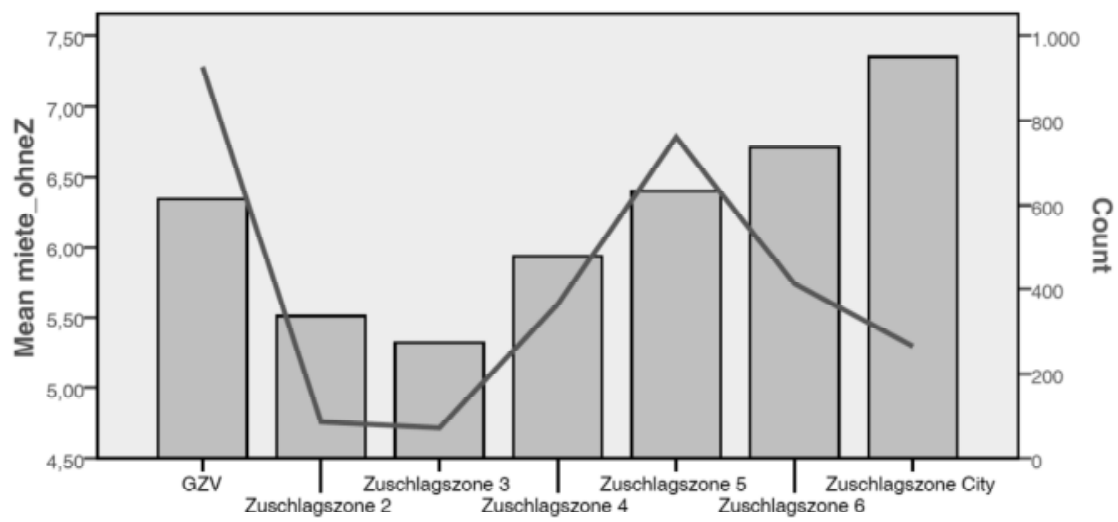

Abbildung 36: Nach Abzug des gesetzlichen Lagezuschlags: keine Einheitsmiete

Bereits die graphische Aufgliederung zeigt: nach Abzug der legalen $\mathrm{Zu}-$ schlagsmöglichkeit ist die Miete dennoch ungleich verteilt. In Gründerzeitvierteln wird eine Miete verlangt, die nach den MA 25 Richtlinien höchstens in der Zuschlagszone 4 oder 5 verlangt werden dürfte. Die Fallzahl (Rechte Beschriftung „Count“) in Zuschlagszone 2 und 3, den wahrhaft weniger guten Lagen, ist auffallend gering.

Die um die Zuschläge bereinigte Miete wurde bei Altbau-Angeboten mittels ANOVA gegen die unabhängige Variable der Lagezuschlagszone getestet; die Unterschiede der bereinigten Miethöhe zwischen den Zuschlagszonen sind signifikant. Tabelle 19 zeigt die Durchschnittswerte in den Lagezuschlagszonen. Die Fallzahl beträgt für diese Darstellung nur 2887, da ausschließlich jene Wohnungen getestet wurden, die eindeutig in den mietengeschützten Bereich fallen. Die Abhängigkeit der (theoretisch) zuschlagsfreien Miethöhe von der einzelnen Lagezuschlagszone ist signifikant, Hypothese 3 kann nicht verworfen werden.

Tabelle 19: Durchschnittsmieten ohne Lagezuschlag von 6,40 Euro/m²

\begin{tabular}{|c|c|c|c|c|c|c|}
\hline \multirow[t]{2}{*}{ miete_ohneZ } & \multirow[b]{2}{*}{$\mathrm{N}$} & \multirow[b]{2}{*}{ Mean } & \multirow{2}{*}{$\begin{array}{c}\text { Std. } \\
\text { Deviation }\end{array}$} & \multirow{2}{*}{$\begin{array}{l}\text { Std. } \\
\text { Error }\end{array}$} & \multicolumn{2}{|c|}{ 95\% Confidence Interval for Mean } \\
\hline & & & & & Lower Bound & Upper Bound \\
\hline GZV & 927 & 6,3444 & 1,83888 & ,06040 & 6,2258 & 6,4629 \\
\hline Zuschlagszone 2 & 86 & 5,5087 & 1,84047 & , 19846 & 5,1141 & 5,9033 \\
\hline Zuschlagszone 3 & 72 & 5,3192 & 1,59571 & ,18806 & 4,9442 & 5,6941 \\
\hline Zuschlagszone 4 & 364 & 5,9354 & 2,12879 & ,11158 & 5,7160 & 6,1548 \\
\hline
\end{tabular}




\begin{tabular}{|c|c|c|c|c|c|c|}
\hline Zuschlagszone 5 & 761 & 6,3999 & 2,52716 & ,09161 & 6,2201 & 6,5798 \\
\hline Zuschlagszone 6 & 412 & 6,7092 & 2,55041 & ,12565 & 6,4623 & 6,9562 \\
\hline City & 265 & 7,3510 & 4,10329 & ,25206 & 6,8547 & 7,8473 \\
\hline Total & 2887 & 6,4015 & 2,47860 &, 04613 & 6,3110 & 6,4919 \\
\hline
\end{tabular}

Es lässt sich feststellen, dass die Mietregulierung in Gründerzeitvierteln (noch) weniger eingehalten wird als in anderen Zuschlagszonen. Die Lage ist auch dort eingepreist, wo sie nicht eingepreist sein dürfte. Es muss an dieser Stelle festgehalten werden, dass auch bessere Lagen nach Abzug des Lagezuschlags, wie er von der MA 25 empfohlen würde, eine hohe Miete von 6,40 Eu$\mathrm{ro} / \mathrm{m}^{2}$ (LZ-Zone 5) aufweisen und im Ersten Bezirk dieser Schnitt sogar auf 7,35 Euro/ $\mathrm{m}^{2}$ ansteigt (obschon zuvor bereits 4,11 Euro/ $\mathrm{m}^{2}$ abgezogen worden waren). Nur 25,3 Prozent der Mietangebote für Altbauwohnungen entsprechen dem Richtwert von 4,91 (vgl. Abbildung 37). Drei Viertel der Mietwohnungen werden de jure zu teuer vermietet. Die mietrechtlichen Zinsbegrenzungen werden regelmäßig ignoriert, zumal in den obigen Zuschlagsberechnungen noch kein Befristungsabschlag von 25 Prozent veranschlagt wurde. Es ist davon auszugehen, dass ein Großteil der Wohnungen befristet vermietet wird.

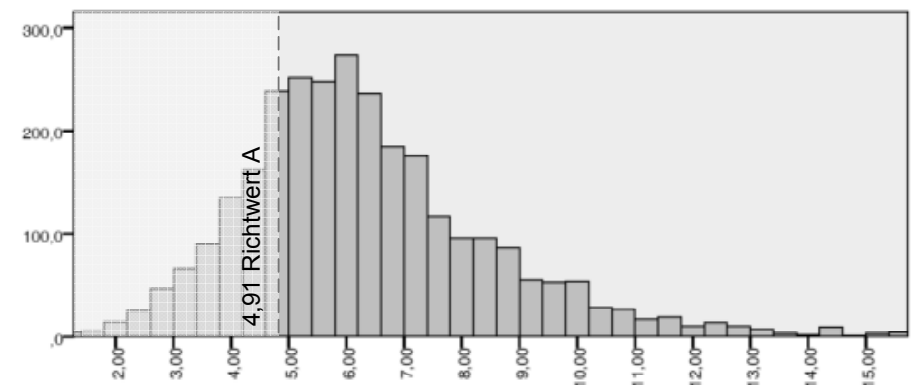
Mean $=6,4024$
Std. Dev, $=2,4786$ $\mathrm{N}=2.885$

Abbildung 37: Verteilung der bereinigten Altbaumieten und die Richtwertgrenze

Verlangen Vermieter in noch besseren Lagen überproportional mehr Miete, somit mehr als gesetzlich erlaubt, oder entspricht die Empfehlung der MA 25 nicht den Marktgegebenheiten? Beides ist vermutlich richtig: die Lagezuschlagsempfehlungen entsprechen nicht dem Marktwert der entsprechenden Lagen (schon gar nicht in Gründerzeitvierteln, wie die vorangegangenen Grafiken zeigen). In den Zuschlagszonen sind sie deshalb nicht gleich ,illegal“. Schließlich kann ein Vermieter hier einen höheren Lagezuschlag durchaus mit seiner Wohnumgebung im Einzelfall rechtfertigen. Beträgt etwa in einer Gegend des 9. 
Bezirks (etwa Richtung Innenstadt) der Grundkostenanteil laut eines von ihm beauftragten Sachverständigen-Gutachtens mehr als 1.000 Euro pro Quadratmeter, dann kann der entsprechende Lagezuschlag dem Mieter legal verrechnet werden. In Gründerzeitvierteln geht diese marktangepasste Zuschlagsmöglichkeit natürlich ins Leere.

\subsubsection{Testbeispiel Wien-Margareten (5. Bezirk)}

Ob das Faktum Gründerzeitviertel einen Einfluss auf die Miethöhe hat, und wie stark dieser ist, wird anhand eines eingegrenzten Testgebiets festgestellt. Ein Paradebeispiel für den Einfluss der Mietregulierung ist der 5. Wiener Bezirk, Margareten. Dieser Bezirk ist zunehmend beliebt, denn er ist umgeben von sehr guten Lagen (4. Bezirk, Naschmarkt, Parks, Wienzeile, etc.). Es handelt sich zudem um jenen ,inneren Bezirk“ (Bez. 1 bis 9), der am meisten Gründerzeitviertel aufweist. Diese zuschlagsfreien Zonen befinden sich im Kern des Bezirks, der jedoch von relativ hohen Zuschlagszonen eingesäumt ist, siehe Abbildung 38.

Die Durchschnittsmiete (Altbau und Neubau) in den Gründerzeitvierteln beträgt 7,72 Euro $/ \mathrm{m}^{2}$. Die Miete in der Zuschlagszone liegt bei $8,13 \mathrm{Euro} / \mathrm{m}^{2}$, und zwar ziemlich unabhängig davon, ob es sich um einen Altbau oder Neubau handelt. Ganz anders verhält sich die Ausprägung der Anwendbarkeit des MRG in den Gründerzeitvierteln: Eine Margaretener Altbauwohnung innerhalb eines Gründerzeitviertels kostet 6,22 Euro gegenüber 8,02 Euro in den angrenzenden Zuschlagszonen. Das Ergebnis der Varianzanalyse ist hoch signifikant.

Dieser Effekt kann nur auf die Begrenzung des Lagezuschlags zurückzuführen sein, womit Hypothese 2 nicht verworfen werden kann. Im unregulierten Neubaubereich überragt die Miete in den Bezirksinneren Gründerzeitvierteln jene in Zuschlagsgebieten sogar leicht (Abbildung 39). Das müsste darauf zurückzuführen sein, dass die Zuschlagszonen des 5. Bezirks größtenteils ausgerechnet entlang des stark befahrenen, sechsspurigen Gürtels liegen, und damit eine schlechtere Wohnqualität aufweisen als die Gründerzeitviertel des Bezirks. Die unmittelbare Nähe zu dieser Verkehrsader dürfte aber zur Gründerzeit ein Qualitätsmerkmal gewesen sein: Schließlich handelt es sich um Zuschlagszonen, was zum Ausdruck bringt, dass der Substandardanteil zum Zeitpunkt der Erbauung relativ gering gewesen ist. Heute steht ein entsprechendes Haus de facto unmittelbar an einer „Autobahn“. 


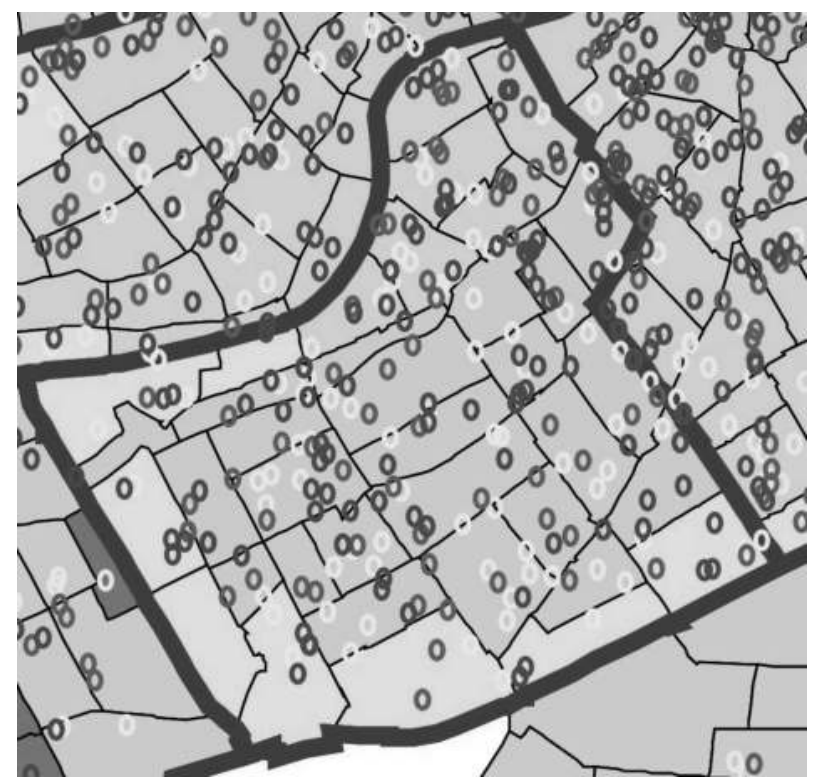

Legende: dunkelgrau $=$ Neubau-Angebote, grau $=$ Altbau, hellgrau $=$ Angebot o.A.

Abbildung 38: Bezirk Margareten, GZV umsäumt von Zuschlagsvierteln

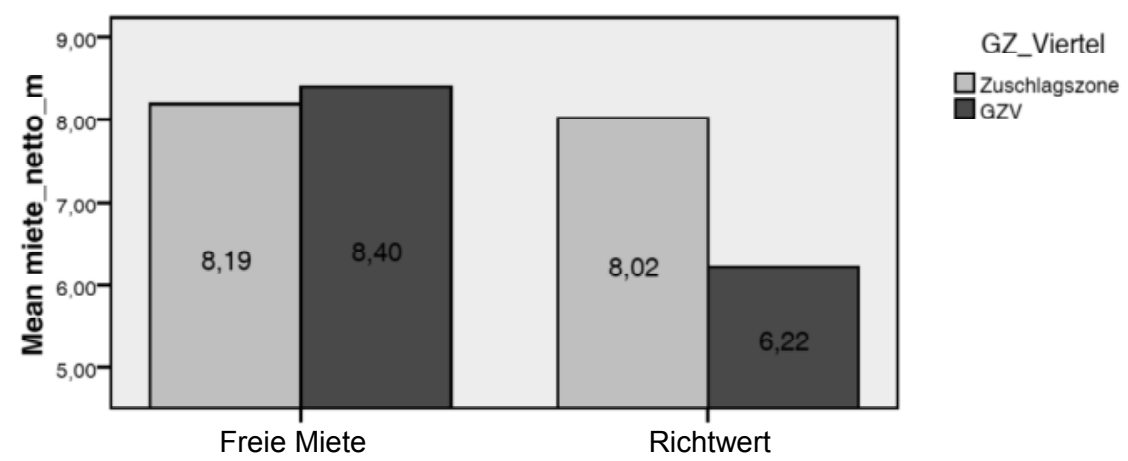

Abbildung 39: Paradox? Freie Mieten sind im Gründerzeitviertel höher

Ein weiterer Test bestätigt Hypothese 2; das Attribut Gründerzeitviertel ist auch auf die um die mietrechtlichen Zuschlagsmöglichkeiten bereinigten Mietangebote ausschlaggebend. Das heißt, selbst nach Abzug der Ausstattungszuschläge, aber auch des Lagezuschlags liegt die Altbaumiete bei $5,73 \mathrm{Euro} / \mathrm{m}^{2}$ in 
Gründerzeitvierteln gegenüber 6,60 Euro in den angrenzenden Lagezuschlagszonen 3 und 4 (selbst nach Abzug des LZ). Dieser Zusammenhang ist mit 0,032 (mittelmäßig) signifikant.

\subsubsection{Grenzbereiche als Graubereich der Gründerzeitviertel}

Hypothese 4 postuliert, dass es besonders in Gründerzeitvierteln, die an gute Lagen angrenzen, zu Nachbarschaftseffekten kommt, welche die verlangten Mieten nach oben treiben und damit noch stärker in den gesetzlichen Graubereich drängen. In anderen Worten: die Nähe zu einer Zuschlagszone führt dazu, dass Mieten in jenen GZV noch überteuerter sind.

Wie bei der Ausarbeitung der Hypothesen gezeigt wurde, ist eine scharfkantige Abstufung der Lagezuschlagsmöglichkeit ganz besonders in jenen Wohngebieten zu erwarten, die einerseits als teure und beliebte Lagen gelten, andererseits jedoch Gründerzeitviertel aufweisen. Wo sich ein Gründerzeitviertel in einer guten Lage befindet, müsste der Marktdruck noch stärker gegen die Regulierung wirken und zu höheren (,,illegaleren“) Mieten führen.

Für diesen Hypothesentest wurden 139 GZV-Zählsprengel aus den Bezirken 2, 3, 5, 7, 9, 14, 15, 16, 17 und 18 als Testgruppe ausgewählt, die an insgesamt 130 Zählsprengel angrenzen, wo ein Lagezuschlag möglich ist. Damit sind innerhalb der erwähnten Bezirke alle Grenzen zwischen Zuschlags- und Zuschlagsfreier Zone nachgebildet und teilweise auch Bezirksübergreifend eine Grenze definiert.

Das Mietangebot ist in Abbildung 40 sichtbar, aufgeteilt nach Gründerzeitvierteln und Zuschlagszonen sowie nach Altbau- und Neubauwohnungen. In Summe fallen 2119 Mietangebote in diese definierten Grenzgebiete (jene ohne Zuordnung zu Altbau/Neubau sind ausgeschieden).

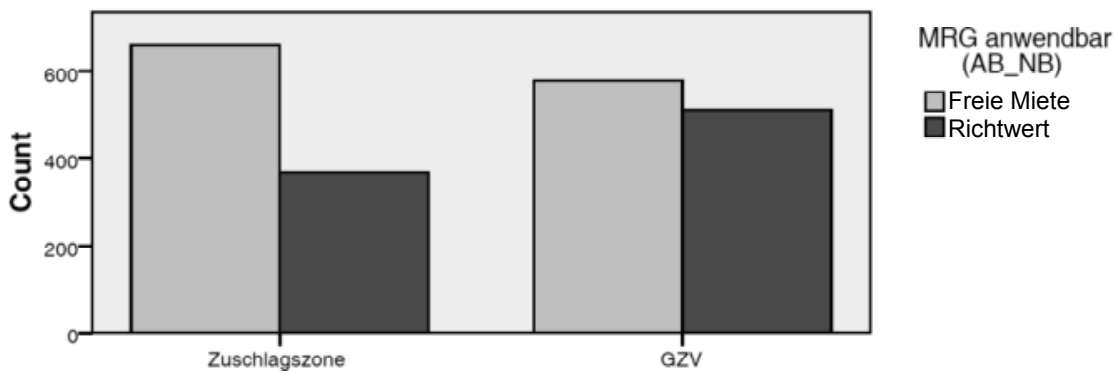

Abbildung 40: Mietangebote in Grenzgebieten zwischen GZV und Zuschlagszonen 
Liegt eine Wohnung im angrenzenden Gründerzeitviertel, so ist die Miete im Durchschnitt günstiger. Das Gründerzeitviertel hat damit einen Einfluss auf die Miethöhe, sowohl im Altbau als auch im Neubausegment. Dieser Einfluss ist signifikant, vor allem im Vollanwendungsbereich (Sig. 0,000), aber auch leicht im frei vermietbaren Neubau-Bereich (Sig. 0,033), vergleiche Tabelle 20.

Tabelle 20: Die Miete ist in Gründerzeitvierteln stets geringer als in Zuschlagszonen

\begin{tabular}{|c|c|c|c|c|}
\hline \multicolumn{2}{|c|}{ MRG anwendbar (AB_NB) } & \multirow{4}{*}{$\begin{array}{r}\mathrm{N} \\
588 \\
534 \\
1122\end{array}$} & \multirow{4}{*}{\begin{tabular}{c|} 
Mean \\
8,8781 \\
8,3347 \\
8,6195
\end{tabular}} & \multirow{4}{*}{$\begin{array}{r}\text { Std. Deviation } \\
2,48117 \\
2,16665 \\
2,35146\end{array}$} \\
\hline Neubau & Zuschlagszone & & & \\
\hline & GZV & & & \\
\hline & Total & & & \\
\hline \multirow[t]{3}{*}{ Altbau } & Zuschlagszone & 324 & 7,4150 & 2,34949 \\
\hline & GZV & 453 & 6,8183 & 1,79001 \\
\hline & Total & 777 & 7,0671 & 2,06172 \\
\hline
\end{tabular}

Betrachtet man ausschließlich den mietengeschützten Vollanwendungsbereich, liegt die Miete in GZV um durchschnittlich 60 Cent unter jener in Zuschlagszonen. Dies allein lässt noch keine Rückschüsse zu, ob die Mietregulierung in Gründerzeitvierteln eingehalten wird oder nicht. Nun wird die Bereinigung der Mietangebote um die gesetzeskonformen Zuschläge für Balkon, Stockwerk, usw. wichtig.

Eine Varianzanalyse mit den bereinigten Daten (miete_ohneZ) zeigt leicht signifikant (Sig. 0,067): Nach Abzug der möglichen mietrechtlichen Zuschläge (sowohl Ausstattung als auch Lage) ist die Grundmiete von Altbauwohnungen in Gründerzeitvierteln sogar höher als in der benachbarten Zuschlagszone. Sie liegt 6,15 bzw. 6,42 Euro pro Quadratmeter (vgl. Abbildung 41).

Zur Erinnerung: gesetzlich im grünen Bereich ist die Altbaumiete nach Abzug von $\mathrm{Zu}$ - und Abschlägen, wenn sie (bei einem unbefristeten Mietverhältnis) bei 4,91 Euro pro Quadratmeter liegt. Dass es sich in jeder Hinsicht um eine Grauzone handelt, wurde bereits ausführlich erklärt. In Gründerzeitvierteln, die an gute und zuschlagsfähige Wohngegenden anschließen, ist diese Grauzone noch größer; Hypothese 4 ist somit bestätigt.

Die Vermieter verrechnen offenbar in GZV höhere Ausstattungszuschläge, um den fehlenden Lagezuschlag zu kompensieren. Oder ganz pragmatisch aus- 
gedrückt: einige Marktteilnehmer berücksichtigen die Richtwertgesetzgebung einfach nicht, vergleiche dazu später Hypothese 6.

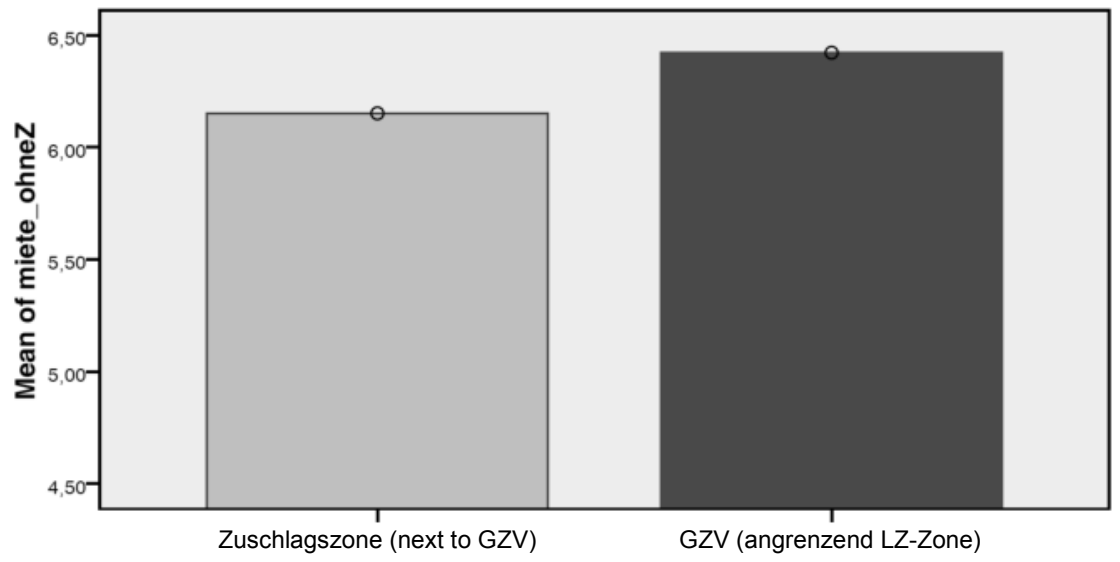

Abbildung 41: Die um Zuschläge bereinigte Altbaumiete ist in GZV sogar höher

Eine ähnliche Beobachtung liefert die bezirksübergreifende Betrachtung der um die gesetzlichen Zuschläge bereinigten Mieten im Altbaubereich in GesamtWien. Theoretisch müsste die bereinigte Miete, die ja der ,mietrechtlichen Normwohnung" entsprechen soll, überall gleich hoch sein - unabhängig von Bezirk oder Lage, in der sich die Wohnung befindet. Die bereinigte Durchschnittsmiete müsste im ersten Bezirk gleich hoch sein wie im 16. Bezirk. Dass dies nicht der Fall ist, wurde bereits in Abbildung 36 gezeigt.

Nun soll ein Test auf die „besseren“ Bezirke (2.-9.) eingeschränkt werden, sowie auf die Bezirke Hernals (17) und Währing (18), die als die „teuersten“ Außenbezirke gelten, in denen auch Gründerzeitviertel existieren ${ }^{71}$. Gründerzeitviertel (GZV) dürften ungeachtet ihrer Bezirks-Postleitzahl nirgendwo einen Lagezuschlag einpreisen.

71 In den teuren 19. (Döbling), 13. (Hietzing) und im Ersten Bezirk gibt es natürlich keine Gründerzeitviertel, daher sind sie hier nicht aufgelistet.

Filter: $\mathrm{plz}=1170$ or $\mathrm{plz}=1180$ or $\mathrm{plz}=1020$ or $\mathrm{plz}=1030$ or $\mathrm{plz}=1040$ or $\mathrm{plz}=1050$ or $\mathrm{plz}=1060$ or $\mathrm{plz}=1070$ or $\mathrm{plz}=1080$ or $\mathrm{plz}=1090$. 


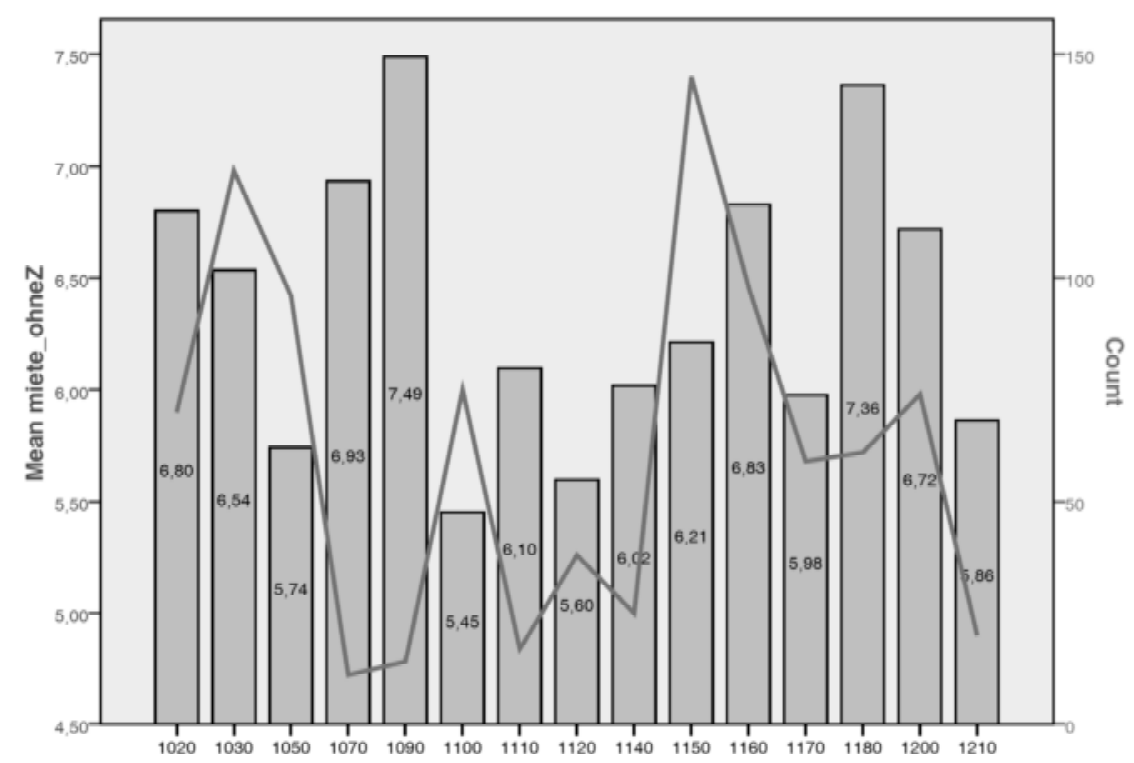

Abbildung 42: Teurere Lagen, höhere Mieten - ungeachtet des Gründerzeitviertel-Stigmas. Grüne Linie: im 7., 9., 11., 14. und 21. Bezirk ist die Fallzahl gering

Es zeigt sich: in guten Bezirken ist die Miete einer Altbau-Wohnung im Gründerzeitviertel sehr wohl bedeutend höher als in schlechteren Bezirken. Die Lage wird eingepreist, obwohl dies in GZV nicht erlaubt wäre. Der Zusammenhang mit dem Bezirk ist signifikant (vgl. Anova in Tabelle 21, bei homogenen Varianzen: 0,004).

Tabelle 21: In Gründerzeitvierteln gibt es einen signifikanten „Bezirkszuschlag“

\begin{tabular}{|l|r|r|r|r|r|}
\multicolumn{1}{c|}{ miete_ohneZ } & & & & & \\
\cline { 2 - 6 } & Sum of Squares & \multicolumn{1}{c|}{ df } & Mean Square & \multicolumn{1}{c|}{ F } & Sig. \\
\hline Between Groups & 272,650 & 14 & 19,475 & 6,213 & 000 \\
Within Groups & 2858,593 & 912 & 3,134 & & \\
Total & 3131,243 & 926 & & & \\
\hline
\end{tabular}

Hypothese 4, dass die Mietregulierung in Gründerzeitviertel besserer Lagen bzw. an Zuschlagszonen angrenzend weniger eingehalten wird, kann daher nicht verworfen werden. Die „Grauzone“ ist in besseren Lagen dunkler schattiert als in schlechteren Lagen. Eine Tatsache bleibt nämlich unbenommen: Selbst unter 
Ausnutzung jeglicher Zuschlagsmöglichkeit des Mietrechts ist ein durchschnittlicher Nettomietzins von 6,80 Euro in einem Gründerzeitviertel in Ottakring (16. Bezirk) de facto unmöglich. Dass eine Grauzone besteht, und zwar im gesamten Mietengeschützen Bereich, ist unbestritten. Das Regulativ bildet in keiner Weise die Marktmiete ab.

\subsubsection{Miethöhe und Entfernung vom Zentrum}

Hypothese 5: Je weiter eine angebotene Wohnung vom CBD entfernt ist, desto günstiger das Mietangebot. Dieser Zusammenhang ist besser im Neubau zu sehen bzw. unter Ausblendung der Gründerzeitviertel (GZV).

Die Herleitung dieser Hypothese wurde bereits in Kapitel 4.1.2 erörtert. Immobilienpreise und Mietpreise steigen mit der Nähe zum Zentrum an. In jeder Stadt gibt es freilich eine Reihe von Subzentren. Vereinfachend wurde die Beobachtung in Wien jedoch auf das Zentrum Innenstadt/Stephansplatz beschränkt.

Nachdem für jedes Mietangebot longitudinale und latitudinale Koordinaten vorhanden sind, wurden diese in Entfernung zu den Koordinaten von Wien Stephansplatz (48.208174, 16.373819) gesetzt. Ein Tausendstel-Grad entspricht ungefähr einer Entfernung von 115 Metern. Die Distanzberechnung in SPSS ist daher eine Schätzung ${ }^{72}$, die zumindest auf $+/-10$ Prozent stimmen dürfte und deren möglicher Fehler zumindest immer gleich groß ist. Von Interesse ist für die Hypothesenprüfung das Verhältnis der Distanz zu den Immobilienpreisen.

Ein Korrelationstest ist signifikant $(0,000)$, die Distanz zum CBD korreliert (Pearson) mit der Nettomiete mit 18,2 Prozent (vgl. Tabelle 22).

Tabelle 22: Signifikante Korrelation zwischen Miete und Entfernung zum CBD

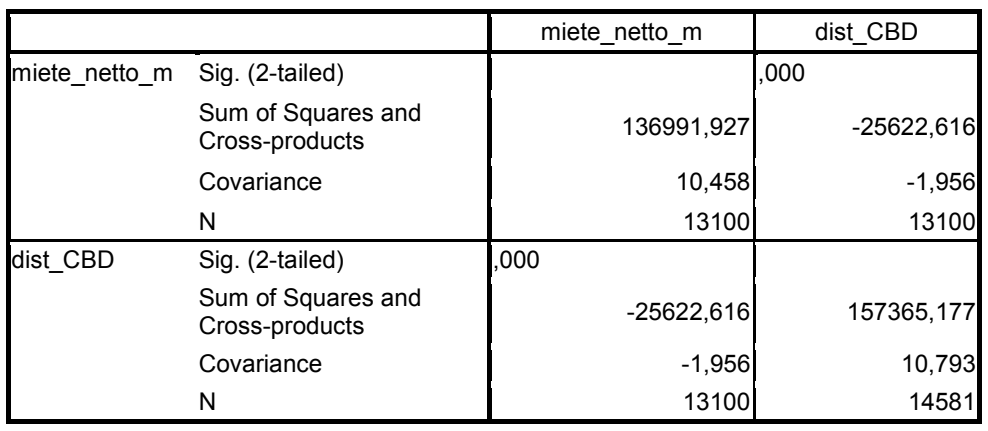

72 Berechnungsformel in SPSS: dist_CBD $=((48.208174-$ lat $) * * 2+(16.373819-10 n) * * 2)$ $* *(1 / 2) * 115$ 
Die Korrelation steigt, wenn Gründerzeitviertel aus der Analyse ausgeblendet werden, auf 0,205 (Sig. 0,000). Ein Ausblenden aller Mietregulierter Angebote erhöht die Korrelation auf 0,222 Prozent für das Neubausegment. Man könnte sagen: Die Mietregulierung und die Lageregulierung beeinträchtigen den „natürlichen“ Verlauf des Rentengradienten, welcher der Theorie nach vom Zentrum abfällt. Die logarithmische Schätzkurve konnte mit $y=10,53+-1,26$ * $\log (\mathrm{x})$ berechnet werden (vgl. Abbildung 43 mit logarithmischer und linearer Schätzkurve, $\mathrm{k}=-0,18)$.

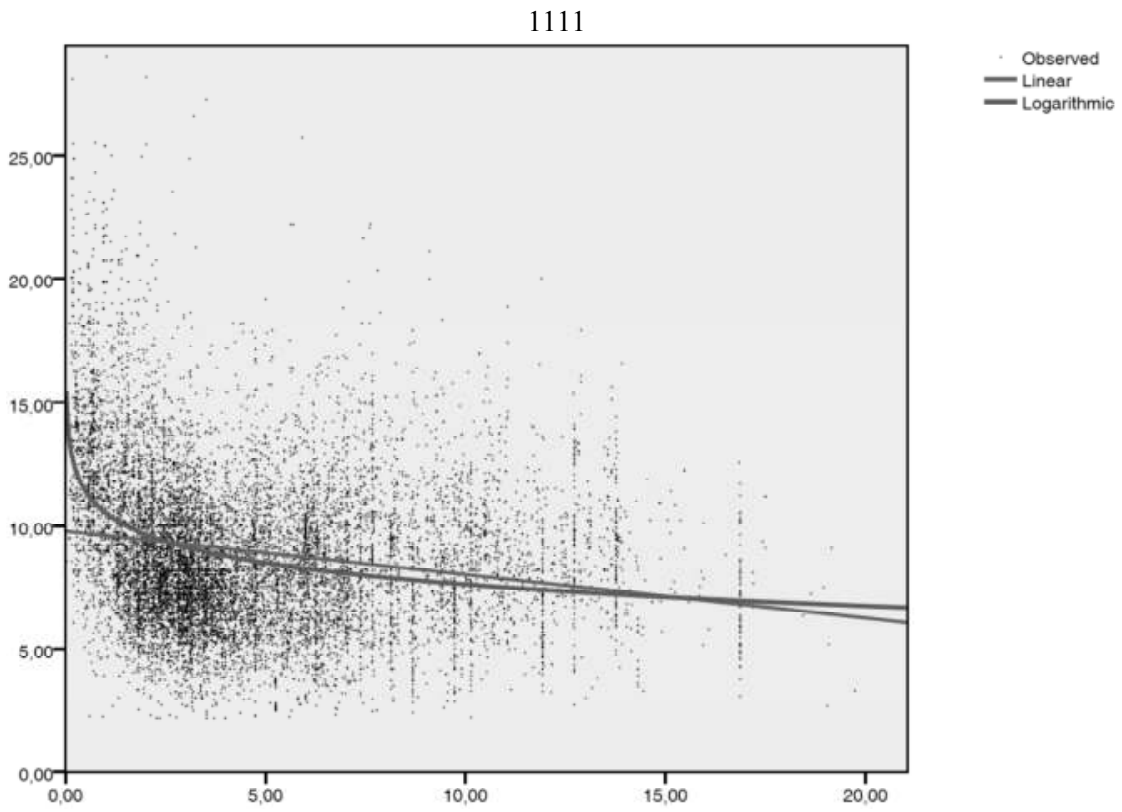

Abbildung 43: Miethöhe (y) in Abhängigkeit von der Entfernung vom Zentrum ( $x$ ) sowie deren Schätzkurven

\subsubsection{Erhaltungszustand unter Mietregulierung}

Hypothese 7: Je geringer der Lagezuschlag ist, desto schlechter ist auch der Erhaltungszustand der angebotenen Wohnungen.

Diese Hypothese leitet sich einerseits aus der Polarisationstheorie nach Gunnar Myrdal ab. Sanierungen lohnen sich in schönen Gegenden eher als in herabge- 
kommenen. Andererseits ist der Zusammenhang zwischen der Stärke der Mietregulierung und dem Erhaltungszustand der Häuser ein in der Theorie viel diskutierter. Auch in Wien konnte über die Nachkriegszeit, als ein strenger Mieterschutz herrschte, bis zur großen Mietrechtsreform in den 90er Jahren beobachtet werden, wie sehr die Instandhaltung der Häuser vernachlässigt wurde oder vernachlässigt werden musste.

Je schlechter die Lage ist - oder im Sinne der Mietregulierung, je geringer der Lagezuschlag ist - desto schlechter muss auch der Ausstattungszustand der angebotenen Wohnungen sein.

Dasselbe müsste nach dieser Hypothese auch für die Anwendbarkeit des Mietrechts gelten: Wohnungen, deren Miete gesetzlich begrenzt ist, werden einen geringeren Ausstattungsstandard aufweisen als Wohnungen, die der freien Mietvereinbarung unterliegen.

Als Indikator für den Erhaltungs- und Ausstattungszustand der jeweiligen Mietwohnung dient die von den Maklern angegebene Variable „Condition“, als Zustand der Wohnung. Die Ausprägungen dafür sind „,sehr gut“, „gut“, „,befriedigend“, „schlecht" und „unbenutzbar", sie wurden in Schulnoten (von 1 bis 5) unterteilt und als „Notenschnitt“ numerisch betrachtet. Dabei wurde eine Ordinalskalierung unterstellt und gemittelt.

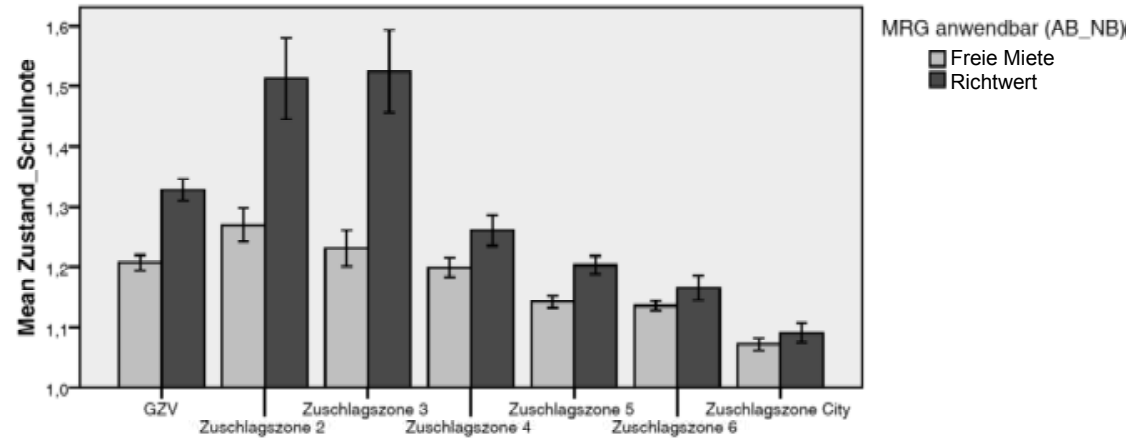

Abbildung 44: Besserer Zustand von besseren Lagen und bei frei vermietbaren Wohnungen Error-Bars zeigen die Standardabweichung

Tatsächlich hängt der durchschnittliche Erhaltungszustand der Wohnungen einerseits von der Lage ab: je höher die Lagezuschlagsmöglichkeit, desto besser ist auch der Zustand der Wohnungen. Auffallend ist auch hier, dass die Gründerzeitviertel (GZV) zwar leicht unterdurchschnittlich abschneiden (1,33 im Altbau, 1,21 im Neubau), dass aber der Erhaltungszustand in Lagezuschlagszone 2 und 3 schlechter ist als in Zone 1 (GZV), vergleiche Abbildung 44 (längere 
Balken bedeuten schlechtere Erhaltungszustände). Der Durchschnitt liegt für alle Bereiche bei 1,20 .

Andererseits hängt der durchschnittliche Erhaltungszustand klar von der Anwendbarkeit des Mietrechts ab. Neubauten (nach 1945) weisen einen besseren Zustand auf (im Schnitt 1,16) als Altbauten $(1,25)$. Nun könnte eingewandt werden, dass dies in der Natur des Baualters liege, dass natürlich die Abnutzung bei Altbauten größer ist als bei Neubauten. Dem kann entgegengehalten werden, dass die Erhaltungsunterschiede zwischen Altbau und Neubau abnehmen, je besser die Lage ist. Im Ersten Bezirk erreicht der durchschnittliche Wohnungszustand eine Schulnote von 1,08; Altbau und Neubau liegen nahezu gleichauf. Die Nullhypothese muss verworfen werden - der Zustand hängt von der Lage ab (Varianzanalyse ist signifikant, vgl. Tabelle 23).

Tabelle 23: Signifikante Zusammenhänge zwischen Ausstattungsnote und Lage

ANOVA

Zustand_Schulnote
\begin{tabular}{|l|r|r|r|r|r|}
\hline & Sum of Squares & df & Mean Square & F & Sig. \\
\hline Between Groups & 62,098 & 6 & 10,350 & 54,796 &, 000 \\
Within Groups & 2442,182 & 12930 &, 189 & & \\
Total & 2504,280 & 12936 & & & \\
\hline
\end{tabular}

Das Ergebnis lässt folgenden Schluss zu: Vermieter von Wohnungen in guten Lagen investieren mehr in die Erhaltung der jeweiligen Wohnung, weil sie diese Investitionen besser in der Miete abbilden können. Der Betrag an höherer Miete, die nach einer Verbesserung des Ausstattungszustands nötig ist, um dessen Kosten zu refinanzieren, ist in guten und in schlechten Lagen gleich. In guten Lagen, wo die Mieten (ganz gesetzeskonform) höher sind, ist der Mietanteil für die Finanzierung der Verbesserungsmaßnahme relativ gesehen geringer als in schlechten Lagen, wo die Verbesserungsmaßnahme den Anteil an (legal verrechenbarer) Miete über einen längeren Zeitraum völlig abschöpfen müsste.

Der Mangel an der Möglichkeit, die Lage ihrem Wert entsprechend einzupreisen einerseits, und die Beobachtung von überhöhten Mieten in GZV andererseits, legen der Verdacht nahe, dass Vermieter eine andere Rechtfertigung für Ihre Miethöhe schaffen. Es könnte etwa vermutet werden, dass Vermieter in GZV einen optisch und technisch hochwertigeren Wohnraum zur Verfügung stellen, damit dies ohne Zweifel zu einem Zuschlag für die Ausstattung zu berechtigen vermag. Auf Basis dieser Annahme ist die folgende Hypothese aufgestellt worden: 
Hypothese 6: Eine fehlende Lagezuschlagsmöglichkeit wird bei Mietverhältnissen durch andere Zuschläge substituiert.

Dass Gründerzeitviertel einen besseren Erhaltungszustand aufweisen als tatsächlich schlechtere Wiener Lagen (Lagezuschlagszone 2 und 3), ist bereits oben gezeigt worden (vgl. Abbildung 44). Dies widerspricht im Grunde genommen der Annahme, dass bessere Lagezuschlagszonen auch Wohnungen mit besseren Erhaltungszuständen beherbergen. Im Sinne der obengenannten Argumentation ist es allerdings schlüssig, dass Vermieter in den prekären Gründerzeitvierteln mehr in die Ausstattungskategorie und die Zuschlagsmöglichkeit für Ausstattung investieren müssen. Nachdem der jeweilige Zuschlag für die Ausstattung nicht leicht festgestellt werden kann (sondern lediglich über ein Gutachten), produziert ein rechtskundiger und in gewissem Maße listiger Vermieter dadurch eine Möglichkeit, seine Zuschlagspolitik zu verschleiern und den Anreiz eines Mieters, die Miethöhe zu beanstanden, durch die ungewisse Höhe der rechtswirksamen Zuschläge zu reduzieren.

Ein Vergleich des durchschnittlichen Ausstattungszustands innerhalb des Grenzgürtels (259 Zählsprengel) zwischen Zuschlagszonen und Gründerzeitvierteln ergibt jedoch, dass die Durchschnittsnote für Ausstattung sehr wohl in Zuschlagszonen besser ist $(1,22)$ als in den angrenzenden Gründerzeitvierteln $(1,31)$, dieser Zusammenhang ist auch signifikant. Der Verdacht, dass Vermieter in GZV sozusagen auf der anderen Straßenseite der Zuschlagszonen mehr in die Ausstattung investieren, um eine „vernünftigere“ Miete zu legalisieren, ist widerlegt.

Allerdings wirkt die Nähe zur Zuschlagszone innerhalb der Gründerzeitviertel. Jene Gründerzeitgebiete, die an Zählsprengel grenzen, die zu einem Lagezuschlag berechtigen, weisen bessere Ausstattungszustände auf, als Gründerzeitviertel in Binnenlage, die nur an Ihresgleichen angrenzen (vgl. Abbildung 45). Der Einfluss der Nähe zur Zuschlagszone auf den Ausstattungszustand der Wohnung (von „sehr gut" bis ,unbenutzbar") ist allerdings nicht signifikant. 


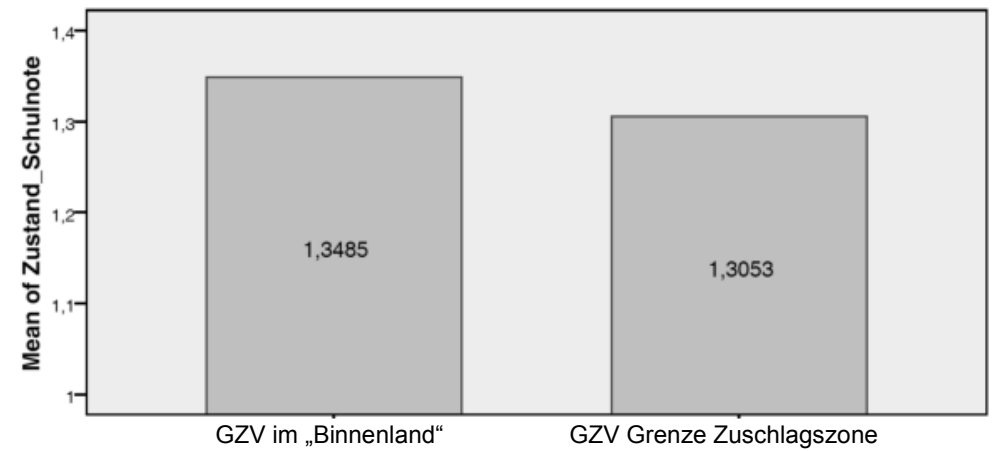

Abbildung 45: Besserer Wohnungszustand in GZV an der Grenze zu Zuschlagszonen

Ein wissenschaftlich fundierter Beleg für die o.g. Hypothese, dass Vermieter in Zuschlagsfreien Zonen andere Zuschläge einpreisen, um eine etwaige zu hohe Miete zu rechtfertigen, kann nur durch eine empirische Felduntersuchung mit Erhebungen an konkreten, vermieteten Wohnungen erbracht werden. Auch frühere Studien (Moser et al. 2002) belegen, dass aufgrund der überhöhten Mieten etwaige Zuschläge inhärent verrechnet werden müssten. Erwähnt wird dieser „Zuschlag“ im Mietvertrag mit keiner Silbe.

\subsubsection{Hedonisches Modell unter Berücksichtigung des mietrechtlichen Einflusses}

Bisher hatte die Fragestellung stets gelautet, ob die im Altbau verlangte Miete den mietrechtlichen Beschränkungen entspricht. In diesem Kapitel soll jedoch der Einfluss des mietrechtlichen Regulativs und anderer preisbestimmender Strukturfaktoren auf die gesamte Miethöhe im Altbaubereich berechnet werden. Dazu ist ein hedonisches Modell nötig, das im Stande ist, diese Faktoren „ceteris paribus" zu interpretieren.

Der vorliegende Datensatz weist eine Reihe von Preis bestimmenden Faktoren auf, die der Literatur nach auch in anderen hedonischen Mietpreismodellen (vgl. Brunauer et al., 2008; Feilmayr 2007) einen signifikanten Einfluss auf die Miete haben: Wohnungsgröße, Balkon/Terrasse/Loggia, Bezirk, Lift (in Zusammenhang mit Stockwerkszahl), Anwendbarkeit des Mietrechts, Lage im Gründerzeitviertel. Diese Faktoren wurden mit dem Logarithmus der Quadratmetermiete (lg_miete_net_m) in Verhältnis gesetzt. 
Tabelle 24: Mietrecht im hedonischen Modell, lineare Regression der Mietangebote

Coefficients $^{a}$

\begin{tabular}{|c|c|c|c|c|c|c|}
\hline \multirow{2}{*}{\multicolumn{2}{|c|}{ Model }} & \multicolumn{2}{|c|}{$\begin{array}{l}\text { Unstandardized } \\
\text { Coefficients }\end{array}$} & \multirow{2}{*}{$\begin{array}{c}\text { Standardized } \\
\text { Coefficients } \\
\text { Beta }\end{array}$} & \multirow[b]{2}{*}{$t$} & \multirow[b]{2}{*}{ Sig. } \\
\hline & & B & Std. Error & & & \\
\hline \multirow[t]{30}{*}{1} & (Constant) & ,831 & 3,940 & & ,211 &, 833 \\
\hline & Zustand_Schulnote &,- 153 &, 008 &,- 185 & $-18,640$ &, 000 \\
\hline & Stockwerk &, 015 &, 001 & ,121 & 10,928 &, 000 \\
\hline & lift & ,037 &, 008 & ,047 & 4,324 &, 000 \\
\hline & year_veraend &, 001 & ,002 & ,003 & 309 &, 757 \\
\hline & $\begin{array}{l}\text { MRG anwendbar } \\
\text { (AB_NB) }\end{array}$ &,- 080 &, 009 &,- 103 & $-8,930$ &, 000 \\
\hline & GZ_Viertel &,- 086 & ,011 &,- 100 & $-7,728$ &, 000 \\
\hline & plz1 &, 526 & ,031 & ,462 & 17,089 &, 000 \\
\hline & plz2 & ,112 & ,033 & ,066 & 3,373 &, 001 \\
\hline & plz3 &, 175 &, 031 & , 135 & 5,595 &, 000 \\
\hline & plz4 & ,222 & ,031 & ,166 & 7,072 &, 000 \\
\hline & plz5 & ,127 & ,034 & ,069 & 3,706 &, 000 \\
\hline & plz6 & ,174 &, 035 & ,084 & 4,984 &, 000 \\
\hline & plz7 & ,191 & ,033 & ,112 & 5,779 &, 000 \\
\hline & plz8 & , 165 & ,034 & ,088 & 4,847 &, 000 \\
\hline & plz9 & ,207 & ,032 &, 147 & 6,525 &, 000 \\
\hline & plz10 &,- 072 & ,035 &,- 037 & $-2,045$ &, 041 \\
\hline & plz11 &,- 021 & ,047 &,- 006 &,- 457 & ,648 \\
\hline & plz12 & ,004 &, 037 & ,002 & , 109 &, 913 \\
\hline & plz13 & ,246 &, 032 & ,158 & 7,696 &, 000 \\
\hline & plz14 & ,039 & ,037 & ,016 & 1,043 &, 297 \\
\hline & plz15 & ,093 & ,037 &, 043 & 2,524 &, 012 \\
\hline & plz16 & ,098 & ,036 &, 045 & 2,707 &, 007 \\
\hline & plz17 & ,091 & ,037 & ,038 & 2,466 &, 014 \\
\hline & plz18 & , 198 & ,032 & ,138 & 6,247 &, 000 \\
\hline & plz19 & ,259 & ,031 & ,211 & 8,433 &, 000 \\
\hline & plz20 &, 080 & ,038 & ,031 & 2,073 &, 038 \\
\hline & plz21 & ,036 & ,037 & ,015 & ,974 & ,330 \\
\hline & plz22 & , 150 & 038 & 056 & 3,907 &, 000 \\
\hline & balc_logg_terr & ,095 & ,007 & ,151 & 13,655 &, 000 \\
\hline
\end{tabular}

a. Dependent Variable: In_miete_net_m 


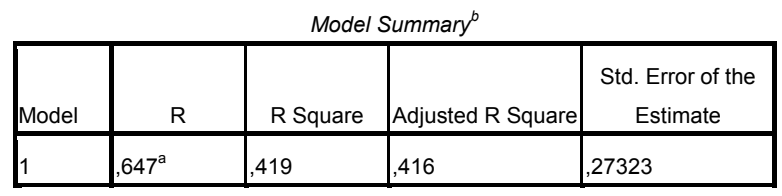

a. Predictors: (Constant), balc_logg_terr, plz1-22, year_veraend, Zustand_Schulnote, Stockwerk, MRG anwendbar (AB_NB), GZ_Viertel,

b. Dependent Variable: In_miete_net_m

Die Ergebnisse der linearen Regression sind in Tabelle 24 dargestellt. Die unabhängigen Variablen erklären 64,7 Prozent der Mietpreis-Varianzen. Signifikant sind insbesondere der Umstand, ob es sich um ein mietengeschütztes Objekt handelt, was die erwartete Miethöhe um 10,3 Prozent reduziert. Das Faktum „Gründerzeitviertel“ reduziert die erwartete Miete um 10,0 Prozent. Die Faktoren Lift (plus 4,7) und ein höheres Stockwerk (plus 12,1 Prozent) haben ebenso signifikanten Einfluss wie der angegebene Ausstattungszustand. Ist dieser um einen Grad schlechter, so reduziert das die erwartete Miete um 18,5 Prozent.

Die einzelnen Wiener Bezirke (mit dem 23. Bezirk als Basis) wurden bewusst als Dummy Variablen geführt. Insbesondere die bereits mehrmals erwähnten beliebtesten Bezirke, 1.-9. Bezirk, sowie 13., 18. Und 19. Bezirk wirken besonders stark auf die Miethöhe, und genau diese Dummys sind erwartungsgemäß hoch signifikant.

\subsubsection{Mieterselektion und soziodemographische Beobachtungen}

Generell ist es schwierig, anhand von statischen Daten post-hoc einen kausalen Zusammenhang zwischen dem Einfluss der Mietregulierung und den lokalen Beobachtungen als abhängige Variablen herzustellen. Ist der Bauzustand in guter Lage besser, weil sich dies bei mietregulierten Wohnungen besser einpreisen lässt, oder liegen teure Mieten deshalb in guter Lage, weil der Bauzustand dort einladender ist? Ähnlich die Betrachtung der folgenden Hypothese: Werden bewusst Ausländer und schlechter gebildete Menschen für Gründerzeitwohnungen ausgesucht, oder zieht der aufgrund eines seinerzeitig hohen SubstandardAnteils relativ günstige Wohnraum gerade bestimmte Bevölkerungsschichten an?

Hypothese 8: In Gründerzeitvierteln (in guten Lagen) kommt es zu einer Mieterselektion: der Anteil an Ausländern ist höher und das Bildungsniveau niedriger als in Nachbar-Sprengeln, wo ein LZ erlaubt ist. 
Der Ausländeranteil und das Bildungsniveau sind generell bei Segregationsstudien wichtige Variablen. Probleme bereitet dabei stets die Frage: was war zuerst? Die niedrigen Bildungsabschlüsse oder das unbeliebte Viertel? Die Henne oder das Ei? Ein kausaler Zusammenhang ist nicht seriös herzustellen (Wieser 2006, 15). Zudem kann Segregation auch einkommensgetrieben sein - Wohnungen sind in Gründerzeitvierteln etwas günstiger - was vor allem dann der Fall ist, wenn ältere Gebäude räumlich konzentriert sind (Giffinger 1998, 1972).

Wohl aber lässt sich ein deskriptiver Zusammenhang herstellen. Die soziodemographischen Daten für dieses Dissertationsprojekt stammen von der Statistik Austria. Einerseits liegen die Daten der letzten vollständigen Zählung von Hauptwohnsitzen, Ausländeranteilen und Bildungsniveaus auf Zählsprengelebene aus dem Jahr 2001 vor, andererseits die aktuellen Daten aus dem Mikrozensus 2010 (zumindest zu Ausländeranteilen). Die Daten über das Bildungsniveau sind jedenfalls 10 Jahre alt.

Die Ergebnisse sind in Abbildung 46 dargestellt, wobei die breiten, hellen Balken den Ausländeranteil 2010, und die schmalen, dunklen Balken den Ausländeranteil 2001 verkörpern. Die Ausländeranteile (EWR und Drittstaatenangehörige im Verhältnis zur Gesamtbevölkerung) wurden mit der Bevölkerungszahl über 15 Jahren gewichtet, um eine Vergleichbarkeit zu ermöglichen.

Je nach Zuschlagszone ist der Anteil an ausländischen Bürgern sehr unterschiedlich verteilt: in Gründerzeitvierteln liegt der Ausländeranteil bei 33 Prozent (gegenüber 29 Prozent im Jahr 2001), in den übrigen innerstädtischen Zuschlagszonen mehr oder weniger unverändert bei 17 bis 20 Prozent. Die Abhängigkeit von der Zuschlagszone ist signifikant, bei homogenen Varianzen.

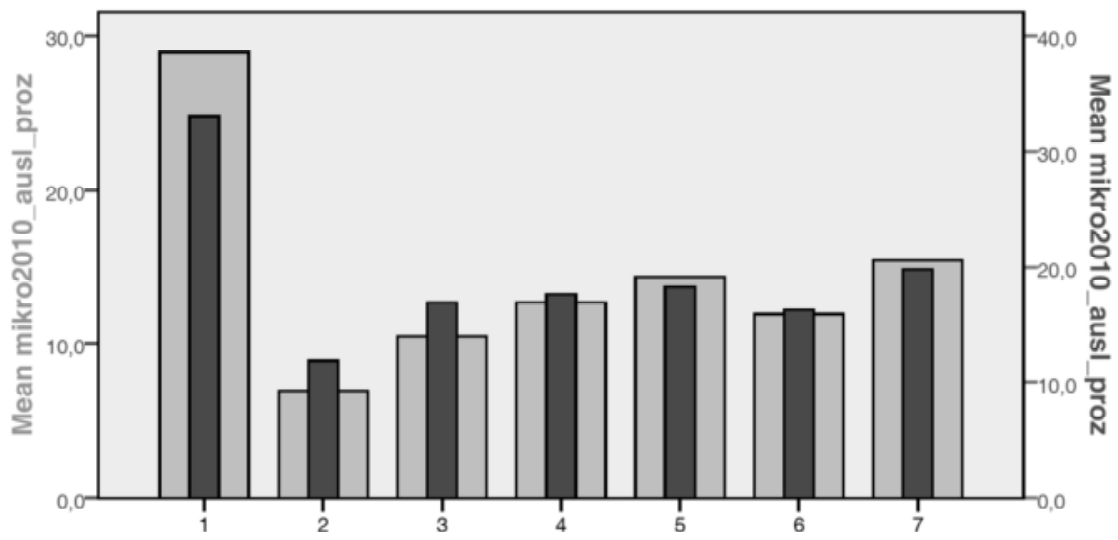

Abbildung 46: Hoher und steigender Ausländeranteil in Gründerzeitvierteln (breite Balken: 2001, schmale Balken: 2010) 
Dasselbe Muster weisen die jeweiligen Zonen beim Bildungsniveau auf. 27 von 100 Wienern haben die Reifeprüfung absolviert, in Gründerzeitvierteln sind es nur 22 Prozent, in den inneren Bezirken (ab Zone 5) mehr als 42 Prozent (siehe Abbildung 47), auch dieses Ergebnis ist signifikant, die Varianzen homogen.

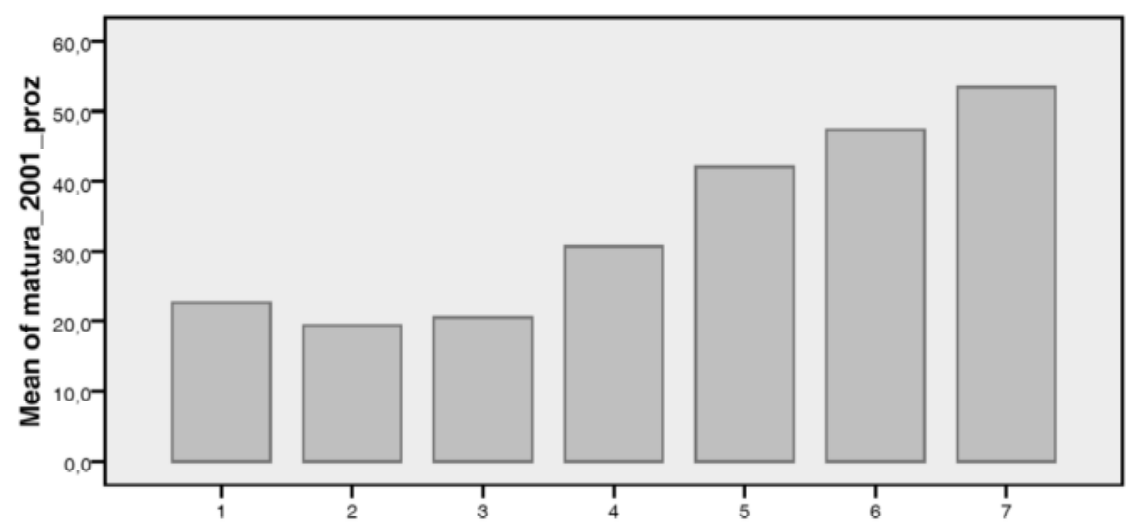

Abbildung 47: Bildungsniveau steigt mit der Zuschlagszone

Im nächsten Schritt sollen nur jene 256 Zählsprengel ausgewählt werden, die an der Grenze zu einem Gründerzeitviertel bzw. zu einer Zuschlagszone liegen (gleiche Auswahl wie oben, vgl. Tabelle 25).

Tabelle 25: Anzahl der Ausgewählten Grenz-Zählsprengel nach LZ-Zone

\begin{tabular}{|ll|r|r|r|r|}
\hline & & LZ_zone & \\
\hline & & Frequency & Percent & Valid Percent & $\begin{array}{c}\text { Cumulative } \\
\text { Percent }\end{array}$ \\
\hline Valid & 1 & 127 & 49,6 & 49,6 & 49,6 \\
& 3 & 33 & 12,9 & 12,9 & 62,5 \\
& 4 & 61 & 23,8 & 23,8 & 86,3 \\
& 51 & 12,1 & 12,1 & 98,4 \\
& 4 & 1,6 & 1,6 & 100,0 \\
& Total & $256^{13}$ & 100,0 & 100,0 & \\
\hline
\end{tabular}

Das Bild ist dasselbe: Das Maturaniveau liegt bei 26,3 Prozent gegenüber 32 Prozent auf der anderen Seite der mietrechtlichen Lagezuschlagsgrenze. Auch der Ausländeranteil ist 2001 in Gründerzeitvierteln doppelt so hoch, 2010 nur

73 Insgesamt liegen 269 Sprengel im definierten Grenzgürtel. Manche fallen aufgrund der geringen Datendichte heraus, daher bleiben für diesen Test nur 256 übrig. 
noch um die Hälfte größer als in den angrenzenden Zuschlagsvierteln (letzteres Ergebnis ist allerdings nicht signifikant).

Oder ist es die geringere Miete, die hinter dem Selektionsmechanismus liegt? Eine Regressionsalayse mit dem Ausländeranteil als abhängige Variable ergibt, dass der Ausländeranteil negativ mit der Miethöhe (Standard Koeffizient -0,093), und positiv mit dem Faktum Gründerzeitviertel (Standard Koeffizient 0,606) korreliert. Beides ist signifikant und erklärt $(\mathrm{R}=)$ 61,8 Prozent des Ausländeranteils.

Die Ergebnisse belegen, dass der hohe Ausländer- und geringe Maturantenanteil in GZV bestimmende Faktoren sind. Ob dies durch bewusste Mieterselektion hervorgerufen ist, wie Hypothese 8 postuliert, kann nicht mit Sicherheit behauptet werden. Indizien, etwa höhere Ausländeranteile an der Grenze zu besseren Zuschlagsvierteln, deuten darauf hin.

\subsubsection{Mietregulierung und Mietangebot}

Hypothese 9: In Gründerzeitvierteln in guten Lagen ist das Mietangebot geringer bzw. rückläufig, da der „Graubereich“ höher ist.

Dass ein Graubereich vor allem in Gründerzeitvierteln besteht, und dass dieser bei GZV in besseren Lagen noch dünkler wird, ist bereits in der Diskussion um Hypothese 3 festgestellt worden. Je ausgeprägter der Graubereich ist, desto weniger Rechtssicherheit hat der Vermieter. Das Risiko, dass Marktmieten nicht legal durchsetzbar sind, steigt mit dem Wert der Lage, der ja selbst über alle Gründerzeitviertel hinweg betrachtet sehr unterschiedlich sein kann. Da es auch in guten Lagen GZV gibt, dort eine höhere Miete verlangt wird und damit auch das Risiko einer Mietzinsherabsetzung steigt, müsste die Flucht aus dem Mietmarkt anhand der Mietangebotszahlen abgebildet werden können.

Es liegen einerseits Mietangebotsdaten (Zahl der Angebote je Zählsprengel) vor, andererseits weiß man anhand des Wohnungsangebots bei der letzten Volkszählung 2001 (Zahl der Wohnungen mit Hauptwohnsitzen, Nebenwohnsitzen und ohne Wohnsitzangabe je Zählsprengel), wie viele Wohnungen in einem jeweiligen Zählsprengel bestehen.

Das Verhältnis zwischen Mietangeboten und Wohnungsbestand ist aber nicht leicht herzustellen. Ein Bias ist vorprogrammiert, schließlich können im Beobachtungszeitraum Wohnungen doppelt angeboten werden. Zum zweiten dürften gerade in den Gründerzeitvierteln viele Wohnungen „ohne Makler“ vermietet werden, wodurch sie vom Datensatz nicht umfasst sind. Es muss daher mit einer Verzerrung gerechnet werden. 
Tatsächlich ist das Mietangebot im Verhältnis zum jeweiligen Wohnungsangebot außerhalb von Gründerzeitvierteln größer (2,42 Prozent gegenüber 1,17 Prozent, siehe Abbildung 48, die Ausprägung zählen den prozentualen Mietumschlag im Verhältnis zum Wohnungsbestand). Dieser Zusammenhang ist signifikant. Dennoch kann er nur als Indiz gewertet werden. Ein Bias kann nicht ausgeschlossen werden, zumal das Verhältnis der Mietwohnungen zu den im Eigentum genutzten Wohnungen nicht einfließt.

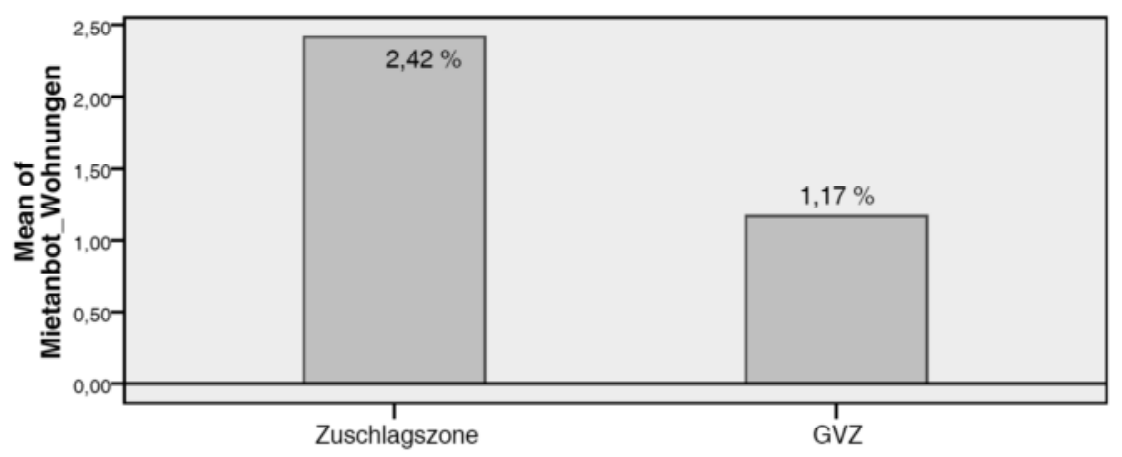

Abbildung 48: Geringeres Mietangebot in Gründerzeitvierteln?

\subsubsection{Mietregulierung und Wohnungsangebot}

Eine der Kernhypothesen dieser Arbeit ist der langfristige negative Effekt des Mietrechts auf das Mietwohnungsangebot. Liegt ein regulierter Preis unter einem Marktpreis, so vertreibt dies langfristig die Anbieter. Die Immobilien existieren natürlich weiterhin, allerdings ändert sich die Eigentümerstruktur. Das regulierte Segment der Privatvermietung ist neben der einzelnen AltbauMietwohnung das klassische Zinshaus, das im Eigentum einer einzelnen Person steht. Ein wesentliches Indiz für den Eigentumswandel ist die Wohnungseigentumsbegründung oder Parifizierung. Sie dient für Hypothese 10 als Indiz für die „Flucht aus dem Mietmarkt“. Es ist lukrativer, Mietshäuser in einzelne Wohnungen zu zerstückeln und an künftige Wohnungseigentümer zu verkaufen, als das gesamte Haus zu vermieten. Auch wenn manche Wohnungseigentümer weiter als Vermieter aktiv sind, entzieht dieser Prozess dem Mietmarkt tendenziell Material. Von Interesse ist nun, wo es verstärkt zu Parifizierungen kommt.

Hypothese 10: In Gründerzeitvierteln in guten Lagen kommt es verstärkt zu Parifizierungen und Abverkäufen von Wohnungen. 
$\mathrm{Ob}$ an einem Haus Wohnungseigentum begründet worden ist, lässt sich nur im Grundbuch erkennen.

\subsubsection{Aufbereitung der Grundbuchsdaten}

In Kapitel 7.2.2 wurde das Parsing der Grundbuchsdaten mittels Perl erläutert. Die dadurch generierte Adresse der jeweiligen Liegenschaften wurde mit einem Python Tool über Google-Maps geocodiert. Die Geocodierung der 124.178 Datensätze dauerte etwa 60 Stunden. Jeder Datensatz enthielt nun Adresse und Lat/Lon-Koordinate.

Die generierten Koordinaten mussten sodann verortet werden, damit eine Zuordnung zum jeweiligen Zählsprengel möglich ist. Für diese Aufgabe wurde mit ESRI-Arcgis gearbeitet. Eine Herausforderung waren die unterschiedlichen Koordinatensysteme, die den einzelnen Shapes zugrundelagen. Das Zählsprengel-Shape wurde in Lambert dargestellt, einer für Österreich üblichen und verzerrungsfreien Projektion. Dieselbe Projektion funktioniert für die longitudinalen und latitudinalen Koordinaten (etwa 48,291923 - 16,2829393) nicht von vornherein. Die verorteten Daten müssen im „Weltsystem“ WGS 1984 dargestellt werden. Das Resultat ist, dass die Darstellungen nicht exakt übereinander liegen, die Grundbuchs-Daten landen bisweilen um mehrere hundert Meter neben dem über das Shape-File projizierten Zählsprengel. Die WGS-84-Projektion wurde dazu wie folgt manipuliert, sodass es verzerrungsfrei in der Lambert Projektion (Österreich) dargestellt werden kann:

X Axis Translation: -586 Meter, Y Axis Translation: -98 Meter, Z Axis Translation: -468 Meter, X Axis Rotation: $+5,1$ Sekunden, Y Axis Rotation : +1,4 Sekunden, Z Axis Rotation: +5,4 Sekunden, Scale Difference: -1,1 ppm

Die verorteten Grundbuchsdaten - insgesamt 95.126 der 124.178 Grundbuchsauszüge konnten über die Adressangabe geocodiert werden - wurden mit Zählsprengeln und mit Zählsprengel-Daten der Statistik Austria auf 1293 Datensätze verschnitten.

\subsubsection{Darstellung des Parifizierungsgrades}

Anhand der Grundbuchsdaten konnte herausgefunden werden, wie viele der Grundbuchskörper parifiziert sind. Dieser „Parifizierungsgrad“ (WE-Objekte / Anzahl der Grundbuchs-Einlagezahlen) ist in Abbildung 49 dargestellt. 


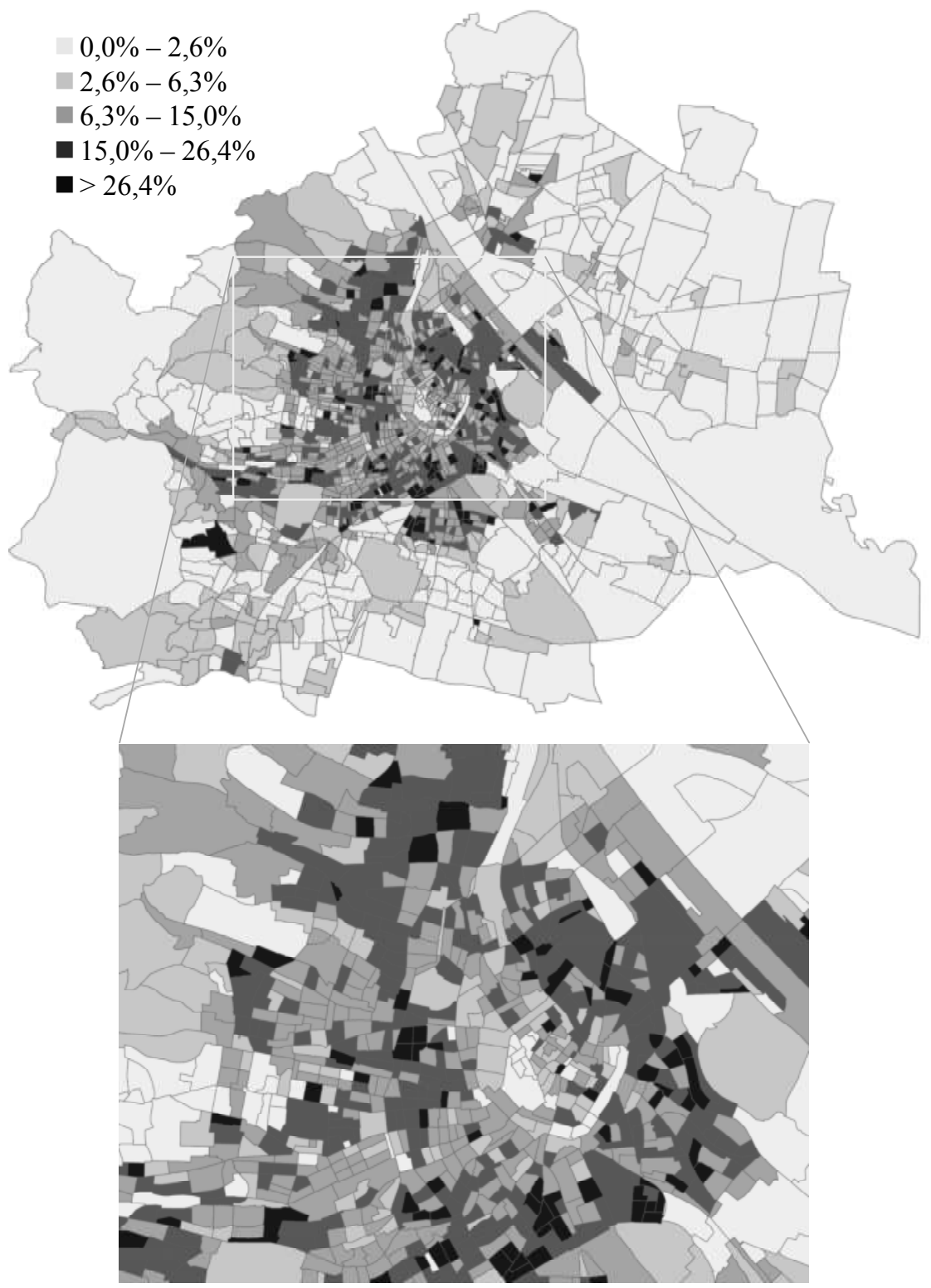

Abbildung 49: Parifizierungsgrad der Wiener Zählsprengel 
Erwartungsgemäß ist gerade im dicht verbauten Stadtgebiet der Anteil der parifzierten Grundbuchskörper am höchsten. Der Erste Bezirk weist auch Gebiete mit geringem Parifizierungsgrad aus. Hier ist auch der Anteil an öffentlichen Bauwerken, die naturgemäß nicht parifiziert sind, sehr hoch.

Die Grafik und die Statistik im Hintergrund sind mit Vorsicht zu betrachten: Ein Grundbuchskörper ist nicht unbedingt ein einzelnes Gebäude. Auch unbebaute Grundstücke haben eine eigene Einlagezahl und sind damit eigenständige Grundbuchskörper. Zudem finden sich bei Gartensiedlungen oder genossenschaftlich organisierten Immobilien gelegentlich sehr viele Gebäude auf einer gemeinsamen Einlagezahl oder sogar auf einem einzigen Grundstück.

Nach der letzten Gebäudezählung der Statistik Austria 2001 gibt es 165.886 Gebäude in Wien, darunter Einfamilienhäuser, Zinshäuser, Palais und Bürogebäude. Allerdings gibt es „nur“ 124.178 Grundbuchsauszüge, und lediglich 95.126 Einlagezahlen, die auch eine Adresse im Grundbuch eingetragen haben, was auf eine höher entwickelte Immobilie (bebaute Baugründe statt Landwirtschaftsflächen, die keine Adresse haben) hindeutet. Zum Beispiel gibt es im Zählsprengel 91601082 im 16. Bezirk lediglich 180 Grundbuchseinträge, aber 770 Gebäude.

Für die Analyse sollen vor allem Gebiete mit hohem Anteil an Einfamilienhäusern ausgeklammert werden. Da für die gegenständliche Hypothese die Gründerzeitviertel und angrenzende Gebiete von Interesse sind, wird lediglich auf jene Gebiete eingeschränkt, die in oder neben Gründerzeitvierteln liegen.

In Abbildung 50 sind auch die einzelnen Gründerzeitviertel umrandet und die Zählsprengel mit dem Parifizierungsgrad schattiert. 


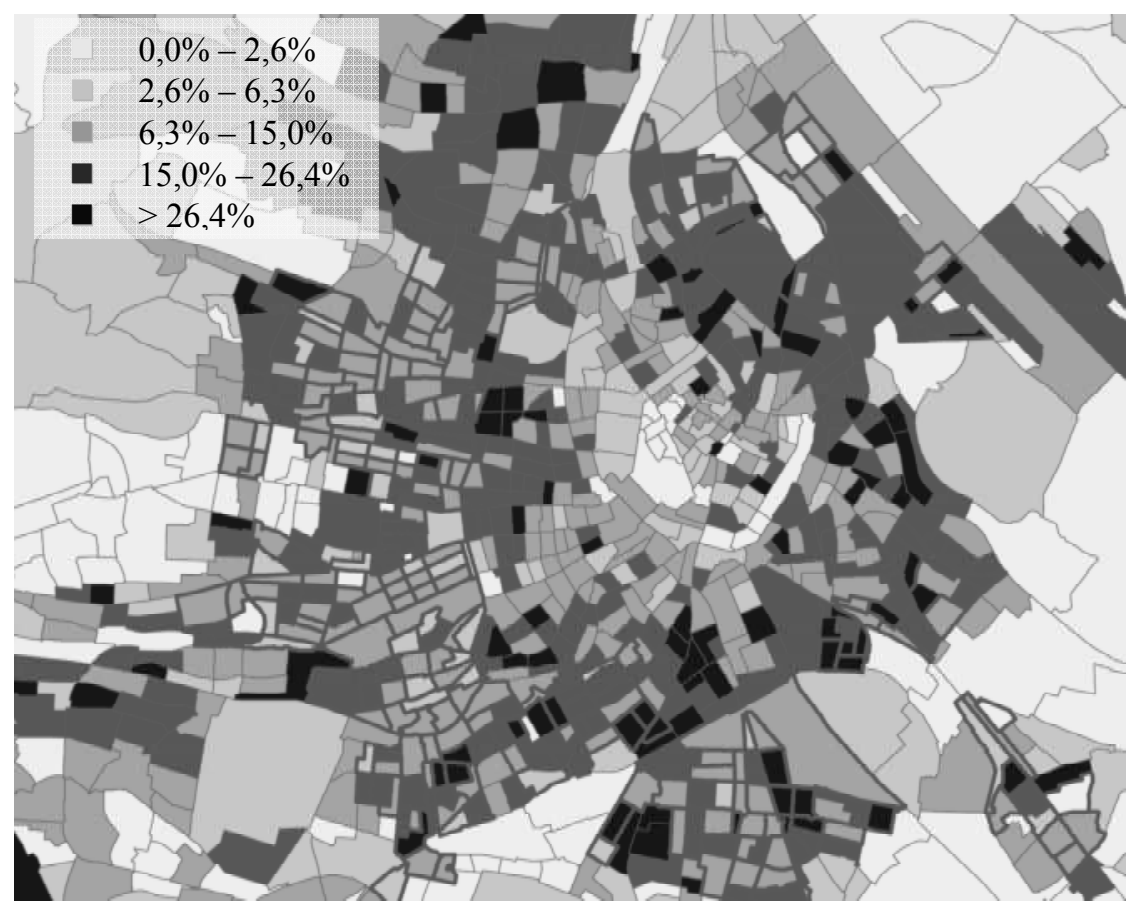

Abbildung 50: Parifizierungsgrad in Gründzeitvierteln und angrenzenen Gebieten

Dass der Parifizierungsgrad in Gründerzeitvierteln überdurchschnittlich ist, deutet zumindest auch Abbildung 51 an. Sie gibt jedoch keinen Hinweis über die Ausprägungen bei einzelnen Gebäudetypen. Die Statistik kann nicht auf Mehrparteienhäuser einschränken, sondern lässt auch Einfamilienhäuser einfließen, die naturgemäß nicht parifiziert sein können. Auch der Anteil der Neubauten, die eher Wohnungseigentumsobjekte sind, bleibt unbekannt. 


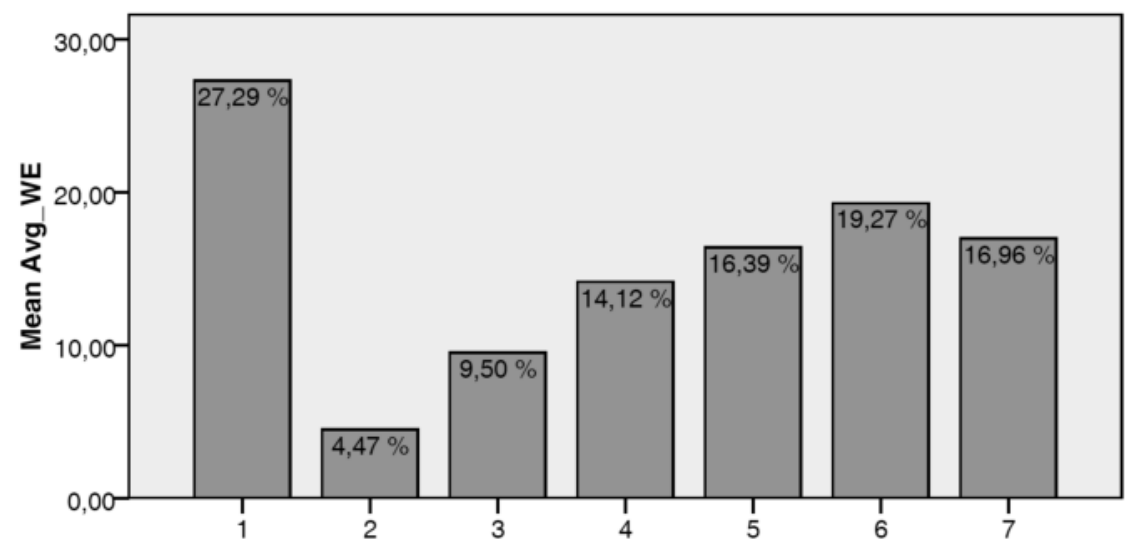

Abbildung 51: Parifizierungsgrad nach Lagezuschlagszone sowie gewichtet nach der Anzahl der Grundbuchskörper (Einlagezahlen)

Es muss daher für einen Beleg der Hypothese auf ein Stadtgebiet eingeschränkt werden, das in sich homogener ist: dicht verbaute Wohngegenden mit sowohl Zuschlagszonen als auch Gründerzeitvierteln. Als geeignet in Bezug auf die erforderliche Bebauungsdichte erscheinen dafür der 1.-9. Bezirk (außer dem 2. Bezirk), sowie der 15. und 20. Bezirk. Die dort gelegenen Zählsprengel weisen im Durchschnitt weniger als 5 Ein- oder Zweifamilienhäuser auf. Von den inneren Bezirken (1.-9.) kommt letztlich nur der 5. Bezirk in Frage, da dieser auch Gründerzeitviertel aufweist. Die nachstehenden Analysen beschränken sich daher auf die dicht verbauten Bezirke Margareten (5.), Rudolfsheim-Fünfhaus (15.) und Brigittenau (20.).

In Abbildung 52 ist der Parifizierungsgrad der drei genannten Bezirke abgebildet, wobei dieser für Gründerzeitviertel (dunkel) und Zuschlagszonen (hell) separat dargestellt ist. Entsprechend der Hypothese ist der Grad der Parifizierung in Gründerzeitvierteln höher als in den Zuschlagszonen der jeweiligen Bezirke. 


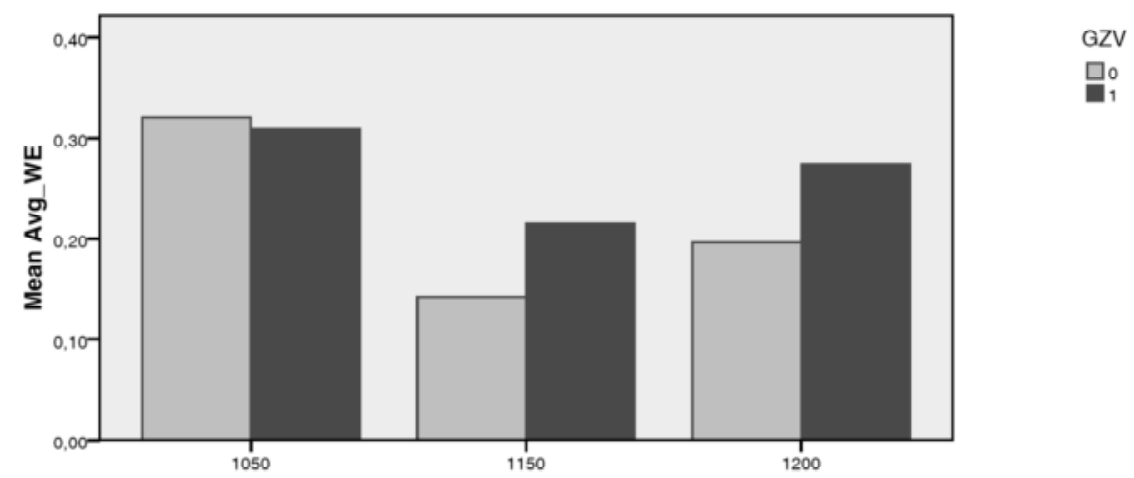

Abbildung 52: Parifizierungsgrad in dicht verbauten Bezirken nach Zuschlagszone

Eine ANOVA zeigt, dass die Unterschiede in den äußeren, dem 15. und 20. Bezirk signifikant sind (Sig. 0,015 bzw. 0,034). Die geringen Unterschiede im 5. Bezirk sind nicht signifikant. Das Ergebnis muss jedoch im Verhältnis zum Gebäudebestand gesehen werden.

Nahezu alle Altbauten vor 1945 und sämtliche Gründerzeithäuser standen zum Zeitpunkt der Erbauung in Alleineigentum. Neubauten der Nachkriegsjahre jedoch wurden oft bereits als Wohnungseigentumsobjekte errichtet. In Gebieten, wo ein höherer Neubaubestand vorhanden ist, muss sich automatisch ein höherer Parifizierungsgrad ergeben, der nicht auf die nachträgliche Wohnungseigentumsbegründung bei Altbauten - dem Untersuchungsgegenstand - zurückgeht.

In Abbildung 53 sind Balkendiagramme abgebildet, die die Zahl der AltbauMehrparteienhäuser (dunkelgrau) den Neubau-Mehrparteienhäusern (hellgrau) gegenüberstellen, je nachdem ob es sich um ein Gründerzeitviertel handelt (oben) oder nicht. 


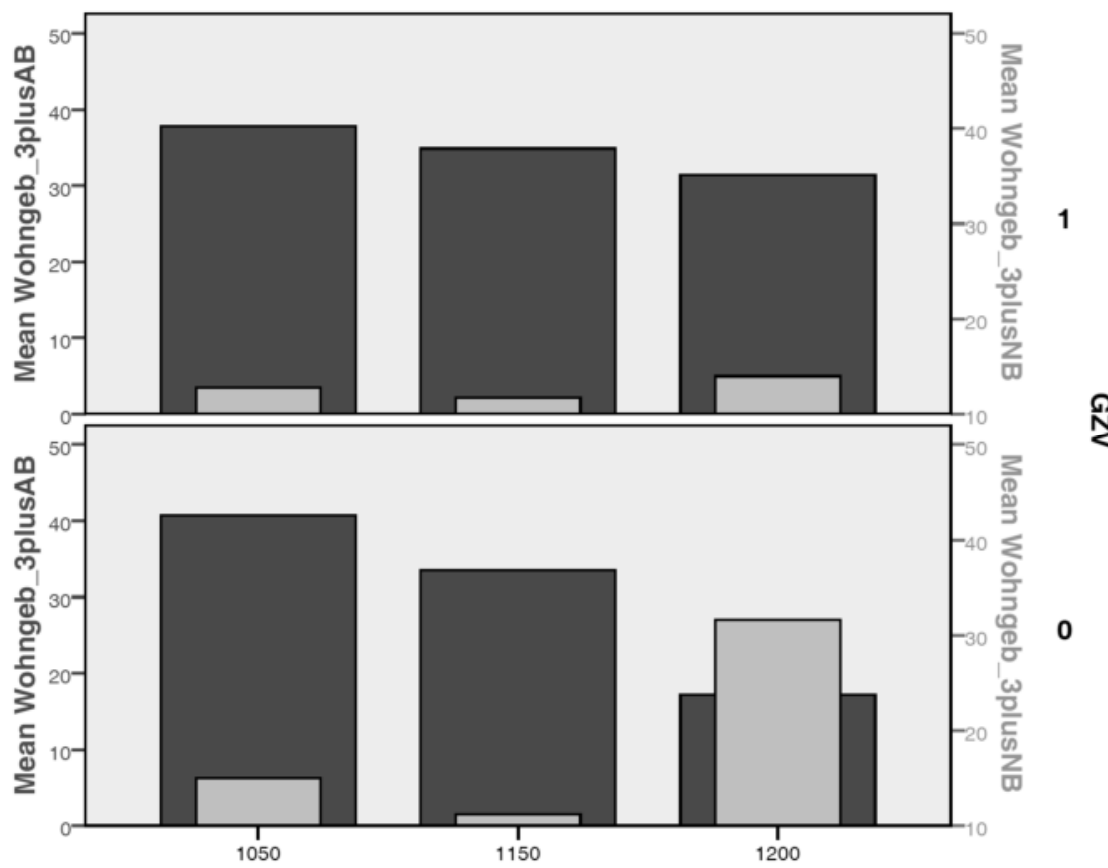

Abbildung 53: Zahl der Altbau (dunkel) und Neubau-Wohnhäuser (hell) nach Bezirken und Zuschlagszone (oben) bzw. Gründerzeitviertel (unten)

Die überwiegende Zahl der Mehrparteienhäuser in Gründerzeitvierteln (GZV=1, oben) sind Altbauten, die vor 1945 errichtet wurden (dunkle, breite Balken). Auch außerhalb der Gründerzeitviertel überwiegen Altbauten bei weitem. Lediglich im 20. Bezirk gibt es in Zuschlagszonen auffallend mehr Neubauten (helle, schmale Balken). Dieses Ergebnis muss sich aus der Baugeschichte ergeben. Gründerzeitviertel waren die dichtest verbauten Wohngegenden der vorigen Jahrhundertwende. Darüber hinausgehend, wo sich heute Zuschlagszonen befinden, waren Fabriken oder Grünflächen vorzufinden. Sie sind heute $\mathrm{Zu}-$ schlagszonen, weil es dort wenige Wohnhäuser, und damit auch weniger Substandardwohnungen (das Kriterium für Gründerzeitviertel) gegeben hat. Inzwischen sind auch diese Zuschlagsgegenden dicht verbaut.

$\mathrm{Da}$ es also in Gründerzeitvierteln noch weniger Neubauten gibt als in den Zuschlagszonen, müsste dies das hypothesebelegende Ergebnis zum Parifizierungsgrad (Abbildung 52) noch verstärken: der Parifizierungsgrad in GZV ist höher, obwohl es weniger Neubauten gibt. 
Kann Hypothese 10 also angenommen werden? Die Daten lassen eine endgültige Aussage nicht zu. Ein Problem bleibt nämlich wie oben beschrieben ungelöst: Es gibt nach der Häuserzählung viel mehr Gebäude als Einlagezahlen. Mehrere Häuser, oder ganze Häuserblöcke, etwa von Genossenschaftsanlagen, stehen auf einer einzigen Einlagezahl. Es lässt sich nicht feststellen, ob ein Parifizierungsgrad von etwa 25 Prozent in einem bestimmten Zählsprengel die Anzahl der nachträglich parifizierten Altbauten zum Ausdruck bringen kann. Schließlich gibt es zumindest in den Bezirken 15 und 20 mehr Neubauten als es Wohnungseigentumsobjekte gibt. Die obige Varianzanalyse (dargestellt in Abbildung 52) wurde unter der Annahme erstellt, dass der Parifizierungsgrad den Anteil der parifizierten Altbauten an der Gesamtanzahl der Altbauten widerspiegelt.

Interessant wäre zu wissen, wie sich die Nachbarschaftseffekte zu Zuschlagszonen auf den Parifizierungsgrad auswirken. Dazu werden ausschließlich die Bezirke 5 und 15 betrachtet (beim 20. Bezirk ist nahezu jedes GZV an eine Zuschlagszone angrenzend, womit die Kontrollgruppe, die „Binnen-GZVs“, fehlt). Die Verteilung der Gebäudetypen ist jedenfalls ausgeglichen: Die Anzahl der Altbauten und Neubauten ist in Gründerzeitvierteln, die von Ihresgleichen umgeben sind, und jenen, die an Zuschlagszonen angrenzen, ungefähr gleich verteilt (vgl. Tabelle 26).

Tabelle 26: Gleiche Anteile an Altbauten und Neubauten über die GZV hinweg

\begin{tabular}{|c|c|c|c|}
\hline \multicolumn{4}{|c|}{ Report } \\
\hline \multicolumn{2}{|c|}{ Grenzgeb } & $\begin{array}{c}\text { Wohngeb_3plus } \\
\text { AB }\end{array}$ & $\begin{array}{c}\text { Wohngeb_3plus } \\
\text { NB }\end{array}$ \\
\hline \multirow[t]{3}{*}{0} & Mean & 36,39 & 12,75 \\
\hline & $N$ & 36 & 36 \\
\hline & Std. Deviation & 13,768 & 11,448 \\
\hline \multirow[t]{3}{*}{1} & Mean & 35,26 & 11,31 \\
\hline & $\mathrm{N}$ & 35 & 35 \\
\hline & Std. Deviation & 15,106 & 8,141 \\
\hline \multirow[t]{3}{*}{ Total } & Mean & 35,83 & 12,04 \\
\hline & $\mathrm{N}$ & 71 & 71 \\
\hline & Std. Deviation & 14,351 & 9,912 \\
\hline
\end{tabular}

Das Ergebnis: Im 15. Bezirk steigt der Parifizierungsgrad an der Grenze zu den Zuschlagszonen von 19,9 Prozent (Binnen-GZV) auf 25,3 Prozent. Dieser Unterschied ist signifikant $(0,023)$ und ein Beleg für die Hypothese.

Im 5. Bezirk steigt der Parifizierungsgrad von 30,5 auf 30,9 Prozent, ist jedoch nicht signifikant. 


\subsection{Limitationen und Artefakte}

Die Datenbasis des Maklersoftware-Vertreibers Edi-Real ist zwar sehr umfassend und für den Wiener Immobilienmarkt neben den Daten von Immobilien.NET die beste automatisiert erhobene. Für die Arbeit lag auch ein umfassender Datensatz von Immobilien.NET vor, der aber letztlich nicht verwendet werden konnte, da die Adressangaben - ein wesentliches Kriterium zur Beurteilung der Lage - nur mangelhaft codiert waren.

Das Datenmaterial von Edi-Real weist Mängel auf, die trotz intensiver Datenbereinigung nicht vollständig behoben werden können. Zwar werden Datensätze entfernt, die nicht zuordenbare Eingaben enthielten, wie „10 Euro“ Gesamt-Nettomiete ${ }^{74}$, oder aber auch Objekte ausgeschieden, die zum Beispiel 1.500 Quadratmeter hatten. Offenbar handelt es sich dabei um eine Hotelpacht o.ä. Zudem werden sämtliche Datensätze ausgeschieden, die keine Angaben zu Quadratmetern oder zur Miete haben, siehe dazu Kap. 7.2. Mietangebote, die mehr als 4.900 Euro und weniger als 50 Euro pro Monat kosten, wurden von vornherein ausgeschieden. Allerdings ist davon auszugehen, dass auch jene Daten, bei denen es sich nicht gerade um „Ausreißer“ handelt, Fehler beinhalten.

Bei den Fehlern handelt es sich immer um Eingabefehler durch den entsprechenden Makler. Fairerweise besteht dessen Aufgabe nicht darin, einen vollständigen Datensatz für die Immobilienplattform zu generieren, sondern potenzielle Kunden für eine Mietwohnung zu finden.

Vollständigkeit ist kein Kriterium, was besonders in Bezug auf das Baujahr bedauerlich ist. Dieses Unterscheidungskriterium ist maßgeblich für die Anwendbarkeit des Mietrechtsgesetzes. Fehlt es, kann nicht festgestellt werden, ob eine bestimmte Wohnung in den mietengeschützten Bereich fällt.

Die Preise auf der Immobilienplattform sind zudem Angebotspreise der Vermieter, und somit de facto keine Marktpreise. Es ist davon auszugehen, dass das eine oder andere Mietangebot noch nachgebessert wird. Die Marktmiete dürfte also knapp unter der Angebotsmiete liegen. Gravierender sind derartige Abweichungen auf dem Eigentumsmarkt. Bei Wohnungsverkäufen gehen die Verhandlungsspannweiten in den zweistelligen Bereich.

Die Preise enthalten aber auch andere Fehler: In manchen Angaben werden die Begriffspaare Netto und Brutto tatsächlich nur nach dem steuerlichen Aspekt unterschieden, die Nettomiete somit etwa mit 600 Euro angegeben, die Bruttomiete mit 660 Euro (Wohnen ist mit 10\% Umsatzsteuer besteuert). Dies verschleiert die tatsächliche Nettomiete, die ja im Gegensatz zur Bruttomiete keine Betriebskostenkomponente enthält. Diese Betriebskosten liegen bei einer

74 Derartige Miethöhen von 20 Euro netto pro Monat gibt es auch heute noch in Wien, allerdings nur bei Mietverträgen, die mindestens 20 Jahre alt sind. 
„Kaltmiete“, wie sie üblicherweise angeboten wird, bei ca. 1,80 Euro pro Quadratmeter und Monat.

Ein Bias dürfte auch aus der unterschiedlichen örtlichen Gewichtung der Angebote rühren. Der Erste Bezirk ist im Verhältnis zu seinem Wohnungsbestand überrepräsentiert. Im Gegensatz dazu gibt es in absoluten Zahlen viele, in relativer Betrachtung aber „wenige“ Angebote aus Außenbezirken, die relativ aktive Mietmärkte beherbergen.

Überrepräsentiert sind auch sehr teure Wohnungen. Wie eingangs erwähnt handelt es sich um Angebotsdaten. Ob sie im Zuge der Preisfindung am Markt noch verhandelt werden, ist gar nicht so relevant. Teure Wohnungen brauchen länger zur Verwertung und erwecken den Anschein eines Ladenhütertums. Deren Angebote finden sich viel länger online als jene für günstige Wohnungen. Da es sich im Grunde um Längsschnittdaten handelt, bei denen derartige niedrig-fluktuierende Angebote nicht gefiltert werden können, muss eine Unschärfe hingenommen werden. Es kann sogar sein, dass eine bestimmte Wohnung trotz aller Vorsicht „,doppelt“ im Angebotspool vorkommt.

Auffallend ist das relativ geringe Altbau-Angebot (vgl. Abbildung 28). Das mag Absicht der Makler sein. Gerade sanierten Gründerzeithäusern ist das Alter nicht unbedingt auf den ersten Blick anzusehen. Ist die verlangte Miete relativ hoch und in einem für eine Mietzinsherabsetzung ,gefährlichen“ Bereich, könnte der Makler das Attribut „Altbau“ kaschieren wollen. Dies ist eine reine Mutmaßung, die sich nicht belegen lässt. Womöglich will man sich aber vor Mietern schützen, die bereits mit der Absicht einer künftigen Mietzinsherabsetzung eine relativ teure Wohnung mieten.

Eine wesentliche Limitation ergibt sich aus der Datenbasis, mit der die Hypothese 10 belegt wurde. Es gibt in Wien doppelt so viele durch die Statistik Austria gezählte Gebäude als es Grundbuchseintragungen gibt. Der Grund liegt darin, dass sich oft mehrere Häuser auf einem Grundstück bzw. einer grundbücherlichen Einlagezahl befinden. Dazu zählen große Genossenschaftsbauten als auch Gartensiedlungen und Kleingartenvereine, die teilweise in schlichtem Miteigentum stehen, aber dutzende Gebäude beherbergen können. Dieser Umstand lässt sich aus Grundbuchsdaten nicht erkennen. Die Gebäudezählung aus 2001 weist für Wien 165.886 Bauten aus, doch aus dem Grundbuch aus 2010 können lediglich 95.126 Adressen gewonnen werden.

Andererseits stellen auch unbebaute Grundstücke und Einfamilienhäuser also Immobilien, an denen niemals Wohnungseigentum begründet werden kann - eigenständige Grundbuchskörper. Damit gehen sie im Prinzip als Divisor in die Statistik zum Parifizierungsgrad ein.

Es muss für die Feststellung des Grades der nachträglichen Parifizierungen bei Altbauten die Annahme getroffen werden, dass ein bestimmter 
Parifizierungsgrad in einem Zählsprengel den Anteil der parifizierten Altbauten an der Gesamtanzahl der Altbauten widerspiegelt. Über das gesamte Stadtgebiet betrachtet ist diese Annahme sicherlich illegitim. Deshalb wurde die entsprechende Analyse auf dicht verbaute Gebiete (5., 15., 20. Bezirk) beschränkt. Dennoch ist von einem Artefakt auszugehen. Auch in diesen Bezirken gibt es weniger Grundbuchskörper als Gebäude.

\subsection{Zusammenfassung der empirischen Ergebnisse}

Die Fragestellung dieses Forschungsprojekts lautet, welche Effekte die Lageregulierung auf Gebiete des Wiener (Altbau-) Wohnungsmarktes hat, in denen eine Lagezuschlagsmöglichkeit durch die Mietregulierung eingeschränkt ist. Aus der Theorie wurden zehn Hypothesen abgeleitet und empirisch getestet.

Hypothese 1: Die Miethöhe ist im mietengeschützten Segment geringer als im unregulierten Neubausegment.

Tatsächlich liegt die um Bewirtschaftungskosten bereinigte Miete im mietengeschützten Altbaubereich um 2,15 Euro unter jener des Neubaubereichs. Diese Neubaumiete dient als Referenz für den „freien“ Markt. Die Regulierung dämpft die Marktmiete rein deskriptiv betrachtet um 22 Prozent (Varianzanalyse, Sig. 0,000). Die Differenz ist aber nicht allein durch die Mietregulierung erklärt, schließlich weisen Altbau-Wohnungen auch einen schlechteren Ausstattungszustand auf. Bereinigt um Ausstattungsmerkmale der Wohnungen, die bei Neubauwohnungen in der Regel hochwertiger sind, drückt der Richtwertmietzins in einer Regressionsanalyse ceterum paribus die Miete um 10,3 Prozent. Hypothese 1 kann nicht verworfen werden, das Mietrecht wirkt sich auf die Miethöhe aus.

Offenbar ist die reglementierte Miethöhe im Altbaubereich kein dogmatisch hingenommenes Regulativ. Die Regulierung wird nicht von allen Teilnehmern beachtet. Es kann angenommen werden, dass die Risikobereitschaft eines Vermieters im Verhältnis zur verlangten Miete steht. Ist diese zu hoch, droht ihm ein Schlichtungsstellenverfahren. Geringere Risikobereitschaft würde demnach niedrigere Mieten bedingen und umgekehrt. Es dürfte in der Praxis wohl weniger der Respekt vor dem Regulativ sein, als die Angst vor einer möglichen Mietzinsherabsetzung, die den Vermieter dazu bringt, zumindest moderate Mietpreise anzubieten. Hier können zumindest Transmissionseffekte nachgewiesen werden, das Mietrecht hat einen preisdämpfenden Effekt.

Hypothese 2: Das Verbot des Lagezuschlags hat einen Einfluss auf die Miethöhe im betroffenen Segment und Gebiet (Gründerzeitviertel). 
Diese Hypothese wurde einerseits an einem Teilmarkt (5. Bezirk) getestet, der aufgrund seiner Anlage prädestiniert dafür scheint. Die Mitte des Bezirks besteht aus Gründerzeitvierteln, die von Zuschlagszonen umsäumt sind. Auch nach Abzug jeglicher Zuschlagsmöglichkeiten, sofern sie anhand des Datensettings berücksichtigt werden konnten, ergibt für Gründerzeitviertel in diesem Teilmarkt eine durchschnittliche Altbau-Miethöhe von 5,73 Euro gegenüber 6,60 Euro in angrenzenden Zuschlagszonen. Der Unterschied ist signifikant $(0,032)$, die Hypothese kann ebenfalls nicht verworfen werden. Zumal auch die Regressionsanalyse, die insgesamt 65 Prozent der Mietvarianzen des kompletten Datensatzes erklärt, für das Faktum Gründerzeitviertel einen Koeffizienten von $-0,100$ ausweist.

Besonders deutlich zeigt sich der Einfluss des Lagezuschlag-Verbots bei Gründerzeitvierteln in einer Auswertung, bei der nur jene betroffenen Gebiete ausgewählt werden, die unmittelbar an hohe Zuschlagszonen angrenzen. Oft ist es eine Straße, die ein Gründerzeitviertel von den Zuschlagszonen abgrenzt, dort ist die Nettomiete im Übrigen um durchschnittlich 60 Cent höher (Sig. 0,000). Dennoch fallen gerade diese an eine Zuschlagszone angrenzenden Gründerzeitviertel in eine Grauzone, siehe Hypothese 4. Nicht nur der Altbaumietmarkt, sondern auch das Neubausegment beschreibt in Gründerzeitvierteln eine leicht niedrigere Miete (wenngleich der Einfluss des GZV im Neubausegment kaum signifikant ist).

Hypothese 3: Die Mietregulierung wird in Gebieten, wo es eine Lagezuschlagsmöglichkeit gibt, eher eingehalten als in Gebieten, wo ein Lagezuschlag verboten ist (Gründerzeitviertel).

Vorweg muss festgehalten werden: Nur jedes vierte Mietangebot für eine Altbauwohnung des vorliegenden Datensatzes liegt nach den mietrechtlichen $\mathrm{Zu}$ - und Abschlägen unterhalb des gesetzlichen Richtwerts von 4,91 Euro pro Quadratmeter. Drei Viertel der Altbauwohnungen werden zu teuer vermietet. Die bereinigte Durchschnitts-Altbaumiete, bei der sämtliche aus dem Datensatz auslesbare Zuschlagsmöglichkeiten bereits abgezogen worden sind, liegt bei 6,40 Euro pro Quadratmeter. Die mietrechtlichen Zinsbegrenzungen werden also regelmäßig ignoriert, zumal anzunehmen ist, dass ein Großteil der Wohnungen befristet vermietet wird, und somit ein abermaliger „Befristungsabschlag“ von 25 Prozent oder 1,23 Euro pro Quadratmeter hinzunehmen wäre.

Die Hypothese beruht darauf, dass die fehlende Zuschlagmöglichkeit in Gründerzeitvierteln den gesetzlich höchstzulässigen Mietzins soweit verringert, dass besonders dort unerlaubt überhöhte Mieten verlangt werden. Tatsächlich weisen Altbauwohnungen in Gründerzeitvierteln eine weit höhere (zuschlagsbereinigte) Miete auf (6,34 Euro) als Altbau-Wohnungen in den Zuschlagszonen 2, 
3 und 4. (5,51 Euro, 5,32 Euro bzw. 5,94 Euro). Die bereinigte Durchschnittsmiete ist erst ab Zuschlagszone 5 höher als in Gründerzeitvierteln. In die Zone 5 fallen Wohnungen in guten Innenstadtlagen, deren Vermieter ihre Zuschläge mittels eines Gutachtens rechtfertigen können. Zuschläge, die es in Gründerzeitvierteln nicht gibt, weswegen sich dort eine Grauzone bildet. Weniger Vermieter möchten sich hier an die Richtwertvorgaben halten. Die bereinigte Miethöhe (auch nach Abzug von Lagezuschlägen) hängt signifikant davon ab, ob und in welcher Zuschlagszone sich die Immobilie befindet. Die Hypothese kann nicht verworfen werden.

Dies zeigt sich insbesondere bei Untersuchungen von Wohnungen in jenen Gründerzeitvierteln, die an Zuschlagszonen angrenzen. Nach Abzug der Lagezuschlagsmöglichkeit, die in der zuschlagslegitimen Nachbarschaft gilt, liegt die bereinigte Nettomiete in GZV sogar um 4,4 Prozent höher als jene in den benachbarten Zuschlagszonen (dieses Ergebnis ist jedoch nur schwach signifikant: $0,067)$.

Hypothese 4: Die schärfsten Abstufungen von höheren zu niedrigeren Lagezuschlagsmöglichkeiten gibt es in ,guten“ Bezirken, in denen Gründerzeitviertel definiert sind. Dort wird die Mietregulierung weniger eingehalten.

Diese Hypothese wurde bereits in vorangegangener Ausführung nachgewiesen. Betrachtet man die bereinigte GZV-Altbaumiete im Bezirksvergleich, so zeigt sich, dass trotz des verbotenen Lagezuschlags offenbar ein statistisch signifikanter „Bezirkszuschlag“ verrechnet wird. In den wenigen Gründerzeitvierteln des 9. Bezirks wird eine (um Ausstattungszuschläge bereinigte) Altbaumiete von 7,49 Euro verlangt. Die Grauzone, in der sich die Vermietung von Altbauwohnungen in GZV bewegt, ist also in guten Lagen noch dunkler schattiert. Die Hypothese ist bestätigt.

Hypothese 5: Je weiter eine angebotene Wohnung vom CBD entfernt ist, desto günstiger das Mietangebot. Dieser Zusammenhang ist besser im Neubau zu sehen bzw. unter Ausblendung der Gründerzeitviertel (GZV).

Erwartungsgemäß fällt in der monozentristischen Stadt Wien die Rentengebotskurve vom Zentrum in Richtung Peripherie ab. Die Nettomiete korreliert mit der Entfernung vom CBD negativ (Koeff: -0,182). Das Mietrecht verzerrt jedoch den kontinuierlichen Rentenabfall in Richtung Peripherie: Werden nur frei vermietbare Neubauten betrachtet, für die die Begrenzungen des Lagezuschlags in den Gründerzeitvierteln nicht gelten, so ist die Korrelation höher $(0,222)$, und natürlich ebenso signifikant $(0,000)$. Die Hypothese kann damit bestätigt werden. 
Hypothese 6: Eine fehlende Lagezuschlagsmöglichkeit wird bei Mietverhältnissen durch andere Zuschläge substituiert.

Dass die Altbaumiete sowohl in Gründerzeitvierteln als auch in Zuschlagszonen ,überhöht“ ist, wurde bereits mehrmals belegt. Auf Basis dieses Befunds ist es logisch, dass Vermieter andere Zuschläge einpreisen, um damit den fehlenden Lagezuschlag zu kompensieren. Anders würde eine korrekte Mietzinsberechnung nicht zu dem Ergebnis führen, dass etwa nach Abzug aller bekannten Zuschlagsmöglichkeiten die verbliebene Nettomiete in Gründerzeitvierteln höher ist als in benachbarten Zuschlagszonen (vgl. Ergebnisse zu Hypothese 3). Der Ausstattungszustand ist in GZV zugleich geringfügig schlechter (1,31 statt 1,22 nach Schulnoten). Leider kann auf Basis dieses Datenmaterials keine wissenschaftlich fundierte Aussage gemacht werden, ob andere Zuschläge als Kompensation des fehlenden Lagezuschlags verrechnet oder gar erfunden werden. Es ist eher davon auszugehen, dass die jeweiligen Vermieter, die in Gründerzeitvierteln ihre Wohnungen anpreisen, gar keine Mietzinsberechnung durchführen. Die Hypothese kann nicht belegt werden.

Hypothese 7: Je geringer der Lagezuschlag ist, desto schlechter ist auch der Erhaltungszustand der angebotenen Wohnungen.

Über den Zustand der angebotenen Mietwohnungen gibt lediglich die Angabe des jeweiligen Maklers Auskunft (,,sehr gut", bis ,unbenutzbar"). Die Abstufungen lassen sich als ordinalskalierte Schulnoten operationalisieren. Altbauten weisen durchgängig einen etwas schlechteren Erhaltungszustand auf. Eine Varianzanalyse weist die Abhängigkeit der Durchschnittsnote von der Lagezuschlagszone klar nach (Sig. 0,000). Wobei Gründerzeitviertel, obschon dort der Lagezuschlag verboten ist, nicht am schlechtesten abschneiden, immerhin besser (Note 1,33) als Zone 2 und 3 (mit Durchschnittsnoten 1,51). Auch das von den Zuschlagszonen rechtlich unberührte Neubausegment weist für Wohnungen in besseren Lagen bessere Zustände auf. Der Zusammenhang ist damit belegt.

Hypothese 8: In Gründerzeitvierteln (in guten Lagen) kommt es zu einer Mieterselektion: der Anteil an Ausländern ist höher und das Bildungsniveau niedriger als in Nachbar-Sprengeln, wo ein LZ erlaubt ist.

Die Annahme dieser Hypothese ist, dass Vermieter gerade in Gebieten, in denen die Marktmiete noch stärker von der Richtwertmiete abweicht, also in Gründerzeitvierteln, ihre Mieter danach selektieren, ob diese das Risiko einer Mietzinsherabsetzung wahrscheinlich machen. Unter der Annahme, dass gebildetere und mit der österreichischen Rechtslage besser vertraute Mieter ein höhe- 
res Risiko darstellen, würde eine etwaige Mieterselektion zur Risikominimierung in GZV eher Ausländer und weniger gut Ausgebildete begünstigen.

Auf Basis von soziodemographischen Daten der Statistik Austria (2001 und 2010) kann nachgewiesen werden, dass der Ausländeranteil sehr stark mit dem Faktum Gründerzeitviertel korreliert. De facto scheinen sich Bewohner aus anderen Ländern geradezu in GZV zu konzentrieren. Der Ausländeranteil (aus EWR und Drittstaaten) beläuft sich auf 33 Prozent und ist in den vergangenen zehn Jahren um 4 Prozentpunkte gestiegen. Der Wiener Schnitt liegt mit 20,7 Prozent Ausländeranteil deutlich darunter. Wie bei allen Segregationseffekten ist es schwierig, die Ursache für diese zunehmende Konzentration kausal zu beweisen. Die hypothetisierte bewusste Mieterselektion ist zumindest ein schlüssiges Argument. Ein kleiner Teil der Ausländerkonzentration wird in der Regressionsanalyse durch die geringere Miethöhe erklärt (Koeff. -0,093), einen Großteil $(0,606)$ macht das Faktum Gründerzeitviertel aus.

Der Bevölkerungsanteil mit Matura ist in GZV (22\%) wiederum unterdurchschnittlich (Durchschnitt Wien: 27 \%). Die Zusammenhänge sind signifikant und belegen zumindest jenen Teil der Hypothese, der eine höhere Ausländerkonzentration und ein geringeres Bildungsniveau postuliert.

Hypothese 9: In Gründerzeitvierteln in guten Lagen ist das Mietangebot geringer bzw. rückläufig, da der „Graubereich“ höher ist.

Das Verhältnis der Mietangebote zum jeweiligen Wohnungsbestand eines Zählsprengels ergibt das relative Mietangebot. Nur 1,17 Prozent der Wohnungen in GZV gelangen von 2005 bis 2010 über die Maklerplattform Edi-Real in den vorliegenden Datensatz. In den Zuschlagszonen (LZ 2 bis 7) sind es immerhin 2,42 Prozent. Dieses Ergebnis ist allerdings mit Vorsicht zu genießen, weshalb ein Beleg für diese Hypothese nicht möglich ist. Die Datenbasis ist mit teuren Wohnungen in guten Lagen übergewichtet. Alleine im ersten Bezirk müsste statistisch gesehen jede neunte vorhandene Wohneinheit auf den Mietmarkt gelangt sein. Hier ist eher von einem Datenbias auszugehen. Zudem dürften Wohnungen gerade in Gründerzeitvierteln vornehmlich ,privat“" vermietet werden und entziehen sich damit jeder Statistik.

Hypothese 10: In Gründerzeitvierteln in guten Lagen kommt es verstärkt zu Parifizierungen und Abverkäufen von Wohnungen.

Dividiert man die Zahl der Wohnungseigentumsobjekte durch die Zahl der Grundbuchskörper, so zeigt sich in Gründerzeitvierteln ein erheblich höherer Parifizierungsgrad als in allen Zuschlagszonen. Dieses Ergebnis ist allerdings erheblichen Limitationen unterworfen, weshalb die Analyse auf drei in sich homogenere Bezirke eingeschränkt wurde. Der 5., 15. und 20. Bezirk gelten als 
dicht bebautes Stadtgebiet und beherbergen sowohl Gründerzeitviertel als auch Zuschlagszonen (als Kontrollgruppe). Tatsächlich sind in den Gründerzeitvierteln etwa 5 Prozentpunkte mehr Häuser parifiziert als in den Zuschlagszonen des jeweiligen Bezirks. Die Unterschiede sind (im 15. und 20. Bezirk) signifikant. Zudem macht es einen Unterschied, ob das Gründerzeitviertel an eine $\mathrm{Zu}$ schlagszone angrenzt: Im 15. Bezirk steigt der Parifizierungsgrad an der Grenze zu den Zuschlagszonen von 19,9 Prozent (Binnen-GZV) auf 25,3 Prozent. Dieser Unterschied ist signifikant und ein Beleg für die Hypothese. Im 5. Bezirk steigt der Parifizierungsgrad von 30,5 auf 30,9 Prozent, ist jedoch nicht signifikant. Die Hypothese kann unter Limitationen bestätigt werden. 



\section{Fazit}

Miete, Lage, Preisdiktat. Spieltheoretiker hätten ihre helle Freude über die verworrenen Zusammenhänge dieser drei Begriffe auf dem Wiener Mietmarkt. Eine kurze Parabel soll dies in einfachen Worten veranschaulichen:

Ein Mieter findet seine Wunschwohnung in einem Zinshaus, und vereinbart dafür einen Mietpreis, den er für angemessen hält. Er weiß vermutlich nicht, dass es eine Preisregel über die ,erlaubte“ Miethöhe gibt. Die Regel ist zudem kompliziert und unpräzis. Wie hoch die Maximalmiete tatsächlich ist, wird erst dann klar, wenn der Mieter seinem Hausherrn ,,den Krieg erklärt", und über ein Gericht die erlaubte Miethöhe festsetzen lässt. Dies kann auch Jahre nach der Anmietung, und sogar lange nach dem Auszug des Mieters erfolgen. Ein Geldsegen für den Mieter, schließlich dürfte seine bezahlte Miete mindestens um ein Drittel zu hoch gewesen sein. Ein Horror für den Vermieter - er muss das über Jahre zu viel kassierte Entgelt mit Zinsen retournieren.

Besonders hoch ist die Rückzahlung in Gründerzeitvierteln. Obschon diese Gegenden sehr zentral gelegen und beliebt sind, und die U-Bahn vor der Haustüre wegfährt, gilt dort die Preisregel, der Richtwert, in seiner strengsten Form. Ob das Haus in einem Gründerzeitviertel liegt, wird man äußerlich kaum erkennen.

Dem Vermieter bereitet das Kopfzerbrechen, denn der Mieter stellt für ihn ein gehöriges Risiko dar. Besser, man sucht sich einen ,,unkomplizierten“ Mietertypus, der nicht im Nachhinein die Stirn besitzt, Ansprüche zu stellen. Freilich, als Hausherr kann man die Wohnung auch zum günstigen Richtwert anbieten. Doch dann stürmen hunderte Mietlustige den Besichtigungstermin, da die Miete weit unter der Marktmiete läge. Und hat man denn etwas zu verschenken?

Am besten, man tut sich den Stress nicht mehr an, parifiziert das Haus, und verkauft die freiwerdenden Objekte als Eigentumswohnungen ab. Auf dem Eigentumsmarkt kann man Einzelwohnungen verkaufen, die das fünfzigfache der Jahresmiete nach dem Richtwert erlösen. Ganz ohne ,schlechtes Gewissen “, denn der Eigentumsmarkt ist nicht reglementiert.

Die Erzählung bringt auf den Punkt, in welchem Spannungsfeld sich der Mietmarkt in Wien befindet. Sie ist zugleich Beobachtung und Resultat der Forschungsarbeit. Wie viel Miete für eine Wohnung verlangt wird, hängt mehr von der Risikobereitschaft des Vermieters ab als von den Merkmalen der Wohnung. Auf dem Mietmarkt entsteht eine Grauzone, die mit steigendem Mietniveau in Zukunft zunimmt - dies jedoch regional unterschiedlich. Im Fokus dieser Dissertation steht die Lageregulierung des Mietrechts, und deren Auswirkungen. 
Das Datenmaterial dafür bilden mehr als 32.000 Mietangebote bis zum Jahr 2010, die größtenteils auf Zählsprengelebene verortet werden konnten, sowie 124.178 Grundbuchsdaten und zahlreiche Datensätze der Statistik Austria.

Der Reihe nach: Auch das strenge österreichische Mietrecht nimmt Rücksicht auf den Markt. Ist die Lage der Wohnung überdurchschnittlich, so kann der Vermieter dafür einen Zuschlag zum gesetzlich festgelegten Richtwert verlangen. Dieser Zuschlag richtet sich nach dem Grundkostenanteil, also nach dem anteiligen Wert des Bodens an der Wohnnutzfläche. Soweit, so gerecht, natürlich kosten Wohnungen im Zentrum das Doppelte, sowohl in Miete, als auch in Kauf. Die Lage ist das einzige Kriterium, bei dem das Mietrecht zumindest ansatzweise auf die Marktentwicklung Rücksicht nimmt. Es sind entsprechende Zuschlagszonen über das ganze Stadtgebiet als Empfehlung definiert, ansonsten gilt die Richtwert-Zinsobergrenze, die dogmatisch festgelegt ist.

Allerdings klassifiziert das Richtwert-Gesetz sogenannte Gründerzeitviertel. Das sind großflächige Gegenden in den äußeren Bezirken, aber auch in sehr beliebten Wohnlagen wie dem 5. Bezirk, weiten Teilen des 2. und 3. Bezirks und vielen anderen relativ attraktiven Lagen. In diesen Gründerzeitvierteln ist ein Lagezuschlag partout verboten, unabhängig davon, wie attraktiv die Wohngegend sein mag. In den vergangenen knapp zwei Jahrzehnten, seit das Richtwertgesetz existiert, hat sich die Stadt stark gewandelt.

Teile der Gründerzeitviertel passen längst nicht mehr in die „GhettoSchublade", in die sie das Gesetzt steckt. Das Mietniveau ist auch dort gestiegen, das zeigt sich vor allem am frei vermietbaren Neubausegment, das von der Einteilung in Zuschlagszonen relativ unbenommen ist. Der Nachfrageüberschuss in Wien sorgt ohnehin für einen angespannten Markt.

Man darf dem Mietrecht zugutehalten, dass es das Mietniveau tatsächlich dämpft. Die Quadratmetermieten in Altbauten, für die der Richtwert nahezu ausschließlich gilt, liegen im Schnitt um netto 2,15 Euro unter den Neubaumieten. In einem hedonischen Modell, das eine Erklärungskraft von 65 Prozent der Mietvarianzen hat (korrigiertes R-Quadrat, also Güte 0,42), konnte der Einfluss des mietrechtlichen Zinskorsetts bereinigt gemessen werden: das Faktum Altbaumiete senkt die Miete ceterum paribus um 10,3 Prozent.

$\mathrm{Da}$ es sich methodisch um ein Quasi-Experiment handelt, wurde als „Kontrollgruppe" das nicht-regulierte Neubausegment gewählt, bzw. jene Altbauwohnungen, die sich in Zuschlagszonen befinden. Die Unterschiede zu diesen Kontrollgruppen sind stets signifikant.

Das Faktum Gründerzeitviertel macht die Miete bereinigt im Schnitt um 10,0 Prozent günstiger. Es handelt sich dabei zumindest um einen Transmissionseffekt, wie etwa am Teilmarkt 5. Bezirk (Margareten) gezeigt wird: die Nettomiete ist in Gründerzeitvierteln (GZV) um 60 Cent pro Quadratmeter günsti- 
ger. Dennoch: in GZV wird aufgrund der fehlenden Lagezuschlagsmöglichkeit gegen die mietrechtlichen Vorschriften noch mehr verstoßen. Gerade dort bildet sich eine Grauzone, die noch dünkler und prekärer wird, wenn das gegenständliche GZV nahe einer Zuschlagszone liegt: nach Abzug aller möglichen mietrechtlichen Zuschläge und des Lagezuschlags - man könnte dies die bereinigte Miete für die Normwohnung nennen - ist diese restliche, rechtlich durchzusetzende Miete in jenen angrenzenden GZV sogar um 4,4 Prozent höher als in den Zuschlagszonen. Die Grenzen zwischen Zuschlagsvierteln und den mietrechtlich stigmatisierten Gründerzeitvierteln verlaufen scharf: oft ist die erlaubte Miethöhe davon abhängig, auf welcher Straßenseite das Haus zufällig steht.

Im Durchschnitt wird in GZV eine Miete von 6,34 Euro pro Quadratmeter verlangt. Rechtlich durchsetzbar wären 4,91 Euro/m² (gültig bis April 2012), wenn das Mietverhältnis unbefristet ist, doch dazu später. In „,besseren“ Bezirken wie dem 9. (Alsergrund) wird auch bei Altbauten in Gründerzeitvierteln eine Miete von 7,49 Euro verlangt. Leider ist ja im Mietrecht kein „Bezirkszuschlag" vorgesehen, was der Mietmarkt wiederum konsequent ignoriert.

Drei Viertel der Vermieter von Altbauwohnungen dürften sich nicht an den Richtwert halten. Die Vermieter gehen damit ein gehöriges Risiko ein. Ihnen droht eine Rückzahlung der Überhöhung über Jahre, bis zur gänzlichen Wertminderung der Wohnung aufgrund eines Mieters, der seinen Mietzins auf unbeschränkte Zeit gerichtlich herabsetzen lässt. Der Theorie nach müssen ökonomisch handelnde Vermieter dieses Risiko einpreisen.

Es muss zudem angenommen werden, dass es auf dem Markt zu Umgehungsmechanismen kommt, wie sie auch in der Literatur zu „rent-regulation“ diskutiert werden. Eine naheliegende Hintertür ist die Selektion eines bestimmten Mietertyps: Menschen, die ein geringes Bildungsniveau haben oder die Rechtslage in Österreich nicht kennen, stellen ein geringeres Risiko in Bezug auf eine drohende Mietzinsherabsetzung dar. Tatsächlich liegt der Ausländeranteil in den prekären Gründerzeitvierteln (33 Prozent im Jahr 2010) signifikant über jenem der angrenzenden Vierteln sowie der gesamten Stadt Wien (20,5 Prozent). Der Ausländeranteil ist in GZV in den vergangenen 10 Jahren zudem überproportional gestiegen. Auch der Bevölkerungsanteil mit Reifeprüfung (Matura) liegt in GZV deutlich, fünf Prozentpunkte, unter dem Maturantenanteil von 27 Prozent über ganz Wien (im Erhebungsjahr 2001). Bei derartigen Segregationsfragen ist allerdings ein kausaler Zusammenhang stets schwer nachzuweisen: kommen die ausländischen und weniger gebildeten Menschen aufgrund der etwas günstigeren Miete in GZV, bildet sich ein ethnischer Agglomerationspunkt, oder kommt es tatsächlich zu einer bewussten Mieterselektion durch die örtlichen Hausherren? Die Zahlen sind als deskriptive Aussagen zu werten. 
Wenn ein Liter Benzin nur noch fünfzig Cent kosten darf, wird der Angebotsmarkt schnell reagieren: niemand würde mehr Benzin verkaufen. Bei Wohnimmobilien ist dieser in der Theorie zur Mietkontrolle viel diskutierte Effekt der Angebotsverknappung ein schleichender, schließlich ist das Angebot bei weitem weniger preiselastisch. Außerdem besteht der Markt nicht nur aus Mietwohnungen, die vermietet werden oder nicht. Seit Mitte der 90er-Jahre scheint es in Wien ein zunehmend attraktives Geschäft zu sein, Mietshäuser zu parifizieren und als Einzelwohnungen abzuverkaufen. Das ist per se nicht schlecht. Doch viele Wohnungseigentümer vermieten nicht, sondern nutzen die Immobilie selbst oder horten sie als Anlage für ihre Wienbesuche und ihre Enkelkinder. Immobilien scheinen in Zeiten finanzieller Unsicherheiten ein zunehmend beliebtes Anlagesegment zu sein, um Geld zu parken. Das entzieht dem Mietmarkt Material. Zugleich weist die Bevölkerungsprognose für Wien lt. Statistik Austria ein Wachstum von derzeit knapp 1,7 Millionen auf knapp 1,9 Millionen Einwohner in 15 Jahren aus. Ein knappes Angebot lässt die Preise steigen.

Geht die Schere zwischen Marktmiete und regulierter Miete in bestimmten Gebieten (etwa Gründerzeitvierteln) auseinander, und ist es zunehmend riskant zu vermieten, so muss das zu einer Flucht aus dem Markt führen. Die Renditen bei Wohnimmobilien sind derzeit niedrig, die Verkaufspreise hoch. Eine wesentliche Hypothese dieser Dissertation ist, dass das Mietangebot insbesondere in GZV zurückgehen muss. Zumindest für den vorliegenden Datensatz stimmt das. Der Anteil an Bestandseinheiten, die über die Maklersoftware Edi-Real, den Datenlieferanten, in den vergangenen fünf Jahren vermietet wurde, liegt bei 1,17 Prozent des Wohnungsbestands laut Gebäudezählung. Über ganz Wien betrachtet sind es 2,42 Prozent. Bei dieser Betrachtung kann jedoch ein Bias nicht ausgeschlossen werden, er ist sogar geradezu wahrscheinlich, da ,gute“ Bezirke im Datensatz überrepräsentiert sind. Die Hypothese über den lokalen Mietangebotsrückgang kann noch nicht belegt werden.

Die „Flucht aus dem Mietmarkt“ lässt sich aber anhand des Parifizierungsgrades bestimmter Wohngegenden ablesen. Diese Messzahl lässt sich nur anhand von Grundbuchsdaten erheben. Dieser Arbeit liegt ein vollständiger Grundbuchsdatensatz der Stadt Wien zugrunde. Die 124.178 Grundbuchsauzüge wurden einem Parsing unterzogen, geocodiert und mit Zählsprengeldaten der Statistik Austria verschnitten.

Das Ergebnis belegt erstmals, wie sich Mietregulierung auf die Eigentümerstruktur von Mietshäusern auswirkt. Gerade in beliebten Gründerzeitvierteln ist das Zerstückeln von Mietshäusern in Eigentumswohnungen weiter fortgeschritten als in anderen Gegenden. Gründerzeitviertel weisen einen signifikant höheren Parifizierungsgrad auf, im Schnitt von über 25 Prozent. Jeder vierte Grundbuchskörper ist ein Wohnungseigentumsobjekt. Anhand einzelner Stadtgebiete 
(5. und 15. Bezirk) wurde festgestellt, dass der Parifizierungsgrad innerhalb der Gründerzeitviertel dort höher ist, wo diese an Zuschlagszonen angrenzen. Der Wert der Immobilien ist dort im Verhältnis zur gesetzlich vorgeschriebenen Mietobergrenze überproportional höher.

Auch wenn diese Ergebnisse unter erheblichen Limitationen betrachtet werden müssen, ist die Tendenz klar: die Vermieter von Zinshäusern können nur dann risikolos ein Geschäft machen, wenn sie ihre Häuser zerteilen. Die Wohnungen werden von einem Käufermarkt sofort aufgesogen und gehen dem Mietmarkt zum Teil langfrist verloren. Diese Entwicklung ist dort am deutlichsten, wo Mietmarkt und Mietregulativ am stärksten auseinanderklaffen, in bereits gut entwickelten und beliebten Gründerzeitvierteln.

Dass das Mietrecht zu Verzerrungen führt, zeigt auch ein Test, bei dem auf die Stadtstrukturtheorie von Alonso (1964) Bezug genommen wird. Derzufolge fällt die Rentengebotskurve vom Zentrum zur Peripherie ab. In einer monozentristischen Stadt wie Wien wenig überraschend: das Zentrum ist exorbitant teuer, je weiter man sich davon entfernt, desto günstiger sind die Mieten. Allerdings konnte auch nachgewiesen werden, dass diese Korrelation davon abhängt, welchen Wohnungsteilmarkt man betrachtet. Die besten Korrelationen $(-0,222)$ erhält das Neubausegment (in Wien ab Baujahr 1945). Das Mietrecht jedoch, und vor allem die Existenz von Gründerzeitvierteln, die das örtliche Mietniveau unnatürlich unter die Marktmiete drücken, führen zu einer Verzerrung (Koeffizient $-0,182)$. Beides ist signifikant.

Signifikant schlechter ist auch der Erhaltungszustand in Altbauwohnungen gegenüber Neubauten (ab 1945). Das ist bereits aufgrund des Baualters nicht weiter verwunderlich. Für die Operationalisierung des Erhaltungszustands wurde auf die Bewertung der Makler zurückgegriffen (,sehr gut“ bis „,unbenutzbar"). In Schulnoten konvertiert kommt eine Neubauwohnung im Schnitt auf 1,16, eine Altbauwohnung auf 1,25. Der Unterschied in Bezug auf die Anwendbarkeit des Mietrechts ist signifikant. In Gründerzeitvierteln ist diese Benotung in beiden Segmenten um 0,06 Noten schlechter, aber beachtlicherweise besser als in den höheren Zuschlagszonen 2 und 3. Hypothetisiert wurde, dass als Kompensation für die fehlende Lagezuschlagsmöglichkeit in GZV andere Zuschläge verrechnet werden. Diese Vermutung kann mit den vorliegenden Datensätzen nicht bestätigt werden. Es ist eher davon auszugehen, dass die jeweiligen Vermieter, die ihre Wohnungen in Gründerzeitvierteln zu ,überhöhten“ Mieten anbieten, gar keine Mietzinsberechnung durchführen.

Bereinigt um sämtliche mietrechtliche Zuschlagsmöglichkeiten, die aus dem Datensatz errechenbar waren (Stockwerkslage, Balkone, etc.) kommt die durchschnittliche Altbauwohnung in GZV auf eine Monatsmiete von 5,73 Euro pro Quadratmeter, gegenüber 6,60 Euro in den Zuschlagszonen (nach Abzug des je 
nach Zone empfohlenen Lagezuschlags). Das legt die prekäre Abweichung zu den gesetzlichen Regulierungsvorschriften offen: Nach dem Richtwertgesetz dürfen diese Wohnungen in Wien nur 4,91 Euro/ $\mathrm{m}^{2}$ (bis April 2012) kosten, sofern sie unbefristet vermietet werden.

Nur noch wenige Vermieter bieten ihre Wohnungen unbefristet an, zu groß ist das Risiko, dass es bei einer Mietzinsherabsetzung, die wie oben gezeigt auch im günstigsten Fall gehörige Summen ausmacht und für die meisten Mieter problemlos durchzusetzen wäre, eine dauerhafte Wertminderung der Wohnung hingenommen werden muss. Für die Befristung des Mietverhältnisses müsste mietrechtlich jedoch ein abermaliger Mietzinsabschlag von 25 Prozent gewährt werden. Dass die Abweichung der verlangten Miete vom Richtwert also bei weitem höher liegen muss als die Ergebnisse bekunden, liegt auf der Hand. Die Gefahr einer kurzfristig noch höheren Rückzahlung nehmen Vermieter hier in Kauf, da sich das Risiko zeitlich auf die befristete Mietdauer beschränkt.

Die wichtigste Frage ist noch nicht beantwortet. Welche Erkenntnisse lassen sich aus dieser Arbeit ableiten? Die bei Altbauwohnungen verlangte Miete, und insbesondere bei solchen in Gründerzeitvierteln, liegt in den meisten Fällen über dem gesetzlichen Richtwert. Zigtausende Mieter in Wien könnten ihre Miete gerichtlich herabsetzen lassen. Sie tun es nicht, da sie über die Möglichkeit nicht Bescheid wissen, oder gar keine Motivation haben, dem Vermieter zu schaden. Schließlich wird in aller Regel die ,überhöhte“ Marktmiete als angemessen und leistbar empfunden.

In Hinblick auf die Rechtssicherheit ist diese Situation unbefriedigend. Zwar wissen die Vermieter, dass sie es mit ihren Mietzinsforderungen nicht übertreiben sollten, doch sogar Mietangebote, die auf dem Mietmarkt als relativ günstig gelten, sind in vielen Fällen bereits überhöht. Dies hemmt Investitionen und versetzt auch redliche Vermieter in eine Position, in der sie sich für ihre angebotene Miethöhe rechtfertigen müssen.

In Anbetracht der verhältnismäßig wenigen Herabsetzungsverfahren dürfte eher das Klagsrisiko der Mieter preisdämpfend wirken, als die Ehrfurcht und Achtung vor einem hochkomplexen und verworrenen Gesetz, das massiv in die autonome Eigentumsverfügung der Vermieter eingreift.

Es ist der politische Wille, die Mieten zu dämpfen. Dieser Wille ist legitim und der Weg über eine „Kostenmiete“ ist einer von mehreren möglichen. Unverständlich ist jedoch, dass die Gestaltung des kostengekoppelten Richtwerts derartig undurchschaubar, künstlich niedrig, und in Hinblick auf die Begrenzung der Lagezuschläge ungerecht erscheint. In einem transparenten Kostenmietensystem hätte die Benachteiligung von Gründerzeitvierteln keinen Platz. Es ist unverständlich, wieso etwa eine Lage im zweiten Bezirk, wie das zunehmend 
beliebte „Stuwerviertel“, kein Stadtgebiet sein darf, in dem die tatsächlich sehr hohen Grundkosten auf die Miete überwälzbar wären.

Die Gesetzeshypothrophie, der das Mietrechtsgesetz in den vergangenen 90 Jahren unterlegen ist, muss durch eine massive Gesetzesreform gelöst werden. Die Miete sollte als natürlicher Allokationsmechanismus von Wohnraum gesehen werden - allenfalls über den Umweg einer echten Kostenmiete. Gesetzliche Mietzinsregulierungen können ein wirksames Medikament im Kampf gegen die tatsächlichen Problemherde sein, nämlich gegen sittenwidrigen Mietenwucher und Übervorteilung von notleidenden Wohnungssuchenden. Die derzeitige Medikation, so die Quintessenz dieser Arbeit, weist viele Nebenwirkungen auf, deren weitere ökonomische Erforschung lohnenswert scheint. 



\section{Literaturverzeichnis}

Abele, Hanns; Höltl, Andrea (2007): Housing in Vienna. In: Andersson, Åke E.; Pettersson, Lars; Strömquist, Ulf (Hg.): European Metropolitan Housing Markets. Berlin, Heidelberg: Springer-Verlag Berlin Heidelberg (Springer-11643/Dig. Serial), S. 241-267.

Albon, Robert; Stafford, D. C. (1987): Rent control. London, New York, New York N.Y.: Croom Helm; Methuen.

Alonso, William (1974): Location and Land Use. toward a general theory of land rent. 5. Aufl. Cambridge, Mass.: Harvard Univ. Press.

Andersson, Åke E.; Pettersson, Lars; Strömquist, Ulf (Hg.) (2007): European Metropolitan Housing Markets. Berlin, Heidelberg: Springer-Verlag Berlin Heidelberg (Springer-11643 /Dig. Serial).

Arnott, Richard (1995): Time for Revisionism on Rent Control? In: Journal of Economic Perspectives, Jg. 9, H. 1, S. 99-120.

Arnott, Richard (1997): Rent Control. Contribution to The New Palgrave Dictionary of Economics and the Law. In: The New Palgrave Dictionary of Economics and the Law.

Arnott, Richard (2002): Rent control. In: Newman, Peter (Hg.): P - Z: The new Palgrave dictionary of economics and the law. London, New York: Palgrave Macmillan (The new Palgrave dictionary of economics and the law, 3).

Arnott, Richard; Igarashi, Masahiro (2000): Rent control, mismatch costs and search efficiency. In: Regional Science and Urban Economics, Jg. 30, H. 3, S. 249-288.

Basu, Kaushik; Emerson, Patrick (2000): The Economics of Tenancy Rent Control. In: The Economic Journal, Jg. 110, S. 939-962.

Basu, Kaushik; Emerson, Patrick (2003): Efficiency Pricing, Tenancy Rent Control and Monopolistic Landlords. In: Economica, H. 70, S. 223-232.

Blaas, Wolfgang; Wieser, Robert (2004): Einfluss von Wohnbauförderung und Richtwertsystem auf die Mietenentwicklung. In: IFIP im Auftrag der AK.

Böhm, Helmut (2003): Das Richtwertzinssystem. Juristische Analyse und Bewertung. verfasst im Auftrag der AK Wien. Wien: Kammer für Arbeiter und Angestellte.

Bradburd, Ralph; Sheppard, Stephen; Bergeron, Joseph; Engier, Eric (2006): The Impact of Rent Control in Non-Walrasian Markets. An Agent-Based Modeling Approach. In: Journal of Regional Science, Jg. 46, H. 3, S. 455491. 
Brunauer, Wolfgang; Lang, Stefan; Wechselberger, Peter; Bienert, Sven: Additive Hedonic Regression Models with Spatial Scaling Factors: An Application for Rents in Vienna. In: Working Papers in Economics and Statistics, Universität Innsbruck, Jg. 2008-17, S. 1-30.

Buzar, Stefan (2005): The Institutional Trap in the Czech Rental Sector. Nested Ciruits of Power, Space and Inequality. In: Economic Geography, Jg. 81, H. 4, S. 381-405.

Camagni, Roberto; Martellato, Dino (2007): The Milan Housing Market. In: Andersson, Åke E.; Pettersson, Lars; Strömquist, Ulf (Hg.): European Metropolitan Housing Markets. Berlin, Heidelberg: Springer-Verlag Berlin Heidelberg (Springer-11643 /Dig. Serial).

Chang, Hsiu-Yun (2008): The Choice of Housing Location. In: Journal of American Acedemy of Business, Cambridge, Jg. 12, H. 2, S. 174-179.

Cheshire, Paul; Sheppard, Stephen (1995): On the price of land and the value of amenities. In: Economica, Jg. 62, H. 246, S. 21.

Czasny, Karl; Köppl, Franz; Rosifka, Walter (1995): Erste Bewertung der Mietrechtsreform. Wien: Kammer für Arbeiter u. Angestellte für Wien (Stadtpunkte).

Daniere, Amrita (1994): Estimating willingness-to-pay for housing attributes. An application to Cairo and Manila. In: Regional Science and Urban Economics, Jg. 24, H. 5, S. 23.

Dasso, Jerome J.; Shilling, James D.; Ring, Alfred A.; Guttery, Randall S. (1995): Real estate. 12th ed. Englewood Cliffs N.J.: Prentice Hall.

Dicken, Peter; Lloyd, Peter; Höpfner, Stephanie (1999): Standort und Raum. Theoretische Perspektiven in der Wirtschaftsgeographie ; 36 Tabellen. Stuttgart: Ulmer (UTB für Wissenschaft: Große Reihe).

Dirnbacher, Wolfgang (2009): MRG. in der Fassung der Wohnrechtsnovelle 2009. Wien: ÖVI Österreichischer Verband der Immobilientreuhänder.

Dirnbacher, Wolfgang; Heindl, Peter; Rustler, Peter (1994): Der Richtwertmietzins. Praxisorientierte Hinweise zur Mietzinsgestaltung. Wien: ÖVI Österreichischer Verband der Immobilientreuhänder.

Dökmeci, Vedia; Önder, Zeynep; Yavas, Abdullah (2003): External Factors, Housing Values and Rents. Evidence from Survey Data. In: Journal of Housing Research, Jg. 14, H. 1.

Drbalek, Christian (1992): Stadtentwicklung und Gemeindebau in Wien. die Wohnbautätigkeit der Stadtgemeinde Wien im Lichte der Urbanisierungsphasen. Wien: Dipl.-Arb. WU-Wien.

Eliskases, Maximilian (2008): Entwicklung zentraler Orte des nördlichen Weinviertels. Wien: Diplomarbeit WU-Wien. 
Feigelfeld, Heidrun; Czasny, Karl; Blaas, Wolfgang; Wieser, Robert (2007): Eigentümerstruktur im Wiener privaten Althausbestand. In: AK-Wien, Jg. $12 / 2007$.

Feilmayr, Wolfgang (2005): Richtwertmieten und freie Mieten in Wien im Jahr 2004. im Auftrag der AK-Wien. Herausgegeben von Institut für Stadt-und Regionalforschung (TU-Wien). AK-Wien. Wien. Online verfügbar unter http://wien.arbeiterkammer.at/pictures/d28/richtwertmieten_studie2005.pd f, zuletzt geprüft am 2.12.2011.

Feilmayr, Wolfgang (2007): Grundstücksmärkte und Immobilienbewertung. In: Stadt- und Regionalforschung TU-Wien Skriptum.

Fujita, Masahisa; Thisse, Jacques-François (2002): Economics of agglomeration. Cities, industrial location, and regional growth. Cambridge: Cambridge Univ. Press.

Gabelar, Sabine (2008): Prozess- und Programm-Management in der Immobilienentwicklung. In: Diplomarbeit WU-Wien, H. Prof. Gareis.

Garmaise, Mark; Moskowitz, Tobias (2002): Confronting Information Asymetries. Evidence From Real Estate Markets. In: Nber Working Paper Series, Jg. 8877, S. 44.

Giffinger, Rudolf (1998): Segregation in Vienna. Impacts of Market Barriers and Rent Regulations. In: Urban Studies, Jg. 35, H. 10, S. 1791-1812.

Glaeser, Edward L.; Luttmer, Erzo F. (2003): The Misallocation of Housing Under Rent Control. In: American Economic Review, Jg. 93, H. 4, S. 1027-1046.

Goetzmann, William; Rouvenhorst, Geert (2000): Gloabl Real Estate Markets Cycles and Fundamentals. In: Nber Working Paper Series, Jg. 7566.

Grampp, William (1950): Some Effects of Rent Control. In: Southern Economic Journal, Jg. 16, H. 4, S. 425-477.

Guntermann, Karl; Norrbin, Stefan (1987): Explaining The Variability Of Apartment Rents. In: AREUEA Journal; , Jg. 15, H. 4.

Hayek, Friedrich August (1930): The repercussions of rent restrictions. reprinted in Verdict on Rent Control, Institute of Economic Affairs, Readings No. 7, London, 1972.

Ho, Michael; Chiu, Rebecca (2002): Impact of accessibility on housing expenditure and affordability in Hong Kong's private rental sector. In: Journal of Housing and the Built Environment, Jg. 17, H. 4.

Jaeger, Franz; Bühler, Stefan (1995): Marktmiete. Schweizer Wohnungsmieten zwischen Politik und Markt. Chur: Rüegger.

Jahn, Wolfgang (1994): Rechts- und wirtschaftspolitische Anmerkungen zum Entwurf eines Bundeswohnrechtsgesetzes sowie zum 3. Wohnrechtsänderungsgesetz unter besonderer Berücksichtigung der Entwicklung des 
Mietrechts und verwandter Rechtsgebiete in Österreich seit 1914. Dissertation. Wien: Universität Wien.

Jongbloed, A. (2008): Soziales Mietrecht in den Niederlanden. In: Wohnrechtliche Blätter, Jg. 21/6, S. 153-172.

Köppl, Franz (20.04.2010): Lagezuschlag in Wien. Interview mit M. Pichlmair. Am 20.04.2010 in Wien.

Kothbauer, Christoph; Malloth, Thomas; Rücklinger, Gottfried (Hg.) (2006): Mietrechtsgesetz, Wohnungseigentumsgesetz, Energieausweis-VorlageGesetz, Richtwertgesetz, Heizkostenabrechnungsgesetz. Wien: Fachverband der Immobilien- und Vermögenstreuhänder.

Kozlowski, M.; Huston, S. (2008): Influence of urban design master plans on property sub-markets. two case studies in Brisbane. In: International Journal of Housing Markets and Analysis, Jg. 1, H. 3.

Kranewitter, Heimo (2007): Liegenschaftsbewertung. 5., völlig überarb. Aufl. Wien: Manz.

Lind, Hans (2001): Rent Regulation: A Conceputal and Comparative Analysis. In: European Journal of Housing Policy, Jg. 1, H. 1, S. 41-57.

Lugger, Klaus (2010): Österreichisches Wohnhandbuch 2010. Innsbruck: Studienverlag.

Lüpkes, Gerhard (1992): Beiträge zur Thünen-Forschung. Eine Studie für National- und Agrarökonomen. Leer: Verl. Grundlagen und Praxis.

MA 25 (2010): Richtlinien für die Ermittlung des Richtwertmietzinses gem. § 16 Abs 2 MRG. ab 1. April 2010.

Maier, Gunther; Tödtling, Franz (2006): Regional- und Stadtökonomik 1. Standorttheorie und Raumstruktur, H. 4. Auflage.

Maier, Gunther; Tödtling, Franz (2006): Regional und Standortökonomik 2. Regionalentwicklung und Regionalpolitik, H. 3. Auflage.

Malpezzi, Stephen; Turner, Bengt (November 2002): A Review of Empirical Evidence on the Costs and Benefits of Rent Control. Veranstaltung vom November 2002, aus der Reihe "The Economics and Politics of Rent Regulation". Stockholm. Online verfügbar unter http://www.bus.wisc.edu/realestate/, zuletzt geprüft am 1.12.2008.

Malpezzi, Stephen; Wachter, Susan (2005): The Role of Speculation in Real Estate Cycles. In: Journal of Real Estate Literature, Jg. 13, 2, S. 21.

Mandl, Philipp (2006): Die Bestimmung des Verkehrswertes von Alten- und Pflegeheimen in Deutschland. Wien: Diplomarbeit WU-Wien, Prof. Maier.

McFarlane, Alastair (2003): Rent stabilization and the long-run supply of housing. In: Regional Science and Urban Economics, Jg. 33, S. 305-333. 
Moser, Peter; Schöffmann, Bernhard; Stocker, Eva (2002): Richtwertmieten in Wien. verfasst im Auftrag der AK-Wien. Herausgegeben von SRZ-Stadtund Regionalforschung GmbH. AK-Wien. Wien. Online verfügbar unter http://wien.arbeiterkammer.at/bilder/d19/Richtwertmieten_in_Wien.pdf, zuletzt geprüft am 2.12.2011.

Mouzakis, Fotis; Henneberry, John (2008): Geographical externalities of local real estate markets. An empirical examination of UK data. In: Journal of European Real Estate Research, Jg. 1, H. 1, S. 58-71.

Müller, Michaela (2007): Die Zulässigkeit des Lagezuschlags bei der Richtwertmietzinsermittlung am Beispiel Wien. Betreut von Herbert Rainer. Wien: FH-Wien.

Newman, Peter (Hg.) (2002): P - Z: The new Palgrave dictionary of economics and the law. London, New York: Palgrave Macmillan (The new Palgrave dictionary of economics and the law, 3 ).

O'Flaherty, Brendan (2005): City economics. Cambridge, Mass.: Harvard Univ. Press.

Olsen, Edgar O. (1969): A Competitive Theory of the Housing Market. In: American Economic Review, H. 59, S. 612-621.

Olsen, Edgar O. (1972): An Econometric Analysis of Rent Control. In: Journal of Political Economy, Jg. 80, H. 6, S. 1081-1100.

Otto Immobiliengruppe (2010): Erster Wiener Zinshaus-Marktbericht. Eine flächendeckende Studie über das Wiener Gründerzeithaus. Herausgegeben von Eugen Otto: Wien.

Prader, Christian (2009): MRG - Mietrechtsgesetz und ABGB-Mietrecht. mit Anmerkungen, Literaturangaben und einer Übersicht der Rechtsprechung. 3. Aufl. Wien: Manz.

Reiner, Thomas; Strong, Ann Louise (1995): Formation of land and housing markets in the Czech Republic. In: Journal of the American Planning Association, Jg. 61, H. 2.

Reithofer, Markus (3.-5. Mai): Mietzinsermittlung aus Sicht des ImmobilienSachverständigen. Richterseminar aus Miet- und Wohnrecht 2010. Veranstaltung vom 3.-5. Mai. Tulbingerkogel.

Rossi, Peter Henry; Freeman, Howard E. (1993): Evaluation. A systematic approach. 5. Aufl. Newbury Park, Calif.: Sage.

Sandner, Roland (1962): Der Mieterschutz in Österreich. Wien: Diss. Hochschule für Welthandel (WU-Wien).

Sigl, Christian (2007): Die Veränderung der räumlichen Wohnbevölkerungsstruktur entlang der Linienführung der U-Bahn am Beispiel Wien. Diplomarbeit WU-Wien, Prof. Maier. 
Stabentheiner, Johannes (2005): Liegenschaftsbewertungsgesetz und bewertungsbezogene Regelungen in AußStrG und EO mit erläuternden Anmerkungen und Rechtsprechung. 2., neu bearb. und erw. Aufl. Wien: Manz (Manzsche GesetzausgabenSonderausgabe, 78).

Stabentheiner, Johannes (2010): Mietrecht. (unter Berücksichtigung der Wohnrechtsnovelle 2009 und der judikativen Entwicklungen zur Erhaltungspflicht). 3. Aufl. Wien: Manz (Manz Rechtstaschenbücher).

Stadt Wien (2008): Richtlinien für die Ermittlung des Richtwertzinses nach $§ 16$ Abs. 2 MRG. § 3 Abs. 4 RichtWG, vom 01.04.2008. Fundstelle: Magistratsabteilung 25 (Stadterneuerung und Prüfstelle für Wohnhäuser).

Stampfer, Michael (1995): Die Anfänge des Mieterschutzes in Österreich. Wien: Manz (Österreichische rechtswissenschaftliche Studien, 27).

Statistik Austria (2010): Wohnen - Ergebnisse der Wohnungserhebung im Mikrozensus, Jahresdurchschnitt 2009. Herausgegeben von Statistik Austria. Wien.

Svarer, Michael; Rosholm, Michael; Munch, Jakob R. (2005): Rent control and unemployment duration. In: Journal of Public Economics, Jg. 89, H. 1112, S. 2165-2181.

Wieser, Robert: Hedonic prices on Vienna's urban residential markets. working paper 2/2006. In: IFIP Centre of Public Finance and Infrastructure Policy, Jg. 2006.

WKO Wirtschaftskammer Österreich: Immobilienpreisspiegel 2010. Herausgegeben von Fachverband der Immobilien- und Vermögenstreuhänder der Wirtschaftskammer Österreich.

Würth, Helmut; Zingher, Madeleine; Kovanyi, Peter (2007): Wohnrecht 2007. 20a. Wien: Manz.

Würth, Helmut; Zingher, Madeleine; Kovanyi, Peter (2009): Miet- und Wohnrecht. MRG und sonstige bestandrechtliche Vorschriften. Kurzkommentar. 22. Auflage. Wien: Manz. 